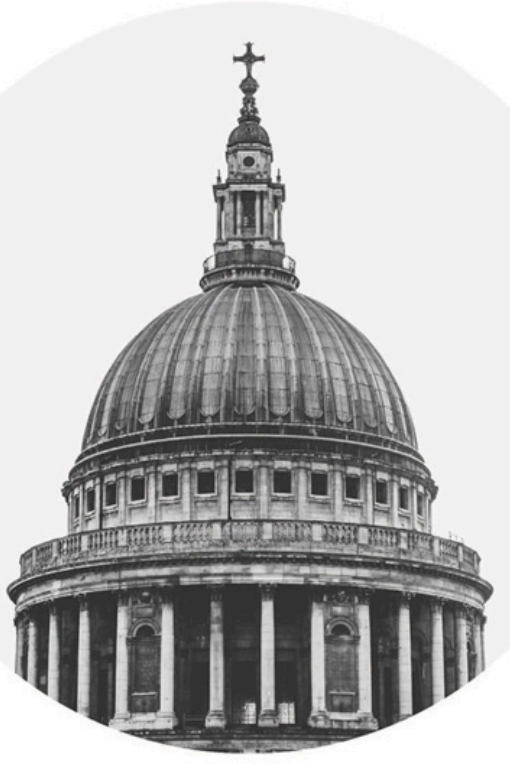

State and Local Government and Politics Prospects for Sustainability

Christopher A. Simon, Brent S. Steel and Nicholas P. Lovrich 

State and Local Government and Politics: Prospects for Sustainability 



\section{State and Local Government and Politics: Prospects for Sustainability}

CHRISTOPHER A. SIMON; BRENT S. STEEL; AND NICHOLAS P. LOVRICH

OREGON STATE UNIVERSITY

CORVALLIS, OR 


\section{() (1) ( (2)}

State and Local Government and Politics: Prospects for Sustainability by Christopher A. Simon, Brent S. Steel \& Nicholas P. Lovrich is licensed under a Creative Commons Attribution-NonCommercial-ShareAlike 4.0 International License, except where otherwise noted.

Publication and ongoing maintenance of this textbook is possible due to grant support from Oregon State University Ecampus.

Suggest a correction (bit.ly/33cz3Q1)

Privacy (open.oregonstate.education/privacy)

This book was produced with Pressbooks (https://pressbooks.com) and rendered with Prince. 


\section{Preface}

Sustainability is about improving the odds of continued existence under preferred conditions. Preferred conditions can entail many things. Nineteenth century writer Henry David Thoreau presented a rather succinct glimpse of a very personal journey to discover the meaning of life lived under preferred conditions. In one of his most insightful chapters "Where I Lived and What I Lived For" in the classic account Walden (or Life in the Woods), Thoreau vowed to confront the "essential facts of life" in terms of modes of living and principles by which to live well.

While Thoreau's soul-searching journey was a highly personal one carried out in a bucolic setting, in a modern society composed of billions of individuals sharing a planet newly aware of its own fragility the generally accepted political, social, and economic institutions and guiding principles defining society as a whole would seem to require the same process of careful soul-searching by the next generation of college-educated persons. As our global society evolves, decisions about what principles and practices should continue to be accepted and what changes should be made ought to result from a sustained, open, and easily accessible dialogue about our individual and collective preferences. It is our hope that this book contributes to that dialog.

In the larger societal sense, sustainability might be easily confused with the concept of "hanging on." Clearly, many great nations and civilizations have experienced both long and painful declines and have sought to remain sustainable despite a growing sense of the inevitable. More positively, sustainability could serve as recognition that without general guidelines for existence, an upward societal trajectory and an improved future is unattainable. Rather than drive society towards eventual disaster, perhaps it would be better to alter course and avoid trouble.

This book is a collective effort to understand and apply 
current conceptualizations of sustainability to a study of state and local government. It is an attempt to focus our attention on a basic understanding of the time-tested institutions and guiding principles likely to take society and governance towards greater advancement. Our work is, however, tempered by a developing understanding of smart growth - growth in productive capacity, quality of life and social justice that does not necessitate large-scale destructive or extractive activity. The growth sought produces widespread mutual benefit, is prudent in design and thoughtful in execution. The growth in question here is mindful of the past, yet builds better lives and futures for our posterity.

It is important to recall that sustainability is neither a conservative nor a liberal concept. Rather, it is built around a basic human need to maintain our collective and individual bearings in an ever-changing world. Throughout time, humans have found their collective and individual bearings through institutional memberships and shared principles. While conservatives and liberals may place varying emphases on aspects of institutions and principles, conservatives and liberals alike desire to maintain core democratic values and are eager to sustain the institutions which give life to those values.

As authors, we seek to provide a book that will help students understand a current conceptualization of sustainability and how it plays out in the governance of the states and localities in the nation. It is a dialogue built on the ideas, experiences and events of many cited scholars and their works, as well as the personal research experiences of the authors themselves.

Our book represents a unique opportunity for three generations of scholars to reflect upon and collectively consider their decades' long research, and the meaning of that research to both the broader society and to students of contemporary politics. Nicholas Lovrich served as a graduate school mentor to Brent Steel, and Brent in turn mentored Christopher A. Simon as an undergraduate and guided him to study with Lovrich. Steel and Lovrich have collaborated on research for over 30 years, while 
Simon has frequently collaborated with Steel and Lovrich for nearly 20 years.

Research experience was not the only guide or source of our inspiration, of course. For Christopher A. Simon, his years of alternately living on a sailboat and a farm brought him close to issues of survival and the wise use of the resources available to both him and his parents, Raffi G. and Susan M. Simon. Along with his youthful experiences sailing the Pacific Ocean and working the tilled farmland of Central Oregon, his parents instilled in him the importance of studying history and philosophy. For Brent Steel, growing up traveling and camping with his grandparents in locations ranging from Alaska, to northern and western Canada, and the mountains of the American west, he learned a deep appreciation for the environment and our need to be sound stewards of our environment so that future generations can enjoy and "soul search" just as Thoreau had done. For Nicholas Lovrich the experience of growing up in an immigrant family in a multi-cultural social setting provided an opportunity to see American society from a slight distance. Viewed from that perspective, it was possible to see the great value present in the inventive and adaptive capacities of Americans in every state and hamlet across the country as they manage the changes brought on by their powerful economic system drawing upon access to vast natural resources and benefiting from wise investment in the education of the nation's youth. 



\section{Chapter I: Introduction and Themes}

\section{I.A - Introduction}

State and local government are the most visible levels of government in the United States. As you leave your family house, apartment, or school dormitory you encounter state and local government services, programs and infrastructure. From traffic lights, streets and highways, water and sewer services, K-12 education, higher education, parks, mass transit, law enforcement, utilities, communications and mass media, and many other activities, state and local governments are either directly involved in offering these services or in regulating organizations hired to provide such services. From the 50 states to the 3,031 county, 19,519 municipal, 16,360 town or township, and 51,146 special purpose governments (which could include school, hospital districts, rural fire districts, soil conservation districts, irrigation districts, regional transportation districts, and many more), the typical citizen encounters state and local government services and programs on a daily basis.

While state and local governments are the most visible and potentially most important on a daily basis for most citizens when compared to the federal government, the generally low levels of interest in and knowledge concerning these governments and the often high levels of cynicism regarding their leaders among citizens is of great concern to many political scientists. ${ }_{-}$Given the importance of civic knowledge to effective participation and democratic 
institutions, how many states require students to take civics and government education? As of 2007, only 29 states require a government or civics course in high school. However limited this coverage may seem, this is a much higher proportion than is present at the university level; only 9 U.S. states require some study of American government, with 5 of these also requiring study of their respective state governments as well. ${ }_{-}^{2}$ Of course, universities and political science departments may require such courses on their own, but courses on state and local government tend to be optional in most colleges and universities. The purpose of this book is to provide an accessible overview and guide to state and local government for students with little to no exposure - and possibly limited interest - in order to encourage lifelong democratic participation and what Russell Dalton calls "engaged citizenship.". ${ }_{-}^{3}$ In an attempt to achieve this purpose, we will present state and local government in a contemporary context by examining the many forces that either promote or threaten social, economic, institutional and environmental sustainability. In using the term sustainability, we make use of the 1987 Brundtland Report definition (also known as Our Common Future): development that meets the needs of the present without compromising the ability of future generations to meet their own needs. The book will make note of where students can go to find additional information on state and local governments, and how citizens can follow the developments of - and even become actively involved in - the unfolding of state and local governance issues that affect their own daily lives.

Each chapter in this book incorporates some of the most important recent research available, and identifies key concepts, which are important to deepen our understanding of state and local government and sustainability. These concepts are highlighted in boldface in the text and are included in the glossary at the end of the book. 


\section{Learning Objectives}

The major topics to be discussed in this introductory chapter include:

- Changing socioeconomic, demographic and technological forces and how they affect state and local governments.

- How many states and communities have responded successfully to these forces to promote sustainability.

- A final summary of the book's themes, and how the book's chapters are organized.

\section{I.B - Forces facing State and Local Governments}

State and local governments currently face many ongoing and numerous new challenges that complicate their task of sustaining current public services and programs. How public officials adapt or do not adapt to these changes will affect the long-term viability of virtually each and every state and local government in the country. As the United States has developed from a rural and agricultural-based economy in the 1700 s into an industrial powerhouse in the 1800 s, and now as it becomes increasingly a postindustrial society with a 
knowledge-based economy and the majority of citizens employed in service sector jobs instead of the agricultural and industrial sectors, state and local governments have had to cope with a wide array of socioeconomic and political changes (see figure 1). Needless to say, the dramatic events of the nation's first major experience with foreign terrorism on September 11, 2001, have added to concerns for homeland security that were scarcely considered prior to that horrific historic event.

\section{ECONOMIC FEATURES:}

\begin{tabular}{llll}
\hline & Pre-Industrial & Industrial & Postindustrial \\
$\begin{array}{l}\text { Sectoral } \\
\text { dominance }\end{array}$ & Agriculture & Manufacturing & Services \\
$\begin{array}{l}\text { Systematic } \\
\text { character }\end{array}$ & Labor intensive & Capital intensive & $\begin{array}{l}\text { Knowledge } \\
\text { intensive }\end{array}$ \\
Technical change & Slow & Rapid & Exponential \\
$\begin{array}{l}\text { Material } \\
\text { condition }\end{array}$ & $\begin{array}{l}\text { Poverty / } \\
\text { Subsistence }\end{array}$ & $\begin{array}{l}\text { Rising } \\
\text { productivity }\end{array}$ & Affluence \\
\hline
\end{tabular}

SOCIAL FEATURES:

\begin{tabular}{llll}
\hline & Pre-Industrial & Industrial & Postindustrial \\
$\begin{array}{l}\text { Population } \\
\begin{array}{l}\text { Population } \\
\text { growth }\end{array}\end{array}$ & Rural & Urban & Megalopolitan \\
Community & Intimate & Moderating & Low or negative \\
$\begin{array}{l}\text { Literacy } \\
\text { Dominant values }\end{array}$ & $\begin{array}{l}\text { Basic / survival } \\
\text { needs }\end{array}$ & $\begin{array}{l}\text { Material } \\
\text { security }\end{array}$ & $\begin{array}{l}\text { Poding } \\
\text { values? }\end{array}$ \\
\hline
\end{tabular}

\section{POLITICAL DIMENSIONS:}




\begin{tabular}{|c|c|c|c|}
\hline & Pre-Industrial & Industrial & Postindustrial \\
\hline Central issue & $\begin{array}{l}\text { "Who shall rule?" } \\
\text { (political order) }\end{array}$ & $\begin{array}{l}\text { Economic Growth } \\
\text { (economic order) }\end{array}$ & $\begin{array}{l}\text { Sustainable } \\
\text { development }\end{array}$ \\
\hline Object of conflict & Office / power & $\begin{array}{l}\text { How to distribute } \\
\text { expanding wealth }\end{array}$ & $\begin{array}{l}\text { Both quantity } \\
\text { and quality of } \\
\text { life issues }\end{array}$ \\
\hline $\begin{array}{l}\text { Attitude toward } \\
\text { authority }\end{array}$ & Deferential & $\begin{array}{l}\text { Supportive (elite } \\
\text { directed) }\end{array}$ & $\begin{array}{l}\text { Challenging } \\
\text { (elite } \\
\text { challenging) }\end{array}$ \\
\hline Governability & Variable & High & $\begin{array}{l}\text { Declining - } \\
\text { "crisis of } \\
\text { confidence" }\end{array}$ \\
\hline
\end{tabular}

Figure 1.1 Socio-economic and Political Characteristics of the United States

A substantial literature has developed examining the social, economic, and political implications of postindustrialism. ${ }_{-}^{4}$ While some degree of definitional disagreement is present among scholars writing in this area, a few commonly agreed upon central features of this new type of society can be identified which help us understand the dynamics of state and local government today. Postindustrial societies - such as the United States, Canada, and the nations of the European Union, Australia, and Japan - are characterized by the following traits:

- economic dominance of the service sector over those of manufacturing and agriculture; complex nationwide communication networks;

- a high degree of economic activity based upon an educated workforce employing scientific knowledge and technology in their work;

- a high level of public mobilization in society (including the rise of historically new social causes such as the civil rights movement, the women's rights movement, the anti-nuclear 
movement, the anti-globalization movement, the environmental movement);

- population and employment growth in urban areas (and subsequent decline in rural areas); and historically unprecedented societal affluence. ${ }_{-}^{5}$

As the United States developed from a small pre-industrial nation of a few small settlements and many farmers and artisans into a modern, continent-spanning postindustrial economy connected to a knowledge-based global economy, different sets of concerns and issues have assumed priority in our collective consideration of public affairs. In the early years of the young country's history, the principal issues of concern were such matters as basic nutrition, shelter, assess to water, safe routes of travel, safety of person and property, etc. Because of such immediate survival and infrastructure concerns, American state and local governments - which were generally small in scale and limited in capacity - accorded little attention to such contemporary issues as environmental protection or other "higher-order needs" such as gender equity and global economic justice.

As the United States moved into extensive mining and natural resource extraction and the large-scale fabrication and manufacturing of durable goods, many issues relating to industrialization became important for American state and local governments. Highly troublesome issues such as unsafe workplaces, unrestrained child labor exploitation, uncontrolled urbanization, inadequate local transportation systems, poor public health services, toxic waste disposal, and inadequate public education systems arose as the industrialization process proceeded. All of these issues were addressed by state and local government regulation in due course, with federal government action coming only after state and local governments took the initiative to address these adverse consequences of industrialization. With the 
ultimate development of a more affluent post-industrial economy and more adequate systems of public regulation, new issues have emerged which reflect a profound concern for global sustainability. Such a historically unprecedented concern for our collective global future translates into particular issues of great importance for the contemporary state and local governments in the United States. Issues regarding water resource protection and conservation, "smart growth" and environmental stewardship-oriented land-use practices, the enforcement of energy-efficient building standards, the implementation of air quality protection measures, the reduction of the impact of carbon emissions on global climate change are all directly involved in promoting sustainable economic development in state and local governments in the United States today.

State and local governments in many areas of the nation face additional challenges in the areas of dramatic demographic shifts (aging populations, racial and ethnic diversification and the influx of large numbers of immigrants), continued urbanization, economic globalization, ongoing technological change, changing social norms, and growing environmental awareness. Thoughtful observers taking note of these changes, such as Roger Kemp, have argued that state and local governments will be affected directly in a number of ways in the twenty-first century. He has observed the following in this regard: "Evolving societal conditions and public perceptions have created trends that require communities to change in order to meet the public's expectation for effective and equitable governance" [emphasis added] (2001: 1). ${ }_{-}^{6}$ These historic changes, closely associated with the advent of postindustrial society, are discussed below to provide a suitable backdrop to our exploration of state and local government in contemporary America. 


\section{I.B.I - Demographic changes:}

People are living longer than ever before, a fact which affects a host of government services, including: (1) increasing costs associated with retirement pensions, healthcare and other social services such as independent, assisted and dependent living arrangements for the aged; (2) increasing demand for senior citizen recreational and leisure activities, including parks, libraries, exercise opportunities; and (3) higher rates of political participation in state and local affairs by senior citizens. Seniors exhibit high rates of political participation when compared to younger cohorts, which means the public policy preferences of seniors may disproportionately affect state and local community decisions (e.g., preference for lower taxes because of fixed retirement incomes, preference for robust spending on public safety and meager spending on education, etc.).

Another important demographic change taking place in much of the country is large-scale immigration from Mexico, Central America, and South America. Such immigration creates new public issues for many communities, including the need for bilingual government services in education, justice and social spheres, new cultural diversity programs, new approaches to housing and transportation services, new types of law enforcement issues arising from claims of biased policing, etc. Hispanics or Latinos are now the largest minority group in the United States and their proportion of the population continues to grow at a rapid rate, and in Florida, New York, Illinois, California and most southwestern states powerful new political voices and advocacy groups articulating Latino demands for state and local government programs and services are adding to the challenges of those governments.

Another demographic trend, which has been in stark 
evidence is the increasing presence of women in the workforce and in state and local government leadership roles. This enhanced presence of women in the workforce and in leadership roles has led to increased emphasis on such issues as family leave policies, daycare provisions, equal employment opportunities, comparable worth compensation policies, sexual harassment, and domestic violence. Due to a variety of factors, including rising educational levels as well as higher percentages of women working outside the household, average family size is declining, potentially leading to more high-density residential areas (townhouses, condominiums, etc.) being created in urban areas. This type of residential settlement pattern places different demands on existing state and local service infrastructure than is associated with the traditional suburban "sprawl" pattern of housing settlement.

\section{I.B.II - Urbanization:}

The United States has been transformed from a rural nation of 3.92 million people in 1790 (our first census of the population) to an urban society of 325 . $^{7}$ million people as of 2010. After a relatively slow rate of urban growth in the eighteenth century, the pace of urbanization picked up dramatically during the nineteenth and early twentieth centuries (see Table 1.1). During the twentieth century, the urban population continued to increase and suburban areas started to develop and grow as well. During the 1980s and 1990s, a substantial number of rural counties in the United States lost population, while urban and suburban counties grew at a rapid rate. The migration of people from rural to urban/suburban counties was driven by the most highly educated and/or skilled younger cohorts leaving rural areas 
to seek jobs or further education in urban core areas.7 These migration patterns have led to the acquisition of increased economic and political power on the part of urban and suburban centers vis-à-vis rural areas and contributed to the political and economic decline of communities whose local economies are based in the rural periphery. ${ }_{-}^{8}$

\begin{tabular}{lll}
\hline Year & Percent Urban & Percent Rural \\
2010 & 81 & 19 \\
2000 & 79 & 21 \\
1990 & 75 & 25 \\
1960 & 70 & 30 \\
1930 & 56 & 44 \\
1900 & 40 & 60 \\
1870 & 26 & 74 \\
1840 & 11 & 89 \\
1810 & 7 & 93 \\
1790 & 5 & 95 \\
\hline
\end{tabular}

Table 1.1 Urban and Rural Population Change in the United States

Urbanization has had a pronounced social, economic and environmental impact on communities throughout the country. A visitor to a major city in the United States will likely experience traffic congestion arising from our love of automobiles, be greeted by smoggy air and haze in the summertime, witness municipal sewage being dumped into rivers, and be shocked by the enormous amounts of trash produced by our mass consumption society. ${ }_{-}^{9}$ Viewed from a regional perspective, that same visitor to a major metropolitan population center might be saddened by a sense of loss of once prime agricultural lands, forests, and woodlands, wildlife habitat, and wetlands due to urban

10 | State \& Local Government \& Politics 
sprawl. ${ }^{10}$ In fact, some of the most divisive political issues in U.S state politics result from urban areas encroaching on rural communities and their land-based economies. ${ }^{11}$ Source: U.S. Department of the Census web site [URL: www.census.gov].

The phenomenon of suburban sprawl has led to the growth of geographically vast metropolitan areas where cities have literally grown into each other, often swallowing up prime agricultural areas and natural landscapes in the process. For example, there are huge continuous urban areas between San Diego and Los Angeles in California, and "the eastern seaboard of the USA, where one-quarter of the national population resides on less than $2 \%$ of the nation's land." - These vast metropolitan areas universally succumb to serious traffic congestion and harmful air quality problems, not to mention the dependence they breed for the consumption of great amounts of petroleum products. ${ }_{-}^{13}$

Continuing growth and geographical dispersion of urban and suburban areas in the United States, along with the decline in natural resource and agricultural sectors of the economy, has led to the service sector employment accounting for over 70 percent of the U.S. economy. Employment in the agricultural and natural resource extraction sectors has declined to less than 2 percent of the contemporary labor force. ${ }_{-}^{14}$ In addition, unemployment and poverty rates are typically higher and wages lower in the rural periphery when compared to the metropolitan areas. ${ }_{-}^{15}$ Substantial economic decline in rural communities can contribute to a felt imperative among its residents to increase natural resource extraction in order to sustain community viability, while continued growth in the urban service industry creates a contrary imperative toward nonmaterial uses of natural environments such as recreation and provision of wildlife habitat. ${ }_{-}^{16}$

Other issues often confronting communities arising from 
urbanization include: escalating land prices due to the gentrification of neighborhoods (i.e., the displacement of low income residents living in inexpensive housing with high income residents living in high cost housing); traffic congestion leading to demands for more freeways, parking lots and possibly mass transportation such as buses and lightrail systems; more expensive construction costs due to the development in densely populated areas; more demands for inner-city services which could include social, educational, public health, public safety, recreation and open space, and economic security issues.

\section{I.B.III - Globalization and Economic Change:}

Globalization is a concept used to describe, among other things, the current worldwide expansion of economic markets in a very broad range of goods and services. The creation of the current global free-market economy was facilitated by a variety of "international regimes" (i.e., treaties and multilateral agreements) such as the GATT (General Agreements on Tariffs and Trade) and institutions such as the World Trade Organization, the World Bank, and the International Monetary Fund. Globalization is based on the economic theory of neoliberalism, a worldview perspective which promotes free trade, continuous economic growth, free domestic markets, maximal individual choice in consumption, reduced government regulation of the economy, and "the advocacy of an evolutionary model of social development anchored in the Western experience and applicable to the entire world."17

In general, neo-liberalism and globalization view economic growth as the primary expression of human progress and believe that the expansion of free trade and the 
promotion of Western consumerism are the proper public policy goals for nations and local communities alike. Critics of globalization, however, point to the phenomenon of international homogenization in culture, lifestyles, and technology that accompanies globalization. This phenomenon is referred to by some opponents of globalization as the "McDonaldization effect." ${ }_{-}$An example of this phenomenon would be the increasingly similar types of suburban shopping areas emerging across communities in the United States, each featuring similar restaurants, clothing stores, c shops, superstores, and the like. Critics point to diminishing local control and loss of cultural diversity, while the advocates of "mall development" point to the sales tax revenue and employment benefits to local communities which are associated with such commonplace contemporary commercial land use development. . $_{-}$

The globalization of the economy creates special problems with states and local communities as they seek to attract and retain businesses and generate employment in an international and national context. Many states and local communities find themselves in a situation where, in order to attract potential employers, they must offer tax concessions and economic development subsidies such as infrastructure and targeted worker training programs. The influx of new numerous chain stores and nationally (or even internationally) franchised businesses causes locally-owned businesses to struggle to survive, often bringing adverse effects on local community culture and resulting in less local influence overinvestment in local, community-based enterprises.

Compounding these global changes are generally constrained state and local government budgets. Unlike the federal government, the ability of the state and local governments to engage in deficit spending is extremely limited - and "balanced budgets" with respect to anticipated revenues and budgeted expenditures are very much the norm 
across the country. State and local government fiscal capacity is generally highly constrained due to the following factors: widespread use of economic incentives (tax concessions and targeted expenditures) for the promotion of economic development; widespread public hostility to raising taxes to support public services and programs; ${ }_{-}^{20}$ the increasing cost of many essential services and entitlements such as healthcare facilities and services, fire protection, police protection, corrections facilities, transportation infrastructure (e.g., streets, roads and bridges), and education; and the increasing demand and cost for new amenities and services characteristic of postindustrial societies such as cultural (visual and performing arts) programs, access to broadband Internet services, public libraries, park and recreation programs, walking and bike trails, museums, etc. To provide these services states and communities have come to rely heavily on a variety of user fees and charges and other nonproperty, non-sales and non-income tax revenues. Steger reminds us in this regard:

Citizens don't mind paying for those services they use, but they will increasingly demand that other taxpayers pay their fair-share of taxes for the cost of providing those "other" services that "they" do not use. This will pose a political problem, since everyone uses selected services but no one uses every public service. 


\section{I.B.IV - Technological Change:}

The growing role of a ceaselessly changing information technology is particularly important to understanding some new issues facing state and local government in our contemporary post-industrial, highly knowledge-based society. The technological infrastructure of communities plays an important role in attracting the knowledge-based businesses characteristic of postindustrial countries, and this modern information technology (IT) infrastructure is becoming an important component of state and local government governance as citizens grow increasingly comfortable in the use of the Internet to access government information, to file required forms, to renew their drivers' licenses, to register to vote, to reserve summer campgrounds, to pay taxes, and to communicate with their elected and career service public officials.

Most state and local governments are heavily reliant on computers and electronic communication - both large servers and desktop computers - to conduct their work. This development has been referred to in a number of ways, including "e-government," "on-line government," and "transformational government." State and local governments are increasingly exchanging information and providing services to businesses and citizens alike in an effort to promote efficiency and increased accountability. A 2002 survey of local governments conducted by the International City/County Management Association (ICMA) found that over 85 percent of municipalities had active websites providing a large variety of services and information for citizens. ${ }_{-}^{22}$ For example, citizens in many states can now acquire their fishing and hunting licenses by using the Internet, they can pay local property and state income taxes online, they can get transportation updates concerning weather, road, and bridge 
construction projects, or traffic congestion from state and local government websites on their personal computers or web-enabled cell phones. Many local governments are even now monitoring their high crime areas and mass transportation corridors by the use of digital video cameras to provide greater protection for citizens - in some areas even monitoring traffic intersections and roads for traffic violations (e.g., speeding or running a red light) in order to issue electronic citations to violators and notices of violations to prosecutors and courts.

Many state and local governments across the country are also using the Internet to engage citizens in the policymaking process, and some are even implementing electronic voting technologies as part of this process. This innovation has been called "e-democracy." Most state governments have established websites that include extensive information concerning all branches of government, various departments and agencies, and information on how and where citizens may contact their elected and career service officials. ${ }_{-}^{23}$ Similarly, new electronic voting technologies are being implemented to speed the counting of ballots as well as providing more userfriendly access for disabled voters. However, e-democracy has also generated considerable controversy because its critics argue that election fraud can occur through difficult to detect software malfunctions or even the electronic manipulation of vote counts.

While e-government and e-democracy are important new technologies consistent with the advent of postindustrial society, important social justice concerns can arise about selectivity in access. For example, recent research has found that the young, the highly educated, the urban, the middle and upper-middle class, and the nation's white citizens are the most likely use the Internet. ${ }^{24}$ In addition, in a recent study of municipal websites research found that "...city size and scale matter in achieving overall web site quality." ${ }_{-} 5$ Smaller and 
more rural local governments have far fewer resources and more limited expertise to develop and maintain websites and Internet services, thus resulting in another type of access gap. Thus, the ability of e-government and e-democracy to deliver on the promise of enhanced service efficiencies and enhanced democracy and social equity remains somewhat in question.

Another related concern that arises from rapid technological innovation in the United States has been referred to by some scholars as the "democracy versus technocracy quandary." ${ }_{-} 6$ As postindustrial governments, state and local governments face many policy problems that are highly technical in nature and require scientific knowledge to manage effectively. As Frank Fischer in Citizens, Experts, and the Environment aptly observes: "The tension between professional expertise and democratic governance is an important political dimension of our time. Democracy's emphasis on equality of citizenship, public opinion, and freedom of choice exists in an uneasy relationship with the scientific expert's rational, calculating spirit.,27

While there are considerable geographical, cultural and economic differences among state and local governments, they all feature democratic systems of governance that have experienced a noteworthy decline in public trust of government (both elected representatives and governmental bureaucracies). ${ }_{-}^{28}$ Along with this diminished trust have come forceful demands for increasing citizen involvement in governance (Inglehart, 1997). The concern that arises in this context is that the demand for the enhancement of direct citizen participation (democracy) and the need for scientific expertise (technocracy) to frame issues and develop appropriate policy options in complex areas of public policy may well come into direct conflict. ${ }_{-}^{29}$ On the one hand, placing too much emphasis on science and technical expertise as the ultimate determinants of policy outcomes risks the erosion of democracy and the progressive diminishment of active 
engagement of the citizenry. ${ }_{-}^{30}$ On the other hand, excessive democracy in the form of the direct involvement of illinformed citizens in policymaking and program implementation may relegate technical and scientific information to such a peripheral role that complex problems will be inadequately addressed by the adoption of "political" solutions reflecting the relative power of a narrow set of intensely interested parties. ${ }_{-}^{31}$

\section{I.B.V - Value Change:}

As discussed above, in the decades following World War II a number of fundamental changes transpired in the United States that have fundamentally changed politics from what had existed in previous years. The shift from an agricultural to an industrial society and then a postindustrial society has led to substantial value change (fundamental cultural realignment) in the United States, and this value change has direct implications for state and local governments. Personal value structures among citizens (particularly younger cohorts) are developing in ways that involve what the widely read psychologist Abraham Maslow termed "higher-order" needs (e.g., social affiliation, quality of life concerns, connection to transcendent values) supplanting more fundamental subsistence needs (e.g., health and safety concerns, material acquisition) as the motivation for much individual and societal behavior. ${ }_{-}^{32}$ Value changes entailing greater attention to postmaterialist needs are thought to have brought about changes in many types of personal attitudes and public policy preferences, including those related to environmental protection, to gender equity, and to global justice and other similar philosophical or worldview issues. $\stackrel{33}{-}$ Some careful 
observers of societal change in postindustrial societies suggest that the development of social movements in the United States relating to consumer protection, women's rights, gay rights, and environmental protection are a clear reflection of societal value change. .34

The development of new values and social movements among citizens has resulted in the questioning of many traditional state and local government institutions and longestablished policies. ${ }_{-}$- Many scholars believe this is most pronounced among what has been labeled the "millennial generation" (born after 1982). When compared to older cohorts, Millennials have been found to be: (1) very optimistic about their own lives and the role of government in their lives; (2) believe that special interest groups currently have too much influence; (3) are more involved in local community based civic activities; (4) more tolerant of gays, race and ethnic diversity; and, (5) very supportive of non-traditional roles for women. Millennials also have been heavily influenced by new communications technologies (e.g., smartphones) and are very comfortable and adept users of social networking sites such as MySpace, Facebook, Twitter, and YouTube.

\section{I.B.VI - Environmental Change and Concern:}

As with the other factors affecting state and local governments, new environmental issues and concerns also reflect the nation's transformation from a pre-industrial agricultural nation in 1776, to the coming of the industrial revolution in the late $1800 \mathrm{~s}$, and then to the development of a postindustrial society in the latter half of the twentieth century. ${ }_{-}^{36}$ From colonial times to the beginning of the twentieth century, environmental policy was primarily framed 
by anthropocentric concerns such as the impact of pollution on human health and the need for the careful conservation of natural areas for future extraction of economically desirable products. The natural environment was seen primarily as something to either conserve or conquer depending on the uses to be made of it to improve the quality of human life; apart from the needs of human beings, the environment per se had no particular value.

The start of the twentieth century witnessed rapid growth in the number of citizens and organized groups interested in the conservation of natural resources. Interest in conservation often arose in reaction to the highly visible widespread abuse and even destruction of public forests and waterways. A new approach to the stewardship of natural resources was adopted in the United States over time based largely on the writings of the visionary Gifford Pinchot. He was a highly respected figure who argued for the development of scientific expertise leading to the intelligent use and development of natural resources and the protection of natural resources for the benefit of future generations. This approach to the natural environment was based on a premise of anthropocentrism - that is, a human-oriented view of nature where human needs, wants, and desires are given preeminent priority in the managing of natural resources. Moreover, it assumes that the nonhuman part of the environment is to be seen as little more than a fund of raw materials for humans to make use of as they see fit. It follows from this premise that providing for human uses and benefits becomes the primary aim of any environmental policy, whether those uses are for commodity benefits (e.g., lumber, food or energy) or for aesthetic or spiritual benefits (e.g., wilderness preservation and outdoor recreation).

By the late 1960s, however, a new environmental policy orientation emerged in some U.S. states and many communities, one which is more "bio-centered" or "eco- 
centered" in its premises ${ }_{-}^{37}$ and in its philosophical character. ${ }^{38}$ The biocentric approach elevates the requirements and value of all-natural organisms, species, and ecosystems to center stage and, in some versions, makes the earth or nature as a whole the focus of "moral considerability." Advocates of this orientation do not ignore human needs, but rather they place such needs in a larger, natural, or ecological context. In addition, adherents to this view of the natural world tend to assume that environmental assets such as mountain ranges, free-running streams, pristine ecosystems, wilderness areas, wildlife, and non-edible animals and plants all have value in and of themselves as bio-diversity assets. This perspective has become an important component of the new social movement advocating the adoption of sustainability-promoting policies and programs in American communities, a topic which we take up next.

\section{I.C - Sustainable and Resilient States and Communities}

The advocacy for sustainable states and communities in postindustrial America has become one of the major social movements of our time. $\frac{39}{-}$ Widespread concern with the longterm carrying capacity of our conventional economic, social, ecological processes and with the institutions required to manage them has led many state and local government officials and civic-engaged citizens to conceive and implement a wide range of innovative policies in pursuit of sustainability. The concept of sustainability refers to the manner in which the social, economic, institutional, and environmental needs 
of a community are met without compromising the ability of future generations to meet their own needs. ${ }^{40}$ Early approaches to addressing sustainability have placed rather differing emphases on these various needs, ${ }_{-}^{41}$ but in general, the four core dimensions of sustainable communities include:

- Social objectives: systematic investment in human capital featuring lifelong education promoting environmental sensitivity and adaptability to change, and social capital enabling the widespread co-production of public goods through both coordinated individual action and enhancing the capacity for effective collective action in behalf of environmental protection. ${ }_{-}^{42}$

- Economic objectives: through public law and policy, and through public-private partnerships, bring about a shift towards "sustainable economics" featuring equitable and competitive arrangements in the marketplace supplying high quality (e.g., non-toxic, organic, non-exploitive), reasonable cost goods and services produced with minimum damage to the environment. 43

- Environmental objectives: protection of the global ecosystem, enhancement of local biodiversity, protection of endangered species, and systematic preservation of natural areas from harm resulting from unsustainable economic exploitation or unwise uses

- Institutional objectives: structural change to promote greater population density as opposed to urban sprawl, promote greater social equity among economic classes and racial/ethnic groups, promote greater attention to intergenerational justice, promote global justice, and enhance mechanisms for civic engagement at the local government level

Many contemporary sustainability efforts being undertaken by state and local governments are directed at meeting pressing environmental concerns, especially those 
that entail health-threatening deterioration of water or air resources or that involve the pending depletion of natural resources upon which the quality of public life of local communities depend. ${ }_{-}^{44}$ At the same time, however, the sustainability efforts taking place in some communities address important issues related to population-based conditions, such as public health epidemics, ${ }_{-} 5$ social and economic inequities leading to violence, $\underset{-}{46}$ and the promotion of greater civic engagement in the process of monitoring quality of life conditions in local communities. ${ }_{-}^{47}$ The principal assumptions underlying the sustainability movement are that the preservation of a quality environment, the use of renewable or highly efficient energy resources, the maintenance of a healthy population with ready access to preventative care and emergency health services, the presence of economic and social equity, and the maintenance of an engaged citizenry will lead to urban areas having sustainable futures in a world wherein global climate change, environmental degradation and natural resource scarcities serve as warning signs that we must change our way of life in many ways to ensure a sustainable future for the next generation. ${ }_{-}^{48}$ As noted by the Development Assistance Committee of the Organization for Economic Cooperation and Development: -49

...we have learned that successful development strategies must integrate a number of key elements: they require a sound and stable policy framework; an emphasis on social development; enhanced public participation by the local population, and notably by women; good governance, in the widest sense; policies and practices that are environmentally sustainable; and better means of preventing and resolving conflict and fostering reconciliation.

The proper balance among what is often referred to as the "three Es" - environment, economy and equity - is widely seen as being central to the achievement of a sustainable 
future. ${ }^{50}$ There are, of course, inevitable tradeoffs associated with seeking to achieve these goals simultaneously. ${ }_{-}^{51}$ The tension between promoting economic growth and the equitable sharing of opportunities that arises from the claims on the use of property as both a private resource and public good creates property conflict. The tension that arises from the competitive claims on the use of natural resources creates a resource conflict. And the challenge of improving the situation of the poor through economic growth while protecting the environment creates a development conflict. Resolving these tensions and conflicts is an ongoing process for virtually all state and local governments in the contemporary United States.

Understanding state and local government sustainability issues and the ability of state and local governments to adapt to change (i.e., display "adaptive capacity" or "resilience") means understanding the dynamics of the key socio-cultural, bio-ecological and governance systems within which American states and their respective communities operate (see Figure 1). A growing body of literature now exists which identifies some of the specific aspects of community affecting adaptive capacity. Infrastructure, diversity of economic activity, dedicated community leadership, access to physical and knowledge resources, levels of social trust and interaction, broad distribution of informal power, and linkages to outside centers of political power all emerge as important factors in promoting sustainability. ${ }_{-}$Community size, degree of geographic isolation, attractiveness of natural features, and past experiences in responding to change further affect a community's vulnerability and/or adaptive capacity. ${ }^{53}$. When a community faced with change displays a greater level of adaptive capacity, outcomes can include: greater economic well-being (including reductions in poverty and wealth inequality among groups), more effective decision-making processes through improved institutional capacity and 
efficiency, and more active participation by concerned parties to ensure that actions match local needs and resources. .4

For example, rural communities are particularly vulnerable to developments such as climate change because their internal capacity and infrastructure available to deal with large-scale change is generally quite limited. As the participants in the U.S. Global Change Research Program concluded in a recent study: "Because rural populations and their communities are highly dependent on the area's natural resources...they are at risk from climate change and from potential increases in climate variability. Rural economies...are economically vulnerable due to lower profits and tax bases, fewer resources, and their reliance on livestock and cropping systems that are often stressed. consequence of these several considerations, that our nation's rural communities may need to approach adaptation to global climate change much differently than do more well resourced and expertise-rich urban jurisdictions.

General determinants of adaptive capacity and sustainable communities can also include the following considerations: $:$ -

- Improved access to resources

- Reduction of poverty

- Lowering of inequities in resources and wealth among groups

- Improved education and information

- Improved infrastructure

- Diminished intergenerational inequities

- Respect for accumulated local experience

- Assurance that responses are comprehensive and integrative, not just technical

- Active participation by concerned parties, especially to ensure that actions match local needs and resources

- Improved institutional capacity and efficiency 


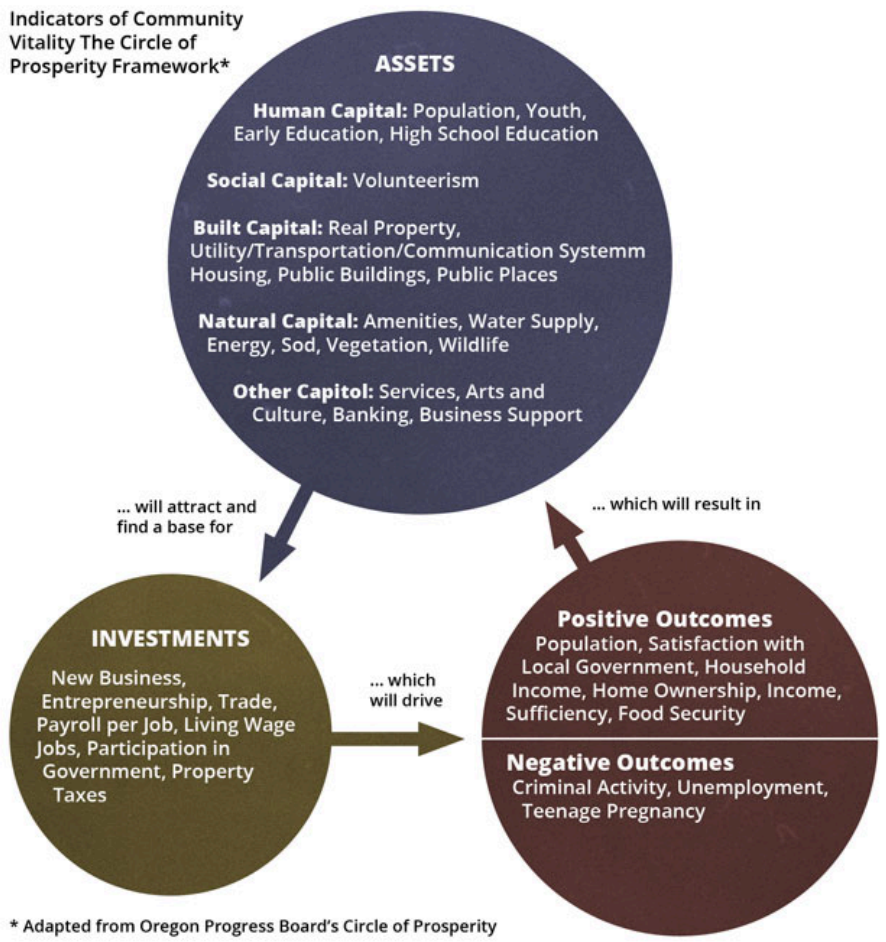

Figure 1.2 Indicators of Community Vitality and Sustainability

"Institutional resiliency," or the ability for local governmental and community-based institutions to withstand or react to major stressors, is affected by institutional "legitimacy, how well they maintain [institutional] capital, and whether their agenda is in line with risks.. ${ }_{-}$The presence of established and effective governmental and community-based institutions increases adaptive capacity as these institutions facilitate management and help community stakeholders deal with various potential risks to sustainability (e.g., economic 
transformation and climate change). Also, such institutions increase the adaptive capacity of a community to the extent they are participatory, proactive and representative of the population. ${ }^{58}$ Proactive institutions increase adaptive capacity by planning ahead through such measures as mitigation of the problem, strategic planning, and the formulation of emergency management plans. ${ }_{-}^{59}$ Therefore, as we proceed through this book, we will identify those factors that promote and those that inhibit economic, social, environmental and institutional sustainability in states and in local governments across the United States.

\section{I.D - Summary and Book Outline}

State and local governments in postindustrial America are facing many long-term and numerous newly emergent demographic, social, technological, and environmental changes that challenge their long-run social, economic, ecological and institutional sustainability. In addition to these macro forces, the recent near-total collapse of the U.S. financial system and the poor performance of the general economy in 2009 pose a serious challenge to sustainable state and local governance - perhaps the greatest challenge since the Great Depression of the late 1930s. This introductory chapter has discussed some of these long term changes and more recent challenges which have arisen briefly, as well as noted some things that American state and local governments can do to meet their respective sustainability challenges. As we discuss different aspects of state and local government in this book, we will identify both potential barriers to and opportunities for the promotion of sustainability and the achievement of resilience through the development of adaptive management capacity. This particular discussion will 
typically appear toward the end of each of the following chapters.

The first section of this book focuses on the diversity of state and local governments in our federal system (Chapter 2), the rapid proliferation and diversity of sustainabilitypromoting practices and policies in state and local governments (Chapter 3), followed by a discussion of the various actors affecting state and local policy processes set forth in Chapter 4.

The second section of the book (Chapters 5 through 9) focuses on the framework and principal institutions of state and local government - what we call "Linkage Mechanisms." A central theme in each of these chapters is how these institutions and their associated governmental processes affect all of our lives in many ways, only some of which we are typically aware. In addition, we will identify where students can access these processes and/or learn more about topics at hand. The final section of the book (Chapters 10 through 12) will focus on important policy developments in state and local government - including the expansion of social programs, changes in education policy, developments in criminal justice (courts, police, and corrections), and trends in taxes and government expenditures.

While the general level of knowledge citizens and students have about state and local government can be somewhat limited, our hope here is to engage readers and promote thoughtful lifelong engaged citizenship with state and local governance. Dalton has defined this type of citizenship as emphasizing "...a more assertive role for the citizen and a broader definition of the elements of citizenship to include social concerns and the welfare of others" (2008: 5). ${ }_{-} 0$ The growing literature on sustainability suggests strongly that this engagement is among the most important components of resilient and sustainable communities (Walker and Salt, 2006). With American youth volunteering for near- 
unprecedented levels of community service in America, and now a historic level of engagement by youth in the 2008 general election, the time for learning about and engaging actively with state and local governments has never been better. 


\section{Terms}

Adaptive Capacity

Anthropocentric Concerns

Brundtland Report

Democracy Versus Technocracy Quandary

E-Democracy

E-Government

Engaged Citizenship

Gentrification

Globalization

Higher-Order Needs

Institutional Resiliency

Linkage Mechanisms

McDonaldization Effect

Neo-liberalism

Postindustrial Society

Post-Materialist Needs

Smart Growth

Sustainability

\section{Discussion Questions}

1. Based on your reading, list and discuss four characteristics of postindustrial society commonly found in the US, Canada, Australia and many nations in the European Union.

2. Based on your reading, list and discuss three 
particular issues of great importance for contemporary state and local governments in the U.S. in terms of promoting sustainable economic development.

3. According to the chapter, list and discuss four core dimensions (objectives) of sustainable communities.

\section{Notes}

1. J. Hibbing and E. Theiss-Morse, "Civics is Not Enough: Teaching Barbarics in K-12," PS: Political Science and Politics. 29 (1996): 57-62.

S. Maced, Democracy at Risk (Washington, DC: Brookings Institution Press, 2005).

S. Mann, "What the Survey of American College Students Tells Us About Their Interest in Politics and Political Science," PS: Political Science and Politics 32 (1999): 263-268.

2. Kedrowski, K., "Civic Education by Mandate: A State-byState Analysis," PS: Political Science and Politics 36 (2003): 225-227.

3. R. Dalton, The Good Citizen: How a Younger Generation is Reshaping American Politics (Washington, DC: CQ Press, 2008).

4. D. Bell, The Coming of Postindustrial Society (New York: Basic Books, 1973).

R. Bellah, R. Madsen, W.M. Sullivan, A. Swidler, and S.M. Tipton, Habits of the Heart: Individualism and Commitment in American Life (New York: Harper and Row, 1985). 
Huntington, S., "Postindustrial Society: How Benign Will it Be?" Comparative Politics 6 (1974): 163-191.

5. W. Galston, "Rural America in the 1990s: Trends and Choices," Policy Studies Journal 20 (1992): 202-11.

R. Inglehart, Modernization and Postmodernization: Cultural, Economic, and Political Change in 43 Societies (Princeton, NJ: Princeton University Press, 1997).

6. R.L. Kemp, "Cities in the 21st Century: The Forces of Change," Local Focus (Salem, OR: League of Oregon Cities, February and April, 2001), p. 1.

7. K. Deavers, "Rural Development in the 1990s: Data and Research." Paper presented at the Rural Social Science Symposium, American Agricultural Economics Association, Baton Rouge, Louisiana, 1989.

8. C. Beale and G. V. Fuguitt. "Decade of Pessimistic Nonmetro Population Trends Ends on Optimistic Note," Rural Development Perspectives 6 (1990): 14-18.

9. L. Cohen, A Consumer's Republic: The Politics of Mass Consumption in Postwar America (New York: Knopf, 2003).

10. R. Louv, Last Child in the Woods: Saving Our Children from Nature-Deficit Disorder (Chapel Hill, NC: Algonquin Books, 2006).

11. D. Rusk, Cities Without Suburbs - Third Edition: A Census 2000 Update (Washington, DC: Woodrow Wilson Center Press, 2003).

12. A.J. McMichael, "Urbanisation and Urbanism in Industrialized Nations, 1850 Present: Implications for Health." In L.M. Schell and Ulijaszek (eds.), Urbanism, Health and Human Biology in Industrialized Countries (Cambridge, UK: Cambridge University Press, 1999), p. 25.

13. M. Carley and I. Christie, Managing Sustainable Development (Minneapolis, MN: University of Minnesota Press, 1993).

J.A. Dunn, Driving Forces: The Automobile - Its Enemies and 
the Politics of Mobility (Washington, DC: Brookings Institution Press, 1998).

14. Organization for Economic Cooperation and Development, OECD Environmental Data: Compendium - 1999 (Paris, France: OECD Publications, 1999).

15. K.M. Johnson and C. L. Beale. "The Rural Rebound: Recent Non-metropolitan demographic trends in the United States" (2001). Retrieved from Internet at URL: http://www.luc.edu/ depts/sociology/johnson/p99webn.html

16. P.O. Stern, O. Young, and D. Druckman (eds.), Global Environmental Change: Understanding the Human Dimensions (Washington, DC: National Academy Press, 1992).

17. M. Steger, Globalism: The New Market Ideology (Boulder, CO: Rowman and Littlefield Publishers, 2002), p. 9.

18. G. Ritzer, The McDonaldization of Society: An Investigation into the Changing Character of Contemporary Social Life (Thousand Oaks, CA: Pine Forge Press, 1999).

19. W. Greider, One World, Ready or Not (New York: Simon and Schuster, 1997).

20. A. O'Sullivan, T.A. Sexton and S.M. Sheffrin, Property Taxes and Tax Revolts: The Legacy of Proposition 13 (New York: Cambridge University Press, 1995).

21. M. Steger, 2002, op. cit. (see reference 17), p. 4.

22. M.J. Moon, "The Evolution of e-Government Among Municipalities: Rhetoric or Reality?" Public Administration Review 62 (2002): 4-24.

23. C.D. Slaton and T.L. Becker, "Increasing the Quality and Quantity of Citizen Participation: New Technologies and New Techniques." In T.J. Johnson, C.E. Hays and S.P. Hays (eds.), Engaging the Public: How Government and the Media Can Reinvigorate American Government (New York: Rowman and Littlefield, 1998).

24. Pew Internet and American Life Project. 2004. Reports: E-Gov and E-Policy. URL: http://www.pewinternet.org/PPF/ r/150/report_display.asp 
25. J. Scott, "Assessing the Quality of Municipal Government Web Sites," State and Local Government Review 37 (2005): 151-165, p. 161.

26. J.C. Pierce, M.A. Steger, B.S. Steel, and N.P. Lovrich, Citizens, Political Communication and Interest Groups: A Study of Environmental Organizations in Canada and the United States (New York: Praeger Publishers, 1992).

27. F. Fischer, Citizens, Experts, and the Environment: The Politics of Local Knowledge (Durham, NC: Duke University Press, 2000), p. ix.

28. J.S. Nye, P.D. Zelikow and D.C. King (eds.), Why People Don't Trust Government (Cambridge: Harvard University Press, 1997).

29. G. McAvoy, Controlling Technocracy: Citizen Rationality and the NIMBY Syndrome (Washington, DC: Georgetown Press, 1999).

30. P. DeLeon, Democracy and the Policy Sciences (Albany, NY: State University of New York Press, 1997).

31. R.P. Nathan, Social Science in Government: The Role of Policy Researchers (Albany, NY: The Rockefeller Institute Press, 2000).

32. A. Maslow, New Knowledge in Human Values (New York: Harper and Row, 1959).

33. R. Inglehart, op. cit. (see reference 5).

34. Ibid.

35. C. Offe, "New Social Movements: Challenging the Boundaries of Institutional Politics," Social Research 52 (1985): 817-868.

36. W. Kempton, W., Boster and J.A. Hartley, Environmental Values in American Culture (Cambridge, MA: MIT Press, 1995).

B.S. Steel and N.P. Lovrich. "An Introduction to Natural Resource Policy and the Environment: Changing Paradigms and Values." In B.S. Steel (ed.) Public Lands Management in the West: Citizens, Interest Groups, and Values (Westport, CN: Praeger Publishers, 1997). 
37. R.E. Dunlap and A.G. Mertig, "The Evolution of the U.S. Environmental Movement from 1970 to 1990: An Overview." In R.E. Dunlap and A.G. Mertig (eds.), American Environmentalism: The U.S. Environmental Movement 1970-1990 (Philadelphia, PA: Taylor and Francis Publishers, 1992).

38. L.W. Milbrath, Learning to Think Environmentally While There is Still Time (Albany, NY: State University of New York Press, 1996).

R. Nash, Rights of Nature: A History of Environmental Ethics (Madison: University of Wisconsin Press, 1992).

39. R.W. Kates, P.M. Thomas, and A.A. Leiserowitz, "What is Sustainable Development? Goals, Indicators, Values, and Practice," Environment 47 (2005): 9-21.

40. World Commission on the Environment and Development, Our Common Future (New York: Oxford University Press, 1987).

41. K. Pezzoli, "Sustainable Development: A Transdisciplinary Review of the Literature," Journal of Environmental Planning and Management 40 (1997): 549-574.

W. Rees, W. "Consuming the Earth: The Biophysics of Sustainability," Ecological Economics. 29 (1999): 23-27.

W. Sachs, Planet Dialectics: Explorations in Environment and Development (London: Zed Books, 1999).

42. D. Halpern, Social Capital (Cambridge, UK: Policy Press, 2005).

43. H. Daly and J. Cobb, 1989. For the Common Good (Boston: Beacon Press, 1989).

44. W. Rees, 1999, op. cit. (see reference 41)

45. R. Prescott-Allen, The Wellbeing of Nations: A Countryby-Country Index of Quality of Life and the Environment (Washington, DC: Island Press, 2001).

46. W. Sachs, 1999, op. cit. (see reference 41)

47. Boston Indicator Project, The Wisdom of Our Choices: 
Boston Indicators of Progress, Change and Sustainability 2000 (Boston, MA: Boston Foundation, 2000).

48. T.M. Parris and R.W. Kates. "Characterizing and Measuring Sustainable Development," Annual Review of Environment and Resources 28 (2003): 559-586.

49. Organization for Economic Cooperation and Development, Shaping the 21st Century: The Contribution of Development Cooperation (Paris: OECD, 1996), p. 4.

50. M. Sagoff, "Can Environmentalists Keep Two Ideas in Mind and Still Function?" Philosophy and Public Policy Quarterly 27 (2007): 2-7.

51. S. Campbell, "Green Cities, Growing Cities, Just Cities? Urban Planning and the Contradictions of Sustainable Development," Journal of the American Planning Association 62 (1996): 296-312.

52. C.M. Duncan, Worlds Apart: Why Poverty Persists in Rural America (New Haven: Yale University Press, 1999).

S. Mendis, S. Mills and J. Yantz, Building Community Capacity to Adapt to Climate Change in Resource-Based Communities. Prepared for the Prince Albert Model Forest, Universtiy of Saskatchewand (Winnipeg: University of Manitoba, 2003).

53. C.C. Harris, G. Brown, G. and W.J. McLaughlin. 1998. "How Resilient are Rural Communities in the Interior Columbia Basin Ecosystem?" Journal of Forestry 96 (1998): 11-15.

54. E. Wall and K. Marzall, "Adaptive Capacity for Climate Change in Canadian Rural Communities," Local Environment 11 (2006): 373-397.

55. U.S. Global Change Research Program, "U.S/ National Assessment of the Potential Consequences of Climate Variability and Change Educational Resources. Regional Paper: Great Plains" (2007). Document retrieved from the Internet at URL: http://www.usgcrp.gov/usgcrp/nacc/education/ greatplains/greatplains-edu-6.htm

56. E. Wall and K. Marzall, 2006, op. cit. (see reference 54). 
57. S. Mendis, S. Mills and J. Yantz, 2003, op. cit. (see reference 52), p. 39.

58. R.D. Putnam, R.D. 1995. "Bowling Alone: America's Declining Social Capital," Journal of Democracy 6 (1995): 65-78.

E. Wall and K. Marzall, 2006, op. cit. (see reference 54).

59. R.D. Brunner, T.A. Steelman, L. Coe-Juell, C.M. Cromley, C.M. Edwards and D.W. Tucker, Adaptive Governance: Integrating Science, Policy and Decision Making (New York: Columbia University Press, 2005).

60. R. Dalton, 2008, op. cit. (see reference 3). 


\section{Chapter 2: Federalism}

\section{A - Introduction}

More than any other aspect of U.S. government structure, federalism contributes significantly to innovation in state, local and national government alike. ${ }_{-}^{1}$ However, it is unlikely that the contemporary impacts of federalism in postindustrial America were fully anticipated by the framers of the U.S. constitution. The Founders were driven to a much greater extent by a desire to strike a balance in political power between a nascent national government and the several preexisting state governments than in promoting innovation and the capacity to adapt to ever changing socio-economic and environmental circumstances. The adoption of a federal form of government at the outset of our nation's history reflected an appreciation for the cultural heterogeneity that characterized the original thirteen states. ${ }_{-}^{2}$ As the intergovernmental relationships between the federal government and the several states have evolved over time, however, federalism in America has repeatedly proven to serve as an important institutional asset in the service of sustainability.

This chapter will demonstrate how a variety of incentive structures propel state and local governments toward greater open-mindedness, experimentation, and learning from experience than is generally the case with the national government. Unlike the more insulated federal government, the several states and their many local governments face increasingly vexing and complex social and economic challenges which cannot be brushed aside in favor of engagement in the rough-and-tumble of global politics and national partisan competition; citizens in our towns, cities, 
counties and states frequently demand that action be taken to address their immediate concerns for the quality of life where they live, and they tend to expect tangible results from their state and local governments.

Law enforcement services and community safety are good examples of such concerns for immediate tangible results. When criminal activity increases in a state or local jurisdiction, citizens often call for stricter laws, stiffer penalties for violations, and more robust enforcement; the sidestepping of issues and the shifting of blame to others are generally not acceptable dodges of responsibility to citizens calling for effective action. The heightened visibility of problems at the state and local level, and the demand for quick solutions to those problems, commonly place a heavy burden on state and local governments for timely action. While this often intense atmosphere can be quite stressful for state and local policymakers, some of the very best and most innovative solutions to tough problems emerge from this setting leading to the development of solutions that promote the sustainability of states and local communities in one location that are often copied, modified and implemented in other state and local government settings across the nation.

The term federalism refers to a formal legal relationship between one or more levels of government vertically organized, and a whole host of relationships between similar levels of government horizontally organized. As Watts notes, the highly regarded late scholar of federalism Daniel Elazar viewed federalism as a complex contractual arrangement; for Elazar federalism represents a form of "shared rule plus self rule - and a balance between cooperation and competition among the general and constituent governments.."3 The structure of American federalism was initially intended to protect pre-existing units of government (the states), and serve as an authoritative method of assigning or dividing responsibilities among the levels of government. In contrast, 
contemporary approaches to American federalism - the result of over a century of change - clearly emphasize collaboration among and across units of government while continuing to respect the distinctive priorities and needs of populations in different state and local jurisdictions. Today, an expansive and flexible understanding of American federalism represents a clear opportunity for innovation rather than representing a strict limitation on what actions any particular level of government is allowed to take.

\section{Learning Objectives}

This chapter will:

- $\quad$ explore the historical evolution of federalism

- discuss different models of federalism which have evolved over time

- outline a model of intergovernmental relations which promotes sustainability in state and local government

- $\quad$ consider the future of American federalism 


\section{B - Units of Government}

While most of us are aware that there is one national government and there are fifty state governments, we often lose sight of the fact that there are other units of government that serve our everyday needs. In fact, in the U.S. there are 90,056 units of government beyond the national government and the fifty state governments. Each of these units of government offers some degree of opportunity for citizens to make their priorities known and to make demands upon government. The existence of such a multitude of governmental bodies provides Americans with myriad opportunities to become involved in the political process and to "make a difference" in the quality of life in their respective communities.

Beyond the prominent national and state governments of which most of us are well aware, there are several additional important types of government that are prominent: counties, municipalities, townships, school districts, and special purpose districts. As of 2012, there are 3,031 counties in the U.S. Some states have very few counties - Delaware contains only three - while some states have many counties for example, Texas has 254 . The number of local governments has increased by 0.6 percent between the 2007 and 2012 Census of Governments, while the overall number of governments has decreased by 22.9 percent from 116,807 in the 1952 Census of Governments. According to the 2012 Census of Governments by the U.S. Census Bureau:

- Illinois leads the nation with 6,968 local governments approximately 2,000 more than second-place Pennsylvania.

- Hawaii has 21 local governments, the fewest of any state.

- Texas remains first in the nation with the most independent school districts at 1,079. Closely behind is California, with 1,025 
independent school districts.

- Seventeen states had more special districts compared with 2007, and 29 had fewer. Five states had no change.

- Ten states had fewer townships because of mergers and consolidations. Kansas decreased the most, moving from 1,353 in 2007 to 1,268 in 2012, a decrease of 85 .

While the growth of the national government is a frequent topic of discussion in the news media, the fact of the matter is that local government is the more dynamic component of public sector growth by quite a margin. Special purpose districts are one of the biggest areas for growth in this regard. There are over 51,146 special purpose districts in the U.S. at this time. The U.S. Bureau of the Census places special purpose districts into four major categories: Natural Resources; Fire Protection; Housing and Community Development; and "Other" Special Districts. Such other special districts relate to water districts, irrigation districts, sewer districts, road districts, public utility districts, port districts, cemetery districts, etc. One rather unique aspect of American federalism is the ability of state and local governments to create special purpose districts. We will see in this chapter how this aspect of American government plays a substantial role in the promotion of community sustainability. $<$ / 


\section{C - Historic Roots of Federalism}

The origin of American federalism offers great insight into the values which define American culture, and which have guided the development of our public institutions. As a governing arrangement, federalism occupies a space somewhere between confederal systems and unified systems. ${ }_{-}^{4}$

The first governing relationship in the "break away" colonies of former British North America was confederal. Following the achievement of independence in the Revolutionary War, the former colonies operated as sovereign governmental powers. The term sovereignty means that a political authority (in this case each colony) recognizes no higher power as a rightful restraint upon its action, and maintains the full right to agree or desist from any collective action with other political authorities of equal status. Under the Articles of Confederation- state sovereignty was duly recognized. The Articles bound the states to little more than a promise to engage in mutual armed defense. The Confederation rather quickly proved to be ineffective at coordinating goals or developing cooperative relationships among and between the thirteen state members.

The confederal governing arrangement was the exact opposite of the form of government from which the colonies had separated - namely, the unitary form of government. Under unitary government, political power is concentrated in a single location in the hands of a single office (the sovereign) or among a centralized national elite (elected or otherwise). All units of government at the sub-national level exist entirely at the mercy of the national government, and they exercise 
only those powers expressly delegated by the sovereign authority. Lacking sovereignty, in unitary forms of government all sub-national units of government can be created and abolished at the will of the sovereign national government.

Under the second American constitutional arrangement the U.S. Constitution (1787) - the Founders shared the belief that the confederal system had not been effective and that a governmental arrangement somewhere between confederal and unitary government would more effectively meet the needs of the new nation.. ${ }_{-}^{6}$ American federalism creates some elements of national sovereignty in particular areas of law and governance, while embedding strong protections for state government in many other areas of public life. ${ }_{-}^{7}$ Over the years the U.S. Supreme Court has had frequent occasion to adjudicate disputes concerning the relative powers of the federal and state governments under the U.S. Constitution, and for the most part those decisions have permitted the national government to extend its powers while at the same time keeping state sovereignty principally in tact.

\section{D - Advantages to Federalism}

Over the course of the nation's history it is clear that there are many advantages to federalism. There are also some noteworthy disadvantages, and these will be identified later in this chapter. For the time being the focus rests on advantages. Six particular advantages merit some discussion here: ${ }_{-}$

1. Myriad of governmental units. Many opportunities 
exist for citizens to directly influence policy decisions in their respective states or communities;

2. Competition between units of government. Competition between jurisdictions for citizens, business investments, and talent may lead to government efficiency. State and local governments tend to become entrepreneurial, offering greater benefits for the tax dollar [1] or reducing tax burdens to attract citizens and businesses seeking to reduce their fixed costs of operation.

3. Incentives to prevent growth in government and promote efficiency. The competitive nature of federalism is comparable to many aspects of free market capitalism. When government is a monopolistic provider, it is more likely to overproduce goods and services.

4. Responsiveness to citizens is enhanced. If a unit of government becomes too costly, citizens can either demand improved services or move elsewhere.

5. Federalism is correlated with local government efforts to support private economic growth. The provision of competitively priced infrastructure resources (e.g., roads, utility services, schools, medical services, recreational amenities, etc.) is a critical ingredient in any model of economic growth. Economic development, in turn, generally creates jobs and enhances household incomes.

6. Federalism stimulates public and private innovation, often in active partnership. The existence of federalism in the U.S. facilitates the systematic "reinvention of government." [2] The speed with which creative solutions to locallyexperienced problems are replicated is enhanced by the progressive professionalization of state and local government employees and the use of the Internet to capture, store, and disseminate information on a national (and even global) scale. 


\section{E - Potential Challenges facing Federalism}

While the advantages of federalism almost certainly outweigh the costs for most scholars writing in this area, federalism does face some potential challenges in application in many circumstances. Three such challenges are:

1. Federalism can produce unequal outcomes between states, across communities, and for individuals living within these different jurisdictions. Unequal outcomes are often associated with economic inequalities due to different levels of economic growth across states, and even within states and local communities. When traveling from city to city, state to state, observe the differences in wealth and opportunity that exist within each location. At times, these differences are function of city or state capacity to sustain an economic base or to evolve with and adapt to changing economic conditions.

Historically, states and cities differed considerably in their level of political and social equality. For decades in many parts of the South, for instance, individual opportunity was systematically biased to benefit whites over persons of color. A devastating Civil War, major amendments to the U.S. Constitution, and a series of landmark statutes and watershed decisions of the U.S. Supreme Court have all worked to overcome serious inequalities brought about by a malevolent manifestation of state's rights in service to racial discrimination - all permitted by the institution of federalism.

2. Federalism potentially produces inefficiency through policy replication. Each state and local government independently formulates, finances and implements public policy. In many ways, this is a good thing because each state and local government has its own special set of circumstances and cultural values encoded in its public policy. However, there are added costs to having each state and local government essentially replicating many policy choices. In 
many cases it would be more efficient to have one uniform policy that efficiently and effectively meets all citizens' needs in a particular area of public life.

3. Federalism can, at times, cloud our understanding of who is responsible for public policy outcomes. In federalism, many units of government overlap and, at times, the policy preferences of different levels of government collide-i.e., their goals might be diametrically opposed. When policy failure results, constituents often want to know why things are either not being accomplished or not being managed in a manner reflecting their preferences. The spectacle of fingerpointing across different levels and units of government leaves citizens confused and, at times, upset with government overall.

\section{F - Models of Federalism}

Political scientists have developed a number of ways to describe and study federalism. In their highly regarded synthesis of prior research in this area published as an article in Publius: The Journal of Federalism, Donald Rosenthal and James Hoefler_ identify a condensed list of models of American federalism featuring the following core concepts:

- dual federalism

- cooperative federalism

- pragmatic federalism

- non-centralized federalism

- nation-centered federalism 


\section{F.I - Dual Federalism:}

According to Lord James Bryce, ${ }_{-}^{12}$ a perceptive British observer of early American political life, the U.S. Constitution represents primarily an attempt to "build a more perfect Union" between the national and state governments. Strengthening the national government provides for a nationwide common market free of tariffs and barriers to commerce, a condition from which all states would benefit. Such a national government could also "provide for the common defense" more effectively than was possible under the Articles of Confederation. While certain governmental powers were expressly enumerated for the national government, the U.S. Constitution recognizes that state sovereignty should be carefully provided for in law. For the advocates of "states' rights" the Tenth Amendment to the Constitution served - then as now - as the guarantee of a balanced relationship between national and state government; that provision of the constitution is known as the "reserved powers" amendment which holds that all governmental powers which are not explicitly granted to the national government in the constitution are reserved to the states and their people. ${ }_{-}^{13}$

In his major work, The American Commonwealth, Lord Bryce noted that even in the post-Civil War period state sovereignty and the notion of dual federalism-namely, two systems fulfilling distinct purposes without any significant overlap in function_-was maintained. States could not be taxed to finance the national government, which is a principle that remains to this day. American states were afforded a significant amount of autonomy in creating their own legal systems and governmental institutions. As long as the authority of the national government was not challenged or constrained in those areas where it was constitutionally 
authorized to act, states retained a significant degree of sovereignty, in some cases exercising powers concurrently shared with the national government. For Bryce, dual federalism was feasible in the 18th and 19th centuries largely because the scope of government action was rather restricted and far less complicated than it is today; both levels of government had a strong sense of enumerated, retained, and concurrent powers being exercised within a workable constitutional legal framework.

The federal-state relationship was fairly simple in the early years of the Republic in part because citizens looked primarily to their local communities to provide the basis of a sustainable existence. Until the early part of the 20th century, most Americans resided in rural settings - primarily in farming communities or small towns. There was relatively little overlap in government units, reducing the probability of conflict over resources, or in terms of the impact of public or private choices.

While the dual federalism model was well suited to its times in pre-industrial America, it suffered from limitations that proved to be insurmountable in due course. Most importantly, the dual federalism model was largely silent on the issue of the protection of individual rights. A focus on community-derived notions of a good society within a state can have the deleterious effect of restricting individual rights and liberties, particularly those of vulnerable minorities. In reflection of the dual federalism concept, in the case Barron v. Baltimore, Maryland (1830) the U.S. Supreme Court narrowly defined the national government's role in protecting the basic liberties and rights of citizens, leaving to the states and their respective constitutions the lion's share of responsibility in this area of American law. The Court ruled that those rights set forth in the Bill of Rights (the first ten amendments to the U.S. constitution) applied to the relationship between states and the national government rather than the relationship 
between citizens and the national government. The Court left it to the states to decide matters such as what constitutes freedom of speech, the right to counsel a jury of one's peers, and due process of law in criminal cases.

Some of the Founders had argued that dual federalism was an unworkable idea, but it took over a century before the social inequities associated with the dual federal model became widely recognized. ${ }_{-}^{15}$ In looking back over the history of American federalism, one could conclude that much of our history has been spent trying to maximize both the exercise of "freedom and the pursuit of happiness" by citizens and provide for the welfare of the nation, its states, and the communities within which our citizens reside. This simultaneous pursuit of individual liberty and collective welfare has always been a challenge for our nation, and it continues to demand the best of our thinking. In the contemporary setting many of our states and local communities endeavor to build a sustainable foundation for life for both present and future generations of Americans.

\section{F.II - Cooperative Federalism:}

The dual federalism model survived the Civil War and remained fairly prominent up until the final decades of the 19th century. The emergence of cooperative federalism - the notion that the presence of urgent shared goals required concerted effort by all levels of government - was, in part, the result of:

- the growth of urbanism and demise of intimate small communities;

- large-scale industrialization and rapid population growth 
through mass immigration;

- The expansion of the role of the national government as the guarantor of individual rights and liberties.

These changes in American society inspired many reformers within cities and in some of the states (i.e., Progressives) to press for government "regulation in the public interest." The growth of corporate capitalism led to major excesses in the use of private power to the detriment of the public good and the exploitation of the most disadvantaged, and in time gave rise to unionization, social regulation and political reform of machine politics arising from the corruption of public institutions. From a sociological perspective, industrialization and urbanization have led to a dispersal of community members so that people are more likely to be highly mobile. Ironically, Americans tended to adopt a lifestyle of personal independence from family and kin and neighbors alike, becoming more distant from one another in terms of private choices. This impermanency created a false sense of independence even though societal interdependence actually increased with innovation with respect to what forms of transportation are used, what forms of energy are consumed, and what food products are consumed.

During this period social inequities grew, both in terms of the stratification of wealthy and impoverished classes and in terms of inequities associated with the status of women, unorganized labor and racial and ethnic minorities. Many influential writers and prominent decision-makers of the time contributed in different ways to the progressive vision for the U.S., one that relied heavily on a cooperative relationship between all levels of government responding in a coordinated way to rapid social change. In many ways, the aforementioned changes challenged the capacity of American democracy, in general, and federalism more particularly, to respond to modern dilemmas using an 18th century model of governance. 
The Progressive reformers of this period believed that many of the positive communitarian aspects of American community and society-the obligation to help neighbors in need, reciprocating a kindness with a kindness in return, volunteering one's time to civic projects, participating in local governance, etc.) -as described in the historical writings on America penned by the foreign observers Alexis de Tocqueville $e_{-}^{16}$ and Lord James Bryce, were in peril. Progressives were at once reflective and visionary in their thinking, embracing an idealized vision of an American past but taking a pragmatic approach of action, free of the constraints created by partisan ideology. The concept of cooperative federalism was developed to expedite the process of addressing serious social and economic problems through forceful governmental action. The combined use of local, state and national government authority in addressing public health and safety was commonplace, with the guiding principle being "use what works best" in the best sense of pragmatism._

Some critics of cooperative federalism have argued that this model of federalism represents a national government attempt to pull power away from the state and local governments. In fact, the roots of Progressivism can be traced directly back to state and local government; it was an idea first born at the local level, not at the national level of public political dialogue. Progressivism recognized many of the very serious social and economic dilemmas that had been largely unaddressed for quite some time: women's rights, minority rights, public health and sanitation problems, food and water safety and availability, homelessness, community planning, open and fair government and elections, and accessible and equitable public education, to name but a few of the major issues-issues that remain important and yet today are not addressed as fully as they should be. How these issues are addressed constitutes the foundation of community sustainability, and affects group and individual rights alike. 
On the state and local level, Progressivism accomplished a great deal in relation to the aforementioned goals. It is fair to say that many national government efforts were noteworthy, but overall were less pronounced than those witnessed at state and local government levels. President Theodore Roosevelt made important in-roads through efforts to promote food and drug safety. Additionally, he challenged the growth of corporate capitalism, which was central to the complex relationship of the individual, the private market, and the public forum. President William Howard Taft's Commission on Economy and Efficiency served as the foundation of the modern bureaucratic systems needed for national government response to progressive demands. Finally, Governor Robert LaFollette (R-Wisconsin) and Governor (and later U.S. President) Woodrow Wilson (D-New Jersey) both campaigned and advanced progressive agendas for political campaign and election reform. Large-scale national progressive reform was not realized until President Franklin D. Roosevelt's New Deal. While critics might claim that many aspects of FDR's efforts were nation-centered, the outcomes of FDR's programs have demonstrated over time that many New Deal programs were, in effect, a reflection of cooperative federalism operating under dire socio-economic conditions.

Cooperative federalism occurs on many points along a continuum of varying locus of action. Top-down models are generally characterized by considerable national government influence in relation to the states. An example of top-down federalism might be seen in the area of environmental policies, which are designed to establish national guidelines for environmental quality for the benefit of all citizens. Conversely, bottom-up federalism often entails innovations originating at the state and local level that, in time, reach national level policy agendas. Welfare reform, for instance, originated at the state level in Wisconsin. The innovation was 
touted as a policy success and became a focus of national policy with the national Welfare Reform Act of 1996. Over the long run, bottom-up and top-down federalism necessitate a cooperative framework; at the very least, government agencies must accede to the concurrent power and authority of another level of government.

Given the examples above, it is tempting to fall into the trap of associating top-down with "liberal" and bottomup with "conservative" political ideologies. In reality, both political liberals and conservatives alternately see value in both ends of the ideological continuum. Although a shift away from the strong nation-centered federalism of the Johnson years (1964-1969) occurred, primarily during the Reagan presidency (1981-1989), that shift tended to slow and retreat during the George H.W. Bush presidency.- 18 Federalism scholar Paul Peterson has pointed out that many of President George W. Bush's policies have moved the Republican agenda towards a more top-down model of federalism. ${ }_{-}^{19}$ Homeland security ${ }_{-}^{20}$ and education reforms such as No Child Left Behind have increased national government influence over state and local government priorities and, to some degree, led to structural changes in the way services are delivered at the local level. ${ }_{-}^{21}$ Natural disasters such as Hurricanes Katrina and Rita illustrate the limits of the national government to solve local problems of substantial scope and scale. . $_{-}^{2}$

By themselves, shifting social and political institutional values do not fully explain the nature ${ }_{-}^{23}$ of cooperative federalism in the United States. Evolving legal theories established by the Supreme Court were critical not only to the constitutional legitimacy of cooperative federalism, but also to the initiation of movement along the top-down/bottom-up federalism continuum. 


\section{F.III - Pragmatic Federalism:}

Rosenthal and Hoefler ${ }_{-}^{24}$ indicate that pragmatic federalism was in part borne out of disenchantment with cooperative federalism. The latter approach was premised on the notion that behavioral science of the 1950s and 1960s could be used to guide national-level policy choices, identifying target populations and meeting needs. Social science would guide policy makers at the national government level to tailor policy responses and interactions with state and local policy makers-in essence, the concept entailed the creation through social science of a cooperative intergovernmental relationship. Unfortunately, many policy prescriptions guided by the behavioral approach failed because the model often ignored many unquantifiable aspects of the policy process such as the interaction between policy institutions, values, preferences, and effective solutions.

Pragmatic federalism is characterized by two unique qualities: (1) flexibility-it is outcome-driven rather than process-driven; and (2) the downplaying of the philosophy of government, meaning the set theories about the proper relationship between the national government and state governments are of limited interest in this model. ${ }_{-}^{25}$ Ad hoc network relationships are considered more important than ex ante approaches (i.e., build the relationship around the problem to be solved rather than make the problem fit around a pre-conceived notion of the relationship).

Several Democratic state governors began to take a significant role in both the identification and advancement of this new approach to federalism. A political scientist, former county administrative officer and later a two-term Maryland Governor, Parris Glendening (and co-author Reeves) wrote one of the earlier accounts of this new model of federalism in a 1984 book entitled Pragmatic Federalism: An 
Intergovernmental View of American Government. In his various roles as local and state official, Glendening's account of pragmatic federalism is built on both theory and practice as he experienced it.

When Glendening and Reeves developed their approach in the mid-1980s, it was in response to a growing interest in the centralizing tendencies on the part of American national government. ${ }_{-}^{26}$ At a time when President Ronald Reagan, a champion of smaller national government, was riding high in the opinion polls, Glendening and Reeves argued that a reversal of the centralizing trend, if it occurred at all, was unlikely to become part of a long-term trend. They argued that the concentration of authority in a centralized government structure was an historical trend that would continue, but that the nature of the trend must be considered and shaped in a manner most beneficial to all stakeholder governments and to public service recipients.

Glendening and Reeves tied three very important phenomena together in their effort to explain the value of pragmatic federalism. First, following on a strong tradition in the academic literature of questioning rigid bureaucratic approaches to policy formulation and implementation, Glendening and Reeves argued for greater reliance on informal relationships between policy actors who are guided by circumstance rather than organizational structure. Second, they favored movement towards proactive street-level policymaking and analysis whenever possible. Finally, a growing trend towards public-private partnerships in solving problems and a shared-governance movement played an important role in shaping Glendening and Reeve's innovative approach to thinking about American federalism.

At the time Glendening and Reeves were writing their account of federalism, Governor Bill Clinton (D-Arkansas) was promoting a similar new governance model. Interestingly, both Glendening and Clinton were raised in relative poverty 
in Florida and Arkansas, respectively. In both cases, they had witnessed first-hand the positive role of government in shaping the lives of the least fortunate members of American society. Both men had gone on to become prominent statelevel politicians in the 1980s. Importantly, neither forgot the role of government in their lives. They also felt that public sentiment regarding the size of the national government had more to do with the outcomes of government operations and less to do with the government's process and policy goals.

The decline of the cooperative federalism model was fueled in part by significant changes to methods of funding programs. Discussed later in this chapter, funding in the form of grants-in-aid emanating from the national level to meet program goals was increasingly made in the form of block grants - revenue transfers which gave state and local governments considerable flexibility in determining specific policy goals and methods of meeting those goals. During the Reagan years, the national government retreated in its support of many policy areas; the public need was still present, but solutions and funding were left up to leaders in state and local governments.

Entrepreneurial-minded state and local government leaders, such as Glendening and Clinton, provide sterling examples of the practicality of pragmatic federalism, which is can be considered an innovation in public management that refines our evolving federal system.- 27 The success of Democratic and Republican policy leaders alike at the state and local level in the last two decades of the 20th century offer time-tested support for a pragmatic approach to federalism-a model in which resources, goals, and public/private stakeholders and entrepreneurs are brought together to craft solutions to priority public concerns. 


\section{F.IV - Non-Centralized Federalism:}

Non-centralized models of federalism can be traced to a growing skepticism over the dominant role of Congress and the national government in intergovernmental relations. In the 1960s, Daniel Elazar wrote his now-classic account Federalism: A View from the States in which he illustrated the considerable and persisting political and social diversity present in the U.S._. In the 1950s and 1960s, a period where cooperative and nation-centered federalism held sway, Elazar's analysis was in contradistinction to commonly held views of federalism that downplayed long-standing state and regional diversity.

Non-centralized federalism tends to look to historically chronicled analysis and community-based approaches for understanding American federalism. Working from the premise that strong democracy relies most immediately on stalwart local communities and robust public and/or private institutions, advocates for non-centralized federalism argue for a more individual-focused approach, relying on the individual consumer acting in market-transaction to solve his or her own dilemmas rather than with the community through collective decision-making. The former approach - built on the principles of communitarianism - is closely tied to pragmatic federalism and to an historical interpretation of community-level decision-making capacity, while the latter approach is often built on classical liberalism, which emphasizes a limited role for government.

Advocates for non-centralized federalism share a common desire to ensure that the citizen-stakeholder plays a critical role in decision-making. In Democracy in America - a book often quoted by non-centralism advocates - Alexis de Tocqueville expresses similar concern regarding the possibility of unwisely limiting the roles of citizen and 
community as decision-making is centralized in the hands of professional administrators.

Not all communities possess an equal capacity for extensive citizen stakeholder participation. Over decades, in some cases centuries, political and social traditions slowly evolve, producing norms of participation and views about the role of citizens, government and the interchange between the two. Elazar places these different traditions under the rubric known as political culture. In his analysis, Elazar identifies three major categories of political and social relationships: individualistic, moralistic, and traditionalistic.

Individualistic political culture fits well within the classical liberal tradition of non-centralized federalism. Within individualistic political cultures, most problems are seen in terms of individual solutions - communal solutions are not highly valued. Individualistic traditions look at most problems in terms of private property rights dilemmas. Solutions, therefore, are viewed as being best identified through the proper transfer of rights. For example, the individualist would see poverty as being best solved through the exchange of property: a person's labor (property) for a salary (property) to be used to purchase food (property). In individualistic political cultures, non-centralized federalism would largely mean limited government at all levels and reliance on the marketplace to meet demands or solve problems.

In moralistic political cultures, problems and solutions are viewed quite a bit differently. Moralists tend to see problems in terms of community dilemmas that must be identified through interchange and community choice. Solutions are proffered in an open public forum and agreement on solutions is generally seen as best determined through widespread mutual agreement. The New England town hall meeting is often held up as a classic example of governance in a moralistic political culture. Non-centralized 
federalism, therefore, is more likely to be viewed as the optimum method of creating an inclusive public dialogue about government and governing. Moralistic political culture is horizontally organized, placing significant emphasis on the role of all individuals regardless of their social status or economic position within society.

Traditionalistic political culture is vertically organized, which means that individuals in positions of power have greater influence in the decision-making process than individuals who hold lower political, social or economic status. In traditionalistic political cultures, a limited view of collective decision-making excludes most citizen-stakeholder voices in the governance process. Citizens in a traditionalistic political culture tend not to expect to play a role in governance at the state and local level-they tend to defer to the aforementioned elites. In traditionalistic political culture, non-centralized federalism may work to the disadvantage of the mass while benefiting elites and their allies.

According to Elazar, traditionalistic political cultures are most prominent in the American South. While conditions have changed a great deal over the last several decades, poverty in the South and responses to poverty provide a solid example of the negative impact of traditionalistic political culture. President Lyndon Johnson's War on Poverty in the 1960s uncovered the extent of political, social, and economic disparity. Traditionalistic elites in the rural South chose to ignore poverty as an issue for reasons related to racial discrimination and contempt of elites for the lower social classes. National government intervention was the first major step towards alleviating poverty in the South, albeit the issues of institutionalized racism and endemic poverty have not entirely faded from the political scene, either in the South or in many other areas of the country.

Based on compelling evidence produced through political culture theory and considerable social science, 
moralistic political culture presents the greatest opportunity for equal access and broadly inclusive dialogue, and widely accepted choices and outcomes. When considering conflict in relation to the non-centralized federalism model, an underlying assumption is that the scope of conflict will be largely contained to the state or local level. In moralistic political cultures, governance is constructed in a way where support for public solutions to identified collective dilemmas is initially strong and remains strong on a consistent and prolonged basis. Individualistic political cultures are less likely to identify problems as requiring collective action - the marketplace is seen as the provider of solutions to individual wants and needs and property rights exchange. As a consequence, a strong central government is not a likely solution for the individualist. Conflict in an individualistic political culture will arise over issues related to property rights exchange and are less likely to be contained at the local level. Non-centralized federalism leads to highly biased governance choices and outcomes. Potentially, non-centralized federalism could increase conflict as citizens actively seek redress at "higher" levels of government when demands or needs are not addressed in local or state governance processes.

\section{G - 2ist Century Network Approaches to Federalism}

Two major conditions led to dramatic change in the character of federalism in the U.S. First, as discussed in Chapter 1, technology has forever changed the way in which governance occurs. 
Reflections on Government in the Old Days

Stepping into a county clerk's office only a generation ago for voter registration, the author found a single employee with index cards and two typewriters-an old manual version and the new electric model. The sheriff's office was not dissimilar-a Polaroid camera and flash bulbs lay on the counter for mug shots-there was a teletype machine for important information coming from the state or national level regarding criminal activity, an enormous vacuum tube contraption called the dispatch center (you didn't dial 911, you dialed " 0 " and asked the operator to be transferred to the police department)-nobody really sat at the dispatch center, but a burning cigarette in an amber colored glass ash tray indicated that someone was around occasionally. There was "The Computer" over in the corner, but nobody really knew how to use it except for the sheriff's young daughter-she played video games on it while she waited for her father to drive her home after school.

Computers are a central part of the governance process at all levels of government today. Initially, computer networks were within a single office and were not connected to other networks. With the advent of the Internet, inter-office networks have expanded exponentially and are increasingly complex - a web of communication connects the government to individuals and to the private sectors. Technology has made it relatively inexpensive and rather easy to transmit large quantities of information very quickly between decision makers in various government offices, and in the process influence choices and create opportunities for coordination and collaboration across jurisdictions. Inter-state and interlocal partnerships (or compacts) and agreements of understanding to coordinate efforts and goals have become a prominent aspect of 21st century federalism. . $_{-}$Building on the idea of pragmatic federalism, the rise of network-based 
federalism means that day-to-day governance is often circumstance-based and informal, with networks forming around problems and then quickly dissipating after solutions have been arrived at and implemented.

A second major condition, which has led to a greater reliance on network-approaches to federalism, is the post 9/11 policy environment and the War on Terrorism. Events related to terrorism and terrorist plots do not honor jurisdictional boundaries. In attacking enemies, terrorist organizations often use the same technological tools that have made our lives easier-the Internet, rapid forms of transportation, and the ability to network globally. Homeland Security policies require interagency communication and collaboration as a condition of the receipt of federal funding. It is the case, of course, that delays in communications posed by jurisdictional squabbles can significantly reduce the ability of government at all levels to plan for and react to emergencies in a timely and effective manner.

A related condition has been the decline of the traditional fiscal federalism relationship. In the 1950s and 1960s, policy goals of the national government-in cooperation with state and local government -were supported with financial resources received from the federal government. This fiscal federalism relationship meant that new policy goals were not as burdensome to state and local government in cost terms as they had been in the past. Beginning with the Reagan and G.H. Bush presidencies, and moving forward into the Clinton, G. W. Bush and Obama eras, the monetary taps of fiscal federalism have decreased: federal resources are now in much more limited supply. Given these conditions, it becomes clear to state and local government leaders that network federalism is a natural solution to reducing costs - essentially, it expands the information and expert "pool" as well as places greater reliance on mutual assistance. . $_{-}$

How is network federalism different than other forms of 
federalism? First, network federalism arrangements are often decentralized to the level of the individual or informal team. Individuals may be assigned to formal organizations, but most of their work is based on highly situational informal relationships or teams that respond to circumstances. For example, law enforcement response to riots and natural disasters is often a function of changing circumstances. Second, the strength of coupling or formal control within and between levels of government or agencies is very limited. Third, power is informally distributed and redistributed depending upon need rather than convention that had been based on formal vertical power distribution.

There are at least three advantages to the newly emerging model of network federalism:

- Reduced cost-while governmental units continue to overlap, collaboration means that wasteful stand-alone efforts are limited;

- Increased effectiveness-network federalism means that individuals converge around a problem based on the nature of a problem at any given moment; and

- Increased unity of purpose-as governmental units begin to work together to create mutually beneficial successes, there is a greater sense of unity, less jurisdictional squabbling and miscommunication.

While network federalism sounds like a laudatory solution, there are at least three potential challenges that must be considered in the years to come:

- Diminished accountability-accountability at all levels of government has posed a challenge. Informal intergovernmental relationships in network federalism means that discovering and rectifying problematic point sources is nearly impossible.

- Groupthink-as intergovernmental or interagency teams 
become more common, group members are more likely to begin to see problems and solutions in a similar manner, essentially eliminating the necessary argumentation that furnishes information about all sides of a problem. Additionally, groupthink can lead to elitist and exclusionary governance processes and outcomes.

- Centralizing trends-network federalism does not mean that all levels of government have equal resources and capacity to respond to governance issues. The national level of government is often thought to be well-funded and highly professional in terms of personnel training and leadership. Networks tend to form around resource providers and leaders as well as those network points where information is most effectively gathered and disseminated. In many instances, it is likely that networks will form around national government actors while state and local actors might serve in a supporting capacity.

\section{H - Federalism and the Core Dimensions of Sustainability}

Federalism can, and frequently does, work towards the accomplishment of the core goals of sustainability. Each unit of government is interconnected to other units of government and, as cooperative and network federalism illustrate, there is a need for all of units of government to face the enduring truth: "we're all in it together!" In other words, while each unit of government must consider its own capacity to achieve sustainability, there is a clear sense that working together 
makes sustainability more likely. In the U.S. federal system, the social objectives dimension of sustainability is achieved through the porosity of government institutions and the multiple points of contact between citizens and overlapping units of government. Strong social capital and the collective action of civic-minded communities are often associated with effective and adaptable government. The economic objectives dimension sustainability is also served by federalism. Sustainable economics means managing resources at the local level, where citizens are more likely to witness the production process at work and can better scrutinize the sustainability of the economic process in relation to negative environmental impacts produced. Understanding the true costs and benefits of achieving what is wanted may refocus local consumer attention on which goods and services really do contribute to sustainability. The environmental dimension of sustainability can benefit from federalism as well. With multiple points of citizen-government interaction, federalism offers greater opportunity to raise awareness of policies that could damage environmental quality. Additionally, local management of the environment and common resources may give citizens greater responsibility for the resources from which they collectively derive benefit-good stewardship practiced by multiple actors in a federal system of governance may serve to remind all parties involved of the many different stakeholders who benefit from well-protected environmental resources. Finally, the institutional dimension of sustainability is well served by federalism. Institutions operating in a sustainable future government may look and operate differently than the nation's current paradigm built around 18th and 19th century public and private institutions constructed in far simpler times. While the desirable values undergirding those institutions might be known-e.g., social and political equity, racial/ ethnic/gender equality, intergenerational justice-effective institutional designs may be less understood. For example, 
network federalism promises to take governance in new and exciting directions; yet, the exact nature of those new and exciting directions will be shaped by the technology of tomorrow. Federalism offers the opportunity to experiment with different institutional designs, to determine what works best, when, and for what purpose.

\section{Exercises}

\section{Federalism: What Can I Do?}

According to public opinion polls conducted by Gallup, a majority of Americans are unaware of the role of the federal government in their local school districts, knowing little is anything about important laws such as the No Child Left Behind Act of 2002 (http://www.gallup.com/poll/1612/Education.aspx). Because education is such an important and expensive function with federal, state and school district levels of governance involved through regulation and finance, informed participation in school board meetings and voting on school funding necessitates some investigation.

1. Contact your local school district to see how federal, state and local governments are involved in financing education.

2. Attend your local school board meeting to learn about pressing issues facing the school district. 
3. Contact your state legislators and state department of education to learn how federal government regulations, such as the No Child Left Behind Act, affect state education policy.

4. Contact a K-12 teacher in your local school district to discuss how federal, state and local policies affect how they teach in their own classroom.

For general information go to: "Education and Federalism," The Nelson A. Rockefeller School of Government, State University of New York: http://www.rockinst.org/education/federalism.aspx

\section{I - Conclusion: Conditions for Sustainable Intergovernmental Relationships}

Readers of this book who are preparing for careers in state or local government or who will work closely with government in one capacity or another will likely deal directly with intergovernmentalism. Intergovernmental relationships are important in the U.S. because the federal model is not clearly defined. In a political system where powers are separated between governmental units at national, state and local levels, 
questions of proper jurisdictional authority will certainly arise in the course of carrying out one's duties or conducting one's business affairs. One noteworthy strength of the U.S. model of federalism lies in the overlapping responsibilities shared by a whole host of governmental units, entities which must cooperate in order to address localized and/or regional problems affecting their constituents. The overlapping responsibilities and duties can be both a source of angst and a source of strength, bringing a diversity of experience and resources with networks of contacts. Network federalism has proven to be the more accepted view of U.S. federalism, and is the source of cooperative federalism or intergovernmentalism.

According to research on sustainable federal systems carried out in the international context, those federal systems that are based in constitutionalism (see Chapter 5) and feature defined powers of each layer of government, are 1. reflective of cultural and geographic diversity, 2. have democratic institutions, and 3. provide adequate resources for governance are the most institutionally sustainable systems. ${ }_{-}^{31}$ One of the most important elements of successful intergovernmental relationships in the U.S. context pertains to resources. Approximately 70 percent of a typical public agency's budget goes to salaries for employees. If proportional weight is any guide, then the most important resource that money buys is people's time, knowledge, skills, and abilities. Another important resource purchased by money is the infrastructure of a governmental body and the tangible goods and services needed to produce a desired governmental outcome. When a county wishes to establish a public health office, money will purchase the time and professional skills of physicians, nurses, and medical supplies needed to accomplish the public health function. If, however, the state or national government mandates certain health practices - such mandates frequently shape the relationship between governmental entities - then commensurate resources are required to meet the 
expectations established by those mandates. A successful intergovernmental relationship often requires the transfer of funds from one unit of government to another. That being said, some careful observers of American government and some state officials question the amount of federal spending and aid they receive in relation to the amount of federal taxes paid by the citizens and businesses of their state.

The data reported in Table 2.1 indicate wide disparity among states with respect to how much is paid in federal taxes versus how much is returned in federal spending and aid. Of course, the amount of money collected and spent by the federal government is related to many factors including, but not limited to: the salary levels of workers in high income states leading to higher federal government revenues through income taxes and other fees; the presence of higher levels of poverty leading to more federal spending on poverty programs and, of course, the presence of strong and influential senior elected officials in Congress steering resources back home to their own state (e.g., "pork barrel" projects and the inclusion of earmarks in agency allocations). 


\begin{tabular}{|c|c|c|c|}
\hline STATE: & $\begin{array}{l}\text { GROSS COLLECTION } \\
\text { OF FEDERAL TAXES } \\
\text { (IN THOUSANDS): }\end{array}$ & $\begin{array}{l}\text { TODAL } \\
\text { FEDERAL } \\
\text { TAXES PAID } \\
\text { PER CAPITA: }\end{array}$ & $\begin{array}{l}\text { FEDERAL AID } \\
\text { AS A } \\
\text { PERCENTAGE } \\
\text { OF STATE } \\
\text { GENERAL } \\
\text { REVENUE \& } \\
\text { STATE RANK: }\end{array}$ \\
\hline Alabama & $\$ 25,070,261$ & $\$ 5,165$ & $34.9 \%$ \#14 \\
\hline Alaska & $\$ 5,717,640$ & $\$ 7,751$ & $26.9 \% \# 40$ \\
\hline Arizona & $\$ 42,631,316$ & $\$ 6,253$ & $35.9 \%$ \#11 \\
\hline Arkansas & $\$ 32,508,761$ & $\$ 10,917$ & $33.5 \%$ \#21 \\
\hline California & $\$ 405,851,295$ & $\$ 10,204$ & $26.0 \% \# 43$ \\
\hline Colorado & $\$ 47,210,720$ & $\$ 8,664$ & 29.1\% \#34 \\
\hline Connecticut & \$59,174,581 & $\$ 16,507$ & $24.6 \%$ \#48 \\
\hline Delaware & $\$ 22,640,853$ & $\$ 23,982$ & 26.7\% \#42 \\
\hline Florida & $\$ 177,389,488$ & $\$ 8,762$ & $33.2 \%$ \#22 \\
\hline Georgia & $\$ 86,446,602$ & $\$ 8,476$ & $36.7 \%$ \#8 \\
\hline Hawaii & $\$ 8,221,290$ & $\$ 5,769$ & $24.8 \% \# 46$ \\
\hline Idaho & $\$ 9,785,027$ & $\$ 5,920$ & $33.8 \%$ \#19 \\
\hline Illinois & $\$ 158,042,273$ & $\$ 12,310$ & 26.8\% \#41 \\
\hline Indiana & $\$ 57,972,825$ & $\$ 8,767$ & $33.0 \%$ \#23 \\
\hline Iowa & $\$ 23,969,391$ & $\$ 7,678$ & $32.6 \%$ \#26 \\
\hline Kansas & $\$ 27,019,291$ & 9,295 & $25.5 \%$ \#45 \\
\hline Kentucky & $\$ 32,708,391$ & $\$ 7,392$ & $38.5 \%$ \#5 \\
\hline Louisiana & $\$ 42,628,150$ & $\$ 9,130$ & $40.1 \%$ \#2 \\
\hline Maine & $\$ 7,464,280$ & $\$ 5,615$ & $36.6 \% \# 9$ \\
\hline Maryland & $\$ 63,936,798$ & $\$ 10,665$ & 29.4\% \#32 \\
\hline Massachusetts & $\$ 108,049,205$ & $\$ 15,927$ & 27.8\% \#37 \\
\hline Michigan & $\$ 77,948,414$ & $\$ 7,860$ & $32.3 \%$ \#27 \\
\hline Minnesota & $\$ 106,927,808$ & $\$ 19,504$ & $25.5 \%$ \#44 \\
\hline Mississippi & $\$ 11,468,660$ & $\$ 3,836$ & 40.9\% \#1 \\
\hline Missouri & $\$ 64,112,504$ & $\$ 10,551$ & $38.0 \% \# 6$ \\
\hline Montana & $\$ 5,805,098$ & $\$ 5,625$ & $39.1 \%$ \#4 \\
\hline
\end{tabular}




\begin{tabular}{|c|c|c|c|}
\hline Nebraska & $\$ 25,103,770$ & $\$ 13,256$ & $31.0 \%$ \#29 \\
\hline Nevada & $\$ 18,450,072$ & $\$ 6,398$ & $24.8 \% \# 47$ \\
\hline $\begin{array}{l}\text { New } \\
\text { Hampshire }\end{array}$ & $\$ 11,314,985$ & $\$ 8,507$ & $28.1 \%$ \#36 \\
\hline New Jersey & $\$ 153,917,572$ & $\$ 17,226$ & 27.3\% \#39 \\
\hline New Mexico & $\$ 8,969,666$ & $\$ 4,312$ & $34.5 \%$ \#17 \\
\hline New York & $\$ 269,716,999$ & $\$ 13,659$ & $32.8 \%$ \#24 \\
\hline $\begin{array}{l}\text { North } \\
\text { Carolina }\end{array}$ & $\$ 78,736,401$ & $\$ 7,846$ & $32.7 \%$ \#25 \\
\hline North Dakota & $\$ 7,711,243$ & $\$ 10,189$ & $16.8 \%$ \#50 \\
\hline Ohio & $\$ 140,981,150$ & $\$ 12,148$ & $35.0 \% \# 13$ \\
\hline Oklahoma & $\$ 33,942,286$ & $\$ 8,687$ & $34.0 \% \# 18$ \\
\hline Oregon & $\$ 31,219,148$ & $\$ 7,757$ & $36.0 \%$ \#10 \\
\hline Pennsylvania & $\$ 136,108,810$ & $\$ 10,640$ & $30.8 \%$ \#30 \\
\hline Rhode Island & $\$ 14,373,318$ & $\$ 13,616$ & $34.7 \%$ \#16 \\
\hline $\begin{array}{l}\text { South } \\
\text { Carolina }\end{array}$ & $\$ 24,086,257$ & $\$ 4,921$ & $30.7 \%$ \#31 \\
\hline South Dakota & $\$ 7,732,128$ & $\$ 9,013$ & $37.2 \%$ \#7 \\
\hline Tennessee & $\$ 62,708,662$ & $\$ 9,508$ & $39.9 \%$ \#5 \\
\hline Texas & $\$ 279,904,425$ & $\$ 10,204$ & $31.8 \%$ \#28 \\
\hline Utah & $\$ 20,178,718$ & $\$ 6,747$ & $28.1 \%$ \#35 \\
\hline Vermont & $\$ 4,495,280$ & $\$ 7,180$ & $33.6 \%$ \#20 \\
\hline Virginia & $\$ 80,242,853$ & $\$ 9,590$ & $22.8 \%$ \#49 \\
\hline Washington & $\$ 73,334,437$ & $\$ 10,242$ & $29.2 \%$ \#33 \\
\hline West Virginia & $\$ 7,374,299$ & $\$ 4,005$ & $34.8 \%$ \#15 \\
\hline Wisconsin & $\$ 51,748,831$ & $\$ 8,972$ & $27.8 \%$ \#38 \\
\hline Wyoming & $\$ 5,284,146$ & $\$ 9,009$ & $35.5 \%$ \#12 \\
\hline
\end{tabular}

Table 2.1 Federal Tax Burden and Expenditures by State-2015 People, themselves, are important resources; however, the structure of the institutions for which people work, as well as the working environment and location do more to shape the 
effectiveness of workers. Individuals working in the Federal Bureau of Investigation, for instance, are often used to working in a particular agency setting with a unique organizational culture. The culture of an agency impacts the disposition of individuals. Professionalism is also an important element in intergovernmental relationships. In terms of elected officials, professionalism is reflected in the level of knowledge, experience and personal and administrative staff support available. Administrative personnel at different levels of government may vary in terms of their experience, level of education, salaries, and training; these are all quite important characteristics of public sector administrative professionalism.

Finally, as the literature on sustainable communities suggests, the social and economic conditions under which a particular level of government or an agency of government operates has a significant impact on intergovernmental relationships. When the U.S. Army Corps of Engineers arrives in a locality intent on building a dam for flood control or power generation, the conditions under which state or local governments' operate will have an impact upon relationships with the Army Corps of Engineers.

While conditions cannot be made uniform across levels of government or jurisdictions, successful federalism requires that political and administrative entities engaged in intergovernmental work come to terms with these differences in working conditions in order to maintain effectiveness and professionalism. Often, variations in these elements of difference become a source of strength in the intergovernmental enterprise as creative synergies are discovered and innovative solutions to difficult problems are crafted. Alternatively, those intergovernmental relationships that ignore these differences or involve the choice of a mistrusting or intensely competitive relationship often produce intergovernmental failure. 


\section{Terms}

Classical Liberalism

Communitarism

Confederal Systems

$\underline{\text { Reserved Powers and the 10th Amendment }}$

Cooperative Federalism

Dual Federalism

Fiscal Federalism

Progressivism

$\underline{\text { Public Goods }}$

Individualistic Political Culture

Moralistic Political Culture

$\underline{\text { Point Sources }}$

Political Culture

Pork Barrel

Mandates

Organization Culture

Traditionalistic Political Culture

\section{Discussion Questions}

1. Why was federalism adopted in the United States? Are the reasons leading to its adoption still relevant in the twenty-first century? 
2. Based on your reading, what are the various models of federalism that developed over time, and what are some of the advantages and disadvantages of each type?

3. In what policy areas should states have more authority vis-à-vis the national government (e.g., social policy such as medical marijuana, abortion, death penalty, K-12 education standards)? In what policy areas should the national government have more authority vis-à-vis the state governments?

\section{Notes}

1. S. Krislov, "American Federalism as American Exceptionalism," Publius: The Journal of Federalism 31(2001): 9-26.

A. Wildavsky, "A Bias toward Federalism: Confronting the Conventional Wisdom on the Delivery of Governmental Services," Publius: The Journal of Federalism 6(1976): 95-120.

J. Yarbrough, "Federalism in the Foundation and Preservation of the American Republic," Publius: The Journal of Federalism 6(1976): 43-60.

2. S. Schechter, "Federalism and Community in Historical Perspective," Publius: The Journal of Federalism 5(1975): 1-14.

R.L. Watts, "Daniel J. Elazar: Comparative Federalism and 
Post-Statism," Publius: The Journal of Federalism 30(2000): 155-168.

3. Ibid, Watts, p. 161.

4. J.F. Zimmerman, "National-State Relations: Cooperative Federalism in the Twentieth Century," Publius: The Journal of Federalism 31(2001): 15-30.

5. J.P. Greene, "The Background to the Articles of Confederation," Publius: The Journal of Federalism 12(4) (1982), 15-44.

Jack Rakove, "The Legacy of the Articles of Confederation," Publius: The Journal of Federalism 12(1982): 45-66.

6. See S. Lakoff, "Between Either/or and More or Less: Sovereignty versus Autonomy under Federalism," Publius: The Journal of Federalism 24(1994): 63-78.

7. J.R. Alexander, "State Sovereignty in the Federal System: Constitutional Protections under the Tenth and Eleventh Amendments," Publius: The Journal of Federalism 26(1986): 1-15.

8. For a related discussion see:

Ostrom, "The Study of Federalism at Work," Publius: The Journal of Federalism 4(1974): 1-17.

9. C. Tiebout, "A Pure Theory of Local Expenditures," Journal of Political Economy 64(1956): 416-424.

10. D. Osborne and T. Gaebler, Reinventing Government (Reading, MA: Addison-Wesley, 1992).

11. D.B. Rosenthal and J.M. Hoefler, "Competing Approaches to the Study of American Federalism and Intergovernmental Relations," Publius: The Journal of Federalism 19(1989): 1-23.

12. J. Bryce, The American Commonwealth (Indianapolis, IN: Liberty Fund, 1995).

13. V.C. Jackson, "State Sovereignty and the Eleventh Amendment in the U.S. Supreme Court: The 1988 Term," Publius: The Journal of Federalism 22(1992): 39-54.

14. The national government tended to focus primary concern in exercising its powers enumerated in the Constitution. One important exception to this general point 
was the passage of the Northwest Ordinance of 1787, which provided for federal government support the development of grammar schools for the provision of basic education. The Northwest Ordinance established an important precedent for the national government; early on, the national government undertook to legislate for the provision of some "public goods" (societal benefits) that states could not fully consider.

15. In many ways, the history of dominant dual federalism reflects Hamilton's conjecture in Federalist Paper \#36 that in a federal system with weak central government powers, powerful state governments may work to advance their own agenda to the detriment of weaker or smaller states and, ultimately, led to the collapse of the federal system as originally instituted.

16. B. Allen, "Alexis de Tocqueville on the Covenanted Tradition of American Federal Democracy," Publius: The Journal of Federalism 28(1998): 1-23.

17. The cooperative federalism model was helped along by major reforms at all three levels of government and within the branches of government, particularly at the national level. Campaigns gave voice to the reformers opinions in a wide audience, and elections produced progressively-minded political leaders. The news media and public interest groups advanced a progressive policy agenda, detailing the social and economic issues to be addressed at all levels of government. The judiciary focused greater attention on the basic rights and liberties guaranteed in the U.S. Constitution, and began the evolutionary process of applying, through legal precedent, nationally-guaranteed rights to public policy making occurring at that state and local level.

18. D.B. Walker, "American Federalism from Johnson to Bush," Publius: The Journal of Federalism 21(1991): 105-119.

19. P.E. Peterson, "The New Politics of Federalism," Spectrum: The Journal of State Government 78(2005): 5-7.

20. See also K. Caruson, S. ManManus, M. Kohen and T. 
Watson, "Homeland Security Preparedness: The Rebirth of Regionalism," Publius: The Journal of Federalism, 34(2005): 143-168.

21. Nathan (1975) discusses how top down federalism can, through the use of resource provision stipulations and mandates, impact the structural arrangements of state and local government. Structural change may have a more lasting and consequential impact on government than simple resource provision that does not require structural changes. Richard P. Nathan, "The New Federalism versus the Emerging New Structuralism," Publius: The Journal of Federalism 5(1975): 111-129.

22. R. Barrales, "Federalism in the Bush Administration," Spectrum: The Journal of State Government 74(2001): 5-6.

D.C. Menzel, "The Katrina Aftermath: A Failure of Federalism or Leadership?" Public Administration Review 66(2006): 808-812.

23. C. Rothfeld, "Federalism in a Conservative Supreme Court," Publius: The Journal of Federalism 22(1992): 21-31.

24. D.B. Rosenthal and J.M. Hoefler, "Competing Approaches to the Study of American Federalism and Intergovernmental Relations," Publius: The Journal of Federalism 19(1989): 1-23.

25. Ibid, p. 7.

26. P.N. Glendening and Mavis M. Reeves, Pragmatic Federalism (Pacific Palisades, CA: Palisades Publishers, 1984).

See also: P.N. Glendening, "Pragmatic Federalism and StateFederal Partnerships," Spectrum: The Journal of State Government 74(2001): 6-8.

27. See Osborne and Gaebler, 1992, op. cit. (see reference 10).

28. D.J. Elazar, Federalism: A View from the States (New York: Crowell, 1966).

29. J.J. Montjoy, "National Center for Interstate Compacts: A New Initiative," Spectrum: The Journal of State Government 77(2004): 8-11. 
J.F. Zimmerman, "Trends in Interstate Relations," Spectrum: The Journal of State Government 77(2004): 5-11.

D.M. Sprague, "Priority Focus for 2005: Interstate Cooperation," Spectrum: The Journal of State Government 77(2004): 3.

30. R.L. Cole and D.A. Taebel, "The New Federalism: Promises, Programs, and Performance," Publius: The Journal of Federalism 16(1986): 3-10.

T. Conlan, "From Cooperatives to Opportunistic Federalism: Reflections on the Half-Century Anniversary of the Commission on Intergovernmental Relations," Public Administration Review 66(2006): 663-676.

P. Eisinger, "Imperfect Federalism: The Intergovernmental Partnership for Homeland Security," Public Administration Review 66(2006): 537-545.

J. Kincaid, "The Crisis in Fiscal Federalism," Spectrum: The Journal of State Government 76(2003): 5-9.

31. M. Filippov, P. Ordeshook, and O. Shvetsova. Designing Federalism: A Theory of Self-Sustainable Federal Institutions (Cambridge: Cambridge Press, 2004).

P. Hobson, and F. St. Hilaire, Reforming Federal-Provincial Fiscal Arrangements: Toward Sustainable Federalism (Montreal: The Institute for Research on Public Policy, 1993) . 


\section{Chapter 3: The New Margins: Sustainability}

\section{A - Introduction}

As noted in Chapter 1, American state and local governments face very difficult challenges which involve issues that have evolved both slowly over a long time, as well as issues that are newly salient due to the advent of postindustrial society and the globalization of commerce and industry. Both domestic migration and immigration by foreigners contribute to a shifting population and change in community demographics in many areas of the country. A trend of considerable duration in the U.S., rural community residents are continuing to move to the nation's major cities; this is particularly the case for single young professional men and women who have acquired some degree of higher education. Immigration issues relate to both documented and undocumented individuals entering U.S. cities in a number of states in search of employment and the opportunity to enjoy the benefits of the American quality of life.

As a consequence of these changes, state and local government public agencies in many areas are struggling to meet the social and economic needs of an ever-changing population. Additionally, infrastructure development including broadband access to the Internet - and the maintenance of the built environment have become growing concerns in many communities across the nation. As local communities evolve towards their new futures, it is clear that the governmental response to global societal change and 
changing local conditions must match the new perspective of community sustainability. One dimension of changing circumstances for state and local government entails private sector firms no longer maintaining their loyalty and reliable ties to local communities. Globalization has meant that worldwide markets greatly affect business location and tenure in particular locations. Additionally, the business sector itself is more fluid, dynamic and "virtual" due to telecommuting and Internet capability. Business owners increasingly work with consultants, contractors and employees in Asia, Europe, Africa, or the Middle East rather than pay salaries to local workers for the desired services rendered. The private sector is more ad hoc than ever before in human history; this fact greatly affects the insularity associated with traditional notions of development. Finally, the longstanding American tradition of the active promotion of civic life has diminished dramatically. As noted by Harvard political scientist Robert Putnam and many other scholars, long-standing civic institutions are clearly on the decline. Some new institutions have arisen to be sure, but they tend to be quite different from those social institutions whose benefits historically contributed to a small-scale, local quality of life and public welfare. Some of these new forms of interaction among people are based in ephemeral Internet spaces - chat rooms and the like - while others entail only superficial interpersonal engagement and/or revolving-door memberships that grow or recede largely based on the nature of the times. A set of transitions that state and local governments must adapt to concerns often dramatic population shifts, the growing presence of the private sector in civic life, and the relative lack of human interaction in contemporary American culture.

So, how do American state and local governments tend to operate under these rapidly changing circumstances? Historically, earlier notions of state and local government 
responsibility and scope of influence must be considered as a starting point for our discussion. Of course, in times of change, the treasured value of stalwartness and loyalty to tradition must give way in some important areas of activity to the recognition of the need for continual and timely innovation if public institutions in state and local government are to remain relevant to the people they serve.

\section{Learning Objectives}

Against these background developments causing a broad range of societal changes in American society, this chapter will discuss the following specific topics:

- a basic model of public policy innovation;

- infrastructure renewal issues present at the state and local government level;

- resource identification and development/ conservation issues;

- and livability issues to be addressed at the state and local government level. 


\section{B - Basic Model of Public Policy Innovation}

Historically, one of the greatest strengths of U.S. democracy in the past has been its ability to remake itself when circumstances require adaptation to change. Government institutions and American society as a whole at critical junctures have faced up to changing conditions requiring the development and implementation of effective policy innovations. Public policy innovation, after all, is clearly in keeping with the spirit of optimism and belief in progress so common in U.S. democracy. The federal system of governance has inspired a propensity to experiment with new approaches to both old persisting problems and new challenges when they arise. Such ongoing experimentation and the frequent replication of successful innovations add importantly to the adaptive capacity of American state and local government. It is certainly no mere accident that the vast majority of the nation's national political leaders began their public service careers at the state and local level of government where great opportunities and need for innovation present themselves..

Public policy innovation in the U.S. is seldom, if ever, a function of one person's abilities or efforts, as might be the case in other more centralized and autocratic regime types. Innovation in U.S. state and local governments is most nearly always a function of the openness to change and willingness to risk the unknown consequences of the adoption of new approaches to old and new problems alike by political, social, and economic institutions in which elected and appointed leaders and citizen stakeholders live, work, make choices and express their policy preferences.

Research conducted in this area is quite plentiful, and this research clearly suggests that there are several common pre-conditions or factors that tend to facilitate public policy 
innovation. Of paramount importance in this regard is the issue of political trust. Political trust relates in part to the process of governance and to the public institutions within which decisions are made. Key questions to consider are the following: Are the institutional rules and practices derived from public institutions viewed as fair and unbiased? Do these institutional rules and procedures encourage innovation and produce outcomes that improve governance and society? Social trust is of equal importance, and this condition relates to the ways in which people interact with one another, publicly and privately, and is often a function of our individual experiences as well as the institutions through which we interact.. A concern in contemporary American culture is the growing isolation of the individual and a related decline in social as well as political trust which follow from that social isolation. The overarching theme of these studies of political culture is the critical role of social capital - the values and norms held by citizens that reflect trust in others, the active pursuit of engagement in networks of interpersonal relations of a wide variety, and standards of interchange among people involving the principles of reciprocity (return a favor with a favor) and mutual respect. As highlighted in the chapter on federalism and intergovernmental relations, the noted scholar Daniel Elazar found that political culture varies greatly across American state and local government settings, and this variation helps shape the capacity for and nature of public policy innovation across the American governmental landscape. ${ }_{-}^{3}$

Demographic characteristics of the settings within which American state and local government function are also of particular importance in the study of public policy innovation and capacity of state and local governments to adapt to societal change. Demographics include such things as: socioeconomic conditions, race/ethnicity make-up of a community, geographical location, and size of area (population 
as well as geographic concentration/dispersement). Socioeconomic conditions relate not only to the relative wealth or poverty present in a state or community but also to the distribution of wealth. Relevant socioeconomic factors also include the education level and type of employment of residents. Wealth, health and level of education greatly influence the capacity of citizens to participate in the governing process wherein they can express their policy preferences and assess proposed policy innovations. Innovation usually means doing something new for the first time or doing something of long-standing practice somewhat differently, and in the process accepting some element of risk in the hope of producing a better future. Clearly, without some degree of wealth, the capacity to assume the risks of innovation is limited. Without health and education, it is difficult to summon the energy and comprehend the need to be innovative; also, lack of health and education often leads to extreme caution and fear of change, usually among the very people for whom innovation would be most beneficial.

The racial and ethnic composition of communities plays a very significant role in public policy and policy innovation in the U.S. In his book Faces of Inequality, ${ }_{-}^{4}$ Rodney Hero argues persuasively that racial and ethnic diversity not only shape citizen perspectives of many policy dilemmas but also influence how state and local governments come to adopt - or avoid considering - timely innovative policy solutions. In short, innovation tends to occur more often in those communities where the diversity of public views of stakeholders is actively incorporated into the public policymaking process. For example, the changing demographic composition of many states and communities across the country requires considerable innovation to meet the needs of increasingly complex local communities. There is strength in the range of perspectives on a problem afforded us by diversity, and public policy innovations that build on this 
strength are much more likely to succeed than those that take a narrow focus on the problem to be addressed.

There is an old saying in the real estate business world - namely, three things, "location, location, and location" determine success. Somewhat the same observation may be made of public policy innovation. Some locations are considerably more amenable to innovation than are others. However, nearly every place in the world has one noteworthy limitation or another, and some have many apparent limitations. Successful policy innovators are able to identify the assets of nearly any location that is, place-based strengths upon which successful innovation can be built. ${ }_{-}^{5}$ For example, many Midwestern, Northern Plains, and Rocky Mountain states and local rural areas within them have lost substantial population due to the decline in family farming; nonetheless, public and private policy entrepreneurs often working in partnership have developed innovations that have slowed economic decline in many agrarian areas and strengthened community-based social and economic benefits. This is the case in places where wind turbines have appeared on the same plains where the nation's grains are still produced, supplementing the incomes of local farmers and building a clean, renewable energy future for future generations. ${ }_{-}^{6}$ Some locations require more sophisticated solutions to difficult problems, but identifying the strengths and assets present in any particular setting is universally important to the policy innovation process.

Size of population and extent of geographic area are also generally important considerations in the occurrence of policy innovation. Metropolitan areas have the advantages of being concentrated in terms of population and infrastructure, conditions that make the implementation of some types of policy innovations somewhat easier than would be the case in areas of sparse population. Many rural areas, in contrast, face a number of major challenges with respect to innovation. Not 
only are many rural areas becoming increasingly diverse as are metropolitan areas, but the physical distances between small communities typical in rural areas makes innovation difficult to formulate and difficult to implement.

The dispositions of political and social leaders clearly shape policy innovation formulation and determine the likelihood of success as well. As noted, innovation involves moving in new directions, often into a somewhat unknown future. Leadership is a key element in innovation because an effective leader is capable of not only conceptualizing future conditions, but a leader also can identify policy innovations that will create desirable future outcomes. For example, Wisconsin Governor Tommy Thompson played a significant leadership role in shaping welfare reform - a policy innovation that led to similar reforms in other states as well as nationallevel reforms enacted by a Republican Congress and signed into law by the Democratic President William Jefferson Clinton in 1996. In many policy arenas, innovation involves more than elected leaders taking the initiative; innovation often also requires that local social and business leaders play a significant role in developing and implementing innovation.

Finally, policy innovation is facilitated to a considerable degree by bureaucratic capacity. The administrative agencies of state and local government play a significant role in formulating and implementing policy innovations. Bureaucratic capacity involves well-trained professionals working in public organizations to meet political and social goals through the timely development and effective implementation of public policy. Attracting and retaining professional, experienced and well-educated people to key positions in public agencies requires that those agencies be adequately funded, professional in operation, and effectively organized to meet ever-changing needs and ambitious goals set out in the policy innovation enterprise.? 


\section{C - Infrastructure Renewal}

The United States is without question a land of vast natural resources. In the past, these seemingly abundant resources were taken largely for granted by Americans. Beginning in the 1960s and 1970s, however, circumstances began to change as access to natural resources such as fossil fuels, water, fertile farmlands, forest stands, and wildlife habitat began to tighten appreciably..$_{-}^{8}$ There was a growing sense that the pursuit of sustainability meant more than building and maintaining a durable infrastructure that could last for long periods of time. Conservation, historic preservation and environmental protection all became increasingly important aspects of the policy landscape at the local, state, and national level alike, affecting the way planning for the future was done at all levels of government. At this point, some public policy areas featuring clear themes of environmental sustainability are making a favorable difference in the promotion of sustainability at the state and local level of government.

\section{C.I - Water and Waste Systems:}

Clean water and sanitary wastewater processing and removal are very important functions of government, dating back virtually millennia. In antiquity, population centers were nearly always established near a water supply for purposes of human food production as well as for direct use (i.e., drinking, 
cooking, and washing). Waste systems were of equal importance; in this regard, contemporary forensic anthropologists provide ample evidence of how waste mismanagement contributed to a reduction in public health with the introduction of preventable risks such as the stagnant water-related diseases like malaria and typhoid fever (for historical background, see Rosen, 1993; Diamond, 1997).

In the 19th century, U.S. cities untreated effluent typically ran in the street gutters and trash was periodically disposed of by the practice of open burning. The potential for water and airborne disease was quite high given these conditions and practices. Highly communicable diseases such as typhoid and tuberculosis were not uncommon under these conditions. In the 1830s, New York City suffered a widespread cholera outbreak that led to the deaths of more than 3,000 people. A similar epidemic in the 1860s led to the death of over 1,000 residents. The New York epidemic was not dissimilar to cholera outbreaks in other urban areas in the U.S. Municipal sanitation laws were in place and were enforced, particularly during the epidemics, and this was indeed a good thing. However, insufficient resources were available to the public health authorities of the day to cope with a growing population and a large immigrant class in many cases bringing with them diseases contracted in other regions of the world or contracted during travel to the U.S. in confined ship's quarters.

Unfortunately, state and local governments in the past often made social and economic choices that were beneficial to their citizens in the short run but had unintended longterm negative consequences - and created externalities (the transferring of costs to others) for other jurisdictions. Spilling wastewater into a river downstream from a town, for instance, is one inexpensive way of removing waste for the upstream party, but this practice has the effect of polluting water for other users downstream who bear the costs of cleaning up the water to make use possible. 
Powerful economic interests at the state and local level often have the capacity to influence policy choices in ways that are personally beneficial, but which are inimical to community sustainability and long-term public health. For example, in many urbanized areas industrial waste disposal in the streets was quite commonplace in the 18th and 19th centuries; to make matters worse, during this era the dominant mode of transportation-horse-drawn carriages-deposited mountains of animal waste in the streets.

In the 19th century, sanitation and water services were frequently provided by private businesses operating for profit. For much of the 19th century, sanitation was a luxury few households could afford $;_{-}^{9}$ the underclass continued to rely on community wells and often remained at high risk for waterborne disease. Yet, as history clearly indicates the absence of uniformly provided water and waste removal services for all households - once epidemics begin - leads to patterns of illness that do not discriminate as to socio-economic classes. 10

During the Progressive Era (c. 1890's-1920's), a concerted effort was made to promote improved sanitation and clean water resources, the cornerstone of public health sustainability..- An important breakthrough in water provision and waste management services came with the establishment of public utility commissions (PUCs) at the municipal or county level, and at the state level in some states.- ${ }_{-}^{12}$ The principal purpose of public utility commission management was, in the words of one typical statute, to provide "service and facilities as shall be safe, adequate, and sufficient."13 PUCs often regulate both the quality of service as well as fix stable prices and provide equitable access to public utilities. ${ }_{-}^{14}$ The establishment in the 1860s of public health departments in New York and other states_. were examples of further water quality and effective waste removal public policy innovations. ${ }_{-}^{16}$ 
While the regulation of water quality and waste management has generally become an accepted part of state and local government function, the methods by which these services are delivered have been the subject of some debate. In retrospect, it remains unclear whether the public provision - through public utilities corporations - of water and waste services led to improved public health outcomes beyond those that might have resulted from the private provision of such services. ${ }_{-}{ }_{-}$Some academic studies have concluded that the private provision of water and waste management services did not produce outcomes dissimilar from public provision. Additionally, critics of publicly-provided water and waste management services charge that by centralizing the functions of water provision and waste management local government became the sole consumer of a good - essentially, a monopoly - which resulted in economic distortion and loss to both taxpayers as well as wage laborers working in utilities enterprises. ${ }_{-}^{18}$ - While these critics have not persuaded many state and local governments to abandon their reliance upon waste management and water provision monopolies, there has been a marked effort to increase resource supplier competition in states and local governments and provide for a more active governance role for utility service consumers. ${ }_{-}^{19}$ In the 1990s, policy entrepreneurs at the state and local level made a pronounced effort to use competition to improve service delivery, in the process often reducing costs to consumers. 20

National policy has an impact upon water quality and waste management, both domestically and internationally.Clean water standards are the principal means by which the federal government becomes involved in water and waste management issues. These two universally present local area services are important aspects for quality of life for existing residents and businesses, and for prospective new residents and businesses. Innovative communities will be wise to invest 
in the building and maintenance of superior quality water systems. ${ }_{-}^{22}$

While states and local governments began many of their public health sustainability efforts in the mid- to late-19th century, the national government stepped up its role in this area substantially in the 1960s and 1970s. The National Environmental Policy Act of 1969 (NEPA), the Clean Air Act of 1970 and the Clean Water Act of 1977 (CWA) gave federal regulatory agencies strong powers to establish standards in the area of water quality and waste management practices. Emergent from the CWA, the National Drinking Water Clearinghouse provides important information on water resources and waste management issues facing state and local governments and many individual property owners across the country. Without stifling state and local policy innovation in this area, federal action on water and waste management issues does serve as a tool to promote a considerable degree of equity of conditions across the nation.

\section{C.II - Government Buildings:}

Government buildings are a very important consideration in state and local government innovation in the 21st century. Unknown to most citizens, government infrastructure investments (including the initial design and construction, the operation over time, and the long-term maintenance) consume a significant portion of all government budgets; these costs increase in relation to both energy costs and building age. Older buildings are becoming increasingly problematic due to risks associated with dangerous (even toxic) materials used in their original construction. Unhealthy wallboard and insulation materials, synthetic carpeting 
emitting noxious fumes, and poor air filtration and circulation systems found in many older buildings present the danger of heightened public health risks to building occupants and workers who maintain the aging structures. The increased costs in areas such as disability and health care benefits paid to these people exposed to unhealthful environments often outweigh the costs associated with new construction.

In addition, older government buildings are often inaccessible to individuals with disabilities, and they feature antiquated wiring systems that cannot accommodate modern information technology. If you have visited older government buildings, these structures tend to be imposing and project a paternalistic relationship between the citizen and government workers that is unlikely to serve the needs of either party very well. The physical structure limits the ability of a public agency to meet the needs of 21st century highly networked organizations, thereby constraining government's ability to respond to ever-changing technology and be sensitive to ever-evolving citizen needs.

Innovative state and local governments across the country are increasingly seeking to reduce building construction, maintenance, and ancillary costs and improve customer service accessibility and service delivery in their jurisdictions. In many instances, state and local governments are opting out of taking on some permanent infrastructure costs through entering into limited-term lease contracts with private office space suppliers. Through long-term renewal lease options, the needed space can be chosen and designed so as to be accessible to a customer base while avoiding the costs of land acquisition, construction bidding, and long-term building maintenance. The final point is especially important in state and local government because of the extent of population growth and migration taking place in many areas. In these circumstances, public service providers in many cases must be located in close proximity to customers if public 
goods and services are to be delivered effectively in many areas.

In the case of new public structure construction, the federal Office of Energy Efficiency and Renewable Energy (EERE) promotes the concept of the whole building design approach (EERE, 2007). The EERE approach to building practice is advocated for residential and commercial buildings as well as for government structures. In essence, building design is viewed holistically, asking architects and engineers to consider the building's purpose, workforce, future, and operations and maintenance costs as a comprehensive whole. In the past, productivity was seen as a function of the individual worker operating within an organization; the whole building design approach views productivity as a function of the physical structure of the workplace as well as of the individuals working there. Customer satisfaction is also related to the physical location of goods and service delivery, and this goal of design also must be factored into building layout and construction in order to comply with the strictures of the whole building design approach. Finally, this integrated approach to infrastructure building plan development calls for maximal energy efficiency and the maximum use of renewable energy systems - both for the purpose of cost reduction and for the promotion of regional and global environmental sustainability.

The Energy Policy Act of 2005, presidential Executive Order 13101 ["Greening the Government through Waste Prevention, Recycling, and Federal Acquisition" (1998)], and Executive Order 13123 ["Greening the Government through Efficient Energy Management (1999)] are three examples of federal government innovation related to innovative government building design. Similar derivative policies exist at the state level in most American states, and many larger governments at the county and municipal local government level have adopted comparable policies. Currently, twenty- 
four states have adopted quite stringent energy standards for existing public buildings and for newly constructed commercial buildings. It is fair to say that sustainabilitypromoting guidelines are in place in most of the nation's population centers for the "greening" of government buildings and that this action qualifies as a timely innovation for the 21st century as state and local governments seek to address global climate change and promote sustainability.

The Pacific Northwest National Laboratory (PNNL) operated by Battelle Corporation for the U.S. Department of Energy contracted with the federal government's General Services Administration (GSA) to conduct a comprehensive analysis of green building innovations, which are a key component of whole building design for the 21st century. The PNNL report concluded that the U.S. Green Business Council's Leadership in Energy and Environmental Design (LEED®) criteria constitutes the prime approach to government (and private sector) building design innovation. "LEED $®$ is not only the U.S. market leader but is also the most widely use[d] rating system employed by federal and state agencies. The existence of this standard makes it possible "to communicate a building's sustainable design achievements with others., ${ }_{-}$

LEED $\AA$ provides a six-dimension set of criteria for achieving sustainable government building design: 1) Sustainable Sites; 2) Water Efficiency; 3) Energy and Atmosphere; 4) Materials and Resources; 5) Indoor Environmental Quality; and 6) Innovation and Design Process:

- A sustainable site is studied in terms of land use impacts of development; accessibility of buildings using alternative transportation systems (e.g., mass transit, bicycles, alternative fuel vehicles); the building location and design in relation to urban renewal project planning; and the reduction of light pollution.

- Water efficiency relates to the use of efficient landscaping to 
include xeriscape design. Water efficiency also relates to the use of low-flow utilities that reduce water consumption and innovative wastewater management systems.

- The energy and atmosphere dimension involves renewable energy and the reduction of ozone-depleting emissions. Additionally, energy demand reduction is an important consideration that can be maximized using natural lighting designs and low energy demand light fixtures and office equipment.

- Materials and Resources relates to the use of recycled content materials, local or regional materials, and efficient building material waste management (separation of waste from recycled materials).

- Indoor environmental quality issues include such things as carbon dioxide monitoring, ventilation and low-emitting construction and design materials. Temperature and light control factors are also critical to indoor environmental quality, with natural lighting placed at a high priority.

- LEED® methodology places special emphasis on inclusive planning processes and innovative multi-disciplinary design exercises, recognizing that new ideas can be developed in some cases and the adoption of best practices can be actively encouraged within a broadly inclusive planning process.

Government building design innovation is important for at least two reasons. First, state and local government buildings are expensive to design, to build and to maintain. Constructing next-generation structures may reduce longterm costs to taxpayers and make government more efficient, effective, and satisfying to citizens or prospective citizens. Second, government acting as a policy innovator can demonstrate a commitment to next-generation building design and thus encourage partnerships between state and local government and private sector enterprise. Commitment to local solutions and material providers means that 
government creates a local demand for next-generation materials and equipment that may lead to spin-off sustainable economic development in states and local communities where such development had not yet been contemplated.

\section{C.III - Urban Re-Development:}

In the 1960s and 1970s urban redevelopment was often driven by multiple concerns - namely, for public safety, for racial equality, and for aesthetic appeal. The post-Second World War era witnessed a tremendous migration to both the cities and the newly created suburbs. Infrastructure renewal in our major cities was desperately needed in the post-War period, but the new development of suburbia competed for capital, for human resources, and for the prioritization of public and private investments alike.

One of the biggest challenges faced by American states and their major cities is the rapid development of major urban areas in developing nations - which collectively are on course to surpass the U.S. in capacity on many critical dimensions within the span of a decade. For example, new suburbs in Indian cities are attracting young professionals from around the globe. In the last decade, China's cities have been consumed with major efforts at redevelopment; building plans in Beijing, for instance, cover an area several times larger than Manhattan. In short, the challenge facing U.S. urban redevelopment innovators is of global dimension. ${ }_{-}^{24}$ If economic and social sustainability is to be achieved, then American cities and states must strive to do at least their fair share to promote sustainability.

The 21st century faces any number of demographic changes and demands. Demographically, contemporary cities 
in much of the country are faced with a growing gentrification process. Young urban professionals, prosperous retirees, and the well-educated New Immigrant class all are seeking succor in urban living. The cost of housing is certainly one critical factor faced by 21st-century urban planners. The quality of life demands of the new urban class requires considerable public policy innovation on the part of state and local government. Many standards associated with pollution, for instance, have less to do with federal clean air standards and regulatory requirements than to aesthetic appeal that either draws or repels such fairly affluent people from city living. Open-air plazas and increased access to natural light are very important to the new prosperous urbanite. Easy access via public transportation is of critical importance, as is access to internet technology and contemporary cultural and educational amenities. The young professional living in U.S. cities today is faced with an ever-changing, highly competitive economic and social environment. The knowledge-based tools needed to navigate contemporary life must be readily available. At a deeper level, urban and suburban redevelopment faces several new challenges in many areas of the country. Lack of community cohesion and sense of place, property rights conflicts, site-specific pollution issues, and access to technology are among the commonplace concerns. In each case, the success of redevelopment efforts hinges on the effective management of a set of relatively new issues for local government officials. These issues are critical to effective redevelopment efforts, requiring innovative thinking and actions in order to maintain effective democratic governance while promoting state, regional, and local sustainability and relevance in a global society featuring an ever-increasing range of geographic choices for living and working for what Richard Florida calls "the creative class."

Neighborhood and community cohesion is a critical part of maintaining the social capital networks so vital to the 
good society and to the good life. In rural areas as well as highly urbanized regions, it has been shown in a wide range of areas that effective government and social institutions require a degree of social interconnectedness_- in the highly itinerant 21st century, local government cannot assume stable longterm civic networks. Additionally, there is some question as to how local neighborhoods and the wider community relate is the relationship complimentary? Evidence tends to indicate that in most cases individuals are more likely to form bonds at the neighborhood level than at a broader community level. The issue becomes especially important in state and local policy innovations intended to restructure society for the future. The new demands for social interconnectedness clearly point to a need to cultivate neighborhood network development. This development work must be done, however, in a manner that reduces the time costs to the individual seeking to broaden their network connections upward to the community level.

While civic networks are seen as an important aspect of urban and suburban redevelopment, other forces tend to divide and separate individuals in economic terms -the developed community phenomenon is a good example of this dilemma. Developed communities can be freestanding homes, condominiums or even entire apartment complexes. Relationships among residents and between residents and developers within gated communities are focused more on economic status homogeneity than on other, more socially beneficial forms of community reflected a bridging of differences in social class and racial and ethnic cultures.

While air and water quality standards are increasingly a function of federal Environmental Protection Agency (EPA) guidelines, there are other site-specific air and water issues which are more often guided by state and local policy innovation. One particularly important example is the issue of noise pollution. ${ }_{-}^{27}$ The issue of noise pollution becomes an 
issue due to a number of factors in modern communities. First-whether in rural, suburban, or urban areas - American communities are increasingly heterogeneous. Also, the population is becoming denser, bringing individuals into closer proximity to one another. With the changing nature of work and the rise of home-based offices and telework, residential areas are de facto mixed-use areas; a residence may be a workspace at various times of the day or night and simultaneously serve as home. Transportation corridors often increase ambient noise in residential areas. Particularly in the areas of the U.S. where peri-urban areas are developing, the suburban fringe may abut traditionally agrarian functions such as farms, dairies, and livestock feedlots; the noise (and odor) of livestock, chemical fertilizers and fungicides and herbicides and heavy machinery will be in evidence in these areas. Demographics may bring young socialites into close proximity with young families or retirees who have quite different lifestyles and noise tolerance patterns.

Several studies have shown that noise pollution is strongly related to problems of social cohesion, and may lead in some cases to public health and even criminal justice problems. Innovations focused on noise pollution relate to more than simply the decibel level of noise in a given community. European researchers have found that one of the best ways to manage noise in the residential environment is to begin by listening to residents and determining the character of the noise present in a community before making decisions about how to manage that noise. Nevertheless, noise is a form of pollution that must be managed as are other hard-causing pollutants. A sustainable community model for state and local policy innovators must carefully take into consideration the role of noise in the development of urban redevelopment plans.

A fourth area of importance in urban redevelopment is related to technology access and use. ${ }_{-}^{28}$ Technology, 
particularly computer-based applications and communications technology, has often been thought of as the foundation of a new age in the U.S. economy and society. Policy innovations that have sought to improve access to communication tools are likely to continue to be at least "one generation" behind current use and demand patterns. Terminal-based e-mail and Internet access have been surpassed by mobile wireless technologies that significantly change the networks of communication. Access and use, for instance, are done entirely at user discretion, allowing the person involved selecting which information and which communication networks will become part of their social, political, and economic virtual world. Additionally, such network relationships are so individualized and also quickly obsolete that would-be policy innovators will have to manage a diversity of tastes in the future rather than design environments with a "typical family of four" construct in mind. In many respects, creating or encouraging the development of a very broadly based and interactive communication network may be a critical precondition to virtually any other innovations in urban redevelopment beyond the provision of a very basic needs infrastructure. It is important to note that not all persons are equally capable of taking advantage of the opportunities for engagement and exploration of personal tastes made possible by the wireless technologies and the increasingly accessible Internet. The millions of Americans in our states and local communities who can be classified as aged and poor are the least likely to be enjoying the benefits of this technology, and regional and urban planning innovations related to technology will require continued efforts to "bridge the digital divide" of accessibility to broadband services and computers; without such efforts the social equity element of sustainability is not addressed and political, social, and economic divisions may deepen rather than lessen. Such divisions, in turn, threaten the adaptive capacity of societies to 
"rally to a common cause" of sustainability-promoting change to confront and overcome the challenges of a planet in peril of human-induced global climate change and natural resource scarcities. In the coming decades, broadened access to information technology and computers in our nation's states and local communities must become a source of adaptive capacity for mobilizing collective action to address our sustainability challenges, not yet another source of political and economic division.

\section{D - Resource Management and Development: Energy and the Environment}

One resource that is critical to modern conceptions of the good life is the availability of energy - both electrical and thermal - for use in private residences and commercial enterprises. In recent years it has become increasingly clear that the major contemporary sources of energy such as fossil fuels (oil and coal) present such a high cost to the health of the environmental that we must rethink our energy future and be prepared to make significant changes in how we travel, how we produce goods and services, and how we design our homes and workplaces. All state and local governments are facing hundreds of policy decisions precisely in this area of energy provision, patterns of consumption, sources of supply, choice of products, and design of workplaces and commercial and residential zoning and building regulations. Far beyond the reach of state and local governments, the U.S. Federal government, international commodity cartels, and multinational energy firms play a major role in shaping energy 
markets, thereby affecting environmental policy choices available to governments. Within those broad constraints of these major actors, however, state and local governments in U.S. do have a great deal of room to shape local decisionmaking about the recycling of re-useable products, about the patterns of energy use and conservation occurring in their jurisdictions, about the alternatives to auto-based transportation which could exist, about the use of LEED@ construction processes and structure, and about similar measures adopted by state and local governments around the nation to promote sustainability. 29

\section{D.I - Energy Policy:}

For over a century our nation has been heavily focused upon fossil energy production and use because of our easy access to coal and oil. In the late 1850s, the first successful oil well began extracting petroleum in Pennsylvania. Since that time, some states and many local communities in the U.S., and elsewhere in the world, have developed entire industries and associated financial systems around the fossil energy paradigm. Early views on the sustainability of a world economy "fueled" by coal and oil resources was built on the faulty premises that the supply of cheap and easily accessible fossil energy would last forever, and that no significant damage was being done to the planet by the burning of these fossil fuels to provide energy for homes, for commercial officers, for transportation, and for industrial production. In the early 1970s, however, that very commonly shared viewpoint of the long-term sustainability of petroleum supplies, in particular, began to change in very significant ways: 
- social and political values at the grassroots community level in many regions of the nation began to focus greater attention on "green" or pro-environment policy initiatives, and public interest groups promoted new conservation-oriented and ecologically-sensitive views of sustainability found to be particularly strong among younger generations;

- in an effort to address social equity concerns, some public utility commissions (PUCs) placed increasingly greater emphasis on equitable energy distribution to privileged and underprivileged households and businesses alike (e.g., in California, the Miller-Warren Energy Lifeline Act of 1972), and some PUCs began to explore the potential role of alternative renewal energy supplies;

- some environmental interests identified alternative modes of living - e.g., "next-generation" building design and reduced toxic emissions - intended to enhance the quality of life in communities in ways that were not injurious to the environment;

- and land use planners focused increasingly more attention on the role of mass transit development in metropolitan areas (e.g., Bay Area Rapid Transit) where burgeoning urban and suburban areas produce insufferable traffic congestion.

While alternative energy slipped from the national policy radar screen for much of the 1980s, a number of states and many local communities continued to explore energy policy innovations. In California, renewable energy systems were encouraged by state tax incentives. Geothermal energy was developed in the Imperial Valley, along the U.S.-Mexico border. Wind energy was harnessed in the Altamont Pass ${ }_{-}^{30}$ region in Northern California. California researchers conducted research on clean coal and "fluid bed" combustion chamber technology for electric generation plants. ${ }_{-}$

In the post-September 11th policy environment, during a period of relatively high petroleum prices and at a time 
when supply futures are questioned the value of state and local energy innovation is now more fully recognized and continues to be actively promoted. Currently, state and local energy innovation is primarily advanced through three principal mechanisms. First, states create markets for renewable energy through renewable energy portfolios (RPSs). RPSs are benchmarks for the portion of energy used by state consumers that must be supplied by renewable sources. In the 23 states with RPSs, either public utilities commissions or state regulatory offices monitor the standards. RPS standards can be met either through direct use of renewable energy by consumers or through the use of green tags. Green tags represent a validation that renewable energy was produced and made available on the electrical grid. Except for the direct impact of emissions at a particular use or production site, green tags have the same effect - that of committing energy producers and consumers alike to renewable zero-emission energy. Green tags can be used for tax credit purposes as well.

Second, states and local governments encourage renewable energy innovation through the use of price subsidies or inducements to renewable energy consumers. During periods of transition to new sources of "clean energy" the market price for green energy tends to be higher than conventional fossil fuel energy; to promote further development of clean energy sources and in time reduce the cost of those sources those responsible parties who generate renewable energy for grid-use or who use renewable energy sources are offered financial incentives to encourage their sustainability-promoting economic choices. Finally, the third form of encouragement that state and local governments use is that of the provision of research money to underwrite applied research in science and engineering for the development of practical sustainable energy infrastructure. 


\section{E - Core Dimensions of Sustainability}

The first chapter outlined four core dimensions of sustainability. In this chapter, we find that policy innovation focusing on sustainability can be characterized as the new margins-the basis for understanding which local and state governments are more likely to manage impending social, political, economic, and environmental change. Sustainability entails maintaining values while adapting to changing conditions. In terms of social objectives, a continued and growing commitment to human capital is of critical importance to sustainability. Historically, modern society has identified certain types of knowledge, particular skills, and specific abilities associated with some types of employment to be essential to promoting "progress" - the basis of modern societies and organizations that often demand highly specialized divisions of labor. Books such as William Whyte's Organization Man and David Riesman's The Lonely Crowd provide moving descriptions of the socially isolating communities created by the type of consumption-driven modernism we have taken to be progress.

Sustainability, however, demands that we rely much more heavily on socially connected and highly inclusive communities and develop the capacity for adaption to change. Preparation for narrowly defined employment will give way to the need for highly skilled yet highly adaptable individuals who can communicate and work with individuals with a wide variety of skill sets from highly varied social and educational backgrounds. In no small measure the educational systems of our nation, from K-12 elementary schools, through secondary schools, and including our higher education institutions will have to become adaptive to the knowledge and training needs of these boundary-spanning experts of the future.

As for economic objectives, sustainability demands that 
we create deeper social and economic relationships focusing on the provision of collective benefits rather than focusing too heavily on the stimulation of economic motivation based on the maximal accomplishment of rational self-interest. Individual economic benefit can emerge when equitable market structures reward individual market innovation and hard work. Sustainability is promoted most effectively, however, when individual economic success leads to community benefit in the form of jobs, infrastructure development, and renewal and the nurturing of a stable tax base to support public programs, which can address social equity goals.

In much the same way, the environmental objectives of sustainability are advanced when effective social and economic structures are in place and state and local governments can appeal to what psychologist Abraham Maslow refers to as "higher-order needs" for beauty and justice. Appealing to consumers as individuals seeking to promote their own self-interest within their broader roles, as community residents will more likely than not serve to incorporate environmental sustainability into the decisionmaking process of citizens. Citizens taking an active concern for the environment would likely translate into a strong market demand arising for products, which would be manufactured locally and marketed in environmentally sound ways.

Finally, institutional objectives require that sustainability become an almost "infectious" concept across state and local government jurisdictions. By means of inter-institutional networking, each sustainable state and local community would serve as a model for other communities and states seeking to accomplish similar goals for their residents. While sustainability is the currently widely seem as the "new margin" for successful community and state development, it cannot be viewed in these zero-sum terms - where each successful community or state competing to gain population and 
resource share comes at the expense of others. Instead, the dynamic must become one of the contagion of best practices, with strong demand from well-informed citizens that effective practices observed elsewhere need to become part of their particular state and local government institutional and policy structure.

\section{Exercises}

\section{Sustainability - What Can I do?}

Here are some everyday things individuals can do to promote sustainable lifestyles and communities:

1. Print your class assignments and papers doublesided, or ask your professor if you can submit electronic versions.

2. Unplug computers and appliances if possible while not in use. This will decrease your energy use and power bill.

3. Turn off lights in rooms when not in use.

4. Bring your own reusable cloth tote bag to the grocery store or university bookstore and avoid using paper and plastic bags.

5. Bring your own mug to the coffee shop. 
6. Replace incandescent lamps with compact fluorescent lamps.

7. Wash your clothes in cold water.

8. Try walking, biking, carpooling or mass transportation to commute to campus.

For general information, go to the Environmental Protection Agency's Sustainability website: http://www.epa.gov/Sustainability/basicinfo.htm\#epa

\section{E.I - Environmental Protection:}

The National Environmental Protection Act of 1970 (NEPA) served as the initial impetus for much state and local policy innovation. State Environmental Policy Agencies (SEPAs) were created in most states in the 1970s to provide an interface with the EPA and to enforce state environmental quality standards. The primary purpose of NEPA was to limit the impact of human action on the natural environment. Under NEPA, all applicable federal agency actions - or the actions of private contractors working with federal agencies - must be evaluated prior to initiation in terms of potential environmental impacts, and if such impacts are anticipated 
plans must be outlined for how harmful impacts will be either or prevented, significantly reduced, or compensated for in some appropriate way.

NEPA was the first comprehensive environmental policy legislation in the U.S. and provided a major impetus for the development of a deeper understanding of environmental health throughout the country. With growing concern for environmental quality issues relating to air and water and wildlife habitat, many state policy innovators saw NEPA and state analogs as presenting an opportunity to consider more carefully the quality of the environment within their own jurisdictions. Using NEPA as a blueprint, state environmental quality standards are in many cases more stringent than federal requirements. Currently, 18 U.S. states have "NEPAlike" requirements enforced by so-called mini-NEPA state agencies. Environmental quality innovations are an important part of promoting sustainable development in states and communities, and they are related to other state or local goals directed toward the promotion of a clean environment, the provision of good public health services, and the provision of strong public safety services to be called upon in the event of natural disasters. Economic vitality is clearly necessary to sustain all of these environmental and community protection efforts, but the recognition is now rather widespread that such commercial and manufacturing activities as take place to provide employment and income and tax revenue to state and local government must be carried out in an environmentally sensitive manner. ${ }_{-}^{33}$ 


\section{F - Livability}

As noted above in the discussion of energy resources, the term sustainability has meant different things to different people at different times. Currently, American states and local communities face significant challenges in how that term understood as entailing the simultaneous achievement of economic vitality, environmental protection, and social equity promotion without diminishing the prospect of future generations - is translated into practical policy goals and programs. The goals of state and local government must simultaneously maintain economic success in various markets - local and global - as well as provide for equal opportunity for healthy living. In the past, these goals have been at odds with each other. While no single state or local community can say it has achieved fully all of these goals and done so in a way to leave the same or better conditions for the next generation, many state and local governments have made noteworthy simultaneous progress toward these goals. The following section seeks to address emergent livability issues in the U.S., and indicate the role that state and local governments in time will come to play in addressing those issues.

\section{F.I - Eldercare Issues:}

As the Baby Boom generation reaches retirement age, the percentage of the population 65 years of age and older is expected to grow rather substantially. According to the Census Bureau, by 2030, all of the baby boomer generation will be older than age 65, which will expand the size of the older population so that 1 in every 5 residents will be retirement 
age. The nation's changing social and economic demographics mean that many older Americans will either have no children or only one child to help them address their needs for care in their old age, increasing the burden on society and individuals trying to balance work with care-giving activities. ${ }_{-}^{34}$ Countless working hours will be devoted to eldercare, reducing productivity and earnings for many young and middle-aged adults. Communities in which is it difficult for the infirm to navigate and where caregiving facilities and services are lacking will likely suffer in terms of attracting workers and retirees alike. Also, the building of an effective caregiving community requires that state and local government must be mindful of the diverse nature of the aging population. . $^{35}$

At the federal level, there are several agencies that deal directly with issues related to eldercare. The three most prominent such agencies are these:

- Administration on Aging

- Centers for Medicare and Medicaid

- Social Security Administration

The Older American Act (OAA) of 1965 (reauthorized 2006) is a federal law that serves as the foundation of many state and local efforts to respond to the dramatic demographic change facing the nation in the coming decade. The OAA established the Administration on Aging and led to the creation of the National Aging Network (NAN), a large network of eldercare service providers. The OAA also promotes the development of senior centers and programs for traditionally underserved populations, such as Native Americans.

Treating the elderly with respect and dignity requires a wide range of services and a great deal of thoughtful planning. Community sustainability in an era of an aging population requires more than just the provision of basic necessities it entails promoting the ability of seniors to maintain quality 
relationships with others, both of their own age and those younger than themselves. Along with state and local resources and community-based organizations (religious and secular), the OAA offers grants-in-aid to states and local communities attempting to serve the needs of the elderly. Innovations in the eldercare area include nutrition programs, employment programs, and disease prevention programs. Additionally, intergovernmental cooperation has helped to build the National Family Caregiver Support Network and Eldercare Network; the former is designed to help caregivers cope with issues related to eldercare and life management. National law has also sought to reduce elder abuse and to promote elder rights. The latter organization is of help to both the elderly and their caregivers, providing information about services available and the location of those services in relation to an elderly person's place of residence. The Eldercare Locator is also helpful in linking an elderly person's work skills with particular jobs, which is of growing interest to Baby Boomers. Many of these new retirees discover that they have not saved sufficiently for their retirement years, that the costs of living in retirement are higher than they expected, and that they will require further years of employment. Of the nearly \$1.4 billion enacted for the Administration on Aging in 2006, \$1.2 billion of the federal allocation was allocated to programs designed to support both state and local government eldercare programming. 


\section{F.II - Social Capital and Civic Life:}

In the timeless classic historical treatise entitled Democracy in America, the French visitor of aristocratic heritage Alexis de Tocqueville described a rather idyllic 19thcentury community-focused existence for Americans he observed during a prolonged visit in the 1830s. Americans throughout the country were witnessed working side-by-side in local communities with neighbors helping neighbors and citizens generally doing their fair share to address shared problems; volunteerism was commonplace and was even relied upon in many situations for the provision of essential governmental services such as firefighting and road maintenance. In his books Making Democracy Work and Bowling Alone, contemporary Harvard political scientist Robert Putnam reported strong correlates between successful robust democratic institutions, high rates of civic volunteerism, and strong social institutions. ${ }_{-}^{36}$ Putnam also pointed out, however, that when civic life declines, democratic institutions show a similar decline. Without dynamic civic institutions and without the active engagement and support of citizens (young and old, well-off and of modest means), state and local government's ability to maintain livable communities in which sustainability is being pursued is severely constrained. Maintaining civic involvement among a diverse set of citizens, encouraging grassroots volunteer-driven efforts to solve problems, cultivating discussion regarding the future desired condition of a community are all important ingredients in successful governance and the pursuit of sustainability.

Several national-level programs being implemented at the state and local government level are designed specifically to help promote civic engagement and encourage community involvement. The Corporation for National and Community 
Service - a federally sponsored non-profit corporation manages AmeriCorps, Learn and Serve America, America Reads, and Senior Corps. Through volunteering in these programs, citizens become more fully aware of the communities in which they live and come to understand the problems government, the non-profit sector, and the private sector are seeking to address as they pursue global, national, regional, state and local sustainability. Volunteerism not only serves the public interest, but also gives the individual volunteer a sense of self-efficacy, personal fulfillment, and generally leads to higher levels of active participation in other dimensions of civic life.

Existing non-profit religious institutions such as synagogues, churches, and mosques also serve a longstanding and significant role in U.S. states and local communities. Houses of worship often draw people from all walks of life into an atmosphere of mutual trust for the pursuit of communal goals. Communality is the primary basis of community in these religious groups; similarities in terms of beliefs, needs and oftentimes worldviews provide the social cement for these aggregations of co-religionists. Civic clubs such as Rotary, Kiwanis, Lions, Moose, and Elks may draw individuals together on the basis of other forms of communality, most frequently based on a mutual commitment to help the less fortunate members of society. Other civic associations include the League of Women Voters, the Civil Liberties Union, municipal and county historical societies, and Chambers of Commerce and offer venues for those interested in community-betterment and desiring the camaraderie that comes from volunteerism.

Another form of civic engagement is participation in the cultural arts. The arts might include local or regional museums focusing on a much broader swath of literary, visual and performing artistic talent. Musical societies and orchestras are also important in drawing together individuals 
from the community. Policy innovations in terms of the promotion of the arts are often overlooked in terms of their significant impact in building sustainable states and local communities. The ability of state and local government to operate effectively and accomplish significant goals through innovation may hinge on something as apparently unrelated as the arts; the fact that one will often see political leaders gather at artistic events and mingle and interact with other citizens outside the setting of formal political institutions to their value.

\section{G - Conclusion}

Extensive policy innovation in pursuit of a sustainable future in an age of global climate change and pending shortages of critical natural resources will be a necessity in the coming decades. State and local government, just as much as the federal government, will have to rise to the challenges to be faced in addressing the three "Es" of sustainability promotion of economic vitality, protection of the environment, and promotion of social equity. $\frac{37}{-}$ This book documents how innovation at the state and local government level have often lead the way for national movements addressing the difficult transitions made by Americans from an agricultural society to an industrial society, and finally from an industrial society to a post-industrial society. American federalism, the flexibility of state constitutional processes, and the wellsprings of social capital in communities throughout the country have in combination given rise to considerable innovation in public policy and in governance practices. We are optimistic that these major elements of state and local 
government in America will lead to the next set of innovations which will bring us closer to a sustainable future wherein we can carry out our obligation to future generations to leave the planet no worse off than we found it.

The realization worldwide that abundance of space, natural resources and seemingly inexhaustible energy supplies are actually limited, and that development has lead to the serious risk of irremediable damage to planet earth, our newest challenge is to discover what innovations in public policy and private actions need to occur to provide for a sustainable future. One hope for the future is for all to live in sustainable local communities that are inclusive of persons of diverse background, nurture citizens young and old, enrich those of high- and pedestrian tastes alike, and treat all equitably with respect to the free pursuit of life, liberty and the pursuit of happiness in a healthful environment. The role of state and local governments in meeting this challenge is certainly great, but the men and women serving in leadership roles in these governments, the public servants serving citizens in the public agencies maintained by these various governments, and the many non-profit and private sector partners of these governments are up to that challenge. If this book hits its mark, we should have new recruits to the cause of sustainability in the years ahead.

\section{Terms}

$\underline{\text { Amenities }}$

Bureaucratic Capacity

Developed Community

Gated Community 
LEED@

Political Culture

$\underline{\text { Political Trust }}$

Price Subsidies

Renewable Energy Portfolios

Social Capital

Whole Building Design

Xeriscape Design

\section{Discussion Questions}

1. Discuss three important pre-conditions or factors that facilitate public policy innovation.

2. Summarize both the proponents' and critics' positions on the relative benefits (or lack thereof) of the development of PUCs.

3. According to the chapter, what are four ways in which views of sustainability of petroleum began to change in the 1970s. 


\section{Notes}

1. D.F. Kettl, "The Gulf of Government," Governing (April, 1998): 12.

2. E.M. Uslaner, The Moral Foundations of Trust (New York: Cambridge University Press, 2002).

3. D.J. Elazar, The American Mosaic: The Impact of Space, Time and Culture on American Politics (Boulder, CO: Westview Press, 1994).

4. R. Hero, Faces of Inequality: Social Diversity in American Politics (New York: Oxford University Press, 1998).

5. R. Middleton, Streamlining Energy Policy: Working More Efficiently, Spectrum: The Journal of State Government 77(2004): 5-8.

6. L.J. Vale, and T.J. Campanella, eds., The Resilient City: How Modern Cities Recover from Disaster (New York: Oxford University Press, 2005).

7. R.T. Cober, D.J. Brown, A.J. Blumenthal, D.D. Doverspike, and P. Levy, "The Quest for the Qualified Job Surfer: It's Time the Public Sector Catches the Wave," Public Personnel Management 29(2000): 479-496.

8. B. Davis, "Western Growth Trends: Pressure on People and Resources," Spectrum: The Journal of State Government 78(2005): 18-19.

9. P.V. Fishback, and D. Lauszus, "The Quality of Services in Company Towns: Sanitation in Coal Towns During the 1920's," The Journal of Economic History 49(1989): 125-144.

K.C. Gaspari and A.G. Woolf, "Income, Public Works, and Mortality in Early Twentieth-Century American Cities," The Journal of Economic History 45(1985): 355-361.

M. Ogle, "Domestic Reform and American Household Plumbing, 1840-1870," Winterhur Portfolio 28(1993): 33-58.

10. S. Schultz, and C. McShane, "To Engineer the Metropolis: Sewers, Sanitation, and City Planning in Late-Nineteenth- 
Century America," The Journal of American History 65(1989): 389-411.

11. For a good historical background, see:

A.M. Scott, "The Progressive Era in Perspective," The Journal of Politics 21(1959): 685-701.

J.A. Tarr, T. Yosie, and J. McCurley, III, "Disputes Over Water Quality Policy: Professional Cultures in Conflict, 1900-1917," American Journal of Public Health 70(1980): 427-435.

12. Many PUCs were initially established to regulate railroads and developed a broader regulatory mission in the early 20th century.

W. Gormley, J. Hoadley, and C. Williams, "Potential Responsiveness in the Bureaucracy: Views of Public Utility Regulation," The American Political Science Review 77(1983): 704-717.

13. J.A. Lapp, "Public Utilities," The American Political Science Review 2(1908): 595.

14. O.C. Hormell, "State Legislation on Public Utilities in 1933," The American Political Science Review 28(1934): 84-93.

15. P. Starr, The Social Transformation of American Medicine (New York: Basic Books, 1982): 184.

16. In his classic account, G. Rosen's A History of Public Health (Baltimore, MD: John Hopkins Press, 1993) demonstrates that public health and sanitation issues have historically been linked in mission, although the link has varied over time and across cultures.

17. W. Troesken, "Typhoid Rates and the Public Acquisition of Private Waterworks, 1880-1920," The Journal of Economic History 59(1999): 927-948.

G.H. Wolff, and M. Palaniappan, "Public or Private Water Management? Cutting the Gordian Knot," Journal of Water Resources Planning and Management (January/February, 2004): 1-3.

18. Bish, and P.D. O'Donahue, "A Neglected Issue in Public- 
Goods Theory: The Monopsony Problem," The Journal of Political Economy 78(1970): 1367-1371.

S. Renzetti, "Municipal Water Supply and Sewage Treatment: Costs, Prices, and Distortions," The Canadian Journal of Economics 32(1999): 688-704.

19. B. Van Vliet and N. Stein, "New Consumer Roles in Waste Water Management," Local Environment 9(2004): 353-366.

20. D. Osborne and T. Gaebler, Reinventing Government: How the Entrepreneurial Spirit is Transforming the Public Sector (Reading, MA: Addison-Wesley, 1992).

21. M.S. Anderson, "Governance by Green Taxes: Implementing Clean Water Policies in Europe, 1970-1990," Environmental Economics and Policy Studies 2(1990): 39-63.

A.K. Biswas, "An Assessment of Future Global Water Issues," Water Resources Development 21(2005): 229-237.

S. Loranger, "Global Water Management: How Do We Begin to Solve the Problems?" Global Water Management Conference (Washington, DC), February 9, 2005.

22. W. Hu, "U.S. Says New York City May Have to Spend $\$ 6$ Billion on Filtration," New York Times, June 1, 2000, pp. B1, B6.

23. K. Fowler, and E. Rauch, Sustainable Building Rating System - Summary, (PNNL-15858) (Richland, WA: Pacific Northwest National Laboratory and the U.S. Department of Energy, 2006), p. v.

24. R. Florida, Cities and the Creative Class (New York: Routledge, 2004).

25. R. Florida, The Rise of the Creative Class (New York: Basic Books, 2002).

26. J.R. Hipp, and A. Perrin, "Nested Loyalties: Local Networks' Effects on Neighborhood and Community Cohesion," Urban Studies 43(2006): 2503-2523.

27. M. Adams T. Cox, G. Moore, B. Croxford, M. Refaee, and S. Sharples, "Sustainable Soundscapes: Noise Policy and the Urban Experience," Urban Studies 43(2006): 2385-2398.

28. M. Crang, T. Crosbie, and S. Graham, "Variable 
Geometries of Connection: Urban Digital Divides and the Uses of Information Technology," Urban Studies 43(2006): 2551-2570.

29. J. Geringer, "The Future of Energy and Supply and Demand in the U.S.," Spectrum: The Journal of State Government 76(2003): 28-32.

C.A. Simon, Public Policy: Preferences and Outcomes, 2nd Edition (New York: Pearson, 2010).

W. Budd, N.P. Lovrich, J.C. Pierce, and B. Chamberlain, "Cultural Sources of Variation in U.S. Urban Sustainability Attributes," Cities: The International Journal of Urban Policy and Planning 25(2008): 257-267.

30. W. Turner, "Private Investors Selling Wind Power to Utilities," New York Times, February 13, 1983, p. A14.

31. M.W. Browne, "New Energy Ideas Emerge as Oil Reserves Dwindle," New York Times, December 31, 1985, C1.

32. M.R. Simmons, Twilight in the Desert: The Coming Saudi Oil Shock and the World Economy (New York: John Wiley, 2005).

33. J. Finkle, "New Economic Development Strategies for the States," Spectrum: The Journal of State Government 75(2002): 23-25.

34. C.D. Austin, E. DesCamp, D. Flux, R.W. McClelland, and J. Sieppert, "Community Development with Older Adults in their Neighborhoods: The Elder Friendly Communities Program," Families in Society: The Journal of Contemporary Social Services 86(2005): 401-409.

E.J. Bolda, J.I. Lowe, G.L. Maddox, and B.S. Patnaik, "Community Partnerships for Older Adults: A Case Study," Families and Society: The Journal of Contemporary Social Services 86(2005): 411-418.

J.E. Swanberg, T. Kanatzar, M. Mendiondo, and M. McCoskey, "Caring for Our Elders: A Contemporary Conundrum for Working People," Families and Society: The Journal of Contemporary Social Services 87(2006): 417-426.

35. H. Li, D. Edwards, and N. Morrow-Howell, "Informal 
Care-giving Networks and Use of Formal Services by InnerCity African American Elderly with Dementia," Families in Society: The Journal of Contemporary Social Services 85(2004): 55-62.

J.W. Min, "Cultural Competency: A Key to Effective Future Social Work with Racially and Ethnically Diverse Elders," Families in Society: The Journal of Contemporary Social Services 86(2005): 347-358.

36. R. Putnam, Bowling Alone: The Collapse and Revival of American Community (New York: Simon and Schuster, 2002).

R. Putnam, Making Democracy Work: Civic Traditions in Modern Italy (Princeton: Princeton University Press, 1993).

37. See historical accounts of successes and failures in societies adapting to changing environments in: J. Diamond, Guns, Germs, and Steel: The Fates of Human Societies (New York: W.W. Norton Publishers, 2005). 


\section{Chapter 4: Key Actors and the Policy Process in State and Local Governments}

\section{A - Introduction}

In this chapter, we describe state and local government policy processes and the various actors and interests that typically seek to influence those processes. Public policy and the policy process have been defined in the following way by most social scientists that study these phenomena:

Policy is what the government says and does about perceived problems. Policymaking is how the government decides what will be done about perceived problems. Policymaking is a process of interaction among governmental and non-governmental actors; policy is the outcome of that interaction. ${ }^{1}$

From this definition of key terms, it is clear that a diverse set of actors can become involved in the making of state and local public policy. Beginning with the perception of a problem, making it an issue for government action, getting it on the government's agenda for consideration, and finally securing relevant government action all entail the involvement of many parties sharing a stake in the form of government action taken.- For many state and local governments the process can become rather complex, featuring a multitude of actors engaged in one or more aspects of policymaking. Broadly speaking, one can place the actors in the state and 
local government policymaking process into one of two broad categories: institutional actors and non-institutional actors.

The institutional actors involved in the public policy process are governments and governmental agencies that deal with public affairs - namely, the subjects of many other chapters in this book, including legislative bodies, executive departments, and the judicial branch. Depending on the policy issue in question, there are often state and local, as well as national-level institutions involved in policy issues arising in our federal system of government. As discussed in other chapters, the United States has a very large number of such agencies and governments due to the federal (as opposed to unitary) nature of the U.S. political system. The separation of powers provided for in both our federal and state constitutions keep our governmental system decentralized; in countries such as Japan, Great Britain or France, where governmental power is more centralized, far fewer such institutional actors become involved in regional and local policymaking.

The non-institutional actors involved in the policy process, a principal focus of this chapter, are diverse and can include political parties (e.g., Republicans and Democrats), interest groups (e.g., the National Rifle Association, the Sierra Club, the National Organization for Women), social movements (e.g., the Civil Rights Movement, the Environmental Movement), non-governmental organizations (NGOs) (e.g., the League of Women Voters, Project Vote Smart), and the mass media (e.g., newspapers, radio, television, the Internet), and individual citizens. These potential actors are fiercely independent of the government and have different types of resources at their disposal, and employ varying strategies in their efforts to influence state and local public policy. This chapter will discuss each of these sets of actors and describe how they may exercise influence over state and local policy processes. More specifically, this chapter will 
accomplish the following goals important for a sound understanding of state and local government and politics:

\section{Learning Objectives}

- review the changing nature of the policy process in postindustrial society,

- $\quad$ examine how citizens can get involved in state and local government policy processes,

- discuss the role of political parties and elections in state and local politics and policymaking,

- discuss the types of interest groups present and the strategies these groups typically use in state and local policy processes,

- review the role of the mass media in policy processes,

- examine how industry and business can often exert significant influence in state and local politics,

- discuss the role of social movements in shaping state and local politics and policy processes,

- compare how policymaking processes differ between various systems including the separation of powers political system found in the U.S. and the integration of powers (parliamentary) political systems found elsewhere,

- briefly present models of how the policy-making process occurs in state and local governments,

- offer suggestions for how policy processes and actors can enhance community sustainability. 


\section{B - Political Participation in Postindustrial America}

Contemporary studies of public participation in postindustrial societies suggest that a new style of politics has emerged over the course of the last several decades. ${ }_{-}^{3}$ This new style of politics is characterized in major part by an expansion of what has been considered appropriate political action. Some scholars who carry out research in this area argue that support for new modes of participation arises out of some specific socio-political changes that occurred in the postwar period._ These scholars note that historically unprecedented economic growth, a prolonged period of prosperity, and relative political stability have created an increasingly better-educated public that places demands on government to address ever-changing problems arising in the management of postindustrial societies - including the challenge of sustainability. The contemporary grassroots citizen organizations and associated social movements that arise in this context are considerably more likely to engage in protest politics or elite challenging political activities such as demonstrations and boycotts - than were previous generations of activists. ${ }_{-}$

Political conflicts arising over increasingly complex issues - such as sustainable development, same-sex marriage, immigration reform and No Child Left Behind educational reform - have generated a multitude of new interest groups, many of which draw citizens into the political process via single-issue concerns as opposed to a broad philosophical orientation to proper governance. One such policy arena with 
this type of political conflict is found in the domain of environmental policy. ${ }_{-}^{6}$ Traditionally, in the United States, environmental management was a process largely insulated from public scrutiny. By the 1970s, however, quite widespread concern became evident concerning the proper management of the natural environment.? Environmental organizations grew in size and proliferated in many economically advanced countries, and these organizations succeeded in mobilizing citizens, in challenging traditional environmental management practices, and in presenting new environmental issues for public debate. ${ }_{-}^{8}$

Given the difficulty ordinary citizens have in dealing with the scientific complexities of environmental issues, the process by which democratic societies confront complex scientific and technical issues involving the broader public interest is important to understand. The formation of NGOs and interest groups is critical in this respect. The emergence of community-based interest groups and social movements has been characterized as an "eruption from below," with demands for increased citizen input in the decision-making process lying at their base. ${ }^{\underline{9}}$ Interest groups and communitybased advocacy groups have pushed for increased democratization as a fundamental component of public policy. In doing so, the activities of interest groups illustrate the inherent tensions existing between a politicized, issue-driven segment of the electorate and "expert" decision-makers operating in the realm of natural resource policy. 10

The prominent political scientist Ronald Inglehart argues that there are two distinct forms of political participation that should be recognized. ${ }_{-}^{11}$ The "elite-directed" mode of political action is represented by socio-political institutions, such as political parties, bureaucratic agencies, labor unions, and industry associations that are hierarchical in nature and mobilize citizens into action in a coordinated, "top-down" fashion. In contrast to this familiar pattern of citizen 
mobilization is the elite-challenging mode of political action, a pattern of political activity that is generally more issuespecific operates outside traditional political channels, and tends to make use of unconventional and sometimes disruptive tactics in an attempt to influence public policy. ${ }_{-}^{12}$

Elite-challenging activism is a form of political action that usually addresses specific policy goals such as a community opposition to the location of a prison in a town or city. ${ }^{13}$ Sometimes this type of community-based political activism has been called "NIMBY" politics (i.e., Not in My Backyard). In the area of elite-challenging environmental activism, Rothenberg has described this particular form of political action in the following terms:

Nonviolent resistance is often an important part of environmental action: lying across the road to block the onslaught of bulldozers, chaining oneself to the floor of a valley as the dammed waters start to rise. These can be powerful forms of protest. The press will take notice, and the public will follow, so the world will learn of your cause. If you are willing to lay your life on the line, they think, you must be quite convinced of the correctness of your position. $\underline{14}$

According to the highly regarded political scientist David Truman, industry groups that perceive threats to existing values often are put on the defensive by such tactics. ${ }_{-}^{15}$ One example of this is the tobacco industry after the demonstration of a link between smoking and cardiac and pulmonary disease. In response to the elite-challenging behavior of consumer, environmental, and social equity advocacy groups (e.g., National Association for the Advancement of Colored People, Sierra Club), industry groups are motivated to establish communication networks and create a common front against new policies that might negatively affect their ability to conduct business as usual.

Chapter 4: Key Actors and the Policy Process in State and Local 
Instead of competing against one another as a market-based economy model would predict, industry-wide groups (e.g., Cattle Ranchers, Wheat Growers, Automobile Manufacturers and Retailers, Real Estate interests) often focus on their lowest common denominator of common interest and work in concert to take advantage of political opportunities to oppose these new groups. Such "coalitions of convenience" have indeed become quite commonplace in many conflicts coming before U.S. state and local governments. The emergence of new "elite challenging" forces in American society has led to the creation of a broad array of interest groups, citizen groups, political party factions, and government agencies becoming active in the state and local government policymaking process. Each of these types of key actors will be addressed briefly in the chapter sections to follow.

\section{C - Interest Groups}

All postindustrial nations, including the United States, are experiencing explosive growth in the number, scope of concerns, and size of interest groups seeking to influence public policy. ${ }_{-}^{16}$ Community-based interest groups and other grassroots organizations concerned with a variety of public policy issues are variously labeled as public interest groups,${ }_{-}^{17}$ citizen groups, ${ }_{-}^{18}$ or social movements. ${ }_{-}^{19}$ These particular terms are used to distinguish between citizen and community-based groups, which as a whole differ in their goals from groups representing either business or professional interests. According to the noted economist Mancur Olson's seminal work The Logic of Collective Action, ${ }_{-}^{20}$ such not-forprofit groups typically experience considerable difficulty 
organizing and mobilizing action. Groups of this type usually seek collective benefits that are often non-material, such as preserving endangered species or promoting civil rights and are inclusive rather than exclusive in nature (that is, the benefit sought will accrue to everyone regardless of their contribution to securing it). Despite these rather formidable obstacles, however, public interest groups have grown dramatically in number and in size in virtually all U.S. states and in urban and rural areas alike in recent decades, and they have become important players in the American state and local government public policymaking process.

Interest groups are highly diverse in terms of their size, the resources at their command, the scope of interest and activities in which they engage, their policy preferences, and their organizational form. They can be involved in a host of state and local government policy issues, including the areas of environmental protection, poverty reduction, public safety, child health and welfare, gender equity, and transportation system reform. Such groups can be of the large-scale membership type organized nation-wide, or they can be community-based and focused on local conditions. International organizations (commonly referred to as 'international nongovernmental organizations, or INGOs), issue-focused think tanks (e.g., The Heritage Foundation, the Vera Institute), and activist organizations (e.g., Habitat for Humanity, Doctors without Borders, the Union of Concerned Scientists) also often engage in policymaking in U.S. state and local governments on a selective basis. According to David Korten of the People-Centered Development Forum, many community-based and grass-roots public interest groups have been effective advocates of public policies that are intended to promote sustainability:

...the environment, peace, human rights, consumer rights and women's movements provide convincing examples of 
the power of voluntary action to change society. This seeming paradox can be explained by the fact that the power of voluntary action arises not from the size and resources of individual voluntary organizations, but rather from the ability of the voluntary sector to coalesce the actions of hundreds, thousands, or even millions of citizens through vast and constantly evolving networks that commonly lack identifiable structures, embrace many chaotic and conflicting tendencies, and yet act as if in concert to create new political and institutional realities. These networks are able to encircle, infiltrate, and even co-opt the resources of opposing bureaucracies. They reach across sectors to intellectuals, press, and community organizations. Once organized, they can, through electronic communications, rapidly mobilize significant political forces on a global scale..$^{21}$

Although interest groups differ quite widely in their human, financial, and organizational resources, ${ }_{-}^{22}$ in general it can be said that community-based and grassroots groups tend to be understaffed and poorly financed in comparison with organizations that represent private sector interests such as the petrochemical industry, the pharmaceutical industry, the telecommunications industry, the insurance industry, agricultural commodity groups, etc. 23 Most community and grassroots nonprofit groups are managed by either an unpaid or poorly compensated staff and claim very few official members, although some have developed large memberships and/or long lists of generous financial contributors and have hired skilled researchers, lawyers, and organizational managers. $\stackrel{24}{ }$ Moreover, interest groups can have two fundamentally different types of memberships - one composed exclusively of individual citizens, and another consisting of representatives of large institutions, business firms, or state and local governments. ${ }_{-}^{25}$ 
Some observers of interest groups also note that there is an increasing use of professional agents such as lobbyists and political consultants, professionals (often former elected public officials) who are adept at influencing policy processes and mobilizing support or posing opposition to public policy initiatives. ${ }_{-}^{26}$ According to the research conducted by political scientist Andrew McFarland, it is as much the skill of such agents that determines the groups' success as it is their size of membership or financial resources. ${ }_{-}^{27}$

Another source of influence and success in the policy process is the formation of coalitions of interests. Such alliances feature numerous smaller groups or businesses as members rather than individual citizens. These coalition-type groups can become a formidable political force due to their pooled financial resources and their freedom from dependence upon highly variable individual membership dues. Another source of group strength identified by political scientist Jack Walker is the role of powerful patrons who are located outside of the group but who provide critical financial and social networking resources. ${ }^{28}$ The support of the many private foundations (e.g., the Nature Conservancy, the Russell Family Foundation, the Northwest Area Foundation, the John D. and Catherine T. MacArthur Foundation), of wealthy individuals (e.g., Bill Gates, Paul Allan, Norton Simon, etc.), and of government agencies (e.g., Environmental Protection Agency, Booneville Power Authority, U.S. Department of Energy) allows some environmental and public health groups to reduce their reliance on individual memberships dues.

A variety of strategies developed to influence the policy process have been identified by social scientists who study the policymaking process in state and local government. Central among these strategies are the various forms of lobbying of elected officials and governmental agencies, the organizing of grassroots activists to mobilize public opinion, the building of coalitions with other like-minded groups, and the making 
of strategic financial contributions to supportive politicians..$^{29}$ The specific strategy (or combination of strategies) used by a particular organization is influenced by various factors, including the types and amounts of resources available to it, the perceived effectiveness of the strategies available, and the governmental structure in place. Large memberships give interest groups an advantage in letter writing, in the staging of public demonstrations, and in the training of volunteers to carry out grassroots activities. In contrast, those organizations possessing few members but commanding large budgets generally wish to focus on influencing the election of key decision-makers or lobbying such decision-makers after the holding of elections. The latter has been the preferred strategy for industry and commercial interests, and as a result, many industrial interests have benefited significantly from governmental programs and from government subsidies.

Regardless of the size of their budgets and memberships, however, Berry observes the following about interest groups: " (they) have strong reasons to convince people at the grassroots of the righteousness of their arguments, believing that changed public opinion will eventually lead to changed elite opinion.. ${ }_{-}^{30}$ This long-term perspective is especially the case in the advocacy of sustainability, in light of the fact that issues of sustainability are becoming popular among citizens in postindustrial countries. ${ }_{-}^{31}$

Table 4.1 provides information derived from a 2015 random sample survey of public interest groups and NGOs involved in the promotion of civil society, or civic engagement and public education on public affairs. ${ }_{-}^{32}$ The diversity of resources used by advocacy groups working in civil society is apparent, as well as the heavy reliance on members and volunteers to raise the resources needed and carry out necessary group activities. Around two-thirds of the groups taking part in the survey have some type of membership in an advocacy group, including individual and institutional 
members; and virtually all of the groups spend a substantial amount of their time pursuing resources rather than directly advocating on behalf of their public policy objectives.

Mean/Median Number of Paid Staff:

Full time:

$9.3 / 4.0$

Part time:

$4.0 / 4.0$

Mean/Median Number of Volunteers:

$11.4 / 8.0$

Individual memberships:

\% Yes:

$84.7 \%$

\% No:

$15.3 \%$

Mean/Median Number of Members:

$363.5 / 221.5$

Individual membership trend last two years:

\% Grown:

30.0

\% Stayed the Same:

52.7

\% Declined:

17.3

Institutional/other types of memberships:

\% Yes:

\% No:

Mean/Median Number of Other Memberships:

$23.3 / 19.0$ 
Types of other members (\% indicating members):

\% Civic/community organizations:

\% Government agencies, etc.:

\% Research organizations:

\% Businesses/corporations:

\% Labor organizations:

\% Clubs:

\% Environmental organizations:

26.5

Budget status last 2-3 years:

\% Increased above inflation:

\% Kept pace with inflation:

\% Decreased:

22.6

Percent time spent finding resources:

$0 \%$ to $10 \%$ :

$11 \%$ to $25 \%$ :

$26 \%$ to $50 \%$ :

$51 \%$ to $75 \%$ :

$76 \%$ to $100 \%$ :

0.0

Budget sources (\% receiving from source):

Membership dues:

Fees for services:

Fundraising activities:

Domestic donors/grants:

National government:

Regional (oblast/state) government:

Municipal government:

Business:

Individual gifts: 67.8 
Table 4.1 NGO Resources and Capacity-2015. (N=175)

The survey in question asked these public interest groups about the types of strategies they used and about the activities in which they engaged, including their interactions with government, the public, other groups, and the mass media. The strategies listed in Table 4.2 range from traditional forms of influence such as lobbying government officials to elitechallenging activities such as organizing and staging political demonstrations and engaging in protests. While many of these groups are active at various levels of government, most groups have more influence in state and local government rather than the national government. This observation substantiates former U.S. House of Representatives Speaker Thomas "Tip" O'Neill's often-quoted remark, "all politics are local." Another finding supportive of the discussion above is that public interest groups promoting a civil society spend a great deal of time trying to educate the public and working in concert with other groups to promote their agenda. Of course, the strategies of such public interest groups and industry-based groups are partially dependent on the structure of government and its potential points of access, as we will note later in this chapter. 
Question: "Given your organization's goals, please indicate how often your organization engages in the following activities (regarding group-state relationships):" [N=175]

$$
\begin{array}{lllll}
\begin{array}{l}
\text { Never } \\
\text { (\%) }
\end{array} & \begin{array}{l}
\text { Infrequently } \\
\text { (\%) }
\end{array} & \begin{array}{l}
\text { Somewhat } \\
\text { Frequently } \\
\text { (\%) }
\end{array} & \begin{array}{l}
\text { Frequently } \\
\text { (\%) }
\end{array} & \begin{array}{l}
\text { Very } \\
\text { Freque } \\
\text { (\%) }
\end{array}
\end{array}
$$

Participation

in the work of

government

$\begin{array}{lllll}0 \% & 9 \% & 34 \% & 34 \% & 23 \%\end{array}$

commissions

and advisory

committees

Contacts with

people in local

and state

$8 \% \quad 14 \%$

$15 \%$

$46 \%$

$18 \%$

government

Contacts with

members of

national

$14 \% \quad 18 \%$

$28 \%$

$24 \%$

$16 \%$

government

Contacts with

leaders of

political

$9 \% \quad 21 \%$

$31 \%$

$27 \%$

$12 \%$

parties

Legal recourse

to the courts

of judicial

$25 \%$

$27 \%$

$31 \%$

$14 \%$

$3 \%$

bodies 
Question: “Given your organization's goals, please indicate how often your organization engages in the following activities (regarding group-public/ group-media relationships):" [N=175]

$\begin{array}{lllll}\begin{array}{l}\text { Never } \\ \text { (\%) }\end{array} & \begin{array}{l}\text { Infrequently } \\ \text { (\%) }\end{array} & \begin{array}{l}\text { Somewhat } \\ \text { Frequently } \\ \text { (\%) }\end{array} & \begin{array}{l}\text { Frequently } \\ \text { (\%) }\end{array} & \begin{array}{l}\text { Very } \\ \text { Frequently } \\ \text { (\%) }\end{array}\end{array}$

Efforts to mobilize public opinion through disseminating information

Organizing demonstrations, protests, $\begin{array}{lllll}18 \% & 34 \% & 32 \% & 10 \% & 6 \%\end{array}$ strikes, or othe

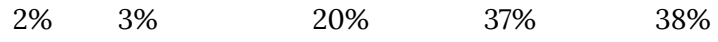
direct actions

Contacts with people in the media

Contacts with other NGOs $3 \%$ $2 \% \quad 5 \%$ $26 \%$ $36 \%$ $31 \%$

Organizing conferences and training for other NGOs

Organizing conferences $\begin{array}{llllll}\text { and training for } & 2 \% & 1 \% & 29 \% & 39 \% & 28 \%\end{array}$ interested citizens

Table 4.2 Strategies and Activities of Interest Groups-2006

Yet another interesting finding derived from this study is the degree of self-perceived success of these groups. The survey results presented in Table 4.3 indicate that 68 percent of the civil society groups believe they are either "effective" or "very effective" in working with citizens. The second-highest level of self-assessed success noted is that of working with local governments, followed by working with state government and working with political parties. Working with 
the national government elicited the lowest level of selfassessed perceived success.

Question: "In your opinion, how effective is your organization in working with the following organizations and citizens?" [N=175]

\begin{tabular}{lllll} 
& $\begin{array}{l}\text { Not } \\
\text { Effective (\%) }\end{array}$ & $\begin{array}{l}\text { Somewhat } \\
\text { Effective (\%) }\end{array}$ & $\begin{array}{l}\text { Effective } \\
\text { (\%) }\end{array}$ & $\begin{array}{l}\text { Very } \\
\text { Effective } \\
\text { (\%) }\end{array}$ \\
$\begin{array}{l}\text { Local } \\
\text { Government }\end{array}$ & $19 \%$ & $32 \%$ & $30 \%$ & $19 \%$ \\
$\begin{array}{l}\text { State } \\
\text { Government }\end{array}$ & $23 \%$ & $38 \%$ & $25 \%$ & $14 \%$ \\
$\begin{array}{l}\text { National } \\
\text { Government }\end{array}$ & $36 \%$ & $36 \%$ & $20 \%$ & $8 \%$ \\
$\begin{array}{l}\text { Political Parties } \\
\text { Citizens }\end{array}$ & $29 \%$ & $32 \%$ & $24 \%$ & $15 \%$ \\
\hline
\end{tabular}

Table 4.3 Self-Perceived Effectiveness of NGOs-2015

\section{D - Social Movements}

As discussed previously, political scientists have identified two distinct forms of political participation intended to influence public policy - i.e., the "elite-directed" and "elite challenging" modes of political action. Contemporary studies of the policy process in postindustrial societies indicate that the elite challenging mode of politics has been very effective in bringing about policy change when it is associated with the development of a social movement. Social movements are broad-based efforts to change societal institutions and practices that emphasize a collective identity reflective of an identifiable set of shared values. Social movements encapsulate a broad range of concerns and engage a large number of organizations and individual citizens who become 
united for a particular cause. Such movements have included the causes of the Prohibition of the Manufacture and Sale of Alcohol, Workers' Rights, Civil Rights, Environmental Protection, and Women's Rights. All of these movements affected state and local politics and public policymaking in state and local government. Currently, the Gay and Lesbian Rights movement is also very active at state and local levels of government. Efforts to promote the recognition of benefits associated with civil unions and the legal recognition of gay marriage are public policy changes being sought by this contemporary social movement.

Sociologists and political scientists who have studied social movements have identified some characteristics associated with social movements that have been successful in the past; these characteristics include the following: ${ }_{-}^{33}$

\section{Sufficient financial resources to recruit and educate new} members and to promote the desired policy outcomes in the general public:

Having sufficient financial support is particularly important in areas where the proposed changes are strongly opposed by groups with substantial resources.

\section{Involving people and organizations with prior grassroots} experience:

Having staff and leadership skilled and experienced in grassroots politics expedites successful organizational efforts. This is likely the case because experienced people are more likely to know which strategies work and which do not work under given circumstances. Experienced people are also more likely to be connected to affected communities and know the political landscape within which the recruitment of movement participants can be accomplished.

3. Identifying emotional issues to motivate people to participate:

This process is known as "dramatic spotlighting," and it occurs in cases wherein events that lead to public outrage are 
carefully highlighted for the media and potential participants. There are many examples of injecting emotion into a natural resource and environmental policy issues - such as the filming of the clubbing of baby seals in annual hunts in Canada by Greenpeace and a 1970's EPA television commercial using a stately Native American elder with tears coming from his eyes after coming upon a polluted river; while these are particularly noteworthy examples, many others could be given.

\section{Using a "micro-mobilization" approach:}

Organizing small informal and formal groups at the local level, all connected to a much larger network or coalition, has been found to be an important component of successful social movements in the past. Having people interact at the local level creates social bonds among otherwise isolated persons, and these bonds increase issue interest and participation in social movement activities. At the same time as local bonds are being built there must be an ongoing connection to a larger movement; locally bonded people scattered across a myriad of communities are more likely to take part in movement activities if they believe large numbers of others are also participating in other localities facing the same problems they are dealing with in their own community. Examples of relatively successful movements would be the women's suffrage movement (i.e., "first wave" feminism), the civil rights movement, and the early environmental movement in the 1960s and 1970s.

\section{The absence of crosscutting cleavages:}

Crosscutting cleavages - such as liberal versus conservative, rural versus urban, etc. within a social movement - often lead to political conflict and undercut efforts at building a large, cohesive and effective movement. Successful social movements in the past have grown more inclusive over time, but start with a core set of fairly uniform actors who maintain a steadfast focus on their shared cause.

\section{Having a diverse and "co-optable" communications}


network:

Successful social movements tend to develop communication networks that connect large and diverse numbers of people to the cause - the greater the number and diversity of people actively participating in the network, the more likely the movement will be successful. The communication network needs to connect individual and group participants in the movement to one another, it needs to connect participants with the mass media, and it needs to connect the movement with potential new participants.

\section{Having capable and competent leadership:}

Articulate and charismatic leaders and organizers are much more likely to inspire emotion and participation than passive followers and inarticulate leaders. If leaders are identified as being too partisan or allied too closely with a particularly divisive interest group, then their ability to lead a broad- based movement is diminished.

\section{Having an optimistic expectation:}

This characteristic of successful social movements is related to sense of efficacy. People have to feel they are joining ranks with large numbers of like-minded people, and that their own participation will contribute to the success of the movement. While this is a very difficult characteristic to engender in contemporary America, with only 60 percent of the eligible population participating in the electoral process it is nonetheless very important for successful social movements. (9) Encouraging solidarity instead of free riding. With many state and local issues in the political sphere, there are many free riders - people willing to sit back and watch others take action and then benefit from those actions without themselves having contributed their fair share. Successful movements are able to move people to take private actions that contribute to collective political action (writing letters, attending public meetings, voting for supportive candidates, 
joining groups, donating money, etc.) despite the temptation to free-ride on the sacrifices of others.

\section{E - Citizens}

As discussed previously, there are a variety of ways that citizens can influence state and local policy processes as discussed above - traditional and elite-challenging methods. Traditional methods would include: ${ }_{-}^{34}$

1. voting in elections.

2. working on political campaigns for candidates or political parties, which could include convincing others how to vote, attending rallies or meetings, and fundraising activities.

3. communal activities such as working with groups to solve community problems or contacting governmental officials.

In contrast, elite challenging or "unconventional" political participation could include:

1. signing petitions

2. participating in lawful demonstrations.

3. participating in boycotts.

4. participating in unofficial strikes.

5. taking part in "sit-ins" and the occupation of buildings or facilities in order to dramatize a claimed injustice.

While citizens can take a number of steps to participate in politics, overall participation in the United States compared to many other democracies is noticeably lower, particularly in recent years. In addition, not all segments in American society participate in elections at equal rates. The statistics displayed 
in Table 4.4 show voting rates for various sociodemographic characteristics in the 2016 general election. In regard to who was most likely to register to vote and then actually vote, the U.S. Census study of the 2016 general election found the following: ${ }_{-}^{35}$

- Women are more likely to vote in the election than men: 63 percent of women reported voting compared to 59 percent of men.

- Voting rates were much higher for older-aged citizens when compared to younger voters -73 percent of citizens 65 years and older voted in the election compared to 43 percent for the 18 to 24 age group.

- The higher the level of educational attainment, the more likely a citizen was to vote; 74 percent of citizens with a bachelor's degree voted compared to 35 percent of those with less than a high school diploma.

- Citizens who are employed are significantly more likely to register and vote than those of lower income and less than full employment. ${ }^{36}$

- There are differences in the likelihood of voting among various ethnic and racial groups, with Non-Hispanic white citizens being significantly more likely to take part in elections as compared to Blacks and Hispanics.

\begin{tabular}{ll}
\hline Race and Hispanic Origin & $\mathbf{2 0 1 6} \mathbf{( \% )}$ \\
White alone, not Hispanic & 65 \\
Black alone & 59 \\
Asian alone & 49 \\
Hispanic (of any race) & 48 \\
\hline & \\
\hline Sex & $\mathbf{2 0 1 6}(\%)$ \\
Men & 59 \\
Women & 63 \\
\hline
\end{tabular}




\begin{tabular}{ll}
\hline Age & $\mathbf{2 0 1 6}(\mathbf{\% )}$ \\
18 to 24 years & 43 \\
25 to 44 years & 56 \\
45 to 64 years & 67 \\
65 plus years & 73 \\
\hline & \\
\hline Educational Attainment & $\mathbf{2 0 1 6}(\%)$ \\
Less than high school graduate & 35 \\
High school graduate or GED & 51 \\
Some college or Associate degree & 63 \\
Bachelor's degree & 74 \\
Advanced degree & 80 \\
\hline & \\
\hline Employment Status & $\mathbf{2 0 1 6}(\%)$ \\
In the civilian labor force & 63 \\
Unemployed & 50 \\
Not in the labor force & 58 \\
\hline
\end{tabular}

Table 4.4 Political Participation by Group in 2016 General Election While there was much interest among many groups in the 2016 General Election, a U.S. Census Bureau Report concluded that:

Voting rates have also historically varied according to age, with older Americans generally voting at higher rates than younger Americans. In 2016, this was once again the case, as citizens 65 years and older reported higher turnout (70.9 percent) than 45 - to 64 -year-olds (66.6 percent), 30- to 44-year-olds (58.7 percent) and 18- to 29-year-olds (46.1 percent). $\frac{37}{}$

The 2016 U.S. Bureau of the Census report on civic participation asked citizens who reported they did not vote 
WHY they did not take part in the election, and they documented the following self-reported reasons:

- 14.3 percent said they were too busy with conflicting schedules.

- 11.7 percent reported they were ill or disabled.

- 15.4 percent indicated they were not interested.

- 24.8 percent did not like any candidates or issues.

- 7.9 percent were out of town.

- 4.4 percent experienced registration problems.

- 3.0 percent said they forgot to vote.

- 2.1 percent found the polling places inconvenient.

- 2.6 percent had transportation problems.

Because a high level of citizen engagement in governance is an important component of civil society and sustainable communities alike, some state and local governments pursuing sustainability have tried to address some of these reasons for not participating with specific public policies. Increasing citizen participation is important to state and local government because:

1. voting and attentiveness to public affairs lie at the heart of the democratic principles upon which the United States was built.

2. citizen participation provides legitimacy to state and local policy decisions to the extent that people recognize that their concerns were incorporated into the laws under which we all must live.

3. citizen engagement can increase the citizens' sense of attachment to the community and engender the "coproduction" of public goods - that is, citizens promote the public welfare by voluntary actions motivated by a sense of civic duty (e.g., recycle to reduce solid waste, maintain safe lighting on private property, make 
donations to the Red Cross, United Way, Community Food Banks and the like to provide for those in need).

4. it helps to maintain and reinforce community networks and social connections, thus increasing the ability of communities and states to respond to natural and economic disasters.

5. heightened public participation also can lead to enhanced momentum to implement new policies and energize community-based initiatives needed to promote sustainability.

Some examples of state and local efforts to increase citizen participation - not only in elections, but also for service on citizen review boards, planning commissions and other venues, include the use of e-government techniques (i.e., providing useful policy-relevant information on the Internet and allowing on-line voter registration), allowing voting before election day, allowing more flexible voter registration opportunities at numerous venues such as on election day, at schools, in hospitals, and in vote-by-mail systems present in Oregon (for all elections) and other states for many state and local elections. Concerning this latter approach of making voting easier, many states that have traditional polling station elections are also allowing a very flexible system for absentee voting by mail.

One argument that some observers have made concerning the relatively lower rates of participation in the U.S. when compared to other postindustrial countries is that we have a large number of elective offices subject to election due to our federal system. It is estimated that 521,000 governmental positions are subject to election nationally when national, state and local offices are combined. The sheer number of positions and candidates that the typical U.S. voter must consider on their ballot is overwhelming. In stark contrast, in many other democratic countries where parliamentary systems are in place (see below), citizens have 
only one or two offices to fill per election, making the electoral process is far less burdensome on the voter.

\section{E.I - Initiative and Referenda:}

One way that citizens can affect public policy and even amend state constitutions or county and city charters directly is through the initiative process. In over a third of the states and in many local governments the initiative provides citizens a process to vote on proposed constitutional amendments, statutes or ordinances. The initiative process originates from a certain number of registered voters (the number depends on the state and the nature of the proposal) signing a petition to place an issue on the ballot. With a sufficient number of validated voter signatures either an indirect or direct initiative process ensues. Under the indirect form, an issue is first referred to state legislature for consideration, and then if the legislature does not enact the measure, that same measure is placed before the electorate to decide. In the direct form of the initiative, a measure is directly forwarded to voters for their consideration without passing through the state legislature. In many states, the legislatures can also refer a specific measure to the voters for approval or disapproval. This process is called a referendum and differs from the initiative process because the measure originates with the legislature. All of these types of votes collectively are referred to as "ballot measures," "propositions," or simply "initiatives," depending on the state.

The initiative and referendum process is thought to have originated in the Greek city-states studied by Aristotle, and both methods of direct legislation by the people have been used at various times throughout the centuries in countries 
such as Switzerland, France, Australia, Ireland, the United Kingdom, and the United States. ${ }_{-}^{38}$ In the United States, the initiative and referendum processes were used by many states to both adopt and later revise their original constitutions. South Dakota was the first state to adopt the initiative process in 1898, followed by Utah in 1900, and then Oregon in 1902.

Twenty-four states now utilize some form of the initiative process. The impetus for the adoption of the initiative process in most states was a growing sentiment among the public that there was widespread corruption in legislative politics whereby the interests of citizens were too often ignored and those of "moneyed interests" were protected by nefarious lobbyists. The presence of patronageridden "political machines" in major cities and many state legislatures, whose exploits were covered in muckraking newspapers by investigative reporters, added to the public distrust of state legislatures at the turn of the century. Within this historical context, the initiative process was adopted as a means to circumvent state legislatures by allowing voters to enact laws directly. It was expected at the time that the initiative process would serve as a check on the state legislature - a warning signal from the people that, if too long ignored, they could take matters into their own hands to pass laws they wanted even if their elected representatives were not prepared to do so.

Arguments commonly made in favor of direct democracy by its advocates include the following: ${ }_{-}^{39}$

- It makes legislatures more responsive to public opinion.

- It allows citizens to take their policy preferences directly to the public for action.

- It stimulates public debate over important policy issues.

- It increases citizen interest and, thus, participation in elections.

- It contributes to higher levels of trust in government. 
Critics of the initiative process offer the following counterarguments. 40

- It often leads to the adoption of poor public policies because the public generally lacks the skills, knowledge, and/or desire to cast informed votes during elections. ${ }_{-}^{41}$

- It promotes the "tyranny of the majority" (majority riding roughshod over the rights of minorities) and is potentially dangerous for disadvantaged minority interests. ${ }_{-}^{42}$

- It often does not reflect the will of the people because those who vote on initiatives often are not representative of the population at large. ${ }^{43}$

- It is controlled by the very interests (i.e., special interests) that it originally sought to circumvent. ${ }_{-}^{44}$

- It does not contribute to more responsive and accountable legislatures.

Yet another way in which citizens can directly, or in some cases indirectly, influence the governmental process is through recall provisions. This citizen empowerment process allows registered voters to petition to recall elected (and in some cases appointed officials) through popular elections. Most states allow recall elections for local government officials, but at the state level only 18 American states permit recall elections to remove elected or appointed officials. A famous example of the use of the recall occurred in 2003 when Governor Gray Davis of California was recalled in connection with the mismanagement of the state's electric energy management policy in a way that made the state's citizens vulnerable to extremely high charges occasioned by the nefarious dealings of the Enron Corporation (some of whose officials are in federal prison today for their role in those dealings). The recall of Governor Davis gave rise to the election of the former movie actor and political novice Arnold Schwarzenegger. 


\section{Exercises}

\section{Citizenship - What Can I do?}

In Professor Russell Dalton's new book, The Good Citizen: How a Younger Generation is Reshaping American Politics (2008), he identifies two types of citizenship where people can get involved in their communities. The first type of citizenship is "dutybased" and the second he calls "engaged." Below are some ways people can participate in both of these types of citizenship.

Duty-based Citizenship reflects traditional forms of political participation:

1. Get registered to vote. Voter registration opportunities exist where you get a driver's license (e.g., Department of Motor Vehicles, etc.), your county courthouse, etc. Several webs

2. Vote in an election. Contact your Secretary of State's website to learn about the election schedule in your jurisdiction.

3. Join a political party. Search the web for local meetings of political parties and attend to see if your views are in line with those of a political party. 
4. Contact your elected representatives by email or letter and let them know how you feel about the issues.

For more information on how you can register to vote, to get involved, and to find information about candidates for office or initiative and referenda, go to Project Vote Smart's website: http://www.votesmart.org/

Engaged Citizenship reflects a new and broader range of activities that includes social concerns and the welfare of others.

5. Participate in providing housing for low-income families through programs such as habitat for Humanity.

6. Volunteer for local Earth Day Activities (April 22) such as beach and park cleanup or an environmental "teach-in."

7. Join a watershed group or council to help protect and improve streams and rivers in your area.

8. Many cities have neighborhood associations 
where community members design programs to enhance community livability.

9. Help your local food bank collect food for needy families.

For more information on how you can volunteer and the opportunities in your community, go to Youth Volunteer Corps of America's website: http://www.yvc.org/ or go to the Americorps' website at: http://www.americorps.gov/

\section{F - Media}

The mass media play an important role in state and local government policy processes. In the U.S. "children spend more time in front of television sets than in school," and more than two-thirds of the people in the country "report they receive all or most of their news from television" - given these facts and given the growth of the electronic mass media it is clear that the media are enormously important as a factor in state and local politics. ${ }_{-}^{45}$ With the advent of worldwide television coverage due to the extensive proliferation of satellite transmitters and receivers, as well as the rapid expansion of the world wide web and the Internet, the transmission of information globally is virtually instantaneous and the potential impact of this information has been enhanced greatly over what it was in the past. The strategic 
use of visual images and the near-real-time dissemination of graphic scenes is a powerful means to create and maintain concern for a specific issue. For example, a picture of a dying bird mired in oil is a great deal more moving than is a short oral "talking head" report that a tanker is leaking crude oil off a coastline somewhere. ${ }^{46}$ This type of strategic media messaging by interest groups and political parties is especially important in an era of globalization where a wider audience has access to new sources of public affairs-relevant information and this audience is being exposed to more diverse messages concerning state and local governance issues than ever in the past.

In addition to noting these aspects of the new potency of the mass media, it needs to be stated that the mass media traditionally perform certain important functions that are essential to state and local government and politics, including the following.

- Formation of public opinion: the mass media provide information and the reporting of diverse viewpoints that help citizens form their own views of public policy issues.

- The mass media help to prioritize public policy issues that come to the attention of state and local government. In one sense, the mass media can serve as a "marketplace" of ideas; in another sense, they help determine what issues come to the attention of policymakers based on their independent assessment of the "newsworthiness" of particular stories and issues.

- The news media, particularly the print media, serve as an important "watchdog" over state and local governments and officials, providing a check on corruption, inadequate attention to matters of public concern, unethical conduct, and bureaucratic malfeasance.

- The media collectively provide an essential link between citizens and their government in a democracy by helping communicate public policy-relevant information, policy 
preferences, and societal values back and forth between citizens and their governmental leaders and civil servants.

According to a 2017 public opinion study conducted by The Pew Research Center, the main source of political and campaign news for most Americans is television (50\%), followed by online sources (43\%), radio (25\%), and newspapers (18\%). $\stackrel{47}{-}$ Additional findings in the 2017 study included the following trends:

- The gap between online and television news consumption is narrowing.

- The use of mobile devices for information continues to grow.

- Older cohorts are "driving the growth in mobile news use."

- Sixty-seven percent of Americans "get at least some news on social media."

- The less educated are increasingly getting their news on social media.

- About a third of Americans "say they often see made-up political news online."

- While social media use is increasing, Americans "have low trust in information from social media."

- The most common pathways to online news are visits directly to sites or through social media. ${ }_{-}^{48}$

The Pew Research Center's annual assessment of the news media in 2018 is somewhat dire for the industry and potentially for an informed electorate:

The audience for nearly every major sector of the U.S. news media fell in 2017 - with the only exception being radio. The evening audience for both local and network TV news declined $7 \%$, while for cable it fell 12\%...Meanwhile, digitalnative news sites' audiences declined by $5 \%$ in terms of monthly unique visitors in 2017...and the circulation for U.S. 
daily newspapers, whose audience has been steadily declining for several decades, fell by $11 \%$ last year. $\underline{49}$

\section{G - Corporations and Economic Interests}

Businesses and multinational corporations are another set of actors that are extremely important in the political life of state and local government. The noted scholar Charles Lindblom argued convincingly that business enjoys a "privileged position" in American politics generally, and in state and local government in particular. In capitalist or market-based economies such as ours, it is private corporations rather than government that run crucial sectors of the society. ${ }_{-}^{50}$ In many democratic countries significant portions of what are private sector businesses in the U.S., such as energy production, airlines, medical care, and health insurance, are "nationalized" and are operated by the government. This fact means that private interests in the U.S. command far more wealth, power and influence vis-à-vis governmental authorities than is the case in virtually any other contemporary democratic nation.

Some critics of American society argue that the power possessed by private corporations has increased markedly in recent decades as a direct consequence of the globalization of local economies and the explosive growth of multi-national corporations. They argue strongly that the combination of these two factors has lead to the exercise of undue corporate influence on state and local governments that are required to regulate and or levy taxes on some of the activities of these powerful interests. The implications of this increasing role for global corporations in local communities replacing locally owned, locally financed and locally operated small businesses are rather ominous for state and local government in the U.S. 
This is the case in part because interests far removed from the community will decide the ultimate fate of that community rather than the community itself, and also because- generally speaking - business interests oppose public policies "that they believe would impose significant new costs on them or otherwise reduce expected profits" regardless of their potential benefit to the broader community..$_{-}$

While virtually all political scientists agree that business interests command a great deal of influence in state and local government, there is disagreement among social scientists on just how much influence business interests actually exercise in the policy process. As the discussion of public policy models found at the end of this chapter illustrates, some scholars make the argument that corporations dominate the policy process, both nationally and internationally, ${ }_{-} 2$ while others argue that business is just one of the many powerful interests involved in the policy process. ${ }_{-}^{53}$ The highly regarded American political scientist Robert Dahl persuasively argues, however, that those who own and control corporate and personal wealth pose special problems for democratic systems and public policy:

...ownership and control contribute to the creation of great differences among citizens in wealth, income, status, skills, information, control over information and propaganda, access to political leaders... [and] differences like these help in turn to generate significant inequalities among citizens in their capacities and opportunities for participating as political equals in governing the state. $\underline{\underline{54}}$

This observation suggests that in the United States and other market-based economies, business interests represent not merely one of many contending interests in state and local governments, but represent among of the most important actors involved in public policymaking in those governments. 


\section{H - Political Parties and Elections}

Political parties are important actors in state and local public policy processes throughout the country. Typically, political parties "reflect a political culture with distinct world views" that are organized to "seek power in government." While the Founding Fathers tried very hard to insulate the new nation from the development of factions and parties through the constitutional arrangements of federalism, separation of powers and checks and balances, they obviously were not entirely successful in that effort. By 1800 the United States was one of the first countries in the world to have nationally organized political parties. With continental expansion and population growth through mass immigration and the resulting expansion of the electorate - in addition to historical reforms enfranchising African Americans and women political parties provided the principal means to mobilize voters through what we have called "elite-directed" politics in our preceding discussion.

Political parties provide a means for the organization and direction of competition for political power. They prioritize issues to be addressed by government and recruit candidates to stand in elections at the national, state and local levels of government. After elections are held, the winning party takes control of the government and the minority party calls into question the majority party's actions in areas where they believe it is subject to criticism that will resonate with citizens in the next election. This constant give and take, action and reaction between the political parties serves to keep the public informed about the actions of their government and aware of alternates possible to existing policies and practices.

Chapter 4: Key Actors and the Policy Process in State and Local

Governments | 159 
Political parties can also facilitate the work of state government if the same party controls both the legislature and governor's office, thus minimizing the often-divisive effect of separation of powers and checks and balances. Divided control of state government by different parties makes governance more difficult, requiring skillful negotiation to bring differing policy preferences into some degree of accord to permit effective action to address the problems requiring government attention. Typically, the presence of divided government at the state level acts to restrain the scope of government initiatives to address public problems and leads the respective parties to request a "mandate to govern" in the next election.

The principal function of political parties in democratic countries is "...the development of a solid and durable linkage between the party's electorate and the policymakers...parties are expected to represent the social composition of those who mandate them and to respond politically to the demands of their electorate. ${ }^{56}$ Some additional functions carried out by political parties in the U.S. include:

- They represent groups of interests in U.S. states and communities. Once elected, however, elected officials not only represent their own party supporters but they also must govern in the interest of all of the constituents in their respective jurisdictions.

- They help to simplify choices for voters by organizing and articulating alternative positions on the issues facing the state and local governments wherein they operate. Parties also help to recruit and educate candidates for public office so that citizens can make judgments as to whom to trust with the grant of public authority in pending elections.

- They can help to stimulate interest in public affairs, in elections, and in democratic governance in general. By explaining their positions on the issues, political parties can help to inform and 
shape public opinion.

There are different types of political parties in democratic countries, with missionary parties and broker parties being two of the major subdivisions. Missionary parties tend to be rather ideological in orientation, in a sense of proclaiming a "mission" to fulfill if elected to office in terms of specific public policies and programs. Missionary parties often enter elections with a "manifesto" or "platform" of specific and detailed policy actions to be undertaken if successful in the election. These parties are able to maintain a focused agenda because they tend to exercise a high degree of control over membership and carefully monitor who is allowed to make use of the party label as a candidate. The political party leadership itself selects who will be the candidates standing in local elections and who will serve as leaders of the party. Missionary parties are most often found in parliamentary-style governments and are seldom seen in state and local politics in the U.S.

In our country, the political parties are far less ideologically oriented and seek to "broker" a multitude of interests in order to appeal to the widest segment of the electorate. Broker parties have weak control over their membership since it is typically self-selected, and those interested in elective office generally nominate themselves in American politics. Candidates for office in our country are selected through the use of primary elections and caucuses - two candidate recruitment processes that allow interested voters within each party to make the selection of their party's candidates instead of the party leadership. The use of primaries to select candidates is a unique feature of American politics when compared to other post-industrial democracies. This practice ensures that political parties in the U.S. are less ideologically cohesive than their counterparts in other countries, and the decentralized power structures of the 
political parties reflecting American federalism ensures, as well, that regional and sectional differences will permeate the national Democratic and Republican parties alike.

American political parties can be generally characterized as centrist concerning policy preferences when compared to parties in other post-industrial nations. Republicans and Democrats draw support from almost every major socioeconomic group, with a few noteworthy exceptions. For example, African American people vote overwhelmingly Democratic (82 percent voted for Hillary Clinton in the 2016 presidential election). Survey data from the Pew Research Center gathered in 2017 indicate that the Republican Party tends to receive disproportionate support from middle- and upper-income groups, whites, and conservatives, while the Democratic Party tends to receive disproportionate support from African Americans, Hispanics, liberals, women of lowerincome, and groups with less education (see Table 4.5). ${ }_{-}^{57}$ That said, neither party has a monopoly of support from any of these groups. Given the socially broad-based support for each party, they are first and foremost interested in winning elections and less interested in remaining ideologically "pure" in all of their actions and public positions. This desire for electoral success generally leads the Republicans and Democrats alike to try to appear ideologically moderate in general elections, and label their opponents as being "extreme" in their views.

\begin{tabular}{lll}
\hline Gender: & Republican/Lean Republican (\%) & $\begin{array}{l}\text { Democrat/Lean Democrat } \\
\mathbf{( \% )}\end{array}$ \\
Women & 37 & 56 \\
Men & 48 & 44 \\
\hline
\end{tabular}




\begin{tabular}{|c|c|c|c|}
\hline Race/Ethnicity: & \multicolumn{2}{|c|}{$\begin{array}{l}\text { Republican/Lean Republican } \\
\text { (\%) }\end{array}$} & $\begin{array}{l}\text { Democrat/Lean } \\
\text { Democrat (\%) }\end{array}$ \\
\hline $\begin{array}{l}\text { African } \\
\text { American }\end{array}$ & \multicolumn{2}{|l|}{8} & 84 \\
\hline Hispanic & \multicolumn{2}{|l|}{28} & 63 \\
\hline White & \multicolumn{2}{|l|}{51} & 43 \\
\hline Age: & \multicolumn{2}{|c|}{$\begin{array}{l}\text { Republican/Lean Republican } \\
\text { (\%) }\end{array}$} & $\begin{array}{l}\text { Democrat/Lean } \\
\text { Democrat (\%) }\end{array}$ \\
\hline Millenials & \multicolumn{2}{|l|}{34} & 58 \\
\hline Generation X & \multicolumn{2}{|l|}{43} & 48 \\
\hline Baby Boomers & \multicolumn{2}{|l|}{46} & 48 \\
\hline $\begin{array}{l}\text { Silent } \\
\text { Generation }\end{array}$ & \multicolumn{2}{|l|}{52} & 43 \\
\hline \multicolumn{2}{|l|}{ Education: } & $\begin{array}{l}\text { Republican/Lean } \\
\text { Republican (\%) }\end{array}$ & $\begin{array}{l}\text { Democrat/Lean } \\
\text { Democrat (\%) }\end{array}$ \\
\hline \multicolumn{2}{|c|}{$\begin{array}{l}\text { High School Graduate } \\
\text { or Less }\end{array}$} & 47 & 45 \\
\hline \multicolumn{2}{|l|}{ Some College } & 45 & 47 \\
\hline \multicolumn{2}{|c|}{$\begin{array}{l}\text { College Graduate and } \\
\text { More }\end{array}$} & 36 & 58 \\
\hline Income: & \multicolumn{2}{|c|}{$\begin{array}{l}\text { Republican/Lean Republican } \\
\text { (\%) }\end{array}$} & $\begin{array}{l}\text { Democrat/Lean } \\
\text { Democrat }(\%)\end{array}$ \\
\hline $\begin{array}{l}\text { Less than } \\
\$ 30,000\end{array}$ & \multicolumn{2}{|l|}{18} & 74 \\
\hline $\begin{array}{l}\$ 30,000 \text { to } \\
\$ 74,999\end{array}$ & \multicolumn{2}{|l|}{25} & 64 \\
\hline$\$ 75,000$ plus & \multicolumn{2}{|l|}{41} & 54 \\
\hline
\end{tabular}

Table 4.5 Party Identification by Demographic Groups-2017 (Total Republican / Lean Republican \%: 42; Total Democrat / Lean Democrat \%: 50)

This "playing toward the middle" approach is re-enforced 
by the fact that many voters characterize themselves as neither Republican nor Democratic in basic leaning, but rather see themselves as independents that can vote for either party's candidates depending on whose message is more appealing. These fundamental conditions motivate each major political party to tolerate a diversity of opinions and accommodate a wide range of policy preferences within their ranks. The American broker style of political parties has allowed both the Democratic Party and the Republican Party to absorb third parties and even broad social movements over the years. This is not to say there are no differences in policy preferences between the parties and their supporters, just that the gap between the parties is relatively narrow in comparison to parties operating in other democratic countries. A recent example of partisan differences between Republican and Democrats can be found in a 2017 Pew Research Center public opinion poll concerning explanations of why people are either rich or poor needs. In that survey, it was found that whereas 56 percent of the Republicans surveyed believe people are poor because of a "lack of effort," only 19 percent of Democrats agreed with this explanation (see Table 4.6).

\begin{tabular}{lll}
\hline $\begin{array}{l}\text { Why a person is } \\
\text { rich: }\end{array}$ & $\begin{array}{l}\text { Republican / Lean } \\
\text { Republican (\%) }\end{array}$ & $\begin{array}{l}\text { Democrat / Lean } \\
\text { Democrat (\%) }\end{array}$ \\
$\begin{array}{l}\text { "Worked harder." } \\
\text { "Had advantages in }\end{array}$ & 21 & 29 \\
\begin{tabular}{l} 
life." \\
\hline
\end{tabular} & $\begin{array}{l}\text { Republican / Lean } \\
\text { Republican (\%) }\end{array}$ & $\begin{array}{l}\text { Democrat / Lean } \\
\text { Democrat (\%) }\end{array}$ \\
\hline $\begin{array}{l}\text { Why a person is poor: } \\
\text { "Lack of effort." }\end{array}$ & 56 & 19 \\
"Circumstances beyond & 32 & 71 \\
control." & &
\end{tabular}

Table 4.6 Partisan Differences Why People Rich and Poor, 2017 Another important feature of the U.S. political party 
scene at both national and state levels is the existence of the two-party system. Since the 1860 s the same two political parties have dominated the American political system Democrats and Republicans. Most Americans today consider themselves to be either Republicans or Democrats, and while an increasing number of Americans are identifying themselves as independents, they still vote for the two main parties at the ballot box.

Third parties have had a tough time establishing themselves in the U.S. because of our single-member district (SMD) form of electoral representation wherein the candidate with the plurality of the vote (not necessarily the majority) wins the election. Many other postindustrial democracies have proportional representation systems with multimember districts (MMDs); such a form of electoral representation tends to encourage multi-party systems because multiple seats are proportionally distributed based on what proportion of the vote a particular party wins.

Two other relatively unique features found in some state and local government elections are the open primary and nonpartisan offices. Open primaries are primary elections where voters do not need to be members of a specific political party in order to vote for that party's candidates. Voters still have to be registered to vote, but can decide to vote for their favorite candidate regardless of which party registration they hold. Most states have closed primary systems, which are preferred by the parties, wherein only persons who are registered members of a political party can vote using the ballot of that political party.

In nonpartisan elections, candidates run for office without listing a political affiliation. Typically, the winning candidate is chosen in a runoff election from the top two vote recipients in the primary election. The candidates in nonpartisan elections are most likely aligned with one of the political parties, but they do not identify themselves as party 
members. Nonpartisan elections are generally held for local government offices in some counties, in many cities, and especially in the case of school district and other local special districts and boards and commissions. Nonpartisan judicial elections are also very common at the state and local levels.

Many members of the public, journalists, and even elected officials themselves decry "partisan politics." The common argument heard is that partisan politics too often leads to stalemate in government and the election of nonresponsive public officials. Because of this supposed tendency, some argue for open primaries in state and local elections to remove the influence of parties. On the other hand, many political scientists and political parties believe that partisanship is generally a good thing in electoral processes because it offers voters cues about the choices facing them. In a sense, you know something about where candidates (or current elected officials) stand on the issues if they identify themselves as Republicans or Democrats.

\section{I - Governmental Structures and the Policy Process}

Parliamentary and separation of powers governments the former exemplified by most European countries, and the latter by the United States - are the two principal forms of democratic governance in the postindustrial countries. In the U.S. we directly elect state governors and members of our state legislatures. Governors typically have the ability to veto acts of their respective legislatures, but legislatures can override that veto by a supermajority (varies between $60 \%$ 
and 2/3s) of both houses in bicameral state legislatures. The governor and one or both of the legislative chambers can be from different political parties, and they can and often do disagree over policy issues. As discussed in other chapters, this political structure is called a "separation of powers" system and can lead to policy "gridlock" where it is very difficult (if not impossible) to pass legislation. In a sense, there are 'many cooks in the kitchen and they all have their own recipe.' Passing legislation in state governments - and the national government - at times can be a very unpredictable and difficult process. A member of the majority party can vote against the wishes of her or his own party and not fear having to run for reelection because the government has fallen; in a parliamentary system, in contrast, the consequence of such a dissenting vote could well be the failure of a sitting government and the need for calling an election. Because of our decentralized political system and weak, broker-type parties, this "gridlock" situation where legislation is very difficult to enact occurs quite often in American state government.

In parliamentary systems such as that of Great Britain citizens only vote for their own member of the House of Commons. The political party that obtains a majority in the House of Commons then forms the government and it is responsible for policy without the undue influence of opposition parties unless the government is part of a ruling coalition of political parties. The leader of the majority party, or head of the coalition, becomes Prime Minister (head of the government). Unlike in the U.S. where one finds a separation of powers, the Prime Minister selects other leading party members to become government ministers, blurring the line between executive and legislative branches of government. The Prime Minister and the other ministers must all be members of Parliament. This political system is typically referred to as featuring integration of powers. 
This characteristic of blurring across executive and legislative branches in parliamentary systems clearly differs from the American state constitutions that established three separate, distinct, and co-equal branches of government. One effect of this clear separation of powers is that the legislative process is much more predictable in the parliamentary system since it is based primarily on the "majority rule" principle as opposed to the checks and balances logic of American constitutional law. In addition to these structural arrangements, there is also a tradition-based system of "collective responsibility" whereby members of Parliament nearly always vote along party lines. You don't see anywhere near the level of vote swapping or shifting coalitions in parliamentary systems as is commonly witnessed in American state governments.

In terms of elections, parliamentary systems make voting decisions relatively simple. Parties run on a set of promises, sometimes referred to as a manifesto or a mandate, which will become the official set of policies for the new government if elected. Party manifestos or mandates are typically quite specific in terms of public policy positions, and parties are expected to implement the mandate if elected. In short, you know where the party stands on a specific issue - say, environmental policy or a social safety net program. And, if a voter doesn't like the current conditions or direction of government policies, she or he knows whom to hold accountable for their policy choices.

Separation of power systems, in contrast, can be quite complicated and confusing for voters since there are multiple officials to select (e.g., governors, upper and lower legislative house members, other state-level offices, judicial offices, and ballot initiatives). In addition, candidates for partisan offices often run personalized campaigns in broker-type parties and are not necessarily representative of established party platforms. Once elected, the voting behavior of such 
candidates can be rather unpredictable as well. Because such candidates are not beholden to their parties so much as to their own campaign organizations in the American setting as opposed to the parliamentary setting, American legislators are particularly open to the exercise of influence by groups and interests which can promise and deliver various forms of campaign support in the next election.

\section{J - A Review of Policy Models}

As noted at the outset of this chapter, public policy has been defined by Thomas Dye in the following way: "whatever governments choose to do or not to do." - While there is general agreement among social scientists that this is a suitable working definition of public policy, there is considerable controversy regarding just how the policy process works in different political jurisdictions. Here we will introduce the two most prominent rival theories in political science and sociology that claim to explain the policy process - namely, pluralist theory and elite theory. Pluralist theory is an ideal-type democratic theory that holds that the American democratic political process is genuinely open to the involvement of any group that wishes to participate. Pluralist theory has many adherents among American political scientists and has deep roots in American political thought. Some of the fundamental constitutional principles embedded in the U.S. Constitution (freedom of speech, freedom of assembly, and freedom to petition government for the redress of grievances) constitute core elements of pluralist theory.

According to Thomas Dye, pluralism or "group theory" works along the following lines:

Chapter 4: Key Actors and the Policy Process in State and Local 
Group theory purports to describe all meaningful political activity in terms of the group struggle. Policymakers are viewed as constantly responding to group pressures bargaining, negotiating, and compromising among competing demands of influential groups. Politicians attempt to form a majority of groups. In so doing, they have some latitude in determining what groups are to be included in the majority coalition.

From this description of the American political system, as seen from a group theory or pluralist perspective, a pluralistic state and local policy process could feature such groups as business interests, teacher's unions, agricultural interests, environmental groups, gay and lesbian rights advocacy groups, etc. All of these groups and interests would be trying to influence the policy process governed by duly elected officials, and no single group or subset of groups would be able to dominate public policy outcomes.

A more critical perspective on the functioning of the political process is offered by the advocates of elite theory. Elite theory proponents describe the policy process as one that is dominated by an elite few whose powerful interests influence policy largely behind the scenes. These elites and their influence over policy are largely removed from the view and awareness of ordinary citizens within society. C. Wright Mills described this perspective exceedingly well in the following passage quoted from his classic book entitled The Power Elite: ${ }_{-}^{61}$

The power elite is composed of men whose positions enable them to transcend the ordinary environments of ordinary men and women; they are in positions to make decisions having major consequences. Whether they do or do not make such decisions is less important than the fact that they do occupy such pivotal positions...they rule the big corporations. They run the machinery of the state and claim 
its prerogatives. They direct the military. They occupy the social structure....

These elites are said to possess the highest forms of education, to command personal and corporate wealth, to secure the services of the best legal and medical services to protect their wealth and health, to be in a position to dictate the values of those in their employ, and to hold disproportionate political power in their hands as a consequence. Moreover, they are described as being generally unresponsive to the needs of the common citizen in society. The masses are periodically appeased with symbolic or minor concessions to their needs, but they are kept largely in the dark about public affairs by a subservient press and a trivialized and entertainment-oriented broadcast media (see a portrayal of this view of American politics in Murray Edelman's classic Politics as Symbolic Action: Mass Arousal \& Quiescence published. ${ }_{-}$All of this adds up to the inescapable conclusion that public policy - seen through this model - would be the direct result of economic and political elite preferences, with little impact being exercised by average citizens acting in their roles of voters and proponents of particular public policy preferences.

Because of the great disparities in wealth present in the United States resulting from the operation of a marketbased economy wherein so much of the economic activity is in private as opposed to public hands, the danger of elite rule is a constant threat to our democratic institutions. Sociologist Ralph Miliband in Divided Societies: Class Struggle in Contemporary Capitalism describes elite theory as seen from an economic class perspective in the following terms: ${ }_{-}^{63}$

...class analysis is largely class struggle analysis. It is a mode of analysis, which proceeds from the belief that class struggle has constituted the central fact of social life from the remote past to the present day. The subject-matter 
of class analysis is the nature of this struggle, the identity of the protagonists, the forms which the struggle assumes from one period to another and from one country to another...This mode of analysis clearly has a very strong 'economic' theme; but it also has strong political and ideological themes, which are intertwined with the economic one...

It is likely that neither the idealized pluralist model nor the hypercritical elitist model captures the full picture of how state and local governments operate in the United States today. It is clear that evidence for the operation of both models can be cited, and that some state and local governments are more pluralistic than others and some are more elite-dominated than others. In those state and local governments where pluralism is present it will be possible for the advocates of sustainability - that is, the simultaneous pursuit of economic vitality, environmental protection, and social equity - to mobilize their forces within the broker parties and candidate-centered electoral processes to gain a strong position for their views. In state and local government settings where elite-dominated politics prevails, however, the forces of sustainability promotion will likely find it exceedingly difficult to make headway toward their goals. 


\section{K - Conclusion: Policy Processes, Actors and Sustainability}

This chapter has shed light on the various actors involved in state and local government governance and the public policy decision-making processes in which they tend to operate. Citizens, interest groups, the mass media, political parties, and social movements were all discussed in this regard. As a general backdrop to that discussion, we have described the changing nature of politics in postindustrial societies and what that historical transition to a period of sustained peace and prosperity has meant for the political processes of advanced democracies, including the United States. The changing nature of state and local politics from decidedly elite-directed to elite-challenging modes of political participation has increased the complexity of policy processes leading to multiple and competing perspectives on who has power and influence and how public policy decisions are actually made in state and local government.

The challenge of moving toward more sustainable forms of economic activity, land use patterns, energy use and production processes, transportation services, public health, and social services, and food production and transport will face virtually all state and local governments in the U.S. in the coming decade. Global climate change may well displace globalization of the marketplace as a principal concern of state and local government officials and the citizens living in communities throughout the country. Community-based citizen groups, the mass media, private corporations, philanthropic foundations, industry-wide associations, public interest groups, and political parties are all going to have to figure out how to work in concert - state-by-state and local community-by-local community - to achieve the level of adaptation to change that sustainability will require. We must 
hope that the promise of pluralism held out by its defenders, as it relates to state and local governments in the U.S., is more a reality than a myth. If entrenched interests and concentrated wealth based on the status quo prevent or delay sustainabilitypromoting adaptations, we may all be dooming our children to a future less inviting than the one we inherited from our own parents.

\section{Terms}

Broker Parties

Caucus

Citizen Groups

Closed Primary

Elite Challenging Politics

Elite Theory

Integration of Powers

Initiative

Institutional Actors

Missionary Party

Multi-member District

Non-institutional Actors

Nonpartisan Offices

Open Primary

Ordinances

Parliamentary System

Pluralist Theory

Primary Election

Proportional Representation

Protest Politics

Public Interest Groups

174 | State \& Local Government \& Politics 
Referendum

Single Member District

Social Movements

Two-Party Systems

\section{Discussion Questions}

1. What are five of the key actors in state and local government in the United States?

2. What role do the political parties play in state and local government as compared to the U.S. Congress? As comparable to their counterparts in other countries?

3. Based on the chapter reading, which theory pluralist theory or elitist theory - do you think better fits the reality of your own state? Your own city or hometown? 


\section{Notes}

1. R.B. Ripley and G.A. Franklin, Congress, the Bureaucracy, and Public Policy, 4th ed. (Chicago, IL: Dorsey Press, 1987).

2. J.W. Kingdon, Bridging Research and Policy: Agendas, Alternatives and Public Policies (New York: Harper Collins, 1984).

3. R. Dalton, Citizen Politics in Western Democracies: Public Opinion and Political Parties in the United States, Great Britain, West Germany and France (Chatham, NJ: Chatham House, 1988).

R. Inglehart and W. Baker, "Modernization, Cultural Change, and the Persistence of Traditional Values," American Sociological Review 65 (1999): 19-51.

G. Wilson, Interest Groups in the United States (Oxford: Oxford University Press, 1981).

4. A. Ciglar and B. Loomis, "Introduction: The Changing Nature of Interest Group Politics." In A. Ciglar and B. Loomis, eds., Interest Group Politics (Washington, DC: Congressional Quarterly, 1983).

R. Inglehart, Modernization and Postmodernization: Cultural, Economic, and Political Change in 43 Societies (Princeton: Princeton University Press, 1997).

5. R. Dalton, 1988, op. cit. (see reference 3).

S. Szabo, "The Successor Generation in Europe," Public Opinion 6 (1983): 9-11.

6. J.C. Pierce, M.A. Steger, B.S. Steel and N.P. Lovrich, Citizens, Political Communication, and Interest Groups: Environmental Organizations in Canada and the United States (New York: Praeger Publishers, 1992).

7. R.E. Dunlap, "Trends in Public Opinion Toward Environmental Issues: 1965-1990." In R.E. Dunlap and A. Mertig, eds., American Environmentalism: The U.S. Environmental 
Movement, 1970-1990 (Philadelphia, PA: Taylor and Francis, 1992).

A.M. McCright and R.E. Dunlap, "Social Movement Identity and Belief Systems: An Examination of Beliefs About Environmental Problems within the American Public," Public Opinion Quarterly 72 (2008): 651-676.

8. L. Caldwell, "Globalizing Environmentalism: Threshold of a New Phase in International Relations." In R. Dunlap and A. Mertig (eds.), American Environmentalism (Philadelphia, PA: Taylor and Francis, 1992).

R.E. Dunlap and R.E. Jones, 2002. "Environmental Concern: Conceptual and Measurement Issues." In R.E. Dunlap and W. Michelson, eds., Handbook of Environmental Sociology (Westport, CT: Greenwood Press, 2002).

9. R. Miliband, Divided Societies: Class Struggle in Contemporary Capitalism (Oxford: Oxford University Press, 1989).

10. G.E. McAvoy, Controlling Technocracy: Citizen Rationality and the NIMBY Syndrome (Washington, DC: Georgetown University Press, 1999).

G.L. Theodori and A.E. Luloff, "Position on Environmental Issues and Engagement in Proenvironmental Behaviors," Society and Natural Resources 15 (2002): 471-482.

11. R. Inglehart, "Changing Paradigms in Comparative Political Behavior." In Ada Finifter, ed., Political Science: The State of the Discipline (Washington, DC: American Political Science Association, 1983).

R. Inglehart, 1997, op. cit. (see reference 4).

12. Cable, Sherry, and Charles Cable. 1995. Environmental Problems Grassroots Solutions: The Politics of Grassroots Environmental Conflict (New York: St. Martins Press).

R. Inglehart, 1997, op. cit. (see reference 4).

13. W. Gamson, "Constructing Social Protest." In H. Johnson and B. Klandermans, eds., Social Movements and Culture (Minneapolis: University of Minnesota Press, 1995). 
14. D. Rothenberg, Hand's End: Technology and the Limits of Nature (Berkeley: University of California Press, 1992).

15. D. Truman, The Governmental Process (New York: Alfred Knopf, 1951).

16. J. Walker, "The Origins and Maintenance of Interest Groups in America," American Political Science Review 77 (1983): 390-406.

17. A. McFarland, Public Interest Lobbies: Decision Making on Energy (Washington, DC: American Enterprise Institute, 1976).

18. D. King and J. Walker, "The Provision of Benefits by American Interest Groups," paper presented at the Annual Meeting of the Midwest Political Science Association (Chicago, IL., 1989).

19. D. Baer and D. Bositis, Politics and Linkage in a Democratic Society (Englewood Cliffs, NJ: Prentice Hall, 1993).

R.D. Beaford, T.B. Gongaware and D.L. Valadez, "Social Movements." In E.F. Borgatta and R. Montgomery (eds.), Encyclopedia of Sociology (New York: Macmillan, 2000).

20. M. Olson, The Logic of Collective Action (Cambridge, MA: Harvard University Press, 1965).

21. D. Korten, NGO Strategic Networks: From Community Projects to Global Transformation, 1990. URL: http://iisd1.iisd.ca/pcdf/1991/stratnet.htm

22. P. Pross, Group Politics and Public Policy (Toronto, Ontario: Oxford University Press, 1984).

23. S. Cable and C. Cable, 1995, op. cit. (see reference 12).

J.C. Pierce et al., 1992, op. cit. (see reference 6).

24. J. Heyman, "Mobilizing Citizens: Citizens' Group Membership and Political Participation," paper presented at the Annual Meeting of the Midwest Political Science Association (Chicago, IL., 1989).

B.S. Steel, J.C. Pierce and N.P. Lovrich, "Tactics and Strategies of Interest Groups in Federal Forest Policy," Social Science Journal 33 (1996): 401-421.

25. D. King and J. Walker, 1989, op cit. (see reference 18) 
26. R. Salisbury, J. Heinz, E. Lauman, and R. Nelson, "Who Works with Whom?" American Political Science Review 81 (1984): 1217-1234.

27. A. McFarland, "Why Interest Groups Organize: A Pluralist Response to Olson," paper presented at the Western Political Science Association Meetings (Seattle, WA., 1989).

28. J. Walker, 1983, op. cit. (see reference 16).

29. J. Berry, The Interest Group Society (Great Britain: Harper Collins, 1989).

D. Baer and D. Bositis, 1993, op. cit. (see reference 19).

30. J. Berry, ibid.

31. R.E. Dunlap and A. Mertig, American Environmentalism: The U.S. Environmental Movement, 1970-1990 (Philadelphia, PA: Taylor and Francis, 1992).

N. Freudenberg and C. Steinsapir, "Not in our Backyards: The Grass-roots Environmental Movement." In R. Dunlap and A. Mertig, eds., American Environmentalism: The U.S. Environmental Movement, 1970-1990 (Philadelphia, PA: Taylor and Francis, 1992).

C.J. Folke, J. Colding, and F. Berkes. 2003. "Synthesis: Building Resilience and Adaptive Capacity in Social-Ecological Systems." In F. Berkes, J. Colding and C. Folke, eds., Navigating Social-Ecological Systems (New York: Cambridge University Press, 2003).

32. B.S. Steel, "National Survey of Non-Governmental Organizations," Oregon Policy Analysis Laboratory, Oregon State University, 2015.

33. J. Gooden and J. Jasper, The Social Movements Reader: Cases and Concepts (New York: Blackwell, 2003).

J. McCarthy and M. Zald, "Resource Mobilization and Social Movements: A Partial Theory," American Journal of Sociology 82 (1977): 1212-1241.

A. Morris and C. McClurg Mueller, Frontiers in Social Movement Theory (New Haven: Yale University Press, 1992). 
C. Tilly, Social Movements, 1768-2004 (Vancouver: University of British Columbia Press, 2004).

34. R. Dalton, 1988, op. cit. (reference 3).

35. U.S. Census, U.S. Voter Turnout Up in 2004, U.S. Census Bureau Report CB05-73 (Washington, DC: U.S. Department of Commerce, Census Bureau, 2005).

36. Ibid, p. 5.

37. U.S. Census Bureau, "Voting in America: A Look at the 2016 Presidential Election." URL:https://www.census.gov/ newsroom/blogs/randomsamplings/2017/05/ voting_in_america.html

38. H. Hahn and S. Kamieniecki, Referendum Voting: Social Status and Policy Preferences (New York: Greenwood Press, 1987).

39. T. Cronin and M. J. Rossant, Direct Democracy: The Politics of Initiative, Referendum, and Recall (Cambridge, MA: Harvard University Press, 1999).

T.R. Dye, Politics in States and Communities,10th ed. (Englewood Cliffs, NJ: Prentice Hall, 2000).

40. D. Magleby, Direct Legislation: Voting on Ballot Propositions in the United States (Baltimore: Johns Hopkins University Press, 1984).

41. A. Campbell, P.E. Converse, W.E. Miller and D.E. Stokes, The American Voter (New York: Wiley, 1960).

P.E. Converse, Philip E. 1964. "The Nature of Belief Systems in Mass Publics." In D. Apter, ed., Ideology and Discontent (New York: Free Press, 1964).

E.R. Smith, The Unchanging American Voter (Berkeley: University of California Press, 1989).

42. J. Citrin, "Who's the Boss? Direct Democracy and Popular Control of Government." In S.C. Craig, ed., Broken Contract: Changing Relationships Between Americans and Their Government (Boulder, CO: Westview Press, 1996).

B. Gamble, "Putting Civil Rights to a Popular Vote," American Journal of Political Science 41(1997): 245-70. 
43. D. Magelby, 1984, op. cit. (see reference 39).

44. D. Broder, Democracy Derailed (New York: Harcourt, Inc., 2000).

R. Ellis, Democratic Delusions: The Initiative Process in America (Lawrence, KS: University Press of Kansas, 2002).

E. Gerber, "Legislative Response to the Threat of Popular Initiatives," American Journal of Political Science 40 (1996): 99-128.

45. T. Dye, Understanding Public Policy, 9th ed. (Upper Saddle River, NJ: Prentice Hall, 1998).

46. R. Scarce, Eco-warriors: Understanding the Radical Environmental Movement (Chicago, IL: The Noble Press, Inc., 1990).

47. Pew Research Center, Key Trends in Social and Digital News Media 2017, October, 4: http://www.pewresearch.org

48. Ibid.

49. Pew Research Center, Five Facts About the State of the News Media in 2017, August 21, 2018. URL: http://www.pewresearch.org/fact-tank/2018/08/21/ 5-facts-about-the-state-of-the-news-media-in-2017/

50. C. Lindblom, Politics and Markets (New York: Basic Books, 1977).

51. G. Porter, J. Brown, and P. Chasek, Global Environmental Politics, 3rd ed. (Boulder, CO: Westview Press, 2000).

52. L. Bennett, News: The Politics of Illusion, 7th ed. (New York: Longman, 2007).

53. J. Thurber, C. Nelson and D. Dulio, Crowded Airwaves: Campaign Advertising in Elections (Washington, DC: Brookings Institution Press, 2000).

54. R. Dahl, A Preface to Economic Democracy (Berkeley: University of California Press, 1985), pp. 54-55.

55. D. Baer and D. Bositis, 1993, op. cit., (see reference 19).

56. R. Cayrol and J. Jaffre, "Party Linkages in France: Socialist Leaders, Followers and Voters." In Political Parties and Linkage, ed., K. Lawson (New Haven: Yale University Press, 1980). 
57. Pew Research Center, Partisan Affiliation Trends, 1992-2017. URL: http://www.people-press.org/2018/03/20/ party-identification-trends-1992-2017/

58. Pew Research Center, "Why People are Rich and Poor: Republicans and Democrats Have Very Different Views," 2017. URL: http://www.pewresearch.org/fact-tank/2017/05/02/ why-people-are-rich-and-poor-republicans-and-democratshave-very-different-views/

59. T. Dye, 1998, op. cit. (see reference 44), p. 2.

60. Ibid, p. 21.

61. C.W. Mills, The Power Elite (London: Oxford University Press, 1956), p. 3-4.

62. M. Edelman, Politics as Symbolic Action: Mass Arousal and Quiescence (Chicago: Markham Publishing Co., 1971).

63. R. Miliband in Divided Societies: Class Struggle in Contemporary Capitalism (Oxford: Clarendon Press, 1989), p. 3. 


\section{Chapter 5: State Constitutions}

\section{A - Introduction}

On November 2nd of 2004 voters in Arkansas, Georgia, Kentucky, Michigan, Mississippi, Montana, North Dakota, Ohio, Oklahoma, Oregon and Utah voted to change their respective state constitutions to make same-sex marriage illegal (which has since been nationally legal with the Supreme Courts 2015 decision in Obergefell, et al. v. Hodges, et al.). Over the last decade voters in some of these same states, and others, have decided to attach additional amendments to their state constitutions to legalize marijuana, to allow physicianassisted suicide, to ban the use of dogs in the hunting of bear and mountain lions, to protect the privilege of gathering some types of edible seaweed, to increase the share of state budgets going to education, to ban abortion, to increase cigarette taxes, to increase the minimum wage, to either limit or increase the scope of taxes and tax rates, among other things.

State constitutions may seem like an unusual place to pursue one's favored public policies - instead of the normal legislative process - but this way of starting our discussion of state constitutions indicates how important foundational documents are in the daily lives of American citizens. Given citizen familiarity with the U.S. Constitution and the institutions of the national government generally is typically quite low in some areas (in this regard, see Table 5.1), popular familiarity with and knowledge of state constitutions is most likely even lower in most areas of the country..- Even among 
the academic community, there has been relatively limited research regarding state constitutions in contrast to the virtual mountain of literature devoted to the decisions and operations of the U.S. Supreme Court regarding the interpretation of the U.S. Constitution and to the selection of members of the federal bench whose terms of office are "for life" (the sole exception from fixed terms of office in the American governmental system).

\begin{tabular}{ll}
\hline & $\begin{array}{l}\text { PERCENT } \\
\text { CORRECT } \\
\text { ANSWER }\end{array}$ \\
$\begin{array}{l}\text { a. Free speech is guaranteed by First Amendment. } \\
\text { b. Republican Party has majority in Senate. }\end{array}$ & $86 \%$ \\
$\begin{array}{l}\text { c. Republican Party has majority in House of } \\
\text { Representatives. }\end{array}$ & $83 \%$ \\
$\begin{array}{l}\text { d. Electoral College formally elects the President. } \\
\text { e. } 22 n d \text { Amendment determines max number of } \\
\text { presidential terms. }\end{array}$ & $76 \%$ \\
f. Vice President casts tie-breaking votes in Senate. & $56 \%$ \\
g. 60 votes needed to end a filibuster in Senate. & $54 \%$ \\
\hline
\end{tabular}

Table 5.1 U.S. Civic Knowledge 2018

While state constitutions don't receive much attention from academic researchers and are accorded only scant public attention, their importance does indeed merit our attention. We decided to include an entire chapter on state constitutions given their direct connection to the question of the active pursuit of sustainability in state and local government. The mere mention of the topic usually tends to arouse fears of boredom born of painful attention to legalistic hair-splitting among students of state and local government. In fact, in 
reality, state constitutions represent a topic of great importance, interesting historical developments, and clear contemporary relevance. As G. Alan Tarr has reminded us:

...the disdain for state constitutions is unfortunate; for one cannot make sense of American state government or state politics without understanding state constitutions. After all, it is state constitution - and not the federal constitution that creates the state government, largely determines the scope of its powers, and distributes those powers among the branches of the state government and between state and locality. ${ }_{-}^{2}$

State constitutions are also important to examine because they often mirror important political, economic and social changes occurring over time. As states have moved from reflecting rural economies characterized principally by natural resource extraction in the seventeenth and eighteenth centuries (mining, timber, fisheries and agriculture), to governing urbanizing industrial economies in the nineteenth and twentieth centuries (manufacturing), to providing guidance to post-industrial and knowledge-based economies in the late twentieth and early twenty-first centuries, citizens and their political representatives have made many revisions to their respective state constitutions - and even replaced them in their entirety when deemed necessary on rare occasion. Such adaptation to change is a key element in the promotion of sustainability.

While there is somewhat of a debate taking place regarding just how adaptive state constitutions have been to changing times and situations, there is little disagreement that constitutions are important documents that set the context and specify the procedures for political processes wherein governors, legislatures, courts, interest groups, local governments, citizens and others seek to influence the course of public policy. Because of the clear importance of state 
constitutions to American state and local politics and to prospects for sustainable governance, this chapter will:

- review the purpose of constitutionalism and constitutions in the states,

- analyze key differences and similarities between state constitutions,

- discuss the various processes available for changing constitutions in the states,

- and examine the role of state constitutions as both barriers to or promoters of sustainability.

\section{B - Purpose of State Constitutions}

According to Francis Wormuth's classic work entitled The Origins of Modern Constitutionalism, "A constitution is often defined as the whole body of rules, written and unwritten, legal and extralegal, which describe a government and its operation." ${ }_{-}^{3}$ The use of constitutions in states mirrors the development of what we call constitutional democracy at our national level of government. At its most basic level, the concept reflects the belief that government can and should be legally limited in its powers, and that its rightful exercise of authority depends on observing these limitations. Government in a democratic country must be accountable to its citizens and operate within the limits placed on how and when governmental power is to be exercised with respect to the rights and privileges of citizens. While most constitutions in the world, including that of the United States, are codified as single written documents, the notion of constitutionalism 
can also include multiple written documents and even some unwritten rules and procedures. In the case of Great Britain, for example, there are various written components of the constitution such as the Magna Carta (1215 AD) and numerous statutes enacted by Parliament, but there are also some unwritten components including principles derived from Common Law and Royal Prerogative.

We can trace the development of constitutionalism back to 500-600 BC in ancient Greece where some city-states had partially written or customary constitutions that were organized, according to the Greek philosopher Aristotle (384-322 BC), into either good or bad forms of the rule of one (kingship versus tyranny), the rule of few (aristocracy versus oligarchy), and the rule of many (polity versus mob rule). Constitutionalism in the United States was influenced by various sources, including developments in Common Law in Great Britain and the well-known writings of enlightenment thinkers such as Jean Jacques Rousseau (1712-1778 AD) and John Locke (1632-1704 AD). ${ }_{-}^{4}$

While the U.S. Constitution is often considered the oldest written constitutional document still in use in the world, several American state constitutions are even older than the U.S. Constitution - stemming from the original charters of the thirteen colonies (see Table 5.1). The constitution of the Commonwealth of Massachusetts is quite likely the oldest written constitutional document still in use; it dates back to 1780. The Fundamental Orders of Connecticut was considered the first written quasi-constitutional document of its kind in the world, dating from 1638. ${ }_{-}^{5}$ Eleven other American states' first constitutions precede the U.S. Constitution of 1787 by at least a decade, illustrating that the concept of constitutionalism was well instilled at the state level well before the creation of our current national government. ${ }^{6}$ In point of fact, many of the framers of the U.S. Constitution meeting in Philadelphia in the late 1780 s were quite heavily 
influenced by their knowledge of and experience with their respective colonial constitutional documents and established governmental practices.

In general, it can be said that state constitutions establish the overall framework of state government, specifying the forms of local governments to be permitted - including all cities, counties, townships and special purpose districts created within its territory. The state constitutions provide for all forms of state and local government finances, establish the state and local tax systems in force, and designate the range of civil liberties to be protected under state law. In a sense, state constitutions represent a form of societal contract between those in elected or appointed office and the rest of society. All disputes concerning the meaning of that contract are settled in state supreme courts. Specifically, the main purposes of state constitutions are (within the limitations placed on states by the U.S. Constitution):

- to define the general purposes and ideals of the several states, including the determination of the common good of citizens,

- to establish republican and accountable forms of government, with legal limits on the powers of government entities and their agencies,

- to provide a framework for governmental structures, including the scope of authority, mechanisms for exercising authority, and procedures for the passage and modification of state laws, local ordinances, and administrative rules and regulations. This framework includes the executive, legislative and judicial branches of state and local government,

- to provide for an independent judiciary that allows citizens to seek court-ordered remedies for illegal actions of government as well as a process to challenge laws they believe to be unconstitutional,

- to provide legal definitions of key concepts (e.g., citizenship, property rights, parental rights, etc.) and prescribe a process 
for establishing basic political rights such as standing for public office and voting,

- to establish and define the powers of local governments, including counties, cities, townships and special-purpose governments,

- to establish the requirements for holding elective and appointed office, as well as setting the terms of office for elected officials,

- to provide for a process of removal of incompetent and corrupt elected or appointed officials, which can include recall and impeachment,

- to define responsibilities for major government departments and agencies, and the principal duties of the individuals heading up those state and local governmental entities,

- to establish a system of taxation and budgetary processes,

- to provide for the public safety of the citizenry, including regulatory authority for civil and criminal actions to be exercised to promote public health and safety and to operate effective civil and criminal justice systems,

- to provide for a process of replacing or revising the state constitution (depending on the state, these processes can include initiatives, referenda, constitutional conventions, and legislative action),

- to establish the rights of citizens, including both "negative" and "positive" rights and freedoms. Negative freedoms are often called "civil liberties," which include freedom of speech and assembly among other rights. Civil liberties are individual or group protections from a potentially oppressive government. Positive rights, on the other hand, are things government can do for citizens, including the provision of education, economic assistance in times of need, timely assistance in times of natural disasters, and the preservation of cultural assets with public libraries and museums,

While these are the major purposes of state constitutions, 
generally speaking, it should be noted here that enormous diversity exists between the states on many of these principles, and this diversity will be discussed in the next section of this chapter. Before we begin this particular discussion we would be wise to heed Robert Maddex's cautionary advice concerning the complexity and dynamic nature of constitutionalism in a federal system:

Unlike national constitutions, state constitutions do not simply stand alone at the apex of a system of laws but are part of an interactive organization of federal and state governments. Federalism, which is an attempt to solve the problems that arise from this interaction between national and state laws, has continued to evolve since the nation was founded. ${ }_{-}^{7}$

\section{C - Content of State Constitutions: Diversity and Similarities}

In broad terms, state constitutions and governmental structures greatly resemble the U.S. Constitution and the national governmental structure because those pre-existing features of government were used as a guide by the framers of the U.S. Constitution. State constitutions differ substantially from state to state, but they are similar in that they are not permitted to contradict the supremacy clause of the U.S. Constitution. Where the U.S. Constitution prescribes a legal standard of democratic governmental form or practice, all state constitutions must be consistent with that standard. In the case of civil liberties, for example, the several states may 
exceed but may not set lower standards for the protection of those rights of citizens than those set by the U.S. Supreme in its interpretation of the Bill of Rights of the U.S. Constitution.

The limits as to what states can and cannot do with respect to the supremacy clause are rather clear (see figure 5.1). The U.S. Constitution sets specific limits on state powers in Article I, Section 10; that section restricts states from printing their own money, entering into international treaties, imposing duties on international trade, and engaging in various other official activities reserved for federal government actions. Article IV, Sections 1 through 4 specify other provisions pertaining to the states, including extradition of individuals accused of a crime in another state, the requirement for a republican form of government, and the process by which new states can be admitted to the union. Importantly, as noted in the chapter on intergovernmental relations in our federal system of government, the Tenth Amendment specifies that any powers not specifically granted to the federal government in the U.S. Constitution are reserved to the responsibility of the states and the people (this is known as the reserved powers clause). 


\section{Article I}

\section{Section 10 - Powers Prohibited of States}

No State shall enter into any Treaty, Alliance, or Confederation; grant Letters of Marque and Reprisal; coin Money; emit Bills of Credit; make any Thing but gold and silver Coin a Tender in Payment of Debts; pass any Bill of Attainder, ex post facto Law, or Law impairing the Obligation of Contracts, or grant any Title of Nobility.

No State shall, without the Consent of the Congress, lay any Imposts or Duties on Imports or Exports, except what may be absolutely necessary for executing it's inspection Laws: and the net Produce of all Duties and Imposts, laid by any State on Imports or Exports, shall be for the Use of the Treasury of the United States; and all such Laws shall be subject to the Revision and Controul of the Congress.

No State shall, without the Consent of Congress, lay any duty of Tonnage, keep Troops, or Ships of War in time of Peace, enter into any Agreement or Compact with another State, or with a foreign Power, or engage in War, unless actually invaded, or in such imminent Danger as will not admit of delay.

\section{Article IV}

\section{Section 1 - Each State to Honor all other}

Full Faith and Credit shall be given in each State to the public Acts, Records, and judicial Proceedings of every other State. And the Congress may by general Laws prescribe the Manner in which such Acts, Records and Proceedings shall be proved, and the Effect thereof.

\section{Section 2 - State citizens, Extradition}

The Citizens of each State shall be entitled to all Privileges and Immunities of Citizens in the several States.

A Person charged in any State with Treason, Felony, or other Crime, who shall flee from Justice, and be found in another State, shall on demand of the executive Authority of the State from which he fled, be delivered up, to be removed to the State having Jurisdiction of the Crime.

(No Person held to Service or Labour in one State, under the Laws thereof, escaping into another, shall, in Consequence of any Law or Regulation therein, be discharged from such Service or Labour, But shall be delivered up on Claim of the Party to whom such Service or Labour may be due.) (This clause in parentheses is superseded by the 13 th Amendment.) 


\section{Section 3 - New States}

New States may be admitted by the Congress into this Union; but no new States shall be formed or erected within the Jurisdiction of any other State; nor any State be formed by the Junction of two or more States, or parts of States, without the Consent of the Legislatures of the States concerned as well as of the Congress.

The Congress shall have Power to dispose of and make all needful Rules and Regulations respecting the Territory or other Property belonging to the United States; and nothing in this Constitution shall be so construed as to Prejudice any Claims of the United States, or of any particular State.

\section{Section 4 - Republican government}

The United States shall guarantee to every State in this Union a Republican Form of Government, and shall protect each of them against Invasion; and on Application of the Legislature, or of the Executive (when the Legislature cannot be convened) against domestic Violence.

\section{Tenth Amendment}

The powers not delegated to the United States by the Constitution, nor prohibited by it to the States, are reserved to the States respectively, or to the people.

Figure 5.1 Key U.S. Constitution Provisions Concerning States

According to research conducted by Christopher Hammons, there have been 145 constitutions in the 50 U.S. states since 1776, with the average constitution remaining in effect for approximately 70 years. On average, American state constitutions are "...almost four times longer than the 7,400-word U.S. Constitution. Most state constitutions contain around 26,000 words.. ${ }_{-}^{8}$ Currently, the shortest state constitution is found in New Hampshire, a document featuring only 9,200 words; in stark contrast, the longest state constitution contains 340,136 words and it is found in Alabama (see Table 5.2). All of the state constitutions are longer than the U.S. Constitution. The reason that state constitutions are longer than the U.S. Constitution is "...because they encompass such a wide range of institutions and powers" due to the dictate of the Tenth Amendment where "powers not delegated to the United States by the Constitution...are reserved to the States, respectively.". ${ }_{-}$In addition, Hammons argues that the number of "statutory-type provisions" found in state 
constitutions - that is, specific mandates for specific public policies - are quite numerous, with the average state having 824 separate provisions, of which "...324 are devoted to particularistic or statutory issues" such as the provision of hail insurance in South Dakota, citizen access to physicianassisted suicide in Oregon, the width of ski runs in New York, and the active promotion of the catfish farming industry in Alabama. 10 


\begin{tabular}{|c|c|c|c|c|c|}
\hline State & Capitol & $\begin{array}{l}\text { Number of } \\
\text { Constitutions }\end{array}$ & $\begin{array}{l}\text { Year Present } \\
\text { Constitution } \\
\text { Implemented }\end{array}$ & $\begin{array}{l}\text { Length } \\
\text { in } \\
\text { Words }\end{array}$ & $\begin{array}{l}\text { Amendments } \\
\text { Adopted }\end{array}$ \\
\hline Alabama & Montgomery & 6 & 1901 & 340,136 & 766 \\
\hline Alaska & Juneau & 1 & 1959 & 15,988 & 29 \\
\hline Arizona & Phoenix & 1 & 1912 & 28,876 & 136 \\
\hline Arkansas & Little Rock & 5 & 1874 & 59,500 & 91 \\
\hline California & Sacramento & 2 & 1879 & 54,645 & 513 \\
\hline Colorado & Denver & 1 & 1876 & 74,522 & 145 \\
\hline Connecticut & Hartford & 4 & 1965 & 17,256 & 29 \\
\hline Delaware & Dover & 4 & 1897 & 19,000 & 138 \\
\hline Florida & Tallahassee & 6 & 1969 & 51,456 & 104 \\
\hline Georgia & Atlanta & 10 & 1983 & 39,526 & 63 \\
\hline Hawaii & Honolulu & 1 & 1959 & 20,774 & 104 \\
\hline Idaho & Boise & 1 & 1890 & 24,232 & 117 \\
\hline Illinois & Springfield & 4 & 1971 & 16,510 & 11 \\
\hline Indiana & Indianapolis & 2 & 1851 & 10,379 & 46 \\
\hline Iowa & Des Moines & 2 & 1857 & 12,616 & 52 \\
\hline Kansas & Topeka & 1 & 1861 & 12,296 & 93 \\
\hline Kentucky & Frankfort & 4 & 1891 & 23,911 & 41 \\
\hline Louisiana & Baton Rouge & 11 & 1975 & 54,112 & 129 \\
\hline Maine & Augusta & 1 & 1820 & 16,276 & 170 \\
\hline
\end{tabular}




\begin{tabular}{|c|c|c|c|c|c|}
\hline Maryland & Annapolis & 4 & 1867 & 46,600 & 218 \\
\hline Massachusetts & Boston & 1 & 1780 & 36,700 & 120 \\
\hline Michigan & Lansing & 4 & 1964 & 34,659 & 25 \\
\hline Minnesota & Saint Paul & 1 & 1858 & 11,547 & 118 \\
\hline Mississippi & Jackson & 4 & 1890 & 24,323 & 123 \\
\hline Missouri & $\begin{array}{l}\text { Jefferson } \\
\text { City }\end{array}$ & 4 & 1945 & 42,600 & 105 \\
\hline Montana & Helena & 2 & 1973 & 13,145 & 30 \\
\hline Nebraska & Lincoln & 2 & 1875 & 20,048 & 222 \\
\hline Nevada & Carson City & 1 & 1864 & 31,377 & 132 \\
\hline $\begin{array}{l}\text { New } \\
\text { Hampshire }\end{array}$ & Concord & 2 & 1784 & 9,200 & 14 \\
\hline New Jersey & Trenton & 3 & 1948 & 22,956 & 38 \\
\hline New Mexico & Santa Fe & 1 & 1912 & 27,200 & 151 \\
\hline New York & Albany & 4 & 1895 & 51,700 & 216 \\
\hline $\begin{array}{l}\text { North } \\
\text { Carolina }\end{array}$ & Raleigh & 3 & 1971 & 16,532 & 34 \\
\hline North Dakota & Bismark & 1 & 1889 & 19,130 & 145 \\
\hline Ohio & Columbus & 2 & 1951 & 48,521 & 162 \\
\hline Oklahoma & $\begin{array}{l}\text { Oklahoma } \\
\text { City }\end{array}$ & 1 & 1907 & 74,075 & 171 \\
\hline Oregon & Salem & 1 & 1859 & 54,083 & 238 \\
\hline Pennsylvania & Harrisburg & 5 & 1968 & 27,711 & 30 \\
\hline Rhode Island & Providence & 3 & 1986 & 10,908 & 8 \\
\hline
\end{tabular}




\begin{tabular}{|c|c|c|c|c|c|}
\hline $\begin{array}{l}\text { South } \\
\text { Carolina }\end{array}$ & Columbia & 7 & 1896 & 22,300 & 485 \\
\hline South Dakota & Pierre & 1 & 1889 & 27,675 & 212 \\
\hline Tennessee & Nashville & 3 & 1870 & 13,300 & 36 \\
\hline Texas & Austin & 5 & 1876 & 90,000 & 439 \\
\hline Utah & $\begin{array}{l}\text { Salt Lake } \\
\text { City }\end{array}$ & 1 & 1896 & 11,000 & 106 \\
\hline Vermont & Montpelier & 3 & 1793 & 10,286 & 53 \\
\hline Virginia & Richmond & 6 & 1971 & 21,319 & 40 \\
\hline Washington & Olympia & 1 & 1889 & 33,564 & 96 \\
\hline West Virginia & Charleston & 2 & 1872 & 26,000 & 71 \\
\hline Wisconsin & Madison & 1 & 1848 & 14,392 & 134 \\
\hline Wyoming & Cheyenne & 1 & 1890 & 31,800 & 94 \\
\hline
\end{tabular}

Table 5.2 State Constitution Characteristics

Many observers argue that longer constitutions featuring many specific mandates make state constitutions overly cumbersome and time-bound, and consequently less likely to last over time. They believe that more streamlined constitutions focusing mostly on institutional issues (e.g., governmental structures and functions) with fewer specific mandates make them more durable and adaptable over time. ${ }_{-}^{11}$ However, contrary to this conventional argument Hammons' research into state constitutions found "...that longer and more detailed design of state constitutions actually enhances rather than reduces their longevity:12 While Hammons does not know for sure why more detailed and longer constitutions can be shown to be more durable, he conjectures that this may occur because such documents provide better mechanisms for conflict resolution by more carefully identifying the rules of 
the game to be followed by parties in dispute. He also notes that the longer "particularistic" constitutions may have proven to be more durable because they provide competing groups a common interest to protect the important foundational document wherein "...their programs are institutionalized."13

While the length of state constitutions varies widely, there are many common themes found in their provisions, including the establishment of government institutions, the specification of powers of these institutions, the procedures to be followed by public institutions in carrying out their work, and the principles of governance to be observed. Regarding the establishment of governmental institutions, the U.S. Constitution allows a wide variety of institutions as long as they represent a republican form of government. Typically, when we talk about institutions in this context of republican government there are two primary issues to consider. First, there is separation of powers versus integration of powers, which concerns how many branches of government will be established. Branches can be divided up by executive, legislative and judicial powers, or integrated into one body, such as done in a European-style parliament. The second issue involves centralization versus decentralization, which concerns how many layers of government will be used and how much power and responsibility each layer will have. Government responsibilities can be centralized at one level of government, or they may be broadly dispersed and decentralized among multiple layers.

For both the separation of powers and centralization vs. decentralization issues state constitutions closely resemble the U.S. Constitution in that power is separated into three branches - executive, legislative and judicial - and government is decentralized; the governmental powers within the states are typically distributed across five possible layers, including counties, cities, townships, school districts, and special purpose districts. For the branches of government found in 
states, the executive branch is headed by a governor instead of a president, each state has two legislative chambers (with the exception of Nebraska which has just a single chamber), and each state has a court of last resort (typically referred to as the state's Supreme Court). As for layers of government, each state has its own procedures for the establishment of local governments, and states differ in how much power and what range of responsibilities those local governments exercise. Forty-eight states have operational county governments (called "boroughs" and "parishes" in Alaska and Louisiana, respectively). While the states of Connecticut and Rhode Island provide for counties as geographic subdivisions of the state, these regional subdivisions do not have functioning governments in those two states.

All fifty states allow for general purpose municipal forms of government, and all states have school and special-purpose (e.g., sewer, mosquito control, rural fire, soil conservation) districts. Twenty states also allow for township governments, which historically have been rural subdivisions of counties, but not always; in fact, today many metropolitan area suburbs with growing populations have spread into previously rural locations.

Other governmental institutions typically seen in state constitutions include the establishment of state offices and officials, including executive agencies and departments such as education, transportation, agriculture, fish and game, natural resources and the environment, attorney general, secretary of state, treasury, revenue, welfare (social services), health, civil service, various advisory boards, commissions, and governing boards for public colleges and universities. Typically, state constitutions also establish institutions such as state prisons, state mental health hospitals, state libraries, and state parks, and states provide for local school districts and other forms of local government-oriented entities to deal with such infrastructure matters as public utilities, irrigation, 
county roads and bridges, park and recreation facilities, local libraries and health clinics and hospitals.

The powers residing in each institution and the state, in general, are also included in state constitutions, such as the legislative power for both upper and lower chambers; executive powers held by the governor and other executive offices such as secretaries of state and attorneys general; judicial powers held by state supreme courts, state appellate courts, and lower courts; powers of taxation and expenditure; powers of local governments; regulatory powers over various areas, including commerce, transportation, environment, business and corporations, criminal justice; powers to claim land or property for public use - and many more. Most state constitutions provide for a plural executive branch, with separate elections for such offices as secretary of state, state treasurer, attorney general, state auditor, and lieutenant governor. A typical U.S. state governmental structure outlined in a state constitution looks very much like that of one of our oldest state constitutions - namely, that of Massachusetts (see figure 5.2). 


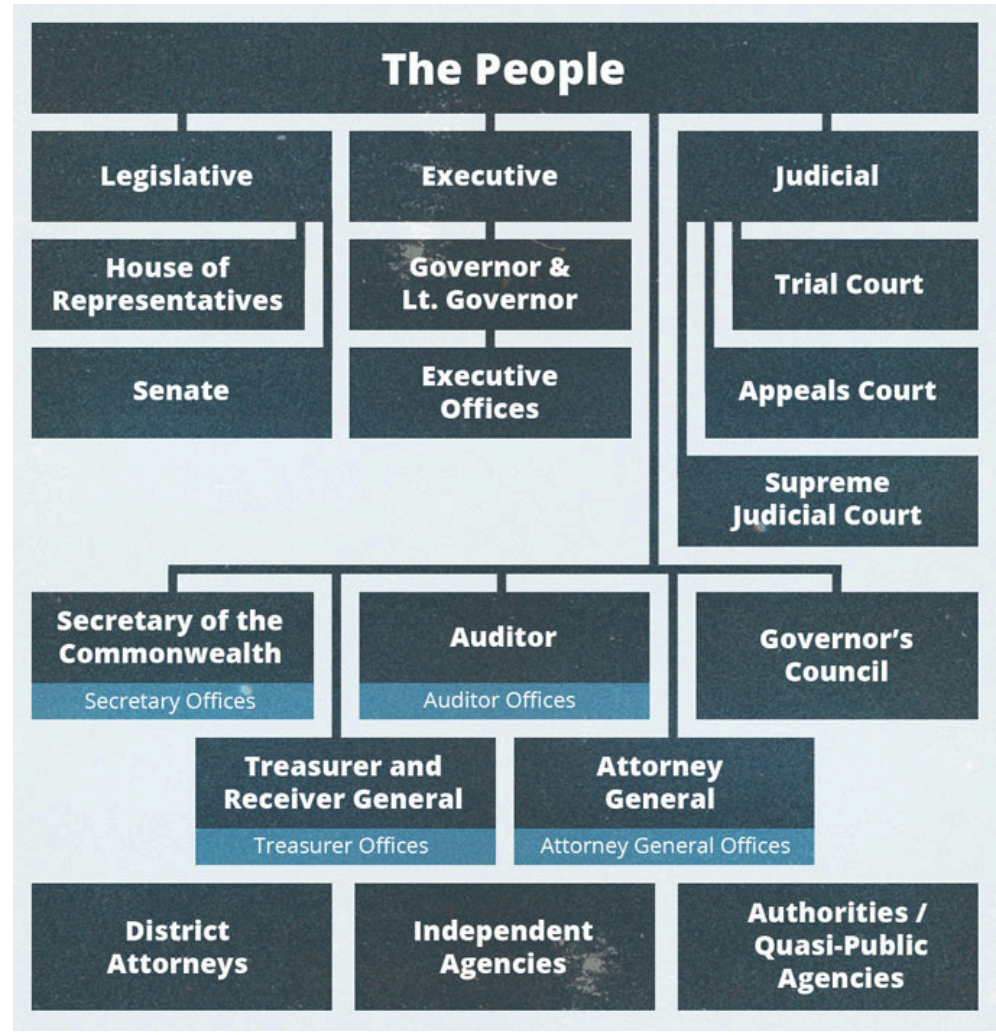

Figure 5.2: Structure of the Commonwealth of Massachusetts.

State constitutions also outline the process and procedures of government as well. These can include but are not limited to: how laws are made, including executive veto and override processes; qualifications for election and office-holding; terms of office; ballot rules; voter registration and election process rules; size of public institutions; rules for the maintenance of official records; impeachment processes; when and where elections will be held, and who is eligible to vote; processes for initiative, referendum, and referral, and many other procedures not listed here. Forty-four U.S. states allow 
governors to veto individual items in appropriation bills, and all but 15 U.S. states mandate the adoption into law of "balanced budgets" (that is, expenditures provided for must match anticipated revenue for the period in question) through their state constitutions. Most state constitutions feature term limits for governors (38 states), and 16 states have set term limits for state legislators in their constitutions as well.

Finally, state constitutions also provide the "guiding principles" of governance. These principles often follow the U.S. Constitution and typically include many items found in the Bill of Rights, including freedom of speech, freedom of religion, governmental accountability, the sovereignty of the people, and the purpose of democratic government being the protection life, liberty, happiness and property. Forty-six states also have provisions similar to the U.S. Constitution's Second Amendment concerning the right to bear arms (California, Iowa, Minnesota and New Jersey are silent on the subject). Only 10 states guarantee the right to privacy in various specific areas, including financial and medical records, but in other states, these rights have been established by state Supreme Court decisions. While these fundamental rights are found in the U.S. Constitution and provide citizens with a "minimal floor of government protection for the individual, the enumerated rights in state constitutions can represent another layer" of protection of individual rights. ${ }_{-}$

Some controversial areas concerning guiding principles found in some state constitutions include attempts to ban or limit abortion rights and feature provisions making English the "official language" of the state in question. For example, many states have changed their constitutions to require parental notification for an abortion, and some states (Colorado, Georgia, and Mississippi) ban abortion even though a complete ban is now unconstitutional given the U.S. Supreme Court's Roe vs. Wade decision.

Eight states have recognized English as their official 
language through a provision in their state constitution, and 21 states have statutory provisions either passed by ballot initiative or legislatively providing for English as the official language for their particular state (see Table 5.3). Most constitutional provisions in this area are similar to that found in California, and that provision reads as follows: "English is the common language of the people of the United States of America and the State of California. This section is intended to preserve, protect and strengthen the English language, and not to supersede any of the rights guaranteed to the people of this Constitution" (Article III, Section 1).

- Alabama: Constitutional Amendment (1990) passed by ballot.

- Alaska: Statutory voter initiative, (1998), suspended by state courts pending appeal.

- Arizona: Constitutional amendment (2006).

- Arkansas: Statute (1987).

- California: Constitutional Amendment (1986).

- Colorado: Constitutional Amendment (1988).

- Florida: Constitutional Amendment (1988). Petition initiative

- Georgia: Legislative Statute $(1986,1996)$.

- Hawaii: Constitutional Amendment (1978) by the legislature.

- Idaho: Legislative Statute (2007).

- Illinois: Statute (1969).

- Indiana: Statute (1984).

- Iowa: Legislative Statute (2002).

- Kansas: Legislative Statute (2007).

- Kentucky: Statute (1984)

- Louisiana: The original constitution was interpreted as having established an official language (1975).

- Mississippi: Legislative Statute (1987).

- Missouri: Legislative Statute (1988).

- Montana: Legislative Statute (1995).

- Nebraska: Constitutional Amendment (1920), by popular vote. 
- New Hampshire: Legislative Statute (1995).

- North Carolina: Legislative Statute (1987).

- North Dakota: Legislative Statute (1987).

- South Carolina: Legislative Statute (1987).

- South Dakota: Legislative Statute (1987).

- Tennessee: Legislative Statute (1984).

- Utah: Statute (2000) passed by petition initiative.

- Virginia: Legislative Statutes (1996).

Table 5.3 English as an Official Language

\section{D - Changing Constitutions}

There are three major methods available to change or amend U.S. state constitutions. The methods include a legislative proposal, a popular initiative, and a constitutional convention. A fourth method, only available in Florida, involves a constitutional commission submitting a proposal directly to the state's voters for their consideration. Additionally, each state has the potential for a "virtual" constitutional amendment through judicial re-interpretation of constitutional provisions. Of the four methods listed, only the constitutional convention provides elected officials an opportunity to collaborate in a deliberative setting on the entire constitution. 


\section{D.I - Legislative Proposal:}

The legislative proposal method is the main avenue used in all the U.S. states to amend their respective constitutions. To demonstrate how heavily this method is used, in the five-year period of 2002-2006 the legislative proposal constituted 68\% of all the amendment proposals, with the initiative process comprising the remaining $32 \%$. This legislative process is ordinarily used for making limited changes, but on rare occasions, the process has been used in some states to propose rather comprehensive revisions of their constitutions.

What makes the legislative constitutional amendment proposal different than simple legislation is the requirement of a large "super-majority" consensus in both houses, with the minimum being two-thirds. In addition, fifteen states have an even more arduous hurdle called "Double Passage." This is an amendment procedure that requires majority consensus by both houses from two separate legislative sessions. Lastly, all states except Delaware require that legislative amendment proposals be submitted to the state's voters for their ultimate approval by a majority vote. With all these requirements, it seems rather a miracle that so many amendments have made it through the approval gauntlet. Contrary to popular belief, the majority of state amendments don't garner the general public's attention or cause controversy at the polls; in fact, about two-thirds of all state amendments deal with rather mundane issues such as state and local governmental structure and debt management, state agency functions, and relatively minor taxation and finance issues. ${ }_{-}$ 


\section{D.II - Constitutional Initiatives:}

The constitutional initiative, also known as the popular initiative, citizen initiative, minority initiative, and the "Oregon System," empowers citizens to propose constitutional amendments directly to voters for their ultimate consideration. Available in 18 states, the process is broken down into either direct or indirect initiatives. The direct initiative process allows for a constitutional amendment proposed by the people to be placed directly on the ballot for voter approval or rejection, while the indirect initiative must first be submitted to the state legislature for consideration before being placed on the popular ballot. Only the states of Mississippi and Massachusetts among the 18 states featuring the initiative process use the indirect initiative process.

Each state has their own requirements for placement on the ballot, but typically an initiative proposal requires a certain percentage of registered voters' signatures before the state's voters can place it on the ballot for consideration. In those states where the initiative is in place, it is particularly important that citizens keep informed about state and local government issues; these issues are very likely to come before them as voters on a regular basis.

The origins of the initiative process go back to 1902 when the Oregon legislature adopted a constitutional amendment to allow residents of Oregon to propose new laws or change the state constitution through a general election ballot measure. ${ }_{-}^{16}$ This is why the initiative process is known nationally as the Oregon System of direct democracy. Its initial purpose was to provide a means to bypass the political status quo and corruption of the late 19th and early 20th centuries. It was felt, and rightly so, that many politicians of the day were "in the pockets" of the large private corporate interests of the day - namely, the railroads and timber companies. In response 
to the positive public opinion developed toward the Oregon System, the initiative process was adopted by 17 additional states and became one of the signature reforms of the Progressive Era. As in the past, those who distrust government still use the initiative today, but there is considerable concern that the process might be somewhat at risk because it tends to empower well-funded special interests that exercise disproportionate access to the ballot box through this process. ${ }_{-}^{17}$

\section{D.III - Constitutional Convention:}

A Constitutional convention is the oldest and most traditional method to propose a new state constitution or extensively revise an existing constitution. The process of initiating a convention begins with a formal call from the legislature, an action which all 50 state legislatures and the District of Columbia have the ability to undertake. Fourteen states also require submitting the question of calling a constitutional convention to their voters,${ }_{-}^{18}$ thereby requiring the legislature to hold such a conclave. While each state has its own requirements in this regard, most states require majority approval by voters (termed "ratification") before a new constitution can be adopted in place of an existing foundational legal framework.

Throughout the history of the United States, there have been relatively few constitutional conventions. As of the end of 2009, there have been only 234 constitutional conventions held in the U.S, with Rhode Island holding the last one in 1992 in an effort to address its dire fiscal challenges; the revision proposed was soundly defeated by 62 percent of the state's voters. ${ }_{-}^{19}$ The trend of decline in the rate of use of 
constitutional conventions has been consistent; in the 20th century, only 62 conventions were held, compared to 144 in the 19th century. There are a number of reasons for this sharp decline, but the biggest possibility is the concern that holding a convention will open up "Pandora's Box" (i.e., unleash a torrent of issues to which no course of action can be agreed to and ultimate resolution of the issue is not possible). Those on both sides of an issue often fear that a convention is an invitation to provide a forum for either reactionary populism - or the devotion of disproportionate attention to matters of temporary importance, thereby allowing the electorate an opportunity to insert provisions on controversial issues such as abortion, balanced budgets, and the death penalty, or address issues unrelated to the purpose giving rise to the convention. 20

For example, in 1997 a coalition of environmental interest groups and teachers' unions in New York mobilized against a convention call. The environmentalists feared the 1894 "Forever Wild" provision that protects the Catskill and Adirondack Preserves would be altered or removed by prodevelopment interests. Teachers, on the other hand, were concerned about losing the constitutional guarantee of public employee pensions. ${ }_{-}^{21}$ The trend of declining use of constitutional conventions is unlikely to change due to the political atmosphere of partisan politics, apathy from the general public, and an overall fear of opening Pandora's Box on the part of many organized interests. Framing a new constitution requires both consensus from political parties and widespread and durable support from the general public. These conditions are seldom met in most states. 


\section{D.IV - Constitutional Commission:}

The constitutional commission is an entity that all states have the ability to use, but few in the general public have ever heard of the process. This is likely due to the fact that, with the exception of Florida, commissions have no direct contact with the public or voters. Each state commission's role and membership varies from that of other states, but traditionally they represent a group of experts who are appointed, usually by the legislature and/or governor, to review the constitution and submit proposed amendments to the legislature or prepare for a constitutional convention. If members are deemed to be impartial, the commission can be successful; legislatures typically consider commission recommendations carefully if the commission is deemed to be unbiased, nonpartisan and expert in constitutional law.

With the decline of constitutional conventions, some states are turning to constitutional commissions to make their constitutions more workable in a time of need for periodic piecemeal amendments. The state of Utah, for example, in 1969 adopted a law to establish the Constitutional Revision Study Commission to study the state's constitution and make periodic revision or amendment recommendations to the governor and state legislature. ${ }_{-}^{22}$ The commission was made permanent in 1997 and given the official title of Constitutional Revision Commission. This entity represents the nation's only permanent constitutional commission; all the other states with such commissions feature bodies, which are the temporary creations of specific, time-bound legislation.

The state of Florida's Taxation and Budget Reform Commission is the only state-level commission that maintains direct contact with the state's voters. Florida's commission has the authority to submit recommended budgetary and taxrelated constitutional changes directly to the voters, without 
prior approval from the legislature. In fact, in 1992 Florida made history when its voters approved amendments submitted by the commission without legislative action.

\section{D.V - Role of the Courts:}

The state courts have a major role in amending state constitutions via their exercise of the power of judicial review. Unlike the U.S. Supreme Court, which under most circumstances won't address "political questions" (legally classified as "nonjusticiable" issues), state appellate courts often rule on a wide range of both procedural and political issues. In the past, state courts of last resort have ruled on issues such as whether a particular state can call a constitutional convention, the validity of procedural mechanisms used in carrying out eminent domain powers, and whether some amendments developed by legislative and popular initiative are consistent with constitutional principles. Because state appellate court judges are elected in most states, unlike their lifetime appointment judicial counterparts in the federal courts, state court judges generally have a stronger sense of connection to "the people" than do members of the federal judiciary. As such, state courts are much more likely than federal courts to issue rulings and hear cases that federal courts would not consider.

Opponents of particular constitutional amendments enacted through the initiative process frequently have used the state courts to question the legality of such amendments in order to prevent them from being placed into effect. For example, opponents of Oregon's ballot initiative 36, which amended the Oregon constitution to say "that only a marriage between one man and one woman shall be valid or legally 
recognized as a marriage, ${ }_{-}^{23}$ unsuccessfully used the state courts to challenge the initiative, arguing in their brief that this statement represented such a radical change to the constitution that only the legislature or constitutional convention should have the ability to make such changes in the foundational framework of Oregon's legal system. State supreme courts can deny a constitutional initiative a place on the ballot on the grounds that the content of the initiative was inconsistent with provisions of the U.S. Constitution. Such was the case in Colorado when a state district court held invalid an initiative intended to restrict the legal status of gays, lesbians, and bisexuals under Colorado law. That ruling was subsequently allowed to stand as precedent in the state.

The role of the state courts known as the exercise of Judicial Federalism is a fairly recent phenomenon emerging in the 1970s when Warren Burger succeeded William Brennan as Chief Justice of the U.S. Supreme Court. As the U.S. Supreme Court lost its liberal majority with the appointment of Burger and began to take a far less progressive stance on civil liberties and social equity cases the high courts in the states began interpreting their own constitutions to establish citizen rights in their states beyond those present in the U.S. Constitution. ${ }_{-}^{24}$ Judicial Federalism is said to occur when state courts address their own state's constitutional claims first in a case, and only consider federal constitutional claims when cases cannot be resolved on state grounds. This phenomenon ties directly into the enhancement of state civil liberties in many states during the 1970s, as state supreme courts worked to secure civil rights and liberties unavailable to their citizens under the U.S. Constitution as that document was being read by the members of the conservative Burger Court. ${ }_{-}^{25}$ This activism on the part of state supreme courts adds an important dimension to the adaptive capacity of state government in the area of the promotion of an essential element of sustainability - namely, the promotion of social equity. Having established this 
capacity for court-initiated adaptation to change, this same capacity for adaptive action could be demonstrated in the area of citizen positive rights relating to governmental actions taken to address global climate change or energy shortages or access to information technology, for example; the social equity dimensions of those policies would have to pass muster with state courts even if the Congress remained silent on these matters.

\section{E - Constitutional Amendment Trends}

Over the past two centuries, U.S. states have amended and revised their constitutions for a wide variety of reasons, whether to change their fiscal structure, to modernize their practices with the times, or to implement requirements for consistency in law coming from the federal courts. Often though, many of these changes featured in amendments to state constitutions have been in reaction to a larger issue or policy matter arising in the nation's political discourse. We can anticipate such revisions to arise in connection to the promotion of sustainability in the years ahead as American state and local governments endeavor to adapt to the challenges of global climate change, ongoing environmental degradation and the growing competition for and scarcity of critical natural resources.

The most prominent trend in state constitutional revision during the 19th century was the creation or complete revision of state constitutions through the constitutional convention process. In all, 41 different states completely revised their respective constitutions a total of 94 times. Thirty of those constitutional conventions were held to create 
entirely new constitutions for former territories that obtained statehood, but the majority of the 94 constitutional conventions were tied to the national turmoil that came before, during and after the American Civil War (1861-1865). Most of the states which left the union adopted a new constitution just prior to or during the Civil War. During the Reconstruction Era ten of the southern states used the convention process to adopt a new constitution, and other unionist states changed their state constitutions to address the change in status of African Americans. ${ }_{-}^{26}$ As a whole, the American states' respective constitutional agendas tended to reflect the political movements of the time, including Jacksonian Democracy prior to the Civil War and the Progressive Era toward the end of the 19th century. ${ }_{-}^{27}$ During the later period, the aims of the Progressive Movement reformers were reflected in the drive on the part of state legislatures and state courts alike to regulate more effectively the growing power and influence of private corporations and to expand the suffrage beyond that of propertied white males. 28

If the 19th century's theme with regard to constitutionalism featured the accomplishment of wholesale constitutional reform through the holding of many constitution conventions, then it can be said that the 20th century was a time of piecemeal reform attained through many amendments. Two potential reasons for this change are the introduction of the initiative process (the Oregon system) and the shift in the general public's perception of patriotism and sense of place. Through much of the 19th century, political activity and patriotism was centered within one's home state, but the Civil War, in the end, preserved the Union and marked the period of ascendance of national over state identity. ${ }_{29}$ This Civil War-related outcome, combined with dramatic population growth, massive immigration from European countries and cross-continental settlement 
occurring during the early 20th century made states' constitutions less of a revered and out-of-reach grand symbol and more of a "working document" to be amended as necessary in order to govern effectively in rapidly changing times. As noted earlier in this chapter, the adoption of the constitutional initiative was part of a broad process of placing democracy more fully within the reach of the general public. This point is a key one with respect to the need for such adaptive modifications of state constitutions to promote the goals of sustainability in the 21st century.

The 20th century also represents a time when American states diverged widely on their approach to civil rights, with some states amending their constitutions to expand rights while others moved in the opposite direction to limit existing rights. Many southern states took the opportunity to amend their constitutions to re-establish dimensions of white supremacy in the aftermath of Reconstruction, ${ }_{-}^{30}$ such as North Carolina's amendments instituting a literacy test and a poll tax. In stark contrast, states in the West, including Wyoming and Colorado, amended their state constitutions to establish women's suffrage well before the 19th amendment to the U.S. Constitution afforded the right of women to vote as a feature of American citizenship. In the later part of the century, there were numerous amendments on civil rights and some expanding of rights that coincided with Judicial Federalism. The particular area of the rights accorded to the criminally accused, however, became a frequent a target of substantial rights restriction; of the 40 rights-restrictive amendments put into place between 1970 and 1986, a total of 30 of these amendments significantly reduced the rights of those facing criminal charges. ${ }_{-}^{31}$

Over time, American states have amended their constitutions to enable them to address various types of economic concerns, as well as to modify the civil liberty provisions of their foundational documents. Those states that 
came to view the power of corporate monopolies and centers of wealth as a threat to the public interest, such as the railroads and the banking and insurance industries, continued the Progressive Era efforts of the late 19th century to curb corporate influence with various constitutional amendments. These amendments permitted robust governmental regulation and shifted greater tax burdens on to these interests. ${ }_{-}^{32}$ Just prior to and during the New Deal Era, many state constitutions were amended to facilitate various social reforms, particularly in the area of workers' rights. Some of these efforts included constitutional amendments to permit workers to unionize, states to establish Workers Compensation funds and minimum wage levels, and states to create public agencies to promote public health and safety through the exercise of rights of inspection of private property. These amendments also ensured the protection of child labor through active state oversight. . $_{-}^{33}$

While it is too early to document definitive trends in state constitutional amendments in the current century, the early years of the 21st century are somewhat reminiscent of those experienced during the past century. Media coverage of state politics may make it appear that most constitutional amendments enacted concern very public and controversial moral issues (e.g., gay rights), but contrary to appearances the majority of state amendments enacted have not attracted the general public's attention. In fact, according to evidence systematically compiled by Albert Strum, about two-thirds of all state amendments enacted in recent years deal with issues such as state and local governmental structure and debt, state agency functions, and rather arcane taxation and public finance policy. .34

A fairly new pattern coming into play relates to a correlation between the amount of constitutional amendment proposals under consideration and their occurrence in evennumbered election years. This pattern is particularly in 
evidence in states with the initiative process. This is no accident, of course, because thoughtful political strategists will propose a particular type of amendment as a tool to draw their respective reliable voter pool to the polls. For example, Ohio's Secretary of State Kenneth Blackwell, who sought the Republican gubernatorial nomination in 2006, opted to delay a tax and expenditure limitation measure from 2005 to 2006 in the hopes that he would benefit from the higher turnout among conservative voters often associated with such measures. $\frac{35}{-}$ In fact, there is speculation that the popularity of the 11 constitutional amendments prohibiting same-sex marriages on the 2004 presidential election ballot, particularly in the "battleground state" (i.e., highly contested state with many electoral college votes) of Ohio, may have helped George W. Bush win the closely contested presidential election over the Democratic candidate John Kerry.

In the past, some state constitutional amendments were enacted in order to protect a state and its residents in areas in which the federal government did not extend desired protection. State environmental regulations (e.g., California's auto emission standards) and "enhanced" bills of rights are examples of this state self-protective amendment phenomenon. In 2004 California's voters approved Proposition 71, known as the California Stem Cell Research and Cures Initiative, which represents a case wherein a state amended its constitution to gain relief from a restrictive federal policy. In this case, the restrictive policy was President George W. Bush's Executive Order of August 9th, 2001, which severely limited the number of stem cell lines eligible for federal government funding. Not only does Proposition 71, codified as California Constitutional Article 35, make stem cell research a right legally protected under the California state constitution, but it also establishes the California Institute for Regenerative Medicine and provides \$3 billion in research funding to be allocated over a ten-year period. ${ }_{-}^{37}$ 
One interesting aspect of Proposition 71 is the impact it is having worldwide. What is considered an economic and research boon for California is giving rise to a "brain drain" for the rest of the world; premier scientists in the field of stem cell research are following the research funding and seeking out the scientific freedom to pursue their work in California research labs and in the state's universities. ${ }_{-}^{38}$ Not only have several states considered legislation to compete with California, but Proposition 71 has shifted the research focus from the National Institutes of Health, the primary federal agency responsible for conducting and supporting medical research, to the U.S. states. According to Daniel Perry of the Coalition for the Advancement of Medical Research, "it's almost like the breakup of the Roman Empire. ${ }_{-}^{39}$

\section{Exercises}

\section{Constitutionalism: What Can I Do?}

Toward the beginning of this chapter, we reported some survey data showing very low levels of knowledge among youth concerning the constitution, rights, and civic knowledge in general (see Table 5.1). These results are consistent with other surveys of civic knowledge in the U.S. (e.g., Milner, 2002). According to in the authors of the classic study What Americans Know About Politics and Why it Matters, political scientists Michael Delli Carpini and Scott Keeter convincingly argue that "...democracy functions best when its citizens are politically informed" (1996: 1). Here are two activities where you can test your level of awareness: 
1. Take the "50 Question Civic Quiz" online and see how you fare:

https://civicsquiz.com/50-question-u-s-civicsquiz/

2. See how well you would do with the "100 Typical Questions Asked By Immigration and Naturalization Service Examiners" for U.S. citizenship:

http://portal.cuny.edu/cms/id/cuny/documents/ informationpage/002887.htm

\section{F - State Constitutions and Sustainability}

As we indicated in the preface, a central theme of this book is the pursuit of sustainability by America's state and local governments. What role do state constitutions play in state and community sustainability? Are state constitutions to be seen as barriers to necessary societal adaptation, or as active channels for adaptive change in the promotion of sustainability and institutional resilience? Some critical observers of state government argue that state constitutions are deeply flawed and that they have become rigid, timebound documents reflecting piecemeal changes reflecting no 
appropriate plan for societal adaptation to change. Given their alleged hidebound nature, these governing documents require evermore amendments so that the states can govern somewhat effectively under their ponderous provisions. In adding amendment after amendment, the problem of new potential barriers to change is made worse yet. It follows from this reasoning that there is considerable potential for a state's constitution to become a barrier to state and local government sustainability. If this is a fair characterization, then it follows that state constitutions have grown into unmanageable documents that inhibit the flexibility required for state and local governments to adapt to major events such as global climate change. Considering the fact that there have been over 7,000 amendments to state constitutions, some of these amendments may well become potential barriers to effective adaptation.

In reviewing the history of state constitutional amendments and revisions with an objective frame of mind, however, it would seem that the many changes, which have been introduced by constitutional amendment, were very often a reasonable response to the politics and major issues of concern of the time. The constitutional amendments adopted in the late 19th and early 20th centuries by-and-large represented alterations that were in keeping with Progressive Era politics, where reformers moved toward the timely professionalization of state and local government and the introduction of new means to promote direct democracy through the initiative process. Later on, in the 20th century, the New Deal Era moved state constitutions towards social reform in the same way, often employing the means allowed by the constitutional amendment process. -40

Thus, one could argue the state constitutional amendment processes themselves neither promote nor bar progress toward community sustainability or resilience, but that history teaches that the political will of the states at any 
particular time has been incorporated effectively into state constitutions through the amendment process. In the past, American states have amended their constitution frequently in response to political and social movements of the time. As society's attention moves more fully to meeting the challenge of global climate change and sustainable development, it seems clear from our assessment of the states' track record of historical adaptation that state constitutions will be able to incorporate appropriate provisions into state constitutions. As demonstrated with California's Proposition 71, if one state can adopt an amendment that has a positive impact on the state, and a number of other states will likely follow suit.

It should be recalled that there are three basic methods of constitutional amendment available to the states; it is worthwhile to ask at this point which of the three major methods of constitutional change is better suited to promote sustainability? While the constitutional convention would be the most efficient method, allowing a thorough revision of the constitution, the potential of such a tool being used in this age of partisan politics and highly organized special interests is quite remote. In contrast, the legislative amendment method has potential in some states; however, the super-majority of both legislative houses' requirement may pose a difficult barrier in many states. Lastly, the popular initiative, which is still only available in 18 states, is the most likely method to be used to promote sustainability in American state and local government. A powerful tool for change, the popular initiative could be used by state-based grassroots groups to place a single amendment at a time in their constitution the difficulty being that sufficient voter signatures must be garnered, and the amendment would need to win the popular vote in statewide balloting. With the potential impacts of global climate change becoming more apparent - for example, rising sea levels, more frequent and more violent storms, earlier snowmelt, extended droughts, raging wildfires and 
fires in heavily forested areas - some states with the initiative process are likely to see ballot initiatives directed toward the promotion of sustainable development and local community resilience into their constitutional fabric. ${ }_{-}^{41}$ The non-initiative states will be witness to these developments in other states and are likely to take up their own versions of these initiatives through legislative action. It is a safe bet that American states will be at the forefront of "thinking globally and acting locally" to confront the challenges of sustainable development and that a likely goal of the advocates of sustainability will be achieving timely amendments to state constitutions. ${ }_{-} 2$

\section{G - The New "Constitutions" of Sustainable Governance}

While state constitutions are important vehicles for promoting the value and institutional shifts associated with sustainable governance, the formal constitution may not move quickly enough in response to changing needs or conditions. Traditional governance viewed many aspects of the constitution and institutional arrangements as steady and continuous. Sustainable governance requires that the constitution be viewed as a general governing structure; however, it is clear that the actual day-to-day process of governance operates as a form of organized chaos, responding to changing conditions, meeting ever-changing demands, and responding to rapid technological change and scientific discovery.

The new "constitutions" of sustainable governance have actually been around for quite a while, but they are playing 
an increasingly prominent role in sustainability. The intergovernmental agreement (IGA) and the memorandum of understanding (MOU) are two such important legal/ institutional tools available to promote sustainability in the coming years. Intergovernmental agreements are directly related to federalism and multi-state arrangements within the American federal system. Intergovernmentalism might involve national-state or national-local agreements or inter-state and inter-local agreements of various kinds. IGAs often recognize the inter-jurisdictional nature of many problems (e.g., the drug trade, human trafficking, rapid diffusion of communicable diseases, acid rain deposition, etc.), with sustainability being one very important current dilemma. In terms of sustainability, the basic question faced by any level of government is: "Can we maintain the existing conditions or achieve an even higher quality of life and provide basic services to future generations of citizens?" Achieving a positive outcome may involve governments working together in a manner in which all achieve positive results and no party loses. IGAs are an attempt to achieve this positive "win-win" outcome for a reasonable cost while retaining the benefits of responsiveness and the unique nature of each participant governing body.

Memoranda of Understanding (MOUs) are legal documents comparable to contracts that define the responsibilities and constraints faced by each governmental party engaged in a mutual effort to achieve a shared policy goal. MOUs define goals and responsibilities of each participating government, oftentimes focusing on particular agencies within these governments. In an era of rapid response to emerging troublesome problems of sustainability, the Service Legal Agreement (SLA) - a specific form of MOU - defines the nature of response by each participating government and each government agency to include agreedupon forms of intergovernmental and interagency planning and communication. 
The proliferation of IGAs, MOUs, and SLAs in recent years is in part an appropriate recognition of the need for sustainable governance networks which respond to change rapidly, effectively, and efficiently while maintaining the higher-order values of the formal constitutional arrangements of participating jurisdictions. This capacity to invent new forms of inter-agency relationships among the states and their local governments is very important, not only because coordinated action is facilitated, but because this process allows citizens to take an active part in their own state and local governments. Sound research instructs that there is a strong association between level of citizen engagement and scale of government; $\stackrel{43}{-}$ if communities were to pass all problems to the national government for resolution, they would likely risk an even greater disengagement of citizens than currently occurring in state and local governments.

\section{H - Conclusion}

State constitutions are a very important aspect of American state and local government because they set forth the supreme law of the state, only subservient to the U.S. Constitution where there is direct federal authority to act. Among other things, state constitutions establish procedures for policy-making, define the structure of state and local government, set the conditions for inter-state and multi-state compacts, set forth requirements for public office, specify state obligations to citizens, enshrine principles of governance, determine the responsibilities of local governments, establish voting rights and determine how elections are to be conducted, and specify processes for 
constitutional change. These are all important functions at any time, but they are of great importance in a time when the challenges of sustainability will confront the leaders of our state and local governments.

The most important function of state constitutions, however, is to establish the rule of law and enforce the principle of limited government. All fifty state constitutions provide protections for individual liberty and freedom of speech and association. Most state constitutions recognize a right to privacy. While these rights mostly reiterate protections provided in the U.S. Constitution, many state constitutions even extend right-based protections for their citizens that go beyond what is found in the national constitution as it is read by the U.S. Supreme Court. State constitutions may offer this same extension for the protection of citizens and their property in the area of sustainable development and local community resilience. Scholars who have studied the capacity for Americans to gain an understanding of difficult public policy issues and in time develop attitudes and policy preferences in line with needed change provide reason for optimism in this regard. ${ }_{-}^{44}$ There are early signs of change in the public's understanding of sustainability noted in this chapter, and it is likely that much more change will be handled by government at the state level as spelled-out in amendments of state constitutions.

\section{Terms}

Constitutional Democracy

General Purpose Government

Intergovernmental Agreement (IGA)

Jacksonian Democracy 
Judicial Federalism

Memorandum of Understanding

New Deal Era

Oregon System

Progressive Era

Republican Government

Reserved Powers

Supremacy Clause

Constitutional Convention

\section{Discussion Questions}

1. What are the primary purposes of state constitutions? How are they both similar to and different from the U.S. Constitution?

2. What are some of the guiding principles found in state governments? From your own point of view, what types of guiding principles belong and do not belong in state constitutions?

3. What are the various procedures available to change constitutions? What methods are available in your state to change the constitution? What is your assessment of the degree to which the states have established an historical track record of adaptability to change in their pattern of constitutional amendments?

4. How do you feel about the "Oregon System" in 
terms of state constitutional amendments? What are some of the positive and negative aspects of allowing citizens to directly amen state constitutions through general election ballot measures?

\section{Notes}

1. G.A. Tarr, Understanding State Constitutions (Princeton, NJ: Princeton University Press, 1998).

2. Ibid, p. 3.

3. F.D. Wormuth, The Origins of Modern Constitutionalism (New York: Harper and Brothers, 1949), p. 3.

4. see J.R. Stoner's classic study Common Law and Liberal Theory: Coke, Hobbes, and the Origins of American Constitutionalism (Lawrence, KS: University Press of Kansas, 1992).

5. R.L. Maddex, State Constitutions of the United States, 2nd ed. (Washington, DC: Congressional Quarterly, 2006).

6. Council of State Governments, ed., The Book of the States, 2006 (Lexington, KY: The Council of State Governments, 2006).

7. R.L. Maddex, 2006, op. cit. (see reference 5), p. xvi.

8. C.W. Hammons, "Was James Madison Wrong? Rethinking the American Preference for Short, Framework-Oriented Constitutions," American Political Science Review 93 (1999): 837-849, p. 840

9. Ibid, p. 840.

10. Ibid, p. 840.

11. A. Blaustein, "Contemporary Trends in Constitution 
Writing." In D. Elazar, ed., Constitutionalism: The Israeli and American Experiences (Baltimore, MD: University Press of America, 1990) and L.M. Friedman, "State Constitutions in Historical Perspective." In Annals of the American Academy of Political and Social Science 496 (1988): 33-42.

12. C.W. Hammons, 1999, op. cit. (see reference 8), p. 837.

13. Ibid, p. 846.

14. R.L. Maddex, 2006, op. cit. (see reference 5), p. xviii.

15. D.S. Lutz, "Toward a Theory of Constitutional Amendment," American Political Science Review 88 (1994): 355-370.

16. Oregon Blue Book, "Initiative, Referendum and Recall Introduction." URL: http://bluebook.state.or.us/state/ elections/elections09.htm

J.M. Swarthout and K.R. Gervais, "Oregon: Political Experiment Station." In F.H. Jonas, ed., Politics in the American West (Salt Lake City: University of Utah Press, 1969).

17. T.E. Cronin, Direct Democracy: The Politics of Initiative, Referendum, and Recall (Cambridge, MA: Harvard University Press, 1989).

18. J. Dinan, "State Constitutional Developments in 2005." In The Book of the States, 2006 (Lexington, KY: Council of State Governments, 2006).

19. J.C. May, "State Constitutions and Constitutional Revision, 1992-93." In The Book of the States, 1992-93 (Lexington: The Council of State Governments, 1994).

20. R.M. Alvarez and J. Brehm, Hard Choices, Easy Answers (Princeton, NJ: Princeton University Press, 2002).

P.J. Galie and C. Bopst, "Changing State Constitutions: Dual Constitutionalism and the Amending Process," Hofstra Law \& Policy Symposium, 27 (Hempstead, NY: Hofstra University, 1996).

21. G. Benjamin and T. Gais, "Constitutional Convention Phobia," Hofstra Law \& Policy Symposium, 53 (Hempstead, NY: Hofstra University, 1996). 
22. Utah State Law Library, "Research Guide: Utah Constitution." URL: www.utcourts.gov/lawlibrary/docs/ constitution_website.pdf

23. Oregon Blue Book 2007, "Constitution of Oregon: 2005 Version." URL: $\quad$ http://bluebook.state.or.us/state/ constitution/constitution15.htm

24. G.A. Tarr, 1998, op. cit. (see reference 1).

25. Ibid.

26. Ibid.

27. see D.J. Boorstin, The Genius of American Politics (Chicago, IL: University of Chicago Press, 1953).

28. R. Seidelman and E.J. Harpham, Disenchanted Realists: Political Science and the American Crisis, 1884-1984 (Albany, NY: State University of New York Press, 1985).

29. G. Benjamin and T. Gais, 1996, op. cit. (see reference 21).

30. G.A. Tarr, 1998, op. cit. (see reference 1).

31. P.J. Galie and C. Bopst, 1996, op. cit. (see reference 20).

32. L.H. Zeigler, "Interest Groups in the States." In V. Gray, H. Jacob and K. Vines, eds., Politics in the American States (Boston, MA: Little, Brown and Co., 1983).

33. C.T. Goodsell, The Case for Bureaucracy: A Public Administration Polemic, 4th ed. (Washington, DC: Congressional Quarterly Press, 2004).

34. D.S. Lutz, 1994, op. cit. (see reference 15).

35. J. Dinan, 2006, op. cit. (see reference 18).

36. J.C. May, "State Constitutional Developments." In The Book of the States, 2005 (Vol. 37) (Lexington, KY: The Council of State Governments, 2005).

37. E. Russo, "Follow the Money - The Politics of Embryonic Stem Cell Research," PLoS Biology 3 (2005): 1167-1171.

38. P.T. Hampton, "U.S. Stem Cell Research Lagging," Journal of the American Medical Association 295 (2006): 2233-2234.

C. Holden, 2005. U.S. States Offer Asia Stiff Competitions. Science 307 (5710), 662-663.

39. Ibid, p. 663. 
40. S. Kelman, Making Public Policy: A Hopeful View of American Government (New York: Basic Books, 1987).

41. S. Bowler, T. Donovan and C.J. Tolbert, eds., Citizens as Legislators: Direct Democracy in the United States (Columbus, OH: Ohio State University Press, 1998).

42. R.J. Burby and P.J. May, Making Governments Plan: State Experiments in Managing Land Use (Baltimore, MD: The Johns Hopkins Press, 1997).

43. R.A. Dahl and E.R. Tufte, Size and Democracy (Palo Alto, CA: Stanford University Press, 1973).

44. B.I. Page and R.Y. Shapiro, The Rational Public: Fifty Years of Trends in Americans' Policy Preferences (Chicago, IL: University of Chicago Press). 


\section{Chapter 6: Legislatures}

\section{A - Introduction}

A legislature is an officially elected assembly formed to make laws for a political unit such as a nation, a state or a local government. The genesis of legislatures traces back to the medieval period when "Althing" (a Nordic word for 'general assembly') was established in Iceland and a uniform code of laws was proclaimed. In more contemporary times, there are various types of legislative forms, including the two most common categories of legislatures - the presidential style systems featuring separation of powers and parliamentarystyle systems featuring integration of powers. ${ }_{-}^{1}$ As discussed in the previous chapter, in political systems reflecting a separation of powers philosophy of governance, a policy adoption vs. policy administration and implementation dichotomy exists separating the legislative branch and the executive branch; in line with this demarcation of responsibilities governmental powers are fairly clearly separated in law and in practice $;_{-}^{2}$ in contrast, in political systems reflecting an integration of powers philosophy of governance members of the executive branch are selected from and are held directly accountable to the legislative branch. ${ }_{-}^{3}$ In the U.S., state legislatures are presidential-style bodies which are primarily in charge of making laws of general-purpose and universal application for the respective states with governors being responsible for the "faithful execution" of state laws. At the local level BOTH generalpurpose governments and single-purpose governments are present. The former provides a wide range of services and serves a diversity of functions, while the latter carries out a 
specific function such as education, the provision of utilities, the irrigation of farmlands, or the provision of transportation services, for example. There are a variety of legislative structures used in local governments, including boards of county commissioners, city councils, school district boards, and a wide variety of more specialized elective boards and commissions that will be discussed in this chapter.

\section{Learning Objectives}

The topics covered in this chapter include:

- The functions of legislatures.

- Noteworthy Variation in the ways state legislatures operate.

- Legislatures in general-purpose local governments.

- Legislatures in single-purpose local government.

- The critical legislative role in promoting sustainability.

\section{B - State Legislatures}

All the U.S. states have a popularly elected legislative branch, and each state constitution specifies the essential features of the composition and method of organization of state legislative bodies. State legislatures are the primary lawmaking bodies of American government, and they are, 
generally speaking, quite similar in structure to the U.S. Congress. The legislature in all cases is a multi-member body of popularly elected representatives. In forty-nine states the legislature is divided into two houses, generally a Senate and a House of Representatives, just as is the U.S. Congress. Only Nebraska features a unicameral (one chamber) legislature. The "upper house" (Senate) is usually significantly smaller than the lower house, which in most states is called the "House of Representatives." Senators are most often elected for fouryear terms, but some states elect their Senators every two years. State representatives usually are elected for two-year terms. In many states, constitutional term limits control the number of terms - consecutive or otherwise - which a legislator is allowed to serve. Most states dictate that each legislative electoral district will elect only one representative and only one senator. However, eight states do allow multimember districts wherein voters elect more than one representative for the lower house of the state legislature.

Nearly all of the American states adopted the bicameral legislature in major part because they wished to allow landowners a major voice in government disproportionate to their number in the electorate. Senators were once elected by county or groups of counties as opposed to population, in a manner similar to the U. S. Senate's apportionment of two Senators per state, regardless of the size of its population. This apportionment of seats in the upper chamber allowed residents in rural and sparsely populated areas of a state to exercise significantly more influence than urban residents within American state legislatures. In 1962 (Baker v. Carr) and again in 1964 (Reynolds v. Sims), however, the United States Supreme Court agreed to hear cases wherein it was argued that the equal protection clause of the 14th Amendment to the U.S. Constitution required that the principle of "one person, one vote" should apply to both houses of American state legislatures. It was reasoned by lawyers arguing for a 
fundamental change in the organization of state legislatures that the U.S. Congress organized membership around a principle of representation by geography because it is a federal system in which the individual states pre-existed the establishment of the United States of American. In the case of the U.S. states, however, they are each unitary governments wherein all citizens, regardless of where they reside (city, suburb, or rural area) are entitled to equal representation.

The U.S. Supreme Court determined in these landmark cases that both chambers of American state legislatures must be based upon population alone. The initial result of these decisions was that state legislatures redrew their upper chamber legislative district lines to reflect population, causing many more legislators to be representing urban areas in upper chambers of American state governments. These legislative districts must be redistricted every ten years when the U.S. Census is taken to assure that they conform to the equal representation ["one person, one vote"] standard as closely as possible. While the manifest intent of redistricting is to ensure equal representation in government, the process of drawing legislative district lines is the responsibility of state legislatures and tends to become highly politicized and partisan in nature in those states which do not establish an independent, bipartisan body to carry out redistricting. In fact, in a number of states' district lines are commonly redrawn to maximize the strength of the majority party and weaken the minority party in a process known as gerrymandering. This process entails concentrating the minority party's voters in as few districts as possible and distributing the majority party's voters in such a way that they are likely to prevail in as many legislative districts as possible.

As the process of gerrymandering indicates, political parties play a very important role in state legislatures. The majority party typically organizes the election of the leader of the lower house (the House Speaker in most cases), and in 
most states, the leader of the upper house (typically the Senate Majority Leader) is put into office on the basis of a partisan vote. The party leadership in both chambers generally appoints legislators to their committee assignments, designates committee chairs in the case of the majority party, and typically controls floor activity fairly tightly. As a result of these decisions influenced greatly by the majority political party, a relatively small number of key legislators in control of a legislative house typically dominate the agenda and content of bills heard during a legislative session.

The powers of state legislatures universally include modifying existing laws and making new statutes, developing the state government's budget, ${ }_{-}^{4}$ confirming the executive appointments brought before the legislature,$_{-}^{5}$ impeaching governors and removing from office other members of the executive branch. ${ }_{-}^{6}$ All these powers and associated activities can be assigned into one of the three major functions performed by state legislators singularly and state legislatures collectively: representation, lawmaking, and balancing the power of the executive (or oversight).

\section{B.I - Representation:}

A major role of a state legislator is to represent the needs and concerns of the people residing in her and his legislative district. Since each legislator is responsible to a relatively small number of constituents coming from a specific geographical area, they are able to address concerns that are not as apparent to statewide officials such as the Governor or State Attorney General. This attention to localized needs can lead to intense debate over conflicting values when, for example, representatives of rural, conservative communities 
are forced to compromise with the interests represented by urban legislators representing liberal constituents.

Legislators also represent the interests of their constituents beyond the formal law-making process. Legislators are often enlisted to make a phone call or write a letter on behalf of a citizen who needs help getting a personal issue addressed or expedited by the state bureaucracy. Research conducted by political scientists has shown that such constituency service pays significant dividends at re-election time, with voters looking favorably on helpful legislators by either volunteering for campaign work or contributing money to re-election campaigns. Key components of sustainability as addressed in the literature include the development of civil society, active representation by elected officials, and the maintenance of continuous interaction between citizens and representatives. In this regard, how legislators interact with their constituents is an important part of the promotion of sustainability in those communities where efforts to promote sustainability require some level of state approval or financial support.

The process of representation works at two distinct levels. First, at an individual representative's level, there is a connection between the legislators and the districts from which they are elected. And secondly - as a unit - the legislature pursues policies that reflect the statewide interests and preferences of citizens.? The process of representation, from the perspective of political scientists, consists of four principal components: maintaining communications with constituents; demonstrating policy responsiveness by reflecting the needs of one's constituency in one's votes on bills and budgets; affecting the allocation of resources across elective districts; and providing individualized service to constituents. ${ }_{-}^{8}$

Another way to think about representation is in terms of the socio-demographic and gender composition of state and 
local legislative bodies. Many observers argue that legislative bodies should, to some significant extent, mirror the public they represent - in terms of race, ethnicity, gender and such - to adequately represent the public at large. In this regard, it should be noted, "in the past, political scientists have convincingly demonstrated that race and gender matter in political representation." ${ }^{\underline{9}}$ Research has consistently shown that in state legislatures "Black legislators sponsor a higher number of Black interest measures and female legislators sponsor a higher number of women's interest measures" when compared to white men._-

In general, "female state legislators are reported to be more liberal than men, even when controlling for party membership, and female state legislators are more concerned with feminist issues than their male counterparts.".11 Research has also found that black women legislators are similar to white women legislators in terms of their support for women's issues - such as affirmative action, comparable worth, public support for daycare, and many other issues. As with black male legislators, black women legislators tend to be strong supporters of minority target policies such as education, health care, and job creation-oriented economic development._ However, research has also found that women legislators are generally as likely as their male counterparts to achieve passage of the legislation they introduce, whereas black legislators are significantly less likely than their white counterparts to get legislation they introduce enacted into law. -

In terms of the actual representation of women and minorities in state and local legislatures, there has been a noteworthy increase in numbers over the last several decades. ${ }_{-}^{14}$ The Center for American Women and Politics, an organization that systematically tracks the number of women in elected office, reports the following in terms of women serving in state legislatures across the country (see Table 6.1):- 
In 1971, women comprised 4.5 percent of state legislators and by 2018 they make up 25.4 percent of legislatures. Since 1971, the number of women serving in state legislatures has more than quintupled.

For example, "Presently, there are 27 states and the District of Columbia that have African American mayors. The cities' populations range from less than 300 to over 2 million people.".16 Some of the explanations given for the lower levels of women and minorities in state and local legislative bodies include cultural, institutional and situational explanations. ${ }_{-}^{17}$ Cultural explanations would include state political culture, which would affect the attitudes toward women and minorities in politics held by citizens and elites. ${ }_{-}^{18}$ Some argue that states with more traditional political cultures deeply entrenched in history - e.g., the southern states - may well view politics as a man's world or the domain of white Americans in comparison to states with more progressive political cultures - e.g., the northeastern or western states (see Table 6.2). ${ }_{-}^{19}$ For women, this political culture aspect of their political environment can have three specific adverse consequences: ${ }_{-}^{20}$

First, women may not run for office because they do not believe it to be appropriate. Second, women may not be highly recruited to run for political office because party officials and other political elites are biased against female candidates. Or third, even women who are not socialized into passive gender roles and who do run despite unsupportive elites face unsympathetic voters at the polls...

A second explanation of low levels of women and minorities in state and local legislatures concerns the institutional arrangements determining electoral success. For example, states with high levels of incumbents re-elected to office would allow for fewer seats being open to competition. ${ }_{-}^{21}$ In addition, states with multi-member districts versus states 
with single-member districts tend to have racially, ethnically and gender-wise more diverse legislatures. ${ }_{-}^{22}$ It has been argued that voters are more willing to support women and minorities when there are multiple choices to make in an electoral setting. A third explanation for lower levels of women and minorities in state and local legislative bodies concerns situational factors such as financial resources, educational levels, and occupation, which all affect the ability to run for office and to establish important political networks to support successful campaigns. In addition, “...women tend to start much later in politics than men, are less likely to be recruited than men, and have more political opportunities closed to them than men."23 


\begin{tabular}{|c|c|}
\hline YEAR & \% OF TOTAL \\
\hline 1987 & $15.7 \%$ \\
\hline 1989 & $17.0 \%$ \\
\hline 1991 & $18.3 \%$ \\
\hline 1993 & $20.5 \%$ \\
\hline 1995 & $20.6 \%$ \\
\hline 1997 & $21.6 \%$ \\
\hline 1998 & $21.8 \%$ \\
\hline 1999 & $22.4 \%$ \\
\hline 2000 & $22.5 \%$ \\
\hline 2001 & $22.4 \%$ \\
\hline 2002 & $22.7 \%$ \\
\hline 2003 & $22.4 \%$ \\
\hline 2004 & $22.5 \%$ \\
\hline 2005 & $22.7 \%$ \\
\hline 2006 & $22.8 \%$ \\
\hline 2007 & $23.5 \%$ \\
\hline 2008 & $23.6 \%$ \\
\hline 2009 & $24.3 \%$ \\
\hline 2011 & $23.7 \%$ \\
\hline 2012 & $23.7 \%$ \\
\hline 2013 & $24.2 \%$ \\
\hline 2015 & $24.3 \%$ \\
\hline 2016 & $24.4 \%$ \\
\hline 2018 & $25.4 \%$ \\
\hline
\end{tabular}

Table 6.1 Women in State Legislatures 


\begin{tabular}{|c|c|c|}
\hline STATE: & & \% WOMEN \\
\hline Arizona & & $40.0 \%$ \\
\hline Vermont & & $40.0 \%$ \\
\hline Nevada & & $38.1 \%$ \\
\hline Colorado & & $38.0 \%$ \\
\hline Washington & & $37.4 \%$ \\
\hline Illinois & & $34.5 \%$ \\
\hline Maine & & $33.9 \%$ \\
\hline Maryland & & $33.5 \%$ \\
\hline Oregon & & $33.3 \%$ \\
\hline \multirow[t]{12}{*}{ Rhode Island } & & $31.9 \%$ \\
\hline & STATE: & \% WOMEN \\
\hline & Wyoming & $11.1 \%$ \\
\hline & Oklahoma & $13.4 \%$ \\
\hline & Louisiana & $12.9 \%$ \\
\hline & West Virginia & $13.0 \%$ \\
\hline & Mississippi & $14.2 \%$ \\
\hline & Alabama & $14.9 \%$ \\
\hline & South Carolina & $15.0 \%$ \\
\hline & Tennessee & $15.9 \%$ \\
\hline & Kentucky & $15.9 \%$ \\
\hline & North Dakota & $18.4 \%$ \\
\hline
\end{tabular}

Table 6.2 States with Highest and Lowest Percentage of Legislators $-2018$

Those that favor legislative diversity have proposed a variety of electoral mechanisms to increase the number of women and racial minorities serving in state and local legislative bodies. Some have suggested the broadened adoption of term limits because the current re-election rate 
of incumbents is very high, while others have suggested the creation of majority Black or Latino districts by carefully drawing election district lines to favor minority districts. ${ }_{-}^{24}$ However, this latter approach to the promotion of diversity in legislative bodies was struck down by the U.S. Supreme Court in Miller v. Johnson 515 U.S. 900 (1995) and Shaw v. Hunt 517 U.S. 899 (1996).

\section{B.II - Lawmaking:}

Policymaking is accomplished through the introduction and passage of bills that eventually become law. The process usually begins with the introduction of bills in either house of the legislature. While bills must be introduced by a legislator, they usually have been crafted by a governor, an attorney general, a public agency, or an interest group. Once a legislator chooses to introduce the legislation other representatives and senators can sign on as co-sponsors, increasing the chance that the bill will survive scrutiny in legislative committees. New bills are referred to policy committees in their chamber of origin. The committee chair decides whether or not to hold a hearing on the bill, and whether or not to hold a committee vote on it. Bills are frequently amended in committee before they are voted out. If the vote in committee is favorable, the bill is forwarded to a rules committee that makes decisions on which bills are placed on the calendar of the chamber to be heard. Bills can be amended once more on the floor, and if passed they are sent to the other chamber for its consideration. If the second chamber amends the bill and passes it, then members of both chambers go to a "conference committee" to determine if the differences between the two versions of the bill can be 
reconciled. If a compromise is achieved, the new bill is sent back to the floor of the Senate and House for a final vote. If the conference committee bill is approved in both houses of the legislature it is then sent to the governor where it will be signed into law, vetoed, or remain unsigned. If a bill is vetoed by the governor, it can return to the legislature for a possible veto override by a "supermajority" (usually twothirds vote) in both chambers. If a governor neither signs nor vetoes a bill, it will become law in two-thirds of the states; in the remaining third of the state's inaction by the governor is referred to as a "pocket veto" and the bill dies (see Figure 6.1). Another way for a bill to become law in some states is a legislative referral, an action by the legislature and the governor that places the legislation on the ballot for voters to decide approval or disapproval. 


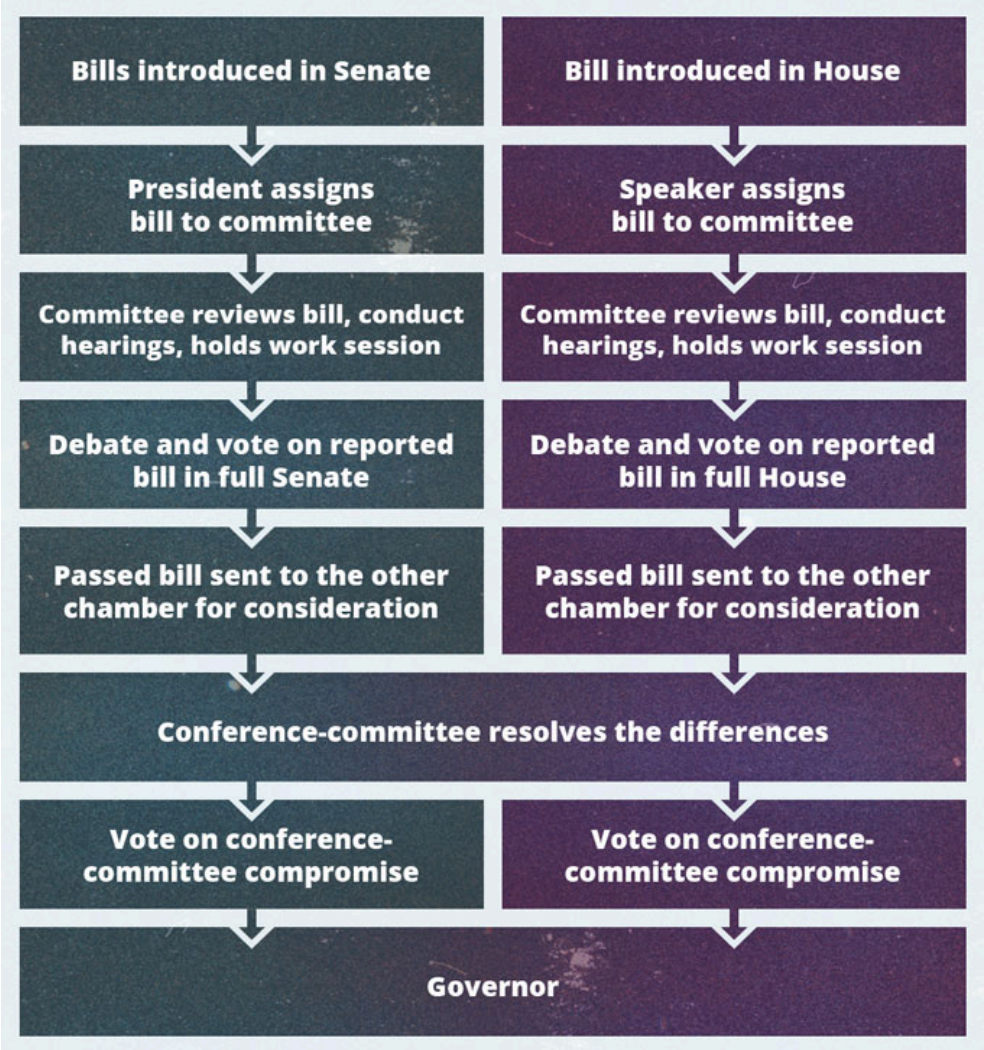

Figure 6.1 The Typical State Legislative Process

\section{B.III - Balancing the Power of the Executive:}

In a separation of powers governmental system, the three branches of government are expected to share power rather than allowing one branch to have disproportionate power over the others. This arrangement of governmental powers has been commonly known as the checks and balances system, a particular vision of governmental design enshrined in the U.S. Constitution by the Founding Fathers. The third principle 
role a legislature plays, therefore, is balancing the power of executive. This balancing role can be achieved by performing legislative oversight that involves the legislature's review and evaluation of selected activities of the executive branch and exercising the "power of the purse" - that is, carrying out the responsibility of developing the state budget. In American government, no funds can be spent by an executive agency unless an express allocation is made by a legislative enactment (the budget is set in a bill enacted into law just as any other statute). A main reason for state legislatures to conduct oversight is that "it has a duty to ensure existing programs are implemented and administered efficiently, effectively, and in a manner consistent with legislative intent."25 The job of exercising legislative oversight is carried out by a combination of standing committees, select committees, and task forces. ${ }^{26}$ In Ohio, for example, three such important oversight committees are the Joint Legislative Committee on Health Care Oversight, the Joint Legislative Committee on Medicaid Technology and Reform, and the Turnpike Legislative Review Committee composed of members of both chambers of the state legislature. ${ }_{-}^{27}$ Common forms of oversight activities include periodic review of administrative rules, the enactment of sunset provisions in legislation, the passage of legislation calling for studies into particular problems or existing programs, the engagement in active fiscal oversight and the provision of advice to executive agencies, and the granting of consent to gubernatorial appointments.

State legislatures assume the role of oversight in order to assure that laws are being implemented efficiently and effectively in the manner originally intended by the legislature. The legislature often evaluates the executive branch's policy and programs through the employment of policy analysts and auditors working for legislative committees. These analysts and auditors attempt to assess progress toward the objectives and goals of policies and 
agencies reflecting the original intent of the legislation. The use of legislative policy analyses and audits has been credited with increasing efficiency and effectiveness in state government, thereby saving taxpayers money and improving program performance.

Legislatures periodically review the rules and regulations employed by the executive branch in order to determine whether the intent of the law is being realized. This review process often accompanies budget hearings and ultimate budget approval for state agencies. If the legislature determines that an agency's rules and regulations are unsatisfactory, they can insist that the rules be modified or suspended; in some cases the legislature retains the right to discontinue support for a program if, in its judgment, the agency in question is not following legislative intent or is determined to have failed to meet the goals set for it. Some states have determined that the "legislative veto" (an action of constraint upon a public agency by a legislature after legislation has been placed into law) is an unlawful violation of the separation of powers. Even without explicitly revoking a rule or regulation by direct action of the legislature after a law has been duly enacted, the legislature can exert great influence over previously enacted statutes by reducing the agency's budgetary allotment in order to encourage more faithful compliance with legislative wishes.

Sunset laws are those pieces of legislation featuring a built-in expiration date for a statute. Legislation of this nature allows the legislature to review, implement changes in, or terminate a program simply by not renewing an existing law. While sunset laws ensure the bureaucracy will be subjected to periodic review, the process of review is often timeconsuming, can be quite costly, but only rarely results in the termination of a program. Bowman and Kearney state in this regard, "sunset reviews are said to increase agency compliance with legislative intent... [but] only 13 percent of the agencies 
reviewed are eventually terminated, thus making termination more of a threat than an objective reality."

The review and control of state (and federal "passthrough") funds is one of the most significant powers exercised by state legislatures. By holding the purse strings at both the state and federal level, the independence of the legislative branch ensures that the bureaucracy and executive branch agency leadership remains quite dependent upon legislative support. Thus, oversight is permitted and the executive branch is prevented from becoming unresponsive to lawmakers and their constituency. Furthermore, by reviewing and controlling federal funds given to the state through intergovernmental programs such as interstate transportation, environmental regulation, Medicaid, etc., legislators are aware of how that federal government transfer money is being spent by the executive branch. Importantly, citizens who wish to know how those federal funds are being spent in this state and localities can contact their legislator and request an accounting. This type of constituent service is an important part of legislative representation. In the area of the promotion of sustainability, your state legislator should be able to provide you with specific, timely information concerning what federal and state programs are in place to address sustainability concerns.

\section{C - Variation Among State Legislatures}

State legislatures vary across the country in terms of their official names, the length of time they stay in session, the number of legislative districts they use, their party affiliations, and the way it operates. For example, state legislatures in 
most states are called "Legislatures;" for example, the Alabama Legislature, the Oklahoma Legislature, the Nevada Legislature, and Montana State Legislature are common names. In some states, however, the state legislature is referred to as the "General Assembly," such as the Virginia General Assembly and the Pennsylvania General Assembly. In the states of Massachusetts and New Hampshire the term "General Court" is used to designate the state legislative branch. For bicameral state legislative bodies, the upper house is most typically called the "Senate," but the terms used for the lower house vary widely across the states (see Table 6.3). Historically, most of the original American colonies were governed by unicameral legislative systems until a gradual process of adoption of bicameralism started and picked up momentum. ${ }_{-}^{29}$ The bicameralism movement was based on respect for the British model of bicameralism of the House of Lords and the House of Commons. ${ }_{-}^{30}$ Today, as noted previously, virtually all (49) state legislatures in the U.S. are bicameral, and only Nebraska has maintained a unicameral legislature (see Table 6.4). 


\begin{tabular}{|c|c|c|c|}
\hline STATE & BOTH BODIES & $\begin{array}{l}\text { UPPER } \\
\text { HOUSE }\end{array}$ & LOWER HOUSE \\
\hline Alabama & Legislature & Senate & $\begin{array}{l}\text { House of } \\
\text { Representatives }\end{array}$ \\
\hline Alaska & Legislature & Senate & $\begin{array}{l}\text { House of } \\
\text { Representatives }\end{array}$ \\
\hline Arizona & Legislature & Senate & $\begin{array}{l}\text { House of } \\
\text { Representatives }\end{array}$ \\
\hline Arkansas & General Assembly & Senate & $\begin{array}{l}\text { House of } \\
\text { Representatives }\end{array}$ \\
\hline California & Legislature & Senate & Assembly \\
\hline Colorado & General Assembly & Senate & $\begin{array}{l}\text { House of } \\
\text { Representatives }\end{array}$ \\
\hline Connecticut & General Assembly & Senate & $\begin{array}{l}\text { House of } \\
\text { Representatives }\end{array}$ \\
\hline Delaware & General Assembly & Senate & $\begin{array}{l}\text { House of } \\
\text { Representatives }\end{array}$ \\
\hline Florida & Legislature & Senate & $\begin{array}{l}\text { House of } \\
\text { Representatives }\end{array}$ \\
\hline Georgia & General Assembly & Senate & $\begin{array}{l}\text { House of } \\
\text { Representatives }\end{array}$ \\
\hline Hawaii & Legislature & Senate & $\begin{array}{l}\text { House of } \\
\text { Representatives }\end{array}$ \\
\hline Idaho & Legislature & Senate & $\begin{array}{l}\text { House of } \\
\text { Representatives }\end{array}$ \\
\hline Illinois & General Assembly & Senate & $\begin{array}{l}\text { House of } \\
\text { Representatives }\end{array}$ \\
\hline Indiana & General Assembly & Senate & $\begin{array}{l}\text { House of } \\
\text { Representatives }\end{array}$ \\
\hline Iowa & General Assembly & Senate & $\begin{array}{l}\text { House of } \\
\text { Representatives }\end{array}$ \\
\hline Kansas & Legislature & Senate & $\begin{array}{l}\text { House of } \\
\text { Representatives }\end{array}$ \\
\hline Kentucky & General Assembly & Senate & $\begin{array}{l}\text { House of } \\
\text { Representatives }\end{array}$ \\
\hline Louisiana & Legislature & Senate & $\begin{array}{l}\text { House of } \\
\text { Representatives }\end{array}$ \\
\hline Maine & Legislature & Senate & $\begin{array}{l}\text { House of } \\
\text { Representatives }\end{array}$ \\
\hline
\end{tabular}




\begin{tabular}{|c|c|c|c|}
\hline Maryland & General Assembly & Senate & House of Delegates \\
\hline Massachusetts & General Court & Senate & $\begin{array}{l}\text { House of } \\
\text { Representatives }\end{array}$ \\
\hline Michigan & Legislature & Senate & $\begin{array}{l}\text { House of } \\
\text { Representatives }\end{array}$ \\
\hline Minnesota & Legislature & Senate & $\begin{array}{l}\text { House of } \\
\text { Representatives }\end{array}$ \\
\hline Mississippi & Legislature & Senate & $\begin{array}{l}\text { House of } \\
\text { Representatives }\end{array}$ \\
\hline Missouri & General Assembly & Senate & $\begin{array}{l}\text { House of } \\
\text { Representatives }\end{array}$ \\
\hline Montana & Legislature & Senate & $\begin{array}{l}\text { House of } \\
\text { Representatives }\end{array}$ \\
\hline Nebraska & Legislature & - & - \\
\hline Nevada & Legislature & Senate & Assembly \\
\hline $\begin{array}{l}\text { New } \\
\text { Hampshire }\end{array}$ & General Court & Senate & $\begin{array}{l}\text { House of } \\
\text { Representatives }\end{array}$ \\
\hline New Jersey & Legislature & Senate & General Assembly \\
\hline New Mexico & Legislature & Senate & $\begin{array}{l}\text { House of } \\
\text { Representatives }\end{array}$ \\
\hline New York & Legislature & Senate & Assembly \\
\hline North Carolina & General Assembly & Senate & $\begin{array}{l}\text { House of } \\
\text { Representatives }\end{array}$ \\
\hline North Dakota & $\begin{array}{l}\text { Legislative } \\
\text { Assembly }\end{array}$ & Senate & $\begin{array}{l}\text { House of } \\
\text { Representatives }\end{array}$ \\
\hline Ohio & General Assembly & Senate & $\begin{array}{l}\text { House of } \\
\text { Representatives }\end{array}$ \\
\hline Oklahoma & Legislature & Senate & $\begin{array}{l}\text { House of } \\
\text { Representatives }\end{array}$ \\
\hline Oregon & $\begin{array}{l}\text { Legislative } \\
\text { Assembly }\end{array}$ & Senate & $\begin{array}{l}\text { House of } \\
\text { Representatives }\end{array}$ \\
\hline Pennsylvania & General Assembly & Senate & $\begin{array}{l}\text { House of } \\
\text { Representatives }\end{array}$ \\
\hline Rhode Island & General Assembly & Senate & $\begin{array}{l}\text { House of } \\
\text { Representatives }\end{array}$ \\
\hline South Carolina & General Assembly & Senate & $\begin{array}{l}\text { House of } \\
\text { Representatives }\end{array}$ \\
\hline
\end{tabular}




\begin{tabular}{|c|c|c|c|}
\hline South Dakota & Legislature & Senate & $\begin{array}{l}\text { House of } \\
\text { Representatives }\end{array}$ \\
\hline Tennessee & General Assembly & Senate & $\begin{array}{l}\text { House of } \\
\text { Representatives }\end{array}$ \\
\hline Texas & Legislature & Senate & $\begin{array}{l}\text { House of } \\
\text { Representatives }\end{array}$ \\
\hline Utah & Legislature & Senate & $\begin{array}{l}\text { House of } \\
\text { Representatives }\end{array}$ \\
\hline Vermont & General Assembly & Senate & $\begin{array}{l}\text { House of } \\
\text { Representatives }\end{array}$ \\
\hline Virginia & General Assembly & Senate & House of Delegates \\
\hline Washington & Legislature & Senate & $\begin{array}{l}\text { House of } \\
\text { Representatives }\end{array}$ \\
\hline West Virginia & Legislature & Senate & House of Delegates \\
\hline Wisconsin & Legislature & Senate & Assembly \\
\hline Wyoming & Legislature & Senate & $\begin{array}{l}\text { House of } \\
\text { Representatives }\end{array}$ \\
\hline
\end{tabular}

Table 6.3 State Legislative Houses 


\section{INDICATORS}

Representation, responsiveness to the majority, responsiveness to diverse and minority interests, responsiveness to powerful interests

\section{UNICAMERAL LEGISLATURE}

A citizen has one representative, favors rule by the majority, deeper understanding of all various interests, 'almost heaven' for special lobbyists

Not necessarily volatile

More

Authority of a legislator is not shared

Concentrates power in one house

Promotes quality by deliberate, careful decision-making

Maybe more efficient in

Efficiency and Economy

Quality of

Decision-Making conducting its business and less costly to operate
BICAMERAL LEGISLATURE

A citizen has two respective representatives, bicameral deliberation, gives voice to disparate points of views, hard for lobbyists to affect legislative activities

Maybe more stable

Less

Authority of a legislator is shared

Concentrates power in a few members

Promotes quality by slowing decision making, by having a second thought, and by requiring approval by two chambers

May require more cost, but also generate more benefits

Table 6.4 Unicameral Legislature and Bicameral Legislature Another difference between state legislatures concerns time status - some states have full-time legislatures meeting frequently on an annual basis, while other states have parttime legislatures that meet biannually and infrequently. Many rural states tend to have a part-time legislature, while the states with larger populations are likely to have full-time legislatures. Texas is an exception in this regard, with the 
second-largest population and a part-time legislature. ${ }_{-}^{31}$ The National Council of State Legislatures has categorized the 50 state legislatures into three basic groups: full-time legislatures, hybrid legislatures, and part-time legislatures. Full-time legislatures "...require the most time of legislators, usually 80 percent or more of a full-time job."32 These legislatures typically feature large staffs and their members are usually paid salaries sufficient to make a decent living. Full-time legislatures are typically found in the states with highly urbanized populations (see Tables 6.5 and 6.6). 


\begin{tabular}{|c|c|c|}
\hline FULL-TIME & HYBRID & PART-TIME \\
\hline California & Alabama & Georgia \\
\hline Florida & Alaska & Idaho \\
\hline Illinois & Arizona & Indiana \\
\hline Massachusetts & Arkansas & Kansas \\
\hline New Jersey & Colorado & Maine \\
\hline Michigan & Connecticut & Mississippi \\
\hline New York & Delaware & Montana \\
\hline Ohio & Hawaii & Nevada \\
\hline Pennsylvania & Iowa & New Hampshire \\
\hline \multirow[t]{14}{*}{ Wisconsin } & Kentucky & New Mexico \\
\hline & Lousiana & North Dakota \\
\hline & Maryland & Rhode Island \\
\hline & Minnesota & South Dakota \\
\hline & Missouri & Utah \\
\hline & Nebraska & Vermont \\
\hline & North Carolina & West Virginia \\
\hline & Oklahoma & Wyoming \\
\hline & Oregon & \\
\hline & South Carolina & \\
\hline & Tennessee & \\
\hline & Texas & \\
\hline & Virginia & \\
\hline & Washington & \\
\hline
\end{tabular}

Table 6.5 State Legislature Types 


\begin{tabular}{llll}
\hline $\begin{array}{lll}\text { LEGISLATURE } \\
\text { TYPE: }\end{array}$ & $\begin{array}{l}\text { AVERAGE TIME SPENT } \\
\text { ON JOB: }\end{array}$ & $\begin{array}{l}\text { AVERAGE } \\
\text { COMPENSATION: }\end{array}$ & $\begin{array}{l}\text { AVERAGE } \\
\text { NUMBER } \\
\text { OF } \\
\text { STAFF: }\end{array}$ \\
Full-type & $84 \%$ & $\$ 82,358$ & 1,250 \\
Hybrid & $74 \%$ & $\$ 41,110$ & 469 \\
Part-time & $57 \%$ & $\$ 18,449$ & 160 \\
\hline
\end{tabular}

Table 6.6 Legislative Job Time, Salary and Staff Size-2015

Legislators elected to hybrid legislatures “...typically say that they spend more than two-thirds of a full-time job being legislators" and their salaries are noticeably higher than parttime legislatures but somewhat lower than those of members of full-time legislatures. ${ }^{33}$ Salaries are typically not sufficient to make a living on legislative pay alone, so additional outside employment is common among these state lawmakers. Hybrid legislatures tend to have intermediate-sized staffs, and they are typically found in states with moderate-sized populations.

Lawmakers in part-time legislatures generally spend “...the equivalent of half of a full-time job doing legislative work. The compensation they receive for this work is quite low and requires them to have other sources of income in order to make a living., ${ }_{-}$- Part-time legislatures are often called "citizen legislatures" and are most often found in rural states with relatively small populations. The legislative staff available to lawmakers in these states are typically few in number.

State legislatures are also diverse in terms of their size and their party composition. Legislators prefer policies that favor the preferences of voters in individual districts, and thus the size of a district matters when considering the implications of certain policies. Table 6.7 shows the number of seats in state upper and lower houses. While some economists have argued that larger legislatures are less efficient and prone to conflict because "...cooperation cannot be sustained in large 
legislatures," there has been little empirical research on this topic. ${ }_{-}^{35}$

In terms of partisan alignment, in 2016 Republicans gained a sizable majority of all legislative seats and won their biggest legislative victory in more than a decade. In 2016, Republican majorities took control of both houses in 30 state legislatures and Democratic majorities control both houses in 10 states. In the other 10 states, the two parties split control of the state legislature, with one party having supremacy in one house and the other party having control of the other chamber (see Table 6.8). ${ }^{36}$ 


\begin{tabular}{|c|c|c|}
\hline STATE & SEATS IN SENATES & $\begin{array}{l}\text { SEATS IN } \\
\text { HOUSES }\end{array}$ \\
\hline Alabama & 35 & 105 \\
\hline Alaska & 20 & 40 \\
\hline Arizona & 30 & 60 \\
\hline Arkansas & 35 & 100 \\
\hline California & 40 & 80 \\
\hline Colorado & 35 & 65 \\
\hline Connecticut & 36 & 151 \\
\hline Delaware & 21 & 41 \\
\hline Florida & 40 & 120 \\
\hline Georgia & 56 & 180 \\
\hline Hawaii & 25 & 51 \\
\hline Idaho & 35 & 70 \\
\hline Illinois & 59 & 118 \\
\hline Indiana & 50 & 100 \\
\hline Iowa & 50 & 100 \\
\hline Kansas & 40 & 125 \\
\hline Kentucky & 38 & 100 \\
\hline Louisiana & 39 & 105 \\
\hline Maine & 35 & 151 \\
\hline Maryland & 47 & 141 \\
\hline Massachusetts & 40 & 160 \\
\hline Michigan & 38 & 110 \\
\hline Minnesota & 67 & 134 \\
\hline Mississippi & 52 & 122 \\
\hline Missouri & 34 & 163 \\
\hline Montana & 50 & 100 \\
\hline Nebraska & 49 & Unicameral \\
\hline Nevada & 21 & 42 \\
\hline
\end{tabular}

256 | State \& Local Government \& Politics 


\begin{tabular}{|c|c|c|}
\hline New Hampshire & 24 & 400 \\
\hline New Jersey & 40 & 80 \\
\hline New Mexico & 42 & 70 \\
\hline New York & 62 & 150 \\
\hline North Carolina & 50 & 120 \\
\hline North Dakota & 47 & 94 \\
\hline Ohio & 33 & 99 \\
\hline Oklahoma & 48 & 101 \\
\hline Oregon & 30 & 60 \\
\hline Pennsylvania & 50 & 203 \\
\hline Rhode Island & 38 & 75 \\
\hline South Carolina & 46 & 124 \\
\hline South Dakota & 35 & 70 \\
\hline Tennessee & 33 & 99 \\
\hline Texas & 31 & 150 \\
\hline Utah & 29 & 75 \\
\hline Vermont & 30 & 150 \\
\hline Virginia & 40 & 100 \\
\hline Washington & 49 & 98 \\
\hline West Virginia & 34 & 100 \\
\hline Wisconsin & 33 & 99 \\
\hline Wyoming & 30 & 60 \\
\hline
\end{tabular}

Table 6.7 Seats in Senates and Houses 


\begin{tabular}{|c|c|c|c|}
\hline STATE & $\begin{array}{l}\text { DEMOCRATS } \\
\text { Senate Seats }\end{array}$ & $\begin{array}{l}\text { REPUBLICAN } \\
\text { Senate Seats }\end{array}$ & $\begin{array}{l}\text { INDEPENDENT } \\
\text { Senate Seats }\end{array}$ \\
\hline Alabama & 8 & 26 & 1 \\
\hline Alaska & 6 & 14 & - \\
\hline Arizona & 12 & 18 & - \\
\hline Arkansas & 11 & 24 & - \\
\hline California & 26 & 14 & - \\
\hline Colorado & 17 & 18 & - \\
\hline Connecticut & 21 & 15 & - \\
\hline Delaware & 12 & 9 & - \\
\hline Florida & 14 & 26 & - \\
\hline Georgia & 17 & 39 & - \\
\hline Hawaii & 24 & 1 & - \\
\hline Idaho & 7 & 28 & - \\
\hline Illinois & 39 & 20 & - \\
\hline Indiana & 10 & 40 & - \\
\hline Iowa & 26 & 24 & - \\
\hline Kansas & 8 & 32 & - \\
\hline Kentucky & 11 & 27 & 1 \\
\hline Lousiana & 14 & 25 & - \\
\hline Maine & 15 & 20 & - \\
\hline Maryland & 32 & 14 & - \\
\hline Massachusetts & 34 & 5 & - \\
\hline Michigan & 11 & 27 & - \\
\hline Minnesota & 39 & 28 & - \\
\hline Mississippi & 20 & 32 & - \\
\hline Missouri & 8 & 24 & - \\
\hline Montana & 21 & 29 & - \\
\hline Nebraska & $\begin{array}{l}\text { Nonpartisan } \\
\text { Election }\end{array}$ & $\begin{array}{l}\text { Nonpartisan } \\
\text { Election }\end{array}$ & $\begin{array}{l}\text { Nonpartisan } \\
\text { Election }\end{array}$ \\
\hline Nevada & 10 & 11 & - \\
\hline
\end{tabular}

258 | State \& Local Government \& Politics 


\begin{tabular}{|c|c|c|c|}
\hline $\begin{array}{l}\text { New } \\
\text { Hampshire }\end{array}$ & 14 & 10 & - \\
\hline New Jersey & 24 & 16 & - \\
\hline New Mexico & 25 & 17 & - \\
\hline New York & 31 & 32 & - \\
\hline $\begin{array}{l}\text { North } \\
\text { Carolina }\end{array}$ & 16 & 34 & - \\
\hline North Dakota & 15 & 32 & - \\
\hline Ohio & 10 & 23 & - \\
\hline Oklahoma & 8 & 39 & - \\
\hline Oregon & 18 & 12 & 2 \\
\hline Pennsylvania & 19 & 31 & - \\
\hline Rhode Island & 32 & 4 & 1 \\
\hline $\begin{array}{l}\text { South } \\
\text { Carolina }\end{array}$ & 17 & 28 & - \\
\hline South Dakota & 8 & 27 & - \\
\hline Tennessee & 5 & 28 & - \\
\hline Texas & 11 & 20 & - \\
\hline Utah & 5 & 24 & - \\
\hline Vermont & 19 & 9 & 2 \\
\hline Virginia & 19 & 21 & - \\
\hline Washington & 24 & 25 & - \\
\hline West Virginia & 16 & 18 & - \\
\hline Wisconsin & 14 & 19 & - \\
\hline Wyoming & 4 & 26 & - \\
\hline
\end{tabular}




\begin{tabular}{|c|c|c|c|}
\hline STATE & $\begin{array}{l}\text { DEMOCRATS } \\
\text { House/Assembly } \\
\text { Seats }\end{array}$ & $\begin{array}{l}\text { REPUBLICANS } \\
\text { House/Assembly } \\
\text { Seats }\end{array}$ & $\begin{array}{l}\text { INDEPENDENT } \\
\text { House/ } \\
\text { Assembly Seats }\end{array}$ \\
\hline Alabama & 33 & 70 & - \\
\hline Alaska & 16 & 23 & 1 \\
\hline Arizona & 24 & 36 & - \\
\hline Arkansas & 35 & 64 & 1 \\
\hline California & 51 & 32 & - \\
\hline Colorado & 34 & 31 & - \\
\hline Connecticut & 86 & 64 & - \\
\hline Delaware & 25 & 16 & - \\
\hline Florida & 39 & 81 & - \\
\hline Georgia & 61 & 117 & - \\
\hline Hawaii & 44 & 7 & - \\
\hline Idaho & 14 & 56 & - \\
\hline Illinois & 71 & 47 & - \\
\hline Indiana & 29 & 71 & - \\
\hline Iowa & 43 & 57 & - \\
\hline Kansas & 28 & 97 & - \\
\hline Kentucky & 50 & 46 & - \\
\hline Lousiana & 42 & 61 & 2 \\
\hline Maine & 78 & 69 & 4 \\
\hline Maryland & 91 & 50 & - \\
\hline Massachusetts & 123 & 34 & - \\
\hline Michigan & 46 & 61 & - \\
\hline Minnesota & 61 & 72 & - \\
\hline Mississippi & 47 & 74 & - \\
\hline Missouri & 45 & 117 & - \\
\hline Montana & 41 & 59 & - \\
\hline Nebraska & Unicameral & Unicameral & Unicameral \\
\hline Nevada & 17 & 25 & - \\
\hline
\end{tabular}




\begin{tabular}{|c|c|c|c|}
\hline $\begin{array}{l}\text { New } \\
\text { Hampshire }\end{array}$ & 160 & 239 & 1 \\
\hline New Jersey & 52 & 38 & - \\
\hline New Mexico & 33 & 37 & - \\
\hline New York & 104 & 43 & - \\
\hline $\begin{array}{l}\text { North } \\
\text { Carolina }\end{array}$ & 45 & 74 & 1 \\
\hline North Dakota & 23 & 71 & - \\
\hline Ohio & 34 & 65 & - \\
\hline Oklahoma & 30 & 71 & - \\
\hline Oregon & 35 & 25 & - \\
\hline Pennsylvania & 84 & 119 & - \\
\hline Rhode Island & 63 & 11 & 1 \\
\hline $\begin{array}{l}\text { South } \\
\text { Carolina }\end{array}$ & 46 & 78 & - \\
\hline South Dakota & 12 & 58 & - \\
\hline Tennessee & 26 & 73 & - \\
\hline Texas & 51 & 98 & - \\
\hline Utah & 12 & 63 & - \\
\hline Vermont & 85 & 53 & 12 \\
\hline Virginia & 34 & 66 & - \\
\hline Washington & 50 & 48 & - \\
\hline West Virginia & 36 & 64 & - \\
\hline Wisconsin & 36 & 63 & - \\
\hline Wyoming & 9 & 51 & - \\
\hline
\end{tabular}

Table 6.8 Party Affiliation in Legislatures Across the States - 2016

The number of bills introduced into legislatures and enacted into law also varies greatly across the American states. For example, 14,823 bills were introduced and 589 bills were enacted into law in New York in 2015. In stark contrast, there were only 391 bills introduced and 204 bills enacted into 
law in Wyoming in the same year. Comparisons are made with the bills introduced and enacted in 2015 regular sessions in Table 6.9. 


\begin{tabular}{|c|c|c|}
\hline STATE & BILLS INTRODUCTIONS & BILLS ENACTMENTS \\
\hline Alabama & 1,210 & 357 \\
\hline Alaska & 575 & 48 \\
\hline Arizona & 1,163 & 324 \\
\hline Arkansas & 2,062 & 1,289 \\
\hline California & 2,370 & 807 \\
\hline Colorado & 682 & 364 \\
\hline Connecticut & 3,202 & 261 \\
\hline Delaware & 370 & 194 \\
\hline Florida & 1,574 & 227 \\
\hline Georgia & 955 & 312 \\
\hline Hawaii & 2,894 & 190 \\
\hline Idaho & 523 & 382 \\
\hline Illinois & 6,534 & 483 \\
\hline Indiana & 1,237 & 258 \\
\hline Iowa & 1,851 & 143 \\
\hline Kansas & 746 & 105 \\
\hline Kentucky & 752 & 117 \\
\hline Louisiana & 1,106 & 469 \\
\hline Maine & 1,455 & 442 \\
\hline Maryland & 2,234 & 495 \\
\hline Massachusetts & 6,988 & 704 \\
\hline Michigan & 1,890 & 269 \\
\hline Minnesota & 4,605 & 80 \\
\hline Mississippi & 2,620 & 347 \\
\hline Missouri & 1,888 & 131 \\
\hline Montana & 1,187 & 457 \\
\hline Nebraska & 664 & 247 \\
\hline Nevada & 1,013 & 556 \\
\hline New Hampshire & 902 & 276 \\
\hline
\end{tabular}




\begin{tabular}{|c|c|c|}
\hline New Jersey & 9,074 & 381 \\
\hline New Mexico & 1,281 & 158 \\
\hline New York & 14,823 & 589 \\
\hline North Carolina & 1,634 & 300 \\
\hline North Dakota & 854 & 484 \\
\hline Ohio & 678 & 45 \\
\hline Oklahoma & 2,112 & 398 \\
\hline Oregon & 2,641 & 848 \\
\hline Pennsylvania & 2,867 & 39 \\
\hline Rhode Island & 2,399 & 423 \\
\hline South Carolina & N.A. & 138 \\
\hline South Dakota & 427 & 258 \\
\hline Tennessee & N.A. & 1,007 \\
\hline Texas & 6,276 & 1,323 \\
\hline Utah & 1,520 & 477 \\
\hline Vermont & 666 & 64 \\
\hline Virginia & 1,919 & 774 \\
\hline Washington & 2,365 & 297 \\
\hline West Virginia & 1,607 & 262 \\
\hline Wisconsin & 1,830 & 356 \\
\hline Wyoming & 391 & 204 \\
\hline
\end{tabular}

Table 6.9 Bills Introductions and Enactments in 2015 Regular Sessions 


\section{D - Legislatures in General-Purpose Local Government}

General-purpose local governments, which include county governments, municipal governments, and town and township governments, provide a wide range of services that affect the day-to-day lives of citizens. Services such as police protection, road, street and bridge infrastructure, parks and recreation, and land use (zoning) are typical duties of generalpurpose governments in the United States. These governments feature both an executive and legislative function, and the executive function is discussed elsewhere. This section focuses on the legislative role of general-purpose local governments whose legislative bodies are boards of county commissions, city councils, and town boards of aldermen or selectmen.

\section{D.I - County Commissions:}

Counties function primarily as the administrative appendages of a state, and thus they implement many state laws and policies (such as carrying out elections) at the local level. The central legislative body in a county government is commonly a board of "commissioners" or "supervisors." Typically, a county commission meets in regular session monthly or bimonthly, and its legislative responsibilities encompass the enactment of county ordinances, the development, and approval of the county budget, and, in some states, the setting of certain tax rates. -37 


\section{D.II - City Councils:}

Municipal government in America originates from the English parish and borough system. The English parish was involved in both church service and road maintenance, while the English borough engaged in commercial and governmental affairs. These traditional aspects of civic society in England were gradually merged into a single entity and developed into the concept of municipality in the United States. ${ }_{-}^{38}$ In contrast to a county, which is an administrative appendage of a state, a city is considered a municipal "corporation" that can produce and implement its own local laws and public policy. For example, the City of New York creates its own sales tax, apart from the New York State sales tax created by the state government. ${ }_{-}^{39}$ The executive branch of city governments is generally organized into one of three basic forms: a mayorcouncil form, a city commission form, and a council-manager form. These executive structures are discussed in detail elsewhere. However the executive authority of the municipality might be organized, the legislative body provided for in each of these three basic forms is typically called a city council, and that legislative body exercises the power to make public policy.

Traditionally, members of most city councils were elected through at-large elections, a practice that often resulted in their becoming somewhat unresponsiveness to some groups in their jurisdiction. In recent decades city councils have tended to emphasize district elections, and as a consequence city councils have become considerably more diverse in terms of gender, race, and ethnicity than they were in the past. Today city legislative bodies are less white and less male and less business-dominated than they were in the past and feature many more African Americans, Hispanics, and women. 


\section{D.III - Town Boards:}

Today, official town and township governments continue to operate in 20 states in three major regions (see Table 6.10).. In terms of legislative process, many of these towns have a tradition of direct democracy through a "town meeting" wherein residents elect town officials, enact ordinances, and adopt a budget. Typically, all available voters are invited to provide input, offer amendments, and vote on township business. These types of local government legislatures are often found in smaller jurisdictions.

\begin{tabular}{ll}
\hline REGIONS & STATES \\
New England & $\begin{array}{l}\text { Maine, Vermont, New Hampshire, Massachusetts, } \\
\text { Connecticut, and Rhode Island }\end{array}$ \\
Mid-Atlantic & New York, New Jersey, and Pennsylvania \\
Mid-West & $\begin{array}{l}\text { Michigan, Ohio, Indiana, Illinois, Wisconsin, Minnesota, } \\
\text { North Dakota, South Dakota, Kansas, Nebraska, and } \\
\text { Missouri }\end{array}$ \\
\hline
\end{tabular}

Table 6.10 Regions and States with Official Towns and Townships

\section{D.IV - The Adapted City:}

Research by Frederickson and Johnson has found that while almost all U.S. cities were initially established as either a council-manager or mayor-council form of government, they typically "adapt" to incorporate the best features of both systems. They found that over-time, cities with councilmanager systems tend to adopt features of mayor-council 
systems "...to increase their political responsiveness," and that cities with mayor-council systems tend to adopt features of council-manager systems "...to improve their management and productivity capabilities. ${ }_{-}{ }_{1}$ Frederickson and Johnson argue that these developments have led to a third form of municipal governance they call the "adapted city." As emphasized in the introductory chapter regarding adaptation to change, this is a characteristic of institutional sustainability - the ability of cities to reform their governmental structures to promote economic and administrative efficiency, and to increase political responsiveness and civil society.

\section{E - Legislatures in Single-Purpose Local Government}

As their name implies, typical single-purpose local governments only have one principal function. These local government entities usually provide services that generalpurpose local governments are either unwilling to perform

or are incapable of performing. ${ }^{42}$ Special district boards and commissions and school district boards constitute the legislative bodies in single-purpose local governments. 


\section{E.I - Special District Boards:}

A special district usually has a population of residents occupying a specific geographic area, features a legal governing authority, maintains a legal identity separate from any other governmental authority, possesses the power to assess a tax for the purpose of supplying certain public services, and exercises a considerable extent of autonomy. ${ }_{-}^{43}$ Special districts have been created for a variety of purposes; for instance, a watershed district aims at promoting the beneficial use of water and a rural hospital district works to maintain health care services to a sparsely populated area. ${ }_{-}^{44}$ In many areas of the country, a sanitary district strives to improve sewerage services, ${ }_{-}-$and a rural fire protection district focuses on providing fire protection through a combination of professional and volunteer firefighters. ${ }_{-} 6$ While the vast majority of the special districts in the U.S. perform a single function, a small proportion of them provides two or more services. Local government units known as county service areas in California, for example, provide police protection, library facilities, and television translator services in some areas of the state.

<<Photo 6-4>>

The category of special district governments includes both independent districts and dependent districts. For independent districts, the board members are generally elected by the public, but in some cases, members are appointed by public officials of the state, counties, municipalities, and town/townships that have joined to form special districts. ${ }_{-} 7$ Dependent districts are governed by other existing legislatures such as a city council or a county board. For instance, the County Service Areas noted above are dependent districts that are governed by their county boards of supervisors. $\stackrel{48}{-}$ The Oceanside Small Craft Harbor District 
in California is a subsidiary organ of the City of Oceanside, and the members of the Oceanside City Council also serve on the District's board. ${ }_{-}^{49}$ To sum up, special districts are independent if the members of boards are independently elected or appointed for fixed term of office; special districts are dependent if they depend on another local government to govern them. ${ }^{50}$ However, they are governed, in their financial and administrative aspects special districts are all considered fiscally 'independent' because they exist as separate legal entities and exercise a high degree of fiscal and administrative independence from the general-purpose governments around them. ${ }^{51}$

\section{E.II - School District Boards:}

As a type of single-purpose local government, a school district serves primarily to operate public primary and secondary schools or to contract for public school services. Its legislative body is typically called a "school board" "board of trustees,,-53 and the members of these boards can be either elected or appointed for fixed terms of office. ${ }_{-}^{54}$ Typically, the school board has five to seven members whose job it is to make policy (e.g., adoption of special programs, approval of grant applications, setting disciplinary rules, going to the public to request passage of school levies, etc.) for the school district. One major issue in policy decisions is the development and enactment of a school district budget.

School districts also consist of both independent and dependent units. Independent school districts are defined as local governments that are fiscally and administratively independent of other government entities, such as townships, municipalities, and counties. They can provide for and 
promote public education, but are not allowed to use their revenues on public goods other than education. Dependent school districts, in contrast, are not counted as separate governments because they are dependent on a 'parent' government that is capable of shifting public expenditure among various public goods. ${ }_{-} 5$ As of 2002, there were 15,029 public school systems in the United States, and of these 13,522 are independent school districts and the other 1,507 can be classified as dependent districts. ${ }_{-} 6$

\section{Exercises}

\section{Legislatures - What Can I do?}

Find out more about state legislatures by visiting the National Council of State Legislators (NCSL) website at: http://www.ncsl.org/ and their public participation website at: http://www.ncsl.org/legislators-staff/ legislators/trust-for-representative-democracy/publicparticipation-and-confidence-in-the-leg541.aspx. The NCSL also has many educational materials located at their "Trust for Representative Democracy" project: http://www.ncsl.org/trust/index.htm

Visit the International City Managers Association's (ICMA) website to find out current issues confronting municipalities at http://icma.org and then use USA.Gov's directory to locate your own county or city government websites at https://www.usa.gov/local-governments Go to 
your own local government's website and see when city council or country commissioner public meetings are held and attend one. Former U.S. Speaker of the House Tip O'Neill once said "all politics is local," go see for yourself what issues are confronting your own local governments.

\section{F - Legislatures and Sustainability}

The United Nations Department of Economic and Social Affairs has highlighted the critical importance of local governments, and hence local government legislative bodies responsible for making laws and ordinances, in the development of sustainable local governments. The authors of the department's report issued in 2004 observe the following in this regard:

Because so many of the problems and solutions being addressed by Agenda 21 have their roots in local activities, the participation and cooperation of local authorities will be a determining factor in fulfilling its objectives. Local authorities construct, operate and maintain economic, social and environmental infrastructure, oversee planning processes, establish local environmental policies and regulations, and assist in implementing national and subnational environmental policies. As the level of governance closest to the people, they play a vital role in educating, mobilizing and responding to the public to promote sustainable development. ${ }_{-}^{57}$

In Governing Sustainable Cities, Evans et al. present a working framework for what factors contribute to community 
sustainability. ${ }_{-}^{58}$ These scholars suggest that sustainability is in major part a function of two community-based components: institutional capacity and social capacity. Institutional capacity is defined in terms of levels of commitment from government officials, the demonstration of political will, investment in staff training, technological mainstreaming, engagement in knowledge-based networks, and provision of legislative support for maintaining network connections. Similarly, social capacity is defined by the degree of inclusion in collective civic efforts of local citizen volunteers, news media, business establishments, representatives of industry, local universities, and local non-governmental organizations. ${ }_{-}-$Based on the possible combinations of institutional and social capacities, Evans and his colleagues identify four potential governance outcomes: $\underset{-}{60}$

- Dynamic governing - communities with 'higher' levels of social and institutional capacity have 'high possibility of accomplishing sustainability-promoting policy outcomes.

- Active government - communities with 'lower' levels of social capacity, but 'higher' levels of institutional capacity have 'medium or fairly high' possibility for accomplishing sustainability-promoting policy outcomes.

- Voluntary governing - communities with 'higher' levels of social capacity, but 'low' institutional capacity, have 'low' possibility for accomplishing sustainability-promoting policy outcomes.

- Passive government - communities with 'low' levels of both institutional and social capacity have little possibility of achieving a sustainable future.

These findings are similar to the argument of Costantinos to the effect that the active support of the state and local government legislative bodies is a critical predictor of sustainable states and communities. This support is accomplished by: 
...developing systems whereby public opinion can be made known to members of the legislature, including (the level of) support to develop their constituency, developing the capacity of the legislature to draft and introduce legislation or amendments to existing legislation on specific subjects. ${ }_{-}^{61}$

\section{G - Conclusion}

It is clear from the material discussed in this chapter that legislative forums in American state and local government represent a vast terrain of widely differing scales and scope of responsibility, traditions of normal operation, and extent of access to professional staff support. Whatever their current arrangements, traditions, and resources, however, it is beyond argument that the observations of the United Nations Department of Economic and Social Affairs are absolutely on target in maintaining the critical importance of the "governments closest to the people" in meeting the challenges of sustainability in our collective lifetimes. ${ }_{-} 2$ The evidence of global climate change, the accumulation of greenhouse gases, the extinction of species, the scarcity of natural resources, the decimation of forests, and the pollution of air and surface waters is no longer a matter of unsettled controversy, and the short time-frame for effectively coping with an endangered global ecological system requires all levels of government to become engaged in "dynamic governing" in service to sustainability.

In each of the chapters to follow it will be seen how the multiple actors - including state legislatures and local boards, commissions, and councils - are striving to perform 
their traditional duties plus take on new responsibilities for passing on a sustainable form of economic and social life to the next generation of Americans. The institutional and social capacities of our states and local communities will be tested in the coming decades, and there are signs that the identification of and dissemination of "best practices" in many sectors for a sustainable future will require the dedicated effort of legislators, public servants, civic groups, and ordinary citizens accepting their civic duty. This challenging work that lies ahead requires informed and active participants in the government processes most directly related to daily life. Some state legislatures such as those in California, Oregon, and Washington are taking the lead in promoting standards for automobile emissions, energy use and carbon sequestration that go beyond federal standards required by the Environmental Protection Agency, thereby challenging the authority of the federal government, while others are watching to see the results of those challenges. Many local government mayors (over 1,000 at this writing) are following the lead of Seattle's Mayor Nichols and the U.S. Conference of Mayors in committing to the Climate Protection Agreement which sets out ambitious goals for reducing greenhouse gases and conserving energy consistent with the Kyoto Accords even though the United States is not a signatory to those international accords. These developments represent a hopeful beginning for the governments closest to the people rising to the challenges of sustainability facing each state government and each local community in the coming years. 


\section{Terms}

Administrative rules

Checks and balances

Constituency service

$\underline{\text { County services area }}$

Dependent (special) districts

General purpose governments

Gerrymandering

Independent (special) districts

Legislative oversight

Legislative referral

Parliamentary style systems

Presidential style systems

Select committees

Single purpose governments

Standing committee

Sunset provisions

Task force

Term limits

\section{Exercises}

\section{Discussion Questions}

1. According to this chapter, what are the major functions that legislatures play in state and local government? 
2. What are some of the similarities and differences in how state legislatures operate?

3. Compare and contrast the roles and functions of general-purpose and single-purpose governments.

4. How can legislatures promote economic, social and ecological sustainability?

5. With respect to the city or town you consider to be your hometown, would characterize it as featuring passive government, voluntary governing, active government, or dynamic governing?

\section{Notes}

1. A. Lijphart, Parliamentary Versus Presidential Government (Oxford: Oxford University Press, 1992).

R.K. Weaver and B. A. Rockman, Do Institutions Matter? Government Capabilities in the United States and Abroad (Washington, DC: Brookings Institution Press, 1993).

2. H.G. Frederickson and K. B. Smith, The Public Administration Theory Primer (Boulder, CO: Westview Press, 2003).

3. D. Woodhouse, Ministers and Parliament: Accountability in Theory and Practice (Oxford: Oxford University Press, 1994). 
4. W. Clarke, W. "Divided Government and Budget Conflict in the U.S. States," Legislative Studies Quarterly 23(1998): 5-22.

5. K.E. Hamm and R. D. Robertson, "Factors Influencing the Adoption of New Methods of Legislative Oversight in the U.S. States," Legislative Studies Quarterly 6 (1981): 133-150.

6. M.J. Gerhardt, The Federal Impeachment Process: A Constitutional and Historical Analysis (Chicago, IL: University of Chicago Press, 2000).

7. A. Rosenthal, Heavy Lifting: The Job of the American Legislature (Washington, DC: CQ Press, 2004).

8. K.L. Barber, "American Government and Politics," American Political Science Review 77 (1983): 1039-1040.

M.E. Jewell, Representation in State Legislatures (Lexington, KY: University Press of Kentucky, 1982).

9. K. Bratton, "The Effect of Legislative Diversity on Agenda Setting: Evidence from Six State Legislatures," American Politics Research 30 (2002): 115-142, p. 115.

10. Ibid, p. 127.

11. E. Barrett, "The Policy Priorities of African American Women in State Legislatures," Legislative Studies Quarterly 20 (1995): 223-247, p. 223.

12. Ibid.

13. Ibid.

14. K. Bratton and K. Haynie, "Agenda Setting and Legislative Success in State Legislatures: The Effects of Gender and Race," Journal of Politics 61 (1999): 658-679, p. 658.

15. Center for American Women in Politics (Eagleton Institute, Rutgers University, 2008): URL: http://www.cawp.rutgers.edu/Facts.html (accessed August $15,2009)$.

16. National Conference of Black Mayors, Mayors of Cities with Populations over 50,000. URL: http://www.ncbm.org/ members of NCBM.html (accessed August 15, 2009).

17. K. Arceneaux, "The Gender Gap in State Legislative 
Representation: New data to Tackle and Old Question," Political Research Quarterly 54 (2001): 143-160.

18. D. Alexander and K. Anderson, "Gender as a Factor in the Attribution of Leadership Traits," Political Research Quarterly 46 (1993): 527-545.

19. V. Sapiro, The Political Integration of Women (Champaign, IL: University of Illinois Press, 1984).

S. Welch, "Women as Political Animals? A Test of Some Explanations for Male-Female Political Participation Differences," American Journal of Political Science 21 (1977): 711-730.

20. K. Arceneaux, 2001, op. cit. (see reference 17), p. 145.

21. R. Darcy and J. Choike, "A Formal Analysis of Legislative Turnover: Women Candidates and Legislative Representation," American Journal of Political Science 30 (1986): 237-255.

22. G. Moncrief, J. Thompson, M. Haddon and R. Hoyer, "For Whom the Bell Tolls: Term Limits and State Legislatures," Legislative Studies Quarterly 17 (1992): 37-47.

23. K. Arceneaux, 2001, op. cit. (see reference 17), p. 145.

24. R. Darcy, S. Welch and J. Clark, Women, Elections and Representation (New York: Longman, 1987).

25. Ohio Legislative Service Commission, A Guidebook for Ohio Legislators, 2007. URL: www.lsc.state.oh.us/guidebook/ (accessed August 15, 2009).

26. L. Braiotta, The Audit Committee Handbook (New York: John Wiley \& Sons, 2004).

27. Ohio Legislative Service Commission, 2007, op. cit. (see reference 25).

28. A. Bowman and R. Kearney, State and Local Government, 6th ed. (Boston, MA: Houghton-Mifflin, 2005), p. 160.

29. M.S. Dulaney, A History and Description of the Nebraska Legislative Process (Lincoln, NE: Nebraska Council of School Administrators., 2002)

30. G. Tsebelis and J. Money, Bicameralism (Cambridge, UK: Cambridge University Press, 1997). 
31. A.W. Richards, "Strategic Planning and Budgeting in the New Texas? Putting Service Efforts and Accomplishments to Work," International Journal of Public Administration 18 (1995): 409-441.

32. National Conference of State Legislatures, Full- and Part-Time Legislatures. URL:

http://www.ncsl.org/programs/press/2004/ backgrounder_fullandpart.htm

33. Ibid.

34. Ibid.

35. O. Koppel, "Public Good Provision in Legislatures: The Dynamics of Enlargements," Economics Letters 83 (2004): 43-47.

36. Council of State Governments, The Book of the States, 2016 (Lexington, KY: Council of State Governments, 2016).

37. As administrative divisions of a state, counties seldom have power to establish their own taxes, but they are often able to adjust tax rates within fixed maximum and minimum parameters.

38. J.F. Zimmerman, Subnational Politics; Readings in State and Local Government (New York: Holt, Rinehart, 1970).

39. H.M. Levin, An Analysis of the Economic Effects of the New York City Sales Tax (Washington, DC: Brookings Institution, 1967).

C.L. Rogers, "Local Option Sales Tax (LOST) Policy on the Urban Fringe," Regional Analysis and Policy 34 (2004): 27-50.

40. A.D. Sokolow, Town and Township Government: Serving Rural and Suburban Communities (New York: Marcel Dekker, 1996).

41. H.G. Frederickson and G.A. Johnson, "The Adapted American City: A Study of Institutional Dynamics," Urban Affairs Review 36 (2001): 872-884, p. 872.

42. K.A. Foster, The Political Economy of Special-purpose Government (Washington, D.C.: Georgetown University Press, 1997). 
43. S. Scott and J. C. Bollens, "Special Districts in California Local Government," Western Political Quarterly 3 (1950): 233-243.

44. T. Loftus and H.G. Rennie, Analysis of Enabling Legislation from a Multi jurisdictional Watershed Perspective. URL: www.storm.warrenswcd.com/Documents/FinalReportOSTF-319-Grant-StormWater-MGT-WatershedBasis.pdf.(accessed August 15, 2009).

45. D.A. Austin, "A Positive Model of Special District Formation," Regional Science and Urban Economics 28 (1998): 103-122.

46. J. Lang, New Urban Renewal in Colorado's Front Range, Issue Paper 2-2007 (Golden, CO: Independence Institute, 2007).

47. H.G. Cisneros, Regionalism: The New Geography of Opportunity (Jefferson, NC: McFarland and Company, 1999).

G. Marks and L. Hooghe, Contrasting Visions of Multi-level Governance (Oxford: Oxford University Press, 2004).

48. K. Mizany and A. Manatt, What's So Special about Special Districts?: A Citizen's Guide to Special Districts in California (Sacramento, CA: California State Legislature, 2002). URL: www.csda.net/images/Whatsso.pdf

49. T. Bui and B. Ihrke, It's Time to Draw the Line: A Citizen's Guide to LAFCOs (Sacramento, CA: California Senate, 2003).

50. K. Mizany and A. Manatt, 2002, op. cit. (see reference 48).

51. U.S. Census Bureau, 2002 Census of Governments. URL: www.census.gov/govs/www/cog2002.html

52. D.J. Condron and V. J. Roscigno, "Disparities Within: Unequal Spending and Achievement in an Urban School District," Sociology of Education 76 (2003): 18-36.

53. A. Feuerstein, "Elections, Voting, and Democracy in Local School District Governance," Educational Policy 16 (2002): 15-36.

54. J.P. Danzberger, "Governing the Nation's Schools: The 
Case for Restructuring Local School Boards," Phi Delta Kappan 75 (1994): 367-373.

55. L. Barrow and C. E. Rouse, "Using Market Valuation to Assess Public School Spending," Journal of Public Economics 88 (2004): 747-1769.

56. U.S. Census Bureau, 2002, op. cit. (see reference 51).

57. United Nations, Department of Economic and Social Affairs. "Local Authorities," URL: www.un.org/esa/sustdev/ documents/agenda21/english/agenda21chapter28.htm

58. B. Evans, M. Joas, S. Sundback and K. Theobald, Governing Sustainable Cities. (London, UK: Earthscan, 2005).

59. Evans, B., M. Joas, S. Sundback and K. Theobald, "Governing Local Sustainability," Journal of Environmental Planning and Management 49 (2006): 849-867.

60. B. Evans, M. Joas, S. Sundback and K. Theobald, 2005, op. cit. (see reference 58).

61. B. Costantinos, "Sustainable Development and Governance Policy Nexus: Bridging the Ecological and Human Dimensions." In Gedeon Mudacumura, Desta Mebratu and M. Shamsul Haque, eds., Sustainable Development Policy and Administration (New York: Taylor and Francis, 2006), p. 68.

62. United Nations, 2009, op. cit. (see reference 57). 


\section{Chapter 7: Executives}

\section{A - Introduction}

The title of this chapter draws an important distinction in our discussion of executive leadership in state and local government; unfortunately, it is a distinction that provides less clarity than one would expect. In 18th and 19th century state and local government, the "executive" was generally thought of in terms of elected leadership; a governor, a state attorney general, a mayor, or perhaps even a sheriff came readily to mind. The executive, therefore, was tied directly to elective office and was often directly accountable to the people via the voting mechanism.

In the mid-to-late 19th and early 20th centuries, however, a major change began to take place in this area. The rise of what is called Progressivism led to a concerted nationwide effort to clean up politics, particularly at the municipal level and over time at the state level, as well. The national government was also affected by Progressive reforms, although perhaps not in the same way or to the same degree this social movement transformed that state and local government.

The chapter informs the reader about the unique qualities of the political and career administrative executive aspects of state and local government. Understanding the offices, both their similarities and their differences, will help the reader gain a better understanding of how state and local executives operate across the country and in the reader's own state and local community. 


\section{Learning Objectives}

This chapter will discuss:

- the power and role of the governor.

- $\quad$ state executive branch leaders.

- $\quad$ the roles of county and city elected leaders.

- special districts as quasi executive/legislative institutions.

- the role of administrative executives.

- the role of executives in sustainability.

\section{B - Governor}

The term Governor has many meanings. On a mechanical device, a governor is something that regulates the speed of a machine, often a complex process. The British for some period used the word when addressing someone worthy of respect. The word also refers to a military commandant. More commonly, a governor is a head of state, a key actor in a governmental body. So, do all of these definitions apply to our current topic: state governors? Unexpected, the answer is Yes! A governor shapes the speed and direction of political debate. The governor is, in fact, a military commander - he or she does have the power to "call up" or activate the state 
National Guard in U.S. states. The office of governor is a position of respect and is the ceremonial head of state as well as being a key actor in a larger governing process.

Prior to the American Revolution, colonial governors served as executive leaders of a Crown Colony. In early colonial days, the powerful landowners chose governors usually white men of wealth and social stature. The governor, along with a quasi-legislative council, led the colony in countless ways - managing resources; developing plans for sustainability and growth; maintaining civic virtue through the enforcement of laws; and making treaties or agreements with indigenous peoples and with other colonies. Governors also appointed individuals to help accomplish key tasks. As the British Colonies became more developed, the Crown government played a much larger role in appointing governors and various administrative executives to serve as representatives of the home nation to collect taxes and assess fees, and to generally enforce the will of the British Monarch and his government on colonists.

In the colonial period just as today, the governor is a key figure for innovative leadership, critical to establishing sustainable states and communities. The often-tragic imperialistic interactions between indigenous peoples and colonists represent a sad chapter in the development of democratic government in our county. It is useful at the outset of this chapter to imagine the circumstances faced by early colonists, moving from the familiarities of the continent of Europe to a place far less familiar and comprehensible to them. An inability on the part of the nation's early colonial governors to be successful innovators could have resulted in widespread disease and death among colonists and native tribes alike.

Leadership then, as is the case today, is only as good as the ability of the leader to persuade others to follow him or her, and this ability is importantly shaped by a leader's 
personality. Popularity is one measure of the ability of a leader to persuade others to follow, ${ }_{1-}^{1}$ to gain followers, and to gain their support for innovative ideas. ${ }_{-}^{2}$ Support can be particularly difficult to gain and maintain when promoting a vision of the future, a time and space unknown and often disturbing in consideration. Innovation requires, along with uncommon insight, boldness of action in the face of the unknown.

The dire consequences of failed innovative executive leadership still exist, but new consequences have emerged. Mass starvation is perhaps less likely, but Homeland Security issues place the governor and his or her staff on the front line as the likely first responders to a crisis, manmade or brought on by the force of Nature. For example, while failed river levees in New Orleans were ultimately a national government failure, the impact of Hurricane Katrina (2005) was immediate and devastating. Louisiana Governor Kathleen Blanco and New Orleans Mayor Ray Nagin were called upon to exercise innovative executive leadership and - in this case as perhaps in no other hurricane-related tragedy of recent memory - the consequences of failed leadership were as bad, if not worse, than issues faced by now long-forgotten colonial governors of centuries past.

In times of relative tranquility, a governor must do two principal things. First, a governor must serve as a chief administrator, managing the steady course of government towards various goals. Second, a governor must consider the future and identify areas where sustainability must be actively pursued. A governor will likely use his or her chief executive role - the role of head of state - to promote policy innovations that will better serve state and local sustainability efforts. The development of sound state and local energy policies is certainly a timely example of gubernatorial leadership; reduced reliance on imported fossil energy and increased development of state and local renewable energy 
sources are timely goals in this respect. Governors' efforts to promote literacy and improved educational attainment, combined with sustainable economic development providing good jobs and a quality lifestyle, are part of efforts to retain young people in states and local communities.- And for those individuals least benefited in society, governors have played a critical role in promoting welfare-to-work programs.

\section{B.I - Terms of Office and Eligibility:}

In the United States, governors hold four-year terms of office. The exception to this occurs when governors are elected via special election to fill a governorship when the current governor has vacated the seat prior to completing his or her term of office. One of the reasons that a sitting governor would not complete his or her term is related to election or appointment to another political office. President George W. Bush was the incumbent governor of Texas when he was elected 43rd U.S. President in 2000. A second reason that a sitting governor vacates the governorship prior to completing a term of office is due to losing a recall election. Governor Gray Davis of California was recalled as governor in October 2003. Following a successful election, the former film celebrity and now politician Arnold Schwarzenegger assumed the governorship. A third reason why a governor might not complete a four-year term of office is due to death, incapacity or violation of residency requirements. While death is determinable, incapacity is not entirely clear and is defined in part through legislative branch determination. At times, governors will declare themselves as being incapable of finishing their proscribed term of office. Finally, a governor might not complete his or her term of office due to resignation 
for reasons other than those mentioned previously. Public corruption or other felony indictments or convictions may lead a sitting governor to resign from office. In 2003, Illinois Republican Governor George Ryan was indicted on federal charges of political corruption, ultimately resulting in conviction on over a dozen counts of public corruption and a six and a half year prison sentence (note: Ryan is appealing the conviction). In 2008, New York Governor Eliot Spitzer resigned from office because of his involvement with a prostitute. Most recently, in 2009 Illinois Governor Rod Blagojevich was impeached and removed from office for corruption charges including allegedly trying to "sell" President Barrack Obama's U.S. Senate seat. 


\begin{tabular}{|c|c|c|c|c|}
\hline STATE & $\begin{array}{l}\text { U.S. } \\
\text { CITIZEN } \\
\text { (YEARS) }\end{array}$ & $\begin{array}{l}\text { STATE } \\
\text { RESIDENT } \\
\text { (YEARS) }\end{array}$ & $\begin{array}{l}\text { QUALIFIED } \\
\text { VOTER (YEARS) }\end{array}$ & $\begin{array}{l}\text { MINIMUM } \\
\text { AGE }\end{array}$ \\
\hline Alabama & 10 & 7 & Checkmark & 30 \\
\hline Alaska & 7 & 7 & Checkmark & 30 \\
\hline Arizona & 10 & - & - & 25 \\
\hline Arkansas & Checkmark & 7 & Checkmark & 30 \\
\hline California & 5 & 5 & Checkmark & 18 \\
\hline Colorado & Checkmark & 2 & - & 30 \\
\hline Connecticut & Checkmark & Checkmark & - & 30 \\
\hline Delaware & 12 & 6 & - & 30 \\
\hline Florida & - & 7 & 7 & 30 \\
\hline Georgia & 15 & 6 & - & 30 \\
\hline Hawaii & 5 & 5 & Checkmark & 30 \\
\hline Idaho & Checkmark & 2 & - & 30 \\
\hline Illinois & Checkmark & 3 & Checkmark & 25 \\
\hline Indiana & 5 & 5 & Checkmark & 30 \\
\hline Iowa & 2 & 2 & Checkmark & 30 \\
\hline Kansas & Checkmark & - & - & - \\
\hline Kentucky & Checkmark & 6 & - & 30 \\
\hline Louisiana & 5 & 5 & Checkmark & 25 \\
\hline Maine & 15 & 5 & - & 30 \\
\hline Maryland & - & 5 & 5 & 30 \\
\hline Massachusetts & - & 7 & - & - \\
\hline Michigan & Checkmark & Checkmark & 4 & 30 \\
\hline Minnesota & Checkmark & 1 & Checkmark & 25 \\
\hline Mississippi & 20 & 5 & Checkmark & 30 \\
\hline Missouri & 15 & 10 & - & 30 \\
\hline Montana & Checkmark & 2 & Checkmark & 25 \\
\hline Nebraska & 5 & 5 & - & 30 \\
\hline Nevada & 2 & 2 & Checkmark & 25 \\
\hline
\end{tabular}




\begin{tabular}{|c|c|c|c|c|}
\hline $\begin{array}{l}\text { New } \\
\text { Hampshire }\end{array}$ & - & 7 & - & 30 \\
\hline New Jersey & 20 & 7 & - & 30 \\
\hline New Mexico & Checkmark & 5 & Checkmark & 30 \\
\hline New York & Checkmark & 1 & - & 25 \\
\hline $\begin{array}{l}\text { North } \\
\text { Carolina }\end{array}$ & 5 & 2 & Checkmark & 30 \\
\hline North Dakota & Checkmark & 5 & Checkmark & 30 \\
\hline Ohio & Checkmark & Checkmark & Checkmark & 18 \\
\hline Oklahoma & 10 & 10 & 10 & 31 \\
\hline Oregon & Checkmark & 3 & - & 30 \\
\hline Pennsylvania & Checkmark & 7 & Checkmark & 30 \\
\hline Rhode Island & 30 days & 30 days & 30 days & 18 \\
\hline $\begin{array}{l}\text { South } \\
\text { Carolina }\end{array}$ & 5 & 5 & - & 30 \\
\hline South Dakota & Checkmark & Checkmark & Checkmark & 18 \\
\hline Tennessee & Checkmark & - & - & 30 \\
\hline Texas & Checkmark & 5 & - & 30 \\
\hline Utah & Checkmark & 5 & Checkmark & 30 \\
\hline Vermont & - & 4 & Checkmark & 18 \\
\hline Virginia & Checkmark & Checkmark & 5 & 30 \\
\hline Washington & Checkmark & Checkmark & Checkmark & 18 \\
\hline West Virginia & Checkmark & 1 & Checkmark & 30 \\
\hline Wisconsin & Checkmark & Checkmark & Checkmark & 18 \\
\hline Wyoming & Checkmark & 5 & Checkmark & 30 \\
\hline
\end{tabular}

Table 7.2 Qualifications for Governors

In most states, when a sitting governor vacates the office prior to his or her term completion, the lieutenant governor becomes either the new sitting Governor or the Acting Governor of a state. The Lieutenant Governor is not unlike that of the Vice President, serving as the chief officer of the 
state senate, occasionally casting tie-breaking votes. Unlike the Vice President, the Lieutenant Governor can be elected as a separate constitutional office and frequently represents a different political party than that of the governor; although, in over a dozen states, the Lieutenant Governor is jointly elected with a Governor. Essentially, vacating the office of governor and the elevation of a lieutenant governor to the governorship would lead to significant changes in policy direction and prioritization

In many states, the eligibility requirements for governor specify a minimum age of thirty years at the time of election to office, but there are noteworthy exceptions. Wisconsin's constitution specifically states that individuals elected to the governorship must simply be qualified electors (18 years old). Other states such as Arizona, Montana, and Nevada require that an elected governor be at minimum 25 years of age. Residency requirements prior to election are typically between five and seven years. Missouri and Oklahoma constitutions require prior state residency of ten years minimum. Mississippi and New Jersey require 20 years minimum U.S. citizenship. Currently, only about half of the state governors are natives of their respective states. Of the non-native governors, 34.1 percent were born in the Northeast; six percent were born in the state of New York. As of 2009, two governors were born outside of the United States. It is fairly well known that Governor Arnold Schwarzenegger of California was born in Austria; less commonly known, Jennifer Granholm, former Governor of Michigan and current cabinet officer in the Obama administration, was born in Canada. 


\begin{tabular}{ll}
\hline TERRITORY & GOVERNOR? \\
American Samoa & Yes \\
Baker, Howland and Jarvis Islands & No \\
Guam & Yes \\
Johnson Atoll & No \\
Kingman Reef & No \\
Midway Islands & No \\
Navassa Island & No \\
Northern Marianna Islands & Yes \\
Puerto Rico & Yes \\
Palmyra Atoll & No \\
U.S. Virgin Islands & Yes \\
Wake Island & No \\
\hline
\end{tabular}

Table 7.1 Governors in the Territorial Possessions

\section{B.II - Term Limits:}

In the last few decades, term limitation has gained heightened interest among voters. The executive branch of the national government saw term limitations come into effect in response to President Roosevelt's unprecedented four consecutive presidential election victories in the 1930s and 1940s. In the 1994 general election, the Republican candidates for the U.S. Congress made a major push for term limitation, promising to serve only two terms of office if elected. Incumbency often appeared to be an advantage that was not easily overcome by a challenger_; term limits were seen as a way to offer fresh alternatives a voice in the electoral process. For good or for ill, the message of term limitations resonated 
with voters. State governors have by no means been immune to voter scrutiny and to term limitation measures.

As of 2007, thirty-seven states have enacted term limitations on their governorship. In some states, terms limits mean that after a governor has served two full terms, he or she must wait four years before being eligible to run again for the governorship. In Wyoming, an individual can only serve eight years as governor in any sixteen-year period. In Virginia, the constitution allows the governor to serve only one four year term; the individual then has two wait four years before being eligible to run for a second term. New Hampshire has a particularly interesting and complex term limitation arrangement with two one-year terms of office followed by a two-year period before the governor is eligible to run for re-election; there are no limits on the number of terms any individual may serve. In six states, Lieutenant Governors are not subject to the same term limitations as Governors, perhaps in recognition of the lesser importance of the Lieutenant Governorship in the policymaking process; although, the Lieutenant Governor does serves as the President of the state Senate and over a long tenure may gain significant influence over closely contested policy measures.

\section{B.III - The Governor's Office:}

Not unlike the president, the governor's office is shaped by the incumbents' personal style and tastes in management. Personality plays a large role in shaping gubernatorial tastes in the governance process. Governors have a personal staff appointed by him or her and organized under the managerial control of a chief of staff. Organization and access of staff to the governor is largely a function of personal management 
philosophy. Some governors are very hierarchical in their management style, often using the chief of staff position to limit access of personnel. In a hierarchical approach, the governor's interaction with staff is usually formal and quite structured. Other governors tend to adopt a collegial approach to management. The role of a chief of staff is more limited. Collegial governors regularly attend informal policy group meetings where discussion is freer flowing and innovations are discussed in an open forum.

It is important to realize that while several other elected positions exist within the executive branch - e.g., secretary of state, attorney general, treasurer, and comptroller (or controller or Auditor). The sub-governor executive offices are not beholden to the governor; while officeholders might meet regularly with the governor, they do not take their direction from him or her.

In addition, an agency's staff exists below the governor's political appointees and/or below that of other elected state executives. In theory, bureaucracy is politically neutral, but organizational and individual values and priorities may subconsciously shape judgment. The ability of a governor and other political executives may be constrained by bureaucracy. Administrative reform ${ }_{-}^{5}$ efforts are, in some instances, an attempt to break down the bureaucratic network and reduce red tape.

As with the president, state governors are generally required to organize and submit an annual or bi-annual budget to the state legislature for consideration. One of the most recognizable and important staff offices, therefore, is the budget office, headed by a governor appointed budget director. The budget office interacts regularly with the governor and other members of his or her personal staff along with other elected executive branch officials, such as the treasurer, secretary of state and comptroller (auditor). The budget office is particularly critical when the opposition party 
controls the state legislature. ${ }_{-}^{6}$ The office serves as an important liaison function in promoting the governor's agenda.

Governors often establish policy advisory groups. Policy groups are often formed around related policy issues, such as crime, education, welfare, transportation, and many others. A governor's chief of staff helps the governor to coordinate the activities of the policy groups and to ensure that the governor's general and specific priorities form the nexus of policy goals. Governors will meet regularly with their policy advisers and discuss legislative priorities and budgeting.

In addition to personal staff, governors rely heavily on appointed boards and commissions. Commissions are often closely tied to specific policy issues in a state and are very important in promoting policy innovations. In relation to issues of sustainability, state energy commissions, for instance, spend considerable time studying the feasibility of alternative energy development in states. Education policy functions often have associated boards or commissions with either appointed or elected officials.

Not unlike the presidency, governors also appoint a cabinet to manage related state administrative departments. In some states, certain policy areas have elected leadership. The State of Washington, for instance, has an elected Superintendent of Public Instruction. California has an elected Labor Commissioner. The presence of other elected executives in specific policy areas serves to limit gubernatorial influence and power.

Despite a large staff and executive office organization, governors are highly dependent on personal characteristics to shape policy and outcomes. In essence, the power to persuade the voters and legislators of the importance and necessity of certain policy priorities cannot be underestimated. Public opinion is a strong influence in shaping a governor's ability to successfully promote a policy agenda. Additionally, 
legislative-gubernatorial relations are oftentimes shaped by party control factors. In a divided government, the governor may face greater challenges in promoting a policy agenda than in times of unified party control. With the exception of Nebraska (a unicameral legislature), there is evidence that when the governor's political party controls the state senate (but not the legislative chamber), then he or she is less limited by the impacts of divided government.

Public opinion research indicates that the public expects governors to pay close attention to state economic trends.? When state unemployment rates rise, the governor's public opinion ratings tend to decline. Conversely, the public is generally supportive of governor's who chase smokestacks that is, successfully pursue economic development in their state; however, public opinion is shaped by the specific type of industrial development pursued. Increasingly, voters insist on clean industries that will not pollute the environment.

It is important to remember that all of the actions of the governor are ultimately shaped by his or her partisan leanings and the partisan climate in which he or she operates at the state level. Beyond the state itself, the governor as a partisan actor, must also work with the state's elected congressional delegation, which may or may not share the governor's policy priorities or visions for innovation. ${ }_{-}^{8}$ 


\section{C - Secretary of State}

In the national government, the secretary of state is an appointed cabinet-level position largely associated with diplomatic affairs; but there are many other functions of secretary of state that involve economic development and partnerships. At the state level, the functions are similar in many respects. International or interstate "diplomacy" is often seen as limited to officially welcoming heads of state or domestic state dignitaries; but secretaries of state also play an important role in informing these visitors about the business climate in a state and the benefits of locating particular industries there. In essence, secretaries of state are key economic development coordinators. The secretaries of state offices in most cases are also responsible for managing business licenses and business development in a state. Given the office's responsibilities in business licensing, it is a natural fit for the secretaries of state offices to manage state archives and other official records - in some instances, the department of motor vehicles or its equivalent reports to the secretary of state.

Perhaps one of the most recognizable functions of the secretary of state, however, is that of managing elections. The office is responsible for officially posting the names of candidates for public office and closely managing the printing and distributing of ballots. Following the casting of these ballots, the secretary of state is responsible for certifying that the election has been conducted honestly and accurately. Many readers will recall Florida Secretary of State Katherine Harris' controversial decision to certify the 2000 presidential election votes despite widespread concern about the accuracy and completeness in counting punch-card ballots in several Florida counties.

Every ten years the U.S. Census Bureau requires the 
redistricting of national, state and local legislative electoral districts to ensure that U.S. citizens enjoy equal political representation. Secretaries of State, the Governor, and the state legislatures all play key roles in deciding on the shape of the districts resulting from this process of realignment of district lines each decade. Partisan and racial gerrymandering - i.e., the intentional creation of districts that will likely ensure particular political party victory or the victory of particular candidates who are persons of a particular race or ethnicity - historically has been and remains a highly controversial issue in many parts of the country. Secretaries of State play a key role in preventing gerrymandering in most states and become involved in perpetuating the practice in a few states.

\section{D - Attorney General}

The state attorneys general serve as the chief judicial advocate for their respective states, representing state interests in all trials, investigations, and appeals involving the state as a legal party. The offices of the attorneys general also have the responsibility of organizing the state's legal profession to provide legal counsel for individuals who cannot afford to pay for their own legal representation in criminal cases. The office of the state attorney general is usually divided into separate divisions for criminal and civil matters. Consumer protection is one of the fastest-growing areas of concern among attorneys general working on the civil side, and violence against women, violence against the elderly, and cybercrime (i.e., computer-based victimization through identity theft or stalking) are the most frequent areas of 
growing attention on the criminal side. The protection of children is another prominent issue facing attorneys general, on both the civil and criminal side. The Amber Alert system, designed to rapidly disseminate information about abducted children, is typically put into place by attorneys general working in concert with local law enforcement in their states.

Attorneys general in some areas have formed close interstate relationships, at times effectively nationalizing legal policy goals. In the 1990s, state attorneys general pooled their resources and talent and pursued litigation against large tobacco companies. Ultimately, the "tobacco settlement" resulting from a federal lawsuit brought by a group of state attorneys general led to the periodic payment of literally billions of dollars in revenue to the states as just compensation for the costs to the states for the treatment of illnesses caused by smoking. In this instance and in others, state attorneys general have demonstrated that their executive powers and abilities extend far beyond state borders, in some respects outpacing the powers of state governors in terms of impact.

\section{E - State Treasurer}

State treasurers administer or supervise the financial transactions taking place in state government. The collection of tax, investment, and transactional revenue is the major feature of the treasurer's job. In the area of tax collections, it is the case that tax revenue does not arrive all at once. State sales taxes, for instance, typically arrive in state coffers monthly from retail merchants who sell taxed goods or services. Gasoline taxes, for example, are levied on individual purchases and tallied by the familiar gas pumps found in every 
service station. A monthly tally is read on each pump and each station operator remits taxes due to the state and federal governments. State treasurers are responsible for managing such financial resources as they are collected, and they are in charge of distributing those resources to state agencies appropriately - that is, according to statutory formulas set forth in the state budget document. While the resources are sitting in state coffers - usually state bank accounts in private banks and investment institutions - the treasurer is responsible for the careful investing of these monies to earn interest, or in the case of longer-term investments to earn dividends and/or gain in market value.

There are many instances where state resources are insufficient to complete budget goals. State legislatures, with the governor's approval, will direct the state treasurer to issue bonds. Bonds are promissory notes, essentially IOUs issued in the name of the state. Investors purchase a bond for a certain amount when such bond issuances are announced. On a pre-determined due date (or "call" date), the principal investment, as well as interest earned, are returned to the investor. External parties rate bonds with expertise in finance in terms of the likelihood of repayment. The best bond rating from Standard \& Poor's, a major private bond-rating corporation, is AAA. Bonds receiving a lower rating entail a greater degree of financial risk, but pay a higher rate of interest. State treasurers actively manage state bond issuances and seek to develop and maintain financial management plans that result in high bond ratings, which save state taxpayers money in interest payments avoided. State treasurers uniformly across the country keep a careful eye on their state bond ratings and play a key role in maintaining financial management practices in state government.

In recent years state treasurers have begun to play an ever-larger role in the development of innovative funding programs for state investments in higher education. As any 
reader would likely know, the cost of a college education has been rising more quickly than the general cost of living. Fortunately, the U.S. Internal Revenue Service allows in its Code 529 provision for the development of individually funded tax-exempt college savings accounts. In order to encourage the continued development of a highly educated labor force, states have joined the federal effort to encourage investment in higher education by also making these plans exempt from state taxation. The monies invested by individuals in 529 plans are administered by the state in conjunction with a predetermined private investment firm, such as Fidelity Investments. State treasurers are responsible for the collection of revenues, the investment of those revenues, and the eventual dispersal of these funds to the parents and children for whom these funds have been saved.

In some states, the state treasurer also plays an important role in state policy innovation by managing grant monies intended to fund novel policy initiatives. In some cases, state treasurers have solicited proposals for local renewable energy projects, workplace health promotion incentives, and sustainable community development. The treasurer reviews the proposals and plays a key role in determining which grant proposals will be funded. The goal of these grant programs is to provide seed funding for ideas that promote the economic viability of the state economy which can be adopted by other localities once the ideas are shown to be worthy of investment. 


\section{F - Superintendent of Public Instruction}

The famed educator Horace Mann in Massachusetts established the first state-level education office in the 1830s. In the seventeenth and eighteenth centuries, elementary and secondary education was either privately administered or seen as entirely a local government function. While public K-12 education remains largely locally administered, Mann's Common School Movement instituted a major state-level role in educational curriculum and organization. Superintendents of public instruction are elected positions, generally featuring a four-year term of office. The superintendent's office has a multitude of functions, with curriculum management being a very important aspect of the superintendent's job. While individual school districts have some influence over curriculum issues, the state office plays a key role in determining the curriculum of basic educational requirements - the basic knowledge, skills, and abilities to which all students should have equal access. The superintendent's office maintains accountability through student testing. Since the No Child Left Behind (NCLB) Act sent into law in 2001, the state office is also responsible for school performance and teacher quality management issues. Other important functions are the management of state finances directed towards basic education, and the management of granting programs originating at the state level or filtered through the state office by the federal government. The superintendent of education and the department offices at the state level play a critical role in managing $\mathrm{K}-12$ education and ensuring the equality of educational opportunity for all students, including the supervision of GED (Graduation Equivalent Degree) programs made available to students who are not able to complete the traditional high school process and the supervision of homeschooling parents. 


\section{G - Local Government Executives}

\section{G.I - County Commissions:}

Counties are among the oldest jurisdictions of government. In Western Europe, counties were units of aristocratic government, the jurisdiction of a Count or an Earl. In our country, the role of county governments has varied considerably over time, and their relative importance has been a function of the social and economic climate of a region. Until relatively recently county governments had remained largely unchanged in their structure and method of operation ${ }_{-}^{9}$ often being viewed as institutional anachronisms. Prior to the nation's large-scale urbanization, the county was the predominant unit of local government. County government served the blocks of farms and ranches that constituted a region's economic base. The industrialization and subsequent urbanization of many areas in the 19th and 20th centuries reduced the power of county commissions considerably. Communities that remain rural and agricultural continue to employ county commissions carrying out their work in rather traditional ways.

Typical county functions focused on public health and welfare, education, criminal justice, roads, and property rights issues. County government often maintained a public hospital and a public health department. Schools were centrally 
located in small rural areas, often found in the county seat of government. The county sheriff's department and county court system (and jail) were generally highly recognizable features of county government. Finally, county government focused considerable attention to the issue of water rights and land use - two issues particularly critical in the arid Southwest.

The primary elected executive leadership in a county is typically the county commission. In many respects the commission serves a dual role as a legislative body, employing a majority-voting rule to determine county policy priorities. In fact, county commissions and other political executives at the county level (e.g., Sheriff) are critical actors of directly managing and delegating key functions of local government. Increasingly, county commissions have appointed county managers, an administrative executive position, to manage the day-to-day operations of counties. In several counties across the country, generally in large counties with significant urban populations, the office of an elected county supervisor has been created by county charter amendment to fill similar functions.

County commissions regularly create "special districts" (units with their own limited taxing authority) and elected or administrative executive positions to deal with specific issues. For instance, the cemetery board in many counties is a creation of the county commission, and the cemetery board executives may be either elected or appointed administrators. Other commonly recognized special districts created by the county commissions and associated executive elected or appointed executive positions involve county parks, housing authorities, and water boards.

County government authority is limited in their function by Dillon's Rule. Dillon's Rule is named after John Dillon who was an Iowa Supreme Court jurist in the mid 19th century. In his book, The Law of Municipal Corporations (originally 
published in 1873) John Dillon argued that state-national government power relations were embedded in the U.S. Constitution, granting the states almost unlimited authority aside from limitations imposed by the Constitution and resulting federal statute. 10 In terms of state-local power relations, Dillon argued that states create local government and hold supreme power over local governments. The noted exception to this is the creation of home rule relationships in which states effectively grant limited - and reversible - power to local government to independently create governmental forms and manage policy formation at the local level.

In recent years, county government across the country has been rejuvenated through a large measure of institutional reform..$_{-}^{11}$ Counties play a very important role in coordinating sub-government activities, many of which overlap in jurisdiction. County government has played a particularly important role in law enforcement, dealing with public health and safety and terrorism-related policies, coordinating multijurisdictional efforts to react to changing conditions such as domestic violence and drug-related youth gang violence. The management of weather-related catastrophe events has also benefited from county government leadership in major ways. In terms of adaptive innovation, many county governments across the country have taken advantage of the opportunity to bring disparate groups together and to provide for an effective hearing for multiple viewpoints and sharing of common goals. County land management is one important method of providing an equitable future for all citizens, particularly as county demographics change and as the values of citizens evolve. In this regard, county governments spearhead some of the most innovative programs in the areas of renewable energy development and broadband access for households across the country. The national organization, the National Associations of Counties [NACO], is an effective voice for innovation and adaptation to changing societal conditions in 
the country, and offers technical advise and services to counties seeking to implement "best practices" in the major areas of sustainability promotion - namely, energy conservation, renewal energy development, alternatives to single-occupancy automobile travel to the workplace, greenhouse gas emission reduction, etc. In recognition of the rejuvenation of county government, in 1991 the ICMA changed its official name from that of the International City Management Association to the International City/County Management Association. The ICMA conventions and technical assistance programs now feature a rich blend of city and county administrators for virtually all types of jurisdictions, large and small, urban, suburban and rural. In this type of setting innovative local government practices, which promote sustainability, are effectively disseminated widely throughout the country.

\section{H $\quad-\quad$ Special Districts \\ Quasi-Executive-Legislative Institutions}

Technically, special districts are units of local government that are not a county, township, or city. The general scope of power and responsibility of a special district is governed by state laws and county ordinances, which provide legal guidelines for the governance and administration of special districts. Special districts often emerge due to the demands of citizens for certain services in their community, and citizens may petition county governments to create special districts as a way to deal with the problems occasioning their concern. Special districts are wide-ranging, offering services such as 
fire protection in rural areas, and water, sewer, and other benefits to individuals within a special district's taxing jurisdiction. Through the process of creating a special district, county and state governments structure a system for the collection of additional revenue to be assigned to a dedicated fund needed by the district to provide services demanded.

Special districts perform the executive role of governing the process of service delivery, but also through governing boards they perform the legislative function of creating policies and regulations related to district and service administration. Additionally, special districts employ their own administrators to execute district policies.

Creating sustainable communities will require the active participation of the many special districts that have proliferated at the local level, each one meeting particular needs and overcoming barriers to effective service delivery. Special district governance and administration is closer to the citizenry than state or national government and may be assumed to be more responsive to local needs. As such, the people active in the establishment, management, and operation of special districts are frequent participants in contemporary local meetings relating to sustainability. These people have demonstrated particular skill at local-level adaptation to change in the past, and they will likely be among the leading voices heard regarding policies needed to address the challenges of global climate change and related problems facing our state and local governments in the years ahead. 


\section{I - Municipal Government}

In municipal government, the most commonly recognized executive position is that of mayor. In most municipal government structures, the mayor is the elected executive in a city. The power of a mayor as an executive, however, is oftentimes limited in many of the same ways as other state and local executives - namely, he or she is heavily dependent on a well-defined organizational structure wherein other actors exercise significant influence. Mayors typically operate within one of three different organizational conditions: strong mayor-council, weak mayor-council, or the commission form of municipal government wherein the role of the mayor is primarily that of coordinator.

\section{I.I - Strong mayor-council:}

One of the most significant powers afforded the mayor is that of budget maker. The mayor's office prepares a budget document that is submitted to the council for review and eventual approval. While the details of the budget are negotiable in the council's deliberative process, the mayor's power and staff support for preparing the budget document provides him or her with significant influence over the budgeting process. In a strong mayor-council system, the mayor administers the budget after council approval, which is another source of mayoral power; the mayor is typically afforded considerable discretion over when budget expenditures will be deferred or possibly even sequestered or rescinded.

In strong mayor-council systems, mayors have 
significant appointment power as well. The mayor can appoint and dismiss numerous administrative municipal agency heads. With the legal power to hire or fire, the mayor does not have to negotiate or compromise with agency heads. As the chief executive in the municipality, in strong mayor-council systems, the mayor's overall agenda is likely to carry the day in most important matters of municipal policy and programs.

While the executive powers of mayors in a strong mayorcouncil system are considerable, there are clear limitations on those powers. Mayors can be limited by the council, and most certainly the voters hold ultimate control over the mayor's continuance in office. Administrative leaders have their own power base as well in the client groups they serve; if the mayor operates with too heavy a hand, then he or she might find himself or herself politically isolated and unable to produce desired outcomes.

Over the course of the nation's history, even the strongest mayors have had to employ positive inducements to achieve their goals. Former Chicago mayor, the late Richard Daley, Sr. who headed a Democratic municipal political machine, found that offering inducements - oftentimes, city jobs for friends or family members of his supporters - was an effective way to build support and to get things accomplished.

As with other executives, strong mayors are only as strong as their level of public support. New York City mayor John V. Lindsay (1966-1973) is a good example of how power is relative to political support. Lindsay came from one of New York City's oldest patrician families, tracing the family connection to the city back to Dutch rule in the 1660s. A handsome and articulate man, Mayor Lindsay graduated from Yale University and served in Congress during the 1960s. A moderate Republican, Lindsay was a strong supporter of civil rights.

New York City elected him mayor in 1966 with the idea that he was a young progressive leader who would do 
an excellent job in bringing the city into the post-civil rights era, continuing to promote the message of social and political equality. Instead, Lindsay's mayoralty was plagued with repeated bouts of civil unrest. Harlem, a predominantly African-American neighborhood on the northern end of Manhattan, witnessed the murder of a police officer responding to a call for service at a local mosque. The neighborhood almost erupted into a riot when police officers descended on the scene. Mayor Lindsay was roundly criticized for ineffective leadership.

In addition to civil unrest, Lindsay called for higher taxes - the highest per capita municipal taxes in the nation; this was a needed but highly unpopular move on his part. Despite higher taxes to support the mayor's public works agenda, the transit, sanitation, and other municipal workers went on strike. Without regularly operating municipal agencies, New York City was often a difficult place to navigate for residents and visitors alike. The worse problems became, the more difficult it was for Lindsay to lead the city. He ultimately left office in 1973, almost universally disliked by both political liberals and conservatives.

One of the most recent examples of how political support can catapult a mayor's popularity also comes from New York City. On September 11, 2001, Mayor Rudolph Giuliani was only weeks away from retiring from a successful two terms in office, having brought down crime levels in the city to record lows. On that fateful September morning, however, his leadership was challenged by the worst terrorist act on U.S. soil in history, when two commercial airplanes were intentionally crashed into the World Trade Center towers located in Lower Manhattan. While the details of that day are well-known, Mayor Giuliani's leadership over the crisis was a sterling example of how a strong mayor system can lead to highly successful outcomes when timely and dramatic action is required. In the weeks and months following the terrorist 
attack, New Yorkers and the U.S. public-at-large nearly universally supported his leadership - he was often referred to as "America's Mayor" as a consequence of his accomplishments.

\section{I.II - Weak mayor-council:}

In a general sense, the concept of weak mayor-council government is nearly self-explanatory. In the weak mayorcouncil form of government, the mayoralty is largely a ceremonial position. Unlike the strong mayor-council system, executive leadership entails a cooperative effort on the part of the entire city council. The council collectively decides and approves appointments. The budget is a collegial endeavor and the mayor is just one of the council members involved in the budgeting process.

A weakened mayoral position is often associated with reducing the potential for political corruption and misuse of power. By dividing power and responsibility among all council members, it is believed that corruption and misuse of power will be limited. Additionally, a weak mayor-council arrangement melds legislative and executive authority. All council members play both legislative and executive roles. Collectively, their leadership traits might produce better outcomes. In the modern city, it may be almost too much to ask one individual to handle all major events-therefore, a cooperative council arrangement could reduce the stress often placed upon a single individual in a strong mayorcouncil system. Conversely, a weak mayor-council government might reduce the ability to assign responsibility. As small sign on President Harry S. Truman's Oval Office desk stated, "The Buck Stops Here." In the case of a divided 
executive, it is unclear where the buck stops - no particular individual is solely responsible for decisions or outcomes.

\section{I.III - Municipal commission government:}

Progressive Era reformers heavily promoted the commission form of municipal government. The first use of this form of government occurred in Galveston, Texas in 1900. A city approximately 360 miles west of New Orleans along the Texas coast, Galveston had been hit by a severe hurricane. Over 6,000 residents died as a result of the severe storm. It has been estimated at over $\$ 17$ million (nearly $\$ 400$ million in current dollars) in property damage occurred. A large percentage of the storm's survivors left the city and moved elsewhere.

The city government divided the responsibilities of the municipality among council members. Each commissioner held executive power over a major public works department (e.g., water, sanitation, and roads). By dividing the executive responsibilities, the city's commissioners were able to accomplish Herculean tasks in their own areas of responsibility. Collectively, commissioners served in a legislative role, determining budgets, voting on policy directions, and approving appointments or dismissals. The mayor, a highly ceremonial figure, was selected either through a vote of the commission as a whole or by general election.

While the details of municipal commissions are discussed elsewhere in the text, the executive power elements of commission government are highly illuminating. By dividing the executive power of commissioners along the lines of public works functions, budget debates were more likely to stake the interest of one public work against others. With a largely 
ceremonial mayoral function and at-large nonpartisan commissioner selection processes, the commission form of government selected individuals based on experience within a public works area with a sense of its relative importance in relation to other public works functions. Outside of emergency situations, the commission form of government can be highly contentious despite its non-partisan membership. A divided executive, the commission model of municipal governance may reduce the capacity of government to promote cooperative decision-making, which may be more common in the council-manager forms of government.

\section{I.IV - City managers as executives:}

During the Progressive Era, municipal government moved away from strong mayoral control over the executive aspects of governance. City managers - an appointed executive became a more common feature in municipal executive leadership. As with county manager developments, Progressive Era reforms leading to the creation of city managers were driven by the desire to professionalize the executive aspects of governance as well as address substantiated and unsubstantiated concerns about the presence of political corruption in local government. It was commonly thought that an appointed manager, serving in an executive/administrative role, would be less likely to engage in corrupt or dishonest dealings than would persons beholden to partisan political interests.

The city manager as a municipal executive position has proven to be a popular form of municipal government, despite the fact that it is a challenging governmental structure. As a non-elected position, the city manager often possesses 
administrative values that undergird his or her approach to executive leadership. Many city managers hold advanced university degrees or have rich experience in urban planning, public administration, and public policy. First and foremost, they are policy and administration experts. Elected council members and the mayor, however, are motivated to a major extent by the electoral process and are quite properly sensitive to changes in the city's political climate. While city managers may arrive at effective and efficient solutions to a municipality's problems, voters may not find those solutions palatable. The result is that council members often dismiss city managers as a politically expedient solution to voter disapproval. The city manager's executive power is only as strong as their level of support from their council. As an executive role, therefore, the city manager concept may be highly effective in the complex world of municipal governance, but the position is often constrained by the shifting fortunes of council members responding to their respective political environments.

Some research has shown that policy and budgeting processes can differ greatly depending on the type of municipal executive system in place. For example, one study found that strong mayor systems have more informal and flexible decision-making processes for capital expenditures (e.g., roads, sewers, water) based on a "case by case" approach, compared to a more formal process with many specifications characterizing city-manager systems. ${ }_{-}^{12}$ 


\section{J - Executives and the Core Dimensions of Sustainability}

State and local government executives play an important role in promoting the core dimensions of sustainability. Investment in human capital is important to all political executives discussed in the chapter. Governors are often key proponents of high-quality K-12 and higher education, as are state superintendents of public instruction. State Treasurers have an important role as well, managing burgeoning 529 (or pre-paid college tuition) plans intended to broaden admission to higher education and make it a long-term affordable goal for young people in various states, cities, and rural areas. Labor commissioners, secretaries of state, city council members, and city managers have a vested interest in building human and social capital. Investments in the building of human capital often reinforce efforts to promote social capital - a societal resource that promotes the coproduction of public goods through the coordinated efforts of individuals.

Sustained state- and local-level investment in human capital will directly impact efforts to promote the development of a sustainable economic base featuring an educated and adaptive workforce capable of adapting to an ever-changing global marketplace. Political executives at the state and local level invest significant portions of their time in creating public laws that will encourage certain types of low environmental impact economic growth, particularly growth that advances the goals of ecological sustainability and which will attract and retain a highly trained workforce. Secretaries of state and labor commissioners, for instance, spend considerable time crafting policies designed to attract sustainable business ventures while simultaneously ensuring that workers operate in productive and safe work environments. Governors often use their visibility to travel 
to other regions of the country or even to other nations to discuss the benefits of business location in their state and local areas. Businesses are often reticent to relocate to a place, which cannot offer long-term opportunity, and as a consequence, the issue of sustainability often becomes an important drawing card. At the same time, states and local areas that demonstrate a strong desire to pursue clean industries that do not damage local resources may put potential new industries on notice - namely, we care deeply about how we live. Local government executives, those most familiar with the needs of local communities and the special resources of an area, are often in the best position to balance the needs of economic development with the long term goals of communities in preserving that which makes a special place in the world so very special.

Those distinctive qualities of a state or a local area often connect up strongly with environmental quality issues. While federal environmental laws have held significant sway in protecting endangered species and ameliorating the effects of environment damage of the past, state and local executives play a prominent role in upholding federal standards. Local land use permitting policies, for instance, can have a tremendous impact on native fish and wildlife species, and on land and water resources. City councils and county commissioners, as well as a host of public agencies, are virtually always the virtual "first line of defense" in protecting and maintaining the environmental goals of sustainable governance.

Local executives serve the institutional goals of sustainability through an emphasis on equitable development plans that reduce resource impacts through reduced urban sprawl. In the past, planning and zoning have been used for the nefarious purpose of de facto discrimination, excluding certain races and ethnicities from living in certain areas. While federal, state and local laws long ago moved away from 
these earlier and dismal times, the core principles of sustainability offer a further reminder that state and local executives must be ever-vigilant to policies that have the effect of excluding individuals from equal and broad participation in social, economic, and political life.

\section{Exercises}

\section{Executives - What Can I do?}

Find out more about state governors by visiting the National Governors' Association (NGA) website at: http://www.nga.org/ and their "Inside the Governors Office" Website to learn about how governors operate on a daily basis.

The National Association of Secretaries of State (NASS) has a lot of information concerning voting and elections, including a "Can I Vote" link that provides information concerning each states' voter rules and procedures: http://nass.org/. Visit the site and see what rules there are for your state concerning absentee ballots, early voting, and where ballot boxes are located.

Visit the City Mayor's Website to learn about how mayors across the world serve as executives: http://www.citymayors.com/.

The National Association of Counties is an excellent source of information for county government. Visit their Website at: http://www.naco.org/ and link to the "Learn About Counties" page and take one of their 
"Test Your Knowledge" quizzes about county government.

\section{K - Executives and Sustainability}

State and local executives can play an important role in promoting sustainability in their jurisdictions. For example, they can suggest and support legislation, issue executive orders, use their powers of suasion as leaders, and establish various advisory boards, commissions, task forces and working groups intended to promote sustainability. Some recent examples of executive efforts at the state and local levels of government include the following.

In 2000 then-Governor Gray Davis issued Executive Order D-16-00 that established a sustainable building policy to: ${ }_{-}^{13}$

Site, design, deconstruct, construct, renovate, operate, and maintain State buildings that are models of energy, water, and materials efficiency; while providing healthy, productive, and comfortable indoor environments and longterm benefits to Californians.

Similarly, in 2001 Oregon's Governor John Kitzhaber supported and signed into law the Oregon Sustainability Act which represented a statewide comprehensive plan to pursue sustainability in all facets of government, including the following goals: ${ }_{-}^{14}$ 


\section{Key Takeaways}

In supporting sustainable communities, state agencies shall seek to enable and encourage local communities to achieve the following objectives:

- Resilient local economies that provide a diversity of economic opportunities for all citizens.

- Workers supported by lifelong education to ensure a globally competitive workforce.

- An independent and productive citizenry.

- Youth supported by strong families and communities.

- Downtowns and main street communities that are active and vital.

- Development that wisely and efficiently uses infrastructure investments and natural resources.

- Affordable housing available for citizens in community centers.

- Healthy urban and rural watersheds, including habitats for fish and wildlife.

- Clean and sufficient water for all uses.

- Efficient use and reuse of resources and minimization of harmful emissions to the environment.

At the municipal level, perhaps one of the most well-known efforts to promote environmental sustainability concerning climate change and the emissions of greenhouse gasses is Seattle, Washington's Mayor Greg Nickels' effort to 
establish the Seattle Climate Action Plan. ${ }_{-}^{15}$ The goal of this initiative is "not only to inform but also to inspire individuals and organizations - both within and outside City government - to take actions that help make Seattle a model of healthy, ecologically sustainable urban living."16- Mayor Nickels has broadened this effort into a national movement called the U.S. Mayors Climate Protection Agreement.- The goal of the agreement was to get 141 cities to attempt to "meet or beat" the international Kyoto Protocol that set limits on greenhouse emissions. While the U.S. Government has not ratified the protocol, as of November 2009 over 1000 mayors have signed the U.S. Mayors Climate Protection Agreement. The agreement calls for participating cities to: ${ }_{-}^{18}$

\section{Key Takeaways}

- $\quad$ Strive to meet or beat the Kyoto Protocol targets in their own communities, through actions ranging from anti-sprawl land-use policies to urban forest restoration projects to public information campaigns;

- Urge their state governments, and the federal government, to enact policies and programs to meet or beat the greenhouse gas emission reduction target suggested for the United States in the Kyoto Protocol

- 7\% reduction from 1990 levels by 2012; and

- $\quad$ Urge the U.S. Congress to pass the bipartisan greenhouse gas reduction legislation, which would establish a national emission trading system. 


\section{L - Conclusion}

Executive leadership serves a very important function in U.S. state and local government. Governors, executive staff and boards, county commissions, mayors and many other executives are the sources of much innovative leadership and policy innovation. Executive functions are either appointed or elected and are either collegial or hierarchical. In all executive positions, there are at least two common dilemmas to be considered. First, expectations of executives generally require a well-developed staff and a strong network of relationships with other executives operating at the national, state, and local level. In other words, executive leadership is highly dependent on support systems to accomplish innovative goals. Second, successful executive leadership is dependent on the ability of leaders to gain the support of others. Elected executives find that they must gain public support in order to accomplish their most important goals, including those of the effective promotion of sustainability. Executives must lead others, convincing both everyday citizens and other elected and appointed officials that a particular direction in governing will lead to sustainable and desirable outcomes. Finally, executives must have a clear sense of the power they exercise over the institutions they represent and the influence that comes from the development of strong connections between national, state, and local governments. When these assets of executive leadership, organizational power, and network-based influence are directed toward the promotion of sustainability in a state, county or city government, remarkable outcomes can be the result. The 1,000+ mayors and county commissioners who have signed on to the Climate Protection Agreement initiative are representative of this potential for positive change. 


\section{Terms}

Commission Government

Dillon's Rule

Gerrymandering

Home Rule

Strong Mayor-Council

Weak Mayor-Council

\section{Exercises}

\section{Discussion Questions}

1. As Table 7.1 illustrates, there is much variation between states in terms of qualifications to be governor. While some states allow 18 year olds to run for office (e.g., California), many other states set the minimum age at 30 years (e.g., Florida). Similarly, there are many differences in residency and citizenship. What do you think should be minimal qualifications for governor, and why?

2. How about the structure of municipal executives - can you think of the benefits and costs of weak versus strong mayor systems? How about the city manager form of government - what benefits and 
costs does this form of executive have in comparison to mayoral systems?

3. Who are the various prominent state executive branch leaders and what function do they serve in state governments?

\section{Notes}

1. D. Coffey, "Measuring Gubernatorial Ideology: A Content Analysis of State of the State Speeches," State Politics and Policy Quarterly 5(2005): 88-103.

2. J. Barth, and M. Ferguson, "The Relationship between Gubernatorial Personality and Public Approval," State Politics and Policy Quarterly 2(2002): 268-282.

3. See R.C. Turner, "The Political Economy of Gubernatorial Smokestack Chasing: Bad Policy and Bad Politics?" State Politics and Policy Quarterly 3(2003): 270-293.

4. J.D. King, "Incumbent Popularity and Vote Choice in Gubernatorial Elections," The Journal of Politics 63 2001): 585-597.

5. R.S. Kravchuk, "The 'New Connecticut:' Lowell Weicker and the Process of Administrative Reform," Public Administration Review 53(1993): 329-339.

6. W. Clarke, "Budget Requests and Agency Head Selection Methods," Political Research Quarterly 50(1997): 301-316.

W. Clarke, "Divided Government and Budget Conflict in the U.S. States," Legislative Studies Quarterly 23(1998): 5-22. 
S.M. Morehouse, "Legislative Party Voting for the Governor's Program," Legislative Studies Quarterly 21(1996): 359-381.

7. S.B. Hansen, "Life is Not Fair: Governors' Job Performance Ratings and State Economies," Political Research Quarterly 52(1999): 167-188.

8. J. Soss, and D.T. Cannon, "Partisan Divisions and Voting Decisions: U.S. Senators, Governors, and the Rise of Divided Federal Government," Political Research Quarterly 48(1995): 253-274.

9. C.T. Stearns, "A Historical Analysis of the American County Institution and Reform: Values and the Case of the Appointed County Executive," Administrative Theory and Praxis 23(2001): 279-284.

see also A.W. Bromage, American County Government (New York: Sears Publishing Company, 1934).

10. J. Dillon, The Law of Municipal Corporations (Cornell, NY: Cornell University Press, 2009).

11. C.T. Stearns, 2001, op. cit. (see reference 9).

12. S. Nunn, "Urban Infrastructure Policies and Capital Spending in City Manager and Strong Mayor Cities," The American Review of Public Administration 26 (1996), 93-112.

13. G. Davis, Sustainable Building Task Force, Executive Order D-16-00. URL: http://www.ciwmb.ca.gov/ GreenBuilding/TaskForce/

14. Oregon Sustainability Act, (Available at: http://www.sustainableoregon.net/sust_act/HB3948.cfm)

15. Seattle Climate Action Plan. URL: http://www.seattle.gov/environment/

16. Ibid.

17. U.S. Mayors Climate Protection Agreement. URL: http://www.usmayors.org/climateprotection /agreement.htm

18. Ibid. 


\section{Chapter 8: Courts}

\section{A - Introduction}

When thinking about courts many of us think about the statute of "Blind Justice" - also known as Lady Justice - that adorns the front of many courthouses around the country. Often portrayed blindfolded and holding balance scales and a sword, the figure represented is Themis, the Greek Goddess of Justice and law. The blindfold she wears represents the impartiality with which justice is served, the scales represent the weighing of evidence on either side of a dispute brought to the court, and the sword signifies the power that is held by those making the ultimate decision arrived at after an impartial and fair hearing of evidence. In fact, in ancient Greece judges were considered servants of Themis, and they were referred to as "themistopolois."

Whether or not state and local court systems in these modern times are providing blind justice as represented by the statute of Themis could be debated. While residents in communities around the country ideally hope their own court system is impartial and immune to outside influences, few who work in or participate in American state court systems believe this is fully true; in fact, there is evidence that suggests that protection from outside influences upon the courts is becoming less and less assured. Judges today are increasingly called upon to make tough public policy decisions, with the outcomes - some of which entail promoting sustainability often being popular with the parties engaged in a particular policy issue. Very often such decisions affect tradeoffs of economic, social and environmental goals, leaving some 
parties pleased and others anxious to "redress the balance" either in new statutory language or through further litigation in the courts. This continuation of the dispute through legal action often involves seeking out "more friendly courts" with more sympathetic judges in which to file their actions.

At the beginning of the American republic, the Founding Fathers clearly believed that the judicial branch would be weak - far weaker than either the Executive or the Legislative branches. In this regard, according to Alexander Hamilton (1788) writing in the Federalist Papers (number 78):

The Executive not only dispenses the honors but also holds the sword of the community. The legislature not only commands the purse but also prescribes the rules by which the duties and rights of every citizen are to be regulated. The judiciary, on the contrary, has no influence over either the sword or the purse; no direction either of the strength or of the wealth of the society; and can take no active resolution whatever. ${ }_{-}$

Simply speaking, Hamilton thought the judicial branch, with its lack of command of either physical or financial resources, could never overpower the two other branches of government.

Contemporary state, county, and municipal courts face many challenges, with some of these challenges placing an impact upon the provision of "Blind Justice" which society expects of its courts. Despite the critical role of courts in state and local government, many citizens are unaware of the importance of their state and local court systems. In a July 2005 survey about civic education carried out by the American Bar Association, only 55 percent of the participants were able to name the three branches of government.- In point of fact, state and local courts have 100 plus times the number of trials and handle five times as many appeals as the federal courts. ${ }_{-}^{3}$ 


\section{Learning Objectives}

This chapter will:

- $\quad$ explore the major aspects of state and local courts.

- discuss how these court systems operate.

- outline selection processes for the judiciary.

- $\quad$ introduce the topic of judicial federalism; including the challenges courts will face in the future.

- discuss the impacts courts have had and will have in the future with respect to the promotion of sustainability.

\section{B - State Court Systems}

Unlike other countries with a single, centralized judicial system the United States operates under a dual system of judicial power - one system of courts operates within each state's constitution, and the other system of courts derives from the provisions of Article III of the United States Constitution. Thus, each state, as well as the federal government, are responsible for enforcing the laws, and state and local courts and federal courts adjudicate both civil and criminal case matters. It follows that Americans are dual citizens; not only are they citizens of the United States of America, but they are citizens of the state, which they reside as well.

With the exception of the appellate process, and possibly in the procedural realm of injunctive relief, the national and 
state courts are virtually separate and distinct entities. For example, since the U.S. Constitution gives the U.S. Congress authority to make uniform laws concerning bankruptcies, state courts largely lack jurisdiction in the matter. On the other hand, the U.S. Constitution does not give the federal government authority over the regulation of family life; in matters of family law (e.g., divorce, child custody, probate, division of property, etc.) a state court would have jurisdiction and a federal court would likely not hear cases._ While operating largely separately, the two systems can come together in the U.S. appellate courts (including the U.S. Supreme Court). The U.S. Supreme Court has final interpretative authority in the country with respect to disputes regarding the meaning of the U.S. Constitution and interpretation of its provisions by all "inferior" (i.e., subordinate) courts in the country. This situation of the coming together of the state and federal courts is a rather rare occurrence and only happens when there is a substantial federal question of law and all remedies at the state level are fully exhausted. Even then, it is entirely left up to the U.S. Supreme Court to decide if it wishes to hear the case. ${ }_{-}^{5}$

State courts were in place after the American Revolution, but with fresh memories of the Colonial Courts controlled as an extension of English rule Americans generally distrusted these state courts. ${ }_{-}^{6}$ Since most states were predominantly rural in the distribution of their populations, conflicts between people tended to be relatively simple and were typically settled informally without the need of court intervention. It wasn't until the mid-19th century that modern unified state court systems emerged, with many of these "upgrades" in the procedures and practices of minor courts coming in response to the many new legal challenges arising from the industrial revolution. With industrialization, the American society was changing so rapidly in so many areas that state legislatures, most of which met for only brief periods of time, neither had 
the time nor the resources to develop statutes to cope with the rising problems. For example, with the advent of labor unions, patent rights and royalties associated with new technology, and complaints over growing corporate monopolies such as utilities and the railroads brought many disputes to the courts for resolution in the absence of governing statutes. ${ }_{-}^{7}$ This set of circumstances resulted in many conflicts entering into state courts through parties asking the courts to use their common law "equity" powers to resolve contentious commercial, real estate, industrial insurance, and similar disputes born of a rapidly industrializing nation.

While general jurisdiction county courts were well established in American society and enjoyed growing legitimacy as the memories of colonial rule faded over time, these courts were neither adequately staffed nor properly organized to address the increasingly complicated problems of the day. When state and local courts became overwhelmed with litigation and lost faith in the legislative process to bring timely relief, the State Bar Associations (the professional licensing association of lawyers in a state) began to orchestrate reform in state court systems. This reformation depended on the separation of powers argument that empowered state supreme courts to create "unified" courts by mandate of the court as opposed to legislative action. More specifically, state supreme courts acted on their own authority as a separate branch of government, establishing a system of courts wherein the state supreme court sits atop a system of interconnected courts, all of which adhere to the same rules and procedures on how cases (criminal, civil and equity) are processed and appeals are made. In due course, state legislatures codified the key elements of unified court operations into state statutory law. In virtually all of the states, this creation of unified court systems resulted in the addition of new jurisdictions, the development of uniform procedures, the 
common training of court personnel, and in many cases, the development of specialized courts such as small claims courts, juvenile courts, and family law courts.

Through the U.S. Constitution (Article 111, Sec. 1) the U.S. Congress has the power to establish "inferior courts" for hearing cases arising from federal law. As previously noted, the interaction between the federal and state courts is relatively rare, with the most notable exception being in the area of Civil Rights. Federal statutes such as the Civil Rights Act and Voting Rights Act can, and have, brought federal and state court systems into close contact. As a general rule, state courts cannot interpret state constitutions in a way that undermines a U.S. Supreme Court ruling by condoning a less protective standard with respect to a civil right recognized to exist in the U.S. Constitution. On the other hand, state courts are permitted to interpret their state constitutions to require greater protections than those required by the federal courts.

Though federal and state court systems happily coexist in most respects, such mutual coexistence is not uniformly the case. For example, during the 1960s there was so much conflict between federal and state courts that a U.S. constitutional revision was proposed calling for the creation of the "Court of the Union," a judicial tribunal which would have addressed the alleged encroachments upon state judicial power by the federal system. ${ }_{-}^{8}$ Even though the "Court of the Union" idea ultimately failed to gain traction with either the public or the legal community, the conflict between the two systems that gave rise to the idea has not fully abated. An example of this conflict is the deep disagreement over capital punishment arising in late 2007.

While waiting for a U.S. Supreme Court decision as to whether the current method of lethal injection represents "cruel and unusual punishment," a violation of the Eighth Amendment of the U.S. Constitution, many of the 36 states using lethal injection as a method of execution placed a de 
facto moratorium on executions. Other states boldly rebuked the U.S. Supreme Court and moved ahead with planned executions, despite the Supreme Court's plea to await the outcome of its hearing of a key case. On November 2, 2007, barely a month after the U.S. Supreme Court agreed to hear the case [granted certiori] on lethal injection, the Florida Supreme Court unanimously ruled that their state's new method for carrying out lethal injections, after changes in the procedure were made which were prompted by a botched execution in December, do not violate the U.S. Constitution's prohibition against cruel and unusual punishment.

\section{C - How State Courts Work}

Comparing one state court to another is like comparing apples to oranges in some respects. Some state court systems are extremely complex, while others are rather simple in their structure. For example, the state of New York, with a population of 19 million residents in the year 2000, are served by approximately 3,500 full-time judges working within 13 different layers of courts. In contrast, California, with almost double the population of New York, has only three layers of courts and employs only 1,600 judges. Even though both California and New York, and their respective local court systems, operate under the same general principles and under the structure of a unified court system, they do not operate in the same way. In order for attorneys to practice law in state courts, they must be able to demonstrate knowledge of that particular state's legal system by either passing the state bar examination or otherwise demonstrating sufficient command of the particular state's system of courts. The caseloads for 
state courts vary widely, and these workloads seem to have little to do with the size of the state's population. Generally speaking, western states' courts, which were formed later in the nation's history, tend to be more modern and simplified when compared to those of longstanding operation in the eastern states.

The organization of state and local courts tends to reflect two major influences: 1) the organizational model set by the federal courts; and 2) each state's judicial preferences as manifested in state constitutions and judiciary statutes. ${ }_{-}^{9}$ The increased influence of states' constitutions within their judicial system, particularly in regards to civil rights, is known as judicial federalism. As the chapter on State Constitutions noted, Judicial Federalism is at play when state courts address the state's constitutional claims first, and only consider federal constitutional claims when extant cases can not be resolved solely upon state grounds.

The legal terminology and structure of each state's court are quite diverse, but they all follow a generic three-tiered structure. At the base is a system of general and limited jurisdiction trial courts of original jurisdiction, with an intermediate set of appellate courts in the middle, and, at the top, the Court of Last Resort (also an appellate court). In addition, many states are increasingly using specialized, sometimes known as problem-solving, courts as needed. The fundamental distinction between trial courts and appellate courts is that trial courts are those of the first instance that decide a dispute by examining the facts. Appellate courts review the trial court's application of the law with respect to the facts as recorded in the official proceedings of the case in question._. Figure 8.1 reflects how a generic three-tiered court system with a specialized court may operate. Some states' court structure, usually those with small populations, may be more simplified than the generic system, while in some cases 
the states' structure is more complex than the diagram implies.

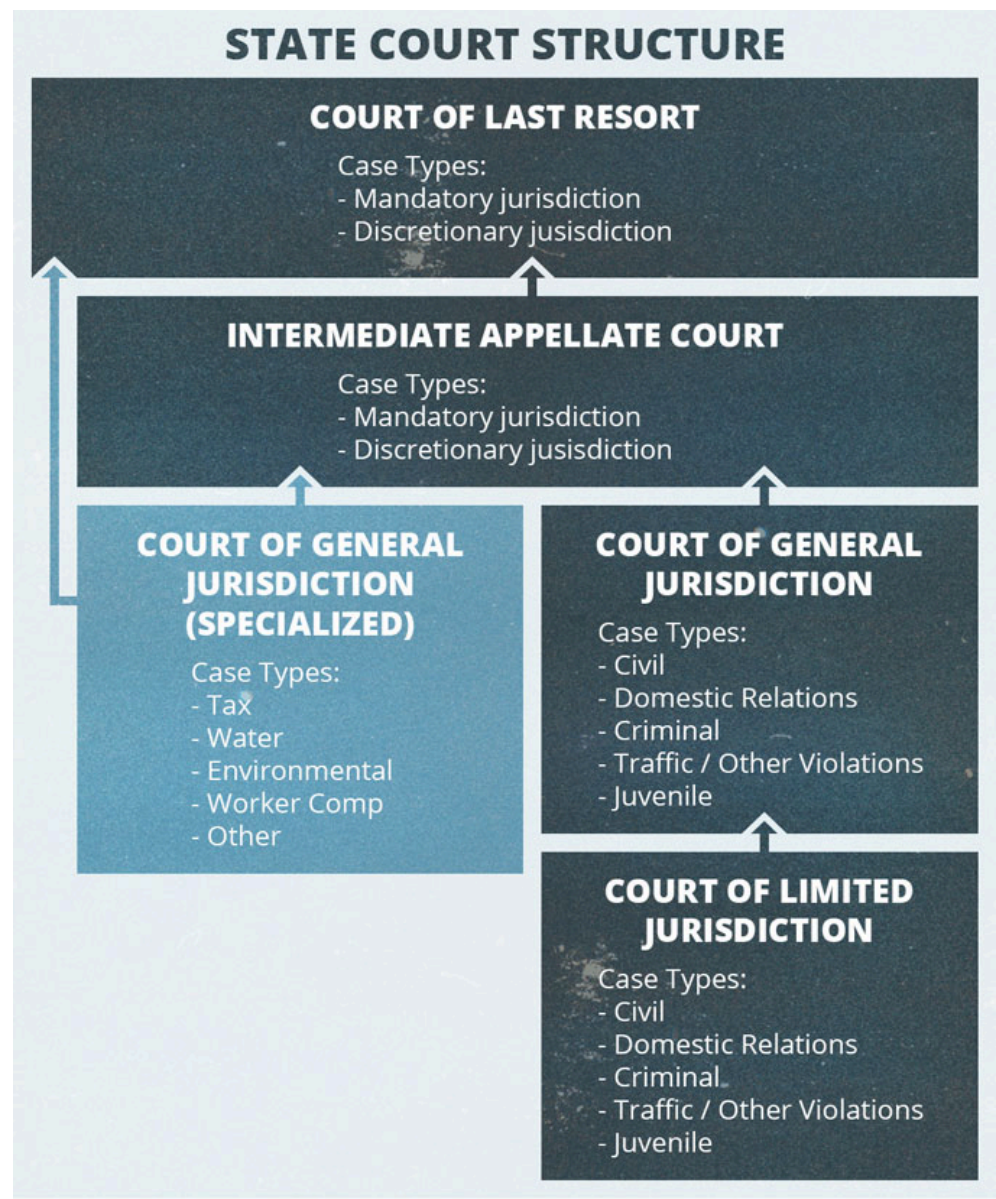

Source: Adapted from Rottman and Strickland, 2006, (see reference 10).

Figure 8.1 State Court Structures 


\section{C.I - Trial Courts:}

Trial courts often don't garner the attention of either states' higher courts or the federal courts, but they represent the veritable workhorses of the court system. Typically, each state has two types of trial courts of original jurisdiction, one of limited jurisdiction and one of general jurisdiction. Funding for trial courts of general jurisdiction generally comes from a combination of state and local sources. In most states, courts of limited jurisdiction are principally funded by local governments.

Trial courts of limited jurisdiction, as the name suggests, deal with specific types of cases and are often presided over by a single judge operating without a jury. Found in all but six states, courts of this type typically hold preliminary hearings in felony cases and exercise exclusive jurisdiction over misdemeanor and ordinance violation cases. ${ }_{-}^{11}$ Geographically, the jurisdiction of these courts varies across the states, but by-and-large they possess either a countywide jurisdiction or serve a specific local government such as a city or town. If there were an entity we could call a "community court," it would be these courts. They are located within or near a community and handle cases arising from misdemeanor offenses and ordinance violations. The courts of this type include, but are not limited to the following:

- Probate Court: Handles matters concerning administering the estate of a person who has died.

- Family Court: Handles matters concerning adoption, annulments, divorce, alimony, custody, child support, and other family matters.

- Traffic Court: Regarding cases involving minor traffic violations.

- Juvenile Court: Handles cases involving delinquent children under a certain age. 
- Municipal Court: This court handles cases involving offenses against city ordinances.

General jurisdiction trial courts are the main trial courts in the state system, and in most cases, the highest trial court. These courts are generally divided into circuits or districts. In some cases, the county serves as the judicial district, but in most states, a judicial district embraces a number of counties, which is why they are often referred to as county courts. General jurisdiction trial courts hear cases outside the jurisdiction of the limited jurisdiction trial courts, such as felony criminal cases and high stakes civil suits. In most states cases are heard in front of a single judge, often with a jury.

\section{C.II - Intermediate Appellate Court:}

Intermediate Appellate Courts go by many names, including Superior Court, Appellate Division, Court of Appeals, and even Supreme Court. With the exception of 11 states, which usually have small populations, states have some form of intermediate appellate courts. The main role of these courts is to hear appeals from trial courts. Any party, except in a case where a defendant in a criminal trial has been found not guilty, who is not satisfied with the outcome from the trial court may appeal to an intermediate appellate court. States' intermediate appellate courts are structured in a variety of ways, but typically they are regionally based and divided into "divisions," "courts" or "districts." For example, Florida has five District Courts of Appeal while more sparsely populated Idaho has a single Court of Appeals. The courts are usually set up with the judges working in panels of three or more (always an odd number), and the majority of judges decides the outcome 
of the cases brought to the court. The appellate courts do not have juries, do not hear from witnesses or review the facts of the case, but instead read briefs and hear arguments from the parties' attorneys to decide issues of law or process raised in the cases brought up on appeal. The majority of the time its decisions are final, but it is possible to appeal to the next appellate court level, often the Court of Last Resort.

\section{C.III - Court of Last Resort:}

All states have a Court of Last Resort, primarily referred to as the Supreme Court, which acts as the state's highest appellate court. In fact, two American states - Oklahoma and Texas - have two Courts of Last Resort; one represents a conventional Supreme Court and the second constitutes a Criminal Court of Appeals. The most common arrangement, found in 28 states, is a seven-judge court; 16 states have five Supreme Court justices, while five states have nine judges. ${ }_{-}{ }_{-}$

With the exception of the 11 states that don't have an intermediate court of appeals, the Courts of Last Resort have discretion as to whether or not they will hear a case. As an appellate court, it hears cases without a jury, focusing on major questions of law and constitutional issues. Many Courts of Last Resort do have original jurisdiction in certain specific matters, such as the reapportioning of legislative districts. The decisions coming from these courts are final, with the extremely rare exception of when the U.S. Supreme Court decides to hear an appeal from a state.

There are two ways a case regarding a state can be heard in the U.S. Supreme Court. The first, and almost nonexistent, is with the U.S. Supreme Court's original jurisdiction, which involves cases between the United States and a state, between 
two or more states, and between a state and a foreign country. These cases typically go through the federal system, therefore rarely involve a decision from a state court. The second path for a state-based case is through the U.S. Supreme Court's appellate jurisdiction. In these instances, the U.S. Supreme Court can choose to hear a case appealed from a state's Court of Last Resort. In order for this to occur, there must be a substantial federal question involved and the case must be viewed as "ripe," meaning the petitioner has exhausted all potential remedies in the state court system and the resolution of the case can set a useful precedent for the future resolution of similar cases.

The Fifth Amendment case of Dolan v. City of Tigard serves as a good example of such a case. This case centered on zoning regulations and property rights. Dolan, an owner of a plumbing supplies store, appealed her claim though the Oregon court system where the Oregon Supreme Court found for the City and rejected the argument that an unconstitutional taking of private property by the government without just compensation occurred as a result of a zoning decision made by the city. As the case involved Fifth Amendment constitutional rights, the federal courts determined that this case raised a question of federal law. Given that essential determination, Dolan was able to appeal her case to the federal courts, and ultimately all the way to the U.S. Supreme Court. The U.S. Supreme Court found in favor of Dolan, causing local governments across the country to take notice of new requirements for determining just compensation in similar cases. 


\section{C.IV - Problem-Solving Courts:}

Problem-solving courts commonly referred to as "specialized courts" dispensing "therapeutic jurisprudence," have emerged in most American states over the past decade. Problem-solving courts relieve overwhelmed legal systems dealing with persons and families whose actions stem from problems better dealt with by "supervised treatment" rather than incarceration or similar forms of punitive governmental sanctions. These courts represent an attempt to craft new, adaptive responses to chronic social, human and legal problems that are resistant to conventional solutions associated with the adversarial process. ${ }_{-}^{13}$

Though lacking a precise definition or legal philosophy, problem-solving courts share a basic theme: a desire to improve the results that courts achieve for victims, litigants, defendants, and communities through a collaborative process rather than the conventional adversarial process. ${ }_{-}^{14}$ Traditional courts tend to focus on the finding of guilt or innocence, entail looking backward in time, and are conducted in an adversarial way. In comparison, specialized courts focus on the identification of therapeutic interventions, seek to affect future outcomes, make use of a collaborative process, and involve a wide range of court-based and community-based services and stakeholders. ${ }_{-} 15$

There are a number of factors that have led to the rise of special courts, including prison (state facilities) and jail (county and city facilities) overcrowding, highly stressed social and community institutions, and increased awareness of social issues such as domestic violence. While increased social awareness has indeed played some role in the development of these specialized courts, the lack of resources available to state and local court systems has been the major driver behind the broadening use of such courts; the caseloads of the courts 
have increased substantially in recent decades while the resources available to the courts have not increased proportionately. For example, from 1984 to 1997 the number of domestic violence cases in state courts increased by 77 percent. ${ }^{16}$ Commenting on rising caseloads, Minnesota Chief Justice Kathleen Blaze stated, "You just move 'em, move 'em, move 'em. One of my colleagues on the bench said, 'you know, I feel like I work for McJustice: We sure aren't good for you, but we are fast." ${ }_{-}$

Problem-solving courts got their start in 1989 when Dade County, Florida experimented with a drug court. The drug court, in an attempt to address the problem of criminal recidivism (re-offense) among illegal drug use offenders, sentenced such repeat offenders to a long-term, judicially supervised drug treatment instead of incarceration. In reflection of Dade County's success with this alternative to incarceration, drug courts taking a similar approach to drug use offenders began to crop up all over the United States. As of April 2007, the U.S. Department of Justice reported that there were 1,699 fully operational drug courts in the United States, and another 62 tribal drug courts. 18

Since this development in 1989, a variety of specialized courts have emerged, primarily designed to tackle difficult social issues. For example, New York City opened its Midtown Community Court in 1993 to target misdemeanor "qualityof-life" crimes, such as prostitution and shoplifting. Instead of relying upon traditional sentencing involving incarceration, offenders were required to pay back the community for the harm they caused by community service work such as cleaning local parks, sweeping streets and painting over graffiti. In addition, to address the underlying cause of the problem behavior, the offenders were mandated to receive "therapeutic" social services, such as counseling, anger management instruction, substance abuse treatment, and job training. ${ }^{19}$ Typically, elements of the local community are also 
engaged in the work of the problem-solving courts by participating on advisory panels, providing volunteer services, and taking part in town hall meetings. The City of Portland, Oregon, for example, opened a number of "Community Courts" throughout the city, in many cases holding court at existing local community centers.

Evidence collected in evaluation studies conducted on many drug courts indicates that these problem-solving courts tend to achieve favorable results with regards to keeping offenders in treatment, reducing their drug use, reducing recidivism, and economizing on jail and prison costs. The rate of retention in drug abuse treatment ordered by drug courts is typically 60 percent, as compared to only 10 to 30 percent for voluntary programs. Moreover, drug court participants have far lower re-arrest rates than do persons taken into the traditional court process. ${ }_{-}^{20}$ Even after fully accounting for administrative and overhead costs, in a two-year period, the drug court in Multnomah County(Oregon) saved \$2.5 million in criminal justice system costs, with an additional savings being made in outside the court system costs such as reduced theft and reduced public assistance payments. Those associated costs were estimated at $\$ 10$ million. ${ }_{-}^{21}$

The types of problem-solving courts are many, but the majority of them fall into the categories of limited or general jurisdiction trial courts (courts of original jurisdiction). The most common specialized courts are those that work on social issues, primarily substance abuse and family courts. Some examples of specialized courts include: gun courts, gambling courts, homeless indigent courts, mental-health courts, teen courts, domestic violence courts, elder courts, and community courts involving lay citizens in the process of arranging for property crime offenders to engage in compensatory justice with respect to those whom they victimized.

Some states have taken it upon themselves to permit the establishment of specialized courts for the protection of 
the environment and for addressing the economic costs and benefits of pursuing sustainability. Such specialized courts have been created to deal with highly complex issues, which require extraordinary scientific and technical knowledge on the part of the court. For example, the State of Montana created a Water Court to expedite and facilitate the statewide adjudication of state water right claims; once the adjudication process is complete the state may dissolve the court. ${ }_{-}^{22}$

In addition to the difficult adjudication of rival water rights claims, Colorado's version of the Water Court has jurisdiction over the use and administration of water and all water matters within its statewide jurisdiction. ${ }^{23}$ Vermont has established an Environmental Court to hear matters on municipal and regional planning and development, to hear disputes over state solid waste ordinances, and to handle cases arising from the enforcement actions of the Vermont Agency of Natural Resources. As matters relating to global climate change and the more rigorous regulation of greenhouse gases arise, it is likely that more specialized courts will be created in other states to deal with the disputes arising from the active pursuit of sustainability in our states and local governments.

States are also developing specialized courts to manage economic disputes that arise in the course of commercial activity (such as business formation, business transactions, and the sale/purchase of business assets). Five states have Tax Courts that deal exclusively with tax disputes. Montana, Nebraska, and Rhode Island developed specialized courts to deal exclusively with Workers' Compensation cases. In many states, which do not have such specialized courts there has been a steady trend in the growth of the number and range of activities of administrative law judges. These "hearings officers" work within administrative agencies, which engage in regulatory actions that give rise to many disputes (environmental regulations, labor/management actions under collective bargaining agreements, compensation for damages 
incurred from state government action on one's property, etc.). These administrative law judges (ALJs) hold quasijudicial hearings, carefully weigh the arguments of the agency and aggrieved citizens, and have the authority to mediate, arbitrate and ultimately decide upon an outcome to a case, which is binding on all parties. While such decisions made by ALJs can be appealed to the courts, state court judges seldom overturn their rulings.

\section{D - Judicial Selection}

The manifest aim of the judicial selection process in the American states is to select a judiciary that is as impartial as the Greek Goddess Themis, but one that is at the same time accountable to the will of the people of the state. Unlike the federal judiciary where lifetime appointments are made to the federal district, circuit and supreme courts, in the states nearly all judges serve for fixed terms of office and most are subject to some method of retention in office-based upon a vote of the people. Each state uses a system of selecting judges they feel is best suited to accomplish the dual goals of impartiality and accountability to the people. In most cases, a state's judicial selection process does not catch the public's attention given the limited knowledge citizens typically command regarding the courts and the actions of their judges; some particularly cynical observers have characterized judicial selection processes as being "about as exciting as a game of checkers...played by the mail."

There is no simple way to describe states with respect to their form of judicial selection system, because judges in different (or even the same levels of courts) within one state 
may be selected through different methods. ${ }_{-}^{25}$ A system to select a judge for the intermediate appellate court, for example, may be different than the system used for the Court of Last Resort, and different again from the system used for recruitment to the trial courts. Making things even more complex, the selection process for subsequent terms may be different than the initial term of office.

No single selection process - such as gubernatorial appointment, merit commission screening for gubernatorial appointment, non-partisan election, partisan election, legislative appointment, nomination to vacancies by county commissioners - currently dominates over other processes, nor do these selection processes within each state remain static over time. For example, in 1980 it was the case that 45 percent of the states used partisan elections and 29 percent of the states used non-partisan elections as their respective methods for selecting judges to trial courts; by 2004, however, those figures were just about reversed; in 2004, 44 percent of the states were using non-partisan elections and 35 percent were using partisan elections for selecting their trial court judges. ${ }_{-}^{26}$

While there are many types of selection processes, four principal processes are used in the U.S. for judicial selection within the states: partisan election, non-partisan election, appointment, and the Merit System (known as the Missouri Plan). No one process dominates the others in extent of use, or in the level of controversy associated with its use. There are some regional differences in evidence in where each type of judicial selection process tends to be concentrated. For example, some of the nation's most conservative states, including Texas and states in the "Deep South," use partisan elections principally, while many Midwest states tend to make use of the gubernatorial appointment process. Table 8.1 shows how each state selects its judiciary as of the present time 


\begin{tabular}{|c|c|c|c|}
\hline & $\begin{array}{l}\text { Court of } \\
\text { Last Resort } \\
\text { Name/s }\end{array}$ & Method of Selection & $\begin{array}{l}\text { Intermediate } \\
\text { Appellate Court/s }\end{array}$ \\
\hline Alabama & $\begin{array}{l}\text { Supreme } \\
\text { Court }\end{array}$ & Partisan Election & $\begin{array}{l}\text { Court of Criminal } \\
\text { Appeals / Court of } \\
\text { Civil Appeals }\end{array}$ \\
\hline Alaska*** & $\begin{array}{l}\text { Supreme } \\
\text { Court }\end{array}$ & Appointment & Court of Appeals \\
\hline Arizona*** & $\begin{array}{l}\text { Supreme } \\
\text { Court }\end{array}$ & Appointment & Court of Appeals \\
\hline Arkansas & $\begin{array}{l}\text { Supreme } \\
\text { Court }\end{array}$ & Nonpartisan Election & Court of Appeals \\
\hline California & $\begin{array}{l}\text { Supreme } \\
\text { Court }\end{array}$ & Appointment & Court of Appeal \\
\hline Colorado*** & $\begin{array}{l}\text { Supreme } \\
\text { Court }\end{array}$ & Appointment & Court of Appeals \\
\hline Connecticut & $\begin{array}{l}\text { Supreme } \\
\text { Court }\end{array}$ & Appointment & Appellate Court \\
\hline Delaware & $\begin{array}{l}\text { Supreme } \\
\text { Court }\end{array}$ & Appointment & - \\
\hline Florida & $\begin{array}{l}\text { Supreme } \\
\text { Court }\end{array}$ & Appointment & $\begin{array}{l}\text { District Courts of } \\
\text { Appeals }\end{array}$ \\
\hline Georgia & $\begin{array}{l}\text { Supreme } \\
\text { Court }\end{array}$ & Nonpartisan Election & Court of Appeals \\
\hline Hawaii & $\begin{array}{l}\text { Supreme } \\
\text { Court }\end{array}$ & Appointment & $\begin{array}{l}\text { Intermediate Court } \\
\text { of Appeals }\end{array}$ \\
\hline Idaho & $\begin{array}{l}\text { Supreme } \\
\text { Court }\end{array}$ & Nonpartisan Election & Court of Appeals \\
\hline Illinois & $\begin{array}{l}\text { Supreme } \\
\text { Court }\end{array}$ & Partisan Election & Appellate Court \\
\hline Indiana ${ }^{* * *}$ & $\begin{array}{l}\text { Supreme } \\
\text { Court }\end{array}$ & Appointment & $\begin{array}{l}\text { Court of Appeals / } \\
\text { Tax Court }\end{array}$ \\
\hline Iowa*** & $\begin{array}{l}\text { Supreme } \\
\text { Court }\end{array}$ & Appointment & Court of Appeals \\
\hline Kansas*** & $\begin{array}{l}\text { Supreme } \\
\text { Court }\end{array}$ & Appointment & Court of Appeals \\
\hline Kentucky & $\begin{array}{l}\text { Supreme } \\
\text { Court }\end{array}$ & Nonpartisan Election & Court of Appeals \\
\hline Louisiana & $\begin{array}{l}\text { Supreme } \\
\text { Court }\end{array}$ & Partisan Election & Court of Appeal \\
\hline
\end{tabular}




\begin{tabular}{|c|c|c|c|}
\hline Maine & $\begin{array}{l}\text { Supreme } \\
\text { Judicial } \\
\text { Court }\end{array}$ & Appointment & - \\
\hline Maryland & $\begin{array}{l}\text { Court of } \\
\text { Appeals }\end{array}$ & Appointment & $\begin{array}{l}\text { Court of Special } \\
\text { Appeals }\end{array}$ \\
\hline Massachusetts & $\begin{array}{l}\text { Supreme } \\
\text { Judicial } \\
\text { Court }\end{array}$ & Appointment & Appeals Court \\
\hline Michigan & $\begin{array}{l}\text { Supreme } \\
\text { Court }\end{array}$ & Nonpartisan Election & Court of Appeals \\
\hline Minnesota & $\begin{array}{l}\text { Supreme } \\
\text { Court }\end{array}$ & Nonpartisan Election & Court of Appeals \\
\hline Mississippi & $\begin{array}{l}\text { Supreme } \\
\text { Court }\end{array}$ & Nonpartisan Election & Court of Appeals \\
\hline Missouri*** & $\begin{array}{l}\text { Supreme } \\
\text { Court }\end{array}$ & Appointment & Court of Appeals \\
\hline Montana & $\begin{array}{l}\text { Supreme } \\
\text { Court }\end{array}$ & Nonpartisan Election & - \\
\hline Nebraska*** & $\begin{array}{l}\text { Supreme } \\
\text { Court }\end{array}$ & Appointment & Court of Appeals \\
\hline Nevada & $\begin{array}{l}\text { Supreme } \\
\text { Court }\end{array}$ & Nonpartisan Election & - \\
\hline $\begin{array}{l}\text { New } \\
\text { Hampshire }\end{array}$ & $\begin{array}{l}\text { Supreme } \\
\text { Court }\end{array}$ & Appointment & - \\
\hline New Jersey & $\begin{array}{l}\text { Supreme } \\
\text { Court }\end{array}$ & Appointment & $\begin{array}{l}\text { Appellate Division } \\
\text { of Superior Court }\end{array}$ \\
\hline New Mexico & $\begin{array}{l}\text { Supreme } \\
\text { Court }\end{array}$ & Partisan Election & Court of Appeals \\
\hline New York & $\begin{array}{l}\text { Supreme } \\
\text { Court }\end{array}$ & Appointment & $\begin{array}{l}\text { Appellate Division } \\
\text { of Supreme Court/ } \\
\text { Appellate Terms of } \\
\text { Supreme Court }\end{array}$ \\
\hline $\begin{array}{l}\text { North } \\
\text { Carolina }\end{array}$ & $\begin{array}{l}\text { Supreme } \\
\text { Court }\end{array}$ & Nonpartisan Election & - \\
\hline North Dakota & $\begin{array}{l}\text { Supreme } \\
\text { Court }\end{array}$ & Nonpartisan Election & - \\
\hline Ohio & $\begin{array}{l}\text { Supreme } \\
\text { Court }\end{array}$ & Partisan Election & Courts of Appeals \\
\hline
\end{tabular}




\begin{tabular}{|c|c|c|c|}
\hline Oklahoma*** & $\begin{array}{l}\text { Supreme } \\
\text { Court/ } \\
\text { Criminal } \\
\text { Court of } \\
\text { Appeals }\end{array}$ & $\begin{array}{l}\text { Appointment/ } \\
\text { Appointment }\end{array}$ & Court of Appeals \\
\hline Oregon & $\begin{array}{l}\text { Supreme } \\
\text { Court }\end{array}$ & Nonpartisan Election & Court of Appeals \\
\hline Pennsylvania & $\begin{array}{l}\text { Supreme } \\
\text { Court }\end{array}$ & Partisan Election & $\begin{array}{l}\text { Superior Court/ } \\
\text { Commonwealth } \\
\text { Court }\end{array}$ \\
\hline Rhode Island & $\begin{array}{l}\text { Supreme } \\
\text { Court }\end{array}$ & Appointment & - \\
\hline $\begin{array}{l}\text { South } \\
\text { Carolina }\end{array}$ & $\begin{array}{l}\text { Supreme } \\
\text { Court }\end{array}$ & Appointment \# & Court of Appeals \\
\hline South Dakota & $\begin{array}{l}\text { Supreme } \\
\text { Court }\end{array}$ & Appointment & - \\
\hline Tennessee & $\begin{array}{l}\text { Supreme } \\
\text { Court }\end{array}$ & Appointment & $\begin{array}{l}\text { Court of Appeals/ } \\
\text { Court of Criminal } \\
\text { Appeals }\end{array}$ \\
\hline Texas & $\begin{array}{l}\text { Supreme } \\
\text { Court/ } \\
\text { Criminal } \\
\text { Court of } \\
\text { Appeals }\end{array}$ & $\begin{array}{l}\text { Partisan Election/ } \\
\text { Partisan Election }\end{array}$ & Court of Appeal \\
\hline Utah*** & $\begin{array}{l}\text { Supreme } \\
\text { Court }\end{array}$ & Appointment & Court of Appeals \\
\hline Vermont & $\begin{array}{l}\text { Supreme } \\
\text { Court }\end{array}$ & Appointment & - \\
\hline Virginia & $\begin{array}{l}\text { Supreme } \\
\text { Court }\end{array}$ & - & Court of Appeals \\
\hline Washington & $\begin{array}{l}\text { Supreme } \\
\text { Court }\end{array}$ & Appointment \# & Court of Appeals \\
\hline West Virginia & $\begin{array}{l}\text { Supreme } \\
\text { Court of } \\
\text { Appeals }\end{array}$ & Nonpartisan Election & - \\
\hline Wisconsin & $\begin{array}{l}\text { Supreme } \\
\text { Court }\end{array}$ & Partisan Election & Court of Appeals \\
\hline Wyoming*** & $\begin{array}{l}\text { Supreme } \\
\text { Court }\end{array}$ & Nonpartisan Election & - \\
\hline
\end{tabular}




\begin{tabular}{|c|c|c|c|}
\hline & Appellate Court Justices & $\begin{array}{l}\text { General } \\
\text { Trial } \\
\text { Court/s }\end{array}$ & $\begin{array}{l}\text { Method of } \\
\text { Selection }\end{array}$ \\
\hline Alabama & $\begin{array}{l}\text { Partisan Election / Partisan } \\
\text { Election }\end{array}$ & $\begin{array}{l}\text { Circuit } \\
\text { Court }\end{array}$ & Partisan Election \\
\hline Alaska*** & Appointment & $\begin{array}{l}\text { Superior } \\
\text { Court }\end{array}$ & Appointment \\
\hline Arizona*** & Appointment & $\begin{array}{l}\text { Superior } \\
\text { Court }\end{array}$ & Appointment \\
\hline Arkansas & Nonpartisan Election & $\begin{array}{l}\text { Chancery/ } \\
\text { Probate } \\
\text { Court/ } \\
\text { Circuit } \\
\text { Court }\end{array}$ & $\begin{array}{l}\text { Nonpartisan } \\
\text { Election }\end{array}$ \\
\hline California & Appointment & $\begin{array}{l}\text { Superior } \\
\text { Court }\end{array}$ & $\begin{array}{l}\text { Nonpartisan } \\
\text { Election }\end{array}$ \\
\hline Colorado*** & Appointment & $\begin{array}{l}\text { District } \\
\text { Court }\end{array}$ & Appointment \\
\hline Connecticut & Appointment & $\begin{array}{l}\text { Superior } \\
\text { Court }\end{array}$ & Appointment \\
\hline Delaware & - & $\begin{array}{l}\text { Superior } \\
\text { Court/ } \\
\text { Court of } \\
\text { Chancery }\end{array}$ & $\begin{array}{l}\text { Appointment/ } \\
\text { Appointment }\end{array}$ \\
\hline Florida & Appointment & $\begin{array}{l}\text { Circuit } \\
\text { Court }\end{array}$ & $\begin{array}{l}\text { Nonpartisan } \\
\text { Election }\end{array}$ \\
\hline Georgia & Nonpartisan Election & $\begin{array}{l}\text { Superior } \\
\text { Court }\end{array}$ & $\begin{array}{l}\text { Nonpartisan } \\
\text { Election }\end{array}$ \\
\hline Hawaii & Appointment & $\begin{array}{l}\text { Circuit } \\
\text { Court }\end{array}$ & Appointment \\
\hline Idaho & Nonpartisan Election & $\begin{array}{l}\text { District } \\
\text { Court }\end{array}$ & $\begin{array}{l}\text { Nonpartisan } \\
\text { Election }\end{array}$ \\
\hline Illinois & Partisan Election* & $\begin{array}{l}\text { Circuit } \\
\text { Court }\end{array}$ & Partisan Election \\
\hline Indiana $* * *$ & $\begin{array}{l}\text { Appointment/ } \\
\text { Appointment/Appointment }\end{array}$ & $\begin{array}{l}\text { Superior } \\
\text { Court/ } \\
\text { Probate } \\
\text { Court/ } \\
\text { Circuit } \\
\text { Court }\end{array}$ & Partisan Election \\
\hline Iowa*** & Appointment & $\begin{array}{l}\text { District } \\
\text { Court }\end{array}$ & Appointment \\
\hline
\end{tabular}




\begin{tabular}{|c|c|c|c|}
\hline Kansas*** & Appointment & $\begin{array}{l}\text { District } \\
\text { Court }\end{array}$ & Appointment \\
\hline Kentucky & Nonpartisan Election* & $\begin{array}{l}\text { Circuit } \\
\text { Court }\end{array}$ & $\begin{array}{l}\text { Nonpartisan } \\
\text { Election }\end{array}$ \\
\hline Louisiana & Partisan Election* & $\begin{array}{l}\text { District } \\
\text { Court }\end{array}$ & Partisan Election \\
\hline Maine & - & $\begin{array}{l}\text { Superior } \\
\text { Court }\end{array}$ & Appointment \\
\hline Maryland & Appointment \# & $\begin{array}{l}\text { Circuit } \\
\text { Court }\end{array}$ & Partisan Election \\
\hline Massachusetts & Appointment & $\begin{array}{l}\text { Supreme } \\
\text { Court }\end{array}$ & Appointment \\
\hline Michigan & Nonpartisan Election & $\begin{array}{l}\text { Circuit } \\
\text { Court }\end{array}$ & $\begin{array}{l}\text { Nonpartisan } \\
\text { Election }\end{array}$ \\
\hline Minnesota & Nonpartisan Election & $\begin{array}{l}\text { District } \\
\text { Court }\end{array}$ & $\begin{array}{l}\text { Nonpartisan } \\
\text { Election }\end{array}$ \\
\hline Mississippi & Nonpartisan Election* & $\begin{array}{l}\text { Circuit } \\
\text { Court }\end{array}$ & $\begin{array}{l}\text { Nonpartisan } \\
\text { Election }\end{array}$ \\
\hline Missouri*** & Appointment & $\begin{array}{l}\text { Circuit } \\
\text { Court }\end{array}$ & Partisan Election \\
\hline Montana & - & $\begin{array}{l}\text { District } \\
\text { Court }\end{array}$ & $\begin{array}{l}\text { Nonpartisan } \\
\text { Election }\end{array}$ \\
\hline Nebraska*** & Appointment** & $\begin{array}{l}\text { District } \\
\text { Court }\end{array}$ & Appointment \\
\hline Nevada & - & $\begin{array}{l}\text { District } \\
\text { Court }\end{array}$ & $\begin{array}{l}\text { Nonpartisan } \\
\text { Election }\end{array}$ \\
\hline $\begin{array}{l}\text { New } \\
\text { Hampshire }\end{array}$ & - & $\begin{array}{l}\text { Superior } \\
\text { Court }\end{array}$ & Appointment \\
\hline New Jersey & Appointment & $\begin{array}{l}\text { Superior } \\
\text { Court }\end{array}$ & Appointment \\
\hline New Mexico & Partisan Election & $\begin{array}{l}\text { District } \\
\text { Court }\end{array}$ & Partisan Election \\
\hline New York & Appointment/Appointment & $\begin{array}{l}\text { Supreme } \\
\text { Court/ } \\
\text { County } \\
\text { Court }\end{array}$ & $\begin{array}{l}\text { Partisan } \\
\text { Election/ } \\
\text { Partisan Election }\end{array}$ \\
\hline $\begin{array}{l}\text { North } \\
\text { Carolina }\end{array}$ & - & $\begin{array}{l}\text { Superior } \\
\text { Court }\end{array}$ & $\begin{array}{l}\text { Nonpartisan } \\
\text { Election }\end{array}$ \\
\hline North Dakota & - & $\begin{array}{l}\text { District } \\
\text { Court }\end{array}$ & $\begin{array}{l}\text { Nonpartisan } \\
\text { Election }\end{array}$ \\
\hline
\end{tabular}




\begin{tabular}{|c|c|c|c|}
\hline Ohio & Partisan Election & $\begin{array}{l}\text { Court of } \\
\text { Common } \\
\text { Pleas }\end{array}$ & Partisan Election \\
\hline Oklahoma*** & Appointment* & $\begin{array}{l}\text { District } \\
\text { Court }\end{array}$ & $\begin{array}{l}\text { Nonpartisan } \\
\text { Election }\end{array}$ \\
\hline Oregon & Nonpartisan Election & $\begin{array}{l}\text { Circuit } \\
\text { Court/Tax } \\
\text { Court }\end{array}$ & $\begin{array}{l}\text { Nonpartisan } \\
\text { Election/ } \\
\text { Nonpartisan } \\
\text { Election }\end{array}$ \\
\hline Pennsylvania & $\begin{array}{l}\text { Partisan Election/Partisan } \\
\text { Election }\end{array}$ & $\begin{array}{l}\text { Court of } \\
\text { Common } \\
\text { Pleas }\end{array}$ & Partisan Election \\
\hline Rhode Island & - & $\begin{array}{l}\text { Superior } \\
\text { Court }\end{array}$ & Appointment \\
\hline $\begin{array}{l}\text { South } \\
\text { Carolina }\end{array}$ & Appointment \# & $\begin{array}{l}\text { Circuit } \\
\text { Court }\end{array}$ & Appointment \\
\hline South Dakota & - & $\begin{array}{l}\text { Circuit } \\
\text { Court }\end{array}$ & $\begin{array}{l}\text { Nonpartisan } \\
\text { Election }\end{array}$ \\
\hline Tennessee & $\begin{array}{l}\text { Partisan Election/Partisan } \\
\text { Election }\end{array}$ & $\begin{array}{l}\text { Circuit, } \\
\text { Criminal, } \\
\text { Chancery, } \\
\text { \& Probate } \\
\text { Court }\end{array}$ & Appointment \\
\hline Texas & Partisan Election & $\begin{array}{l}\text { District } \\
\text { Court }\end{array}$ & Partisan Election \\
\hline Utah*** & Appointment & $\begin{array}{l}\text { District } \\
\text { Court }\end{array}$ & Appointment \\
\hline Vermont & - & $\begin{array}{l}\text { Superior } \\
\text { Court/ } \\
\text { District } \\
\text { Court }\end{array}$ & $\begin{array}{l}\text { Appointment/ } \\
\text { Appointment }\end{array}$ \\
\hline Virginia & Appointment \# & $\begin{array}{l}\text { Circuit } \\
\text { Court }\end{array}$ & Appointment \\
\hline Washington & Nonpartisan Election & $\begin{array}{l}\text { Superior } \\
\text { Court }\end{array}$ & $\begin{array}{l}\text { Nonpartisan } \\
\text { Election }\end{array}$ \\
\hline West Virginia & - & $\begin{array}{l}\text { Circuit } \\
\text { Court }\end{array}$ & Partisan Election \\
\hline Wisconsin & Nonpartisan Election & $\begin{array}{l}\text { Circuit } \\
\text { Court }\end{array}$ & $\begin{array}{l}\text { Nonpartisan } \\
\text { Election }\end{array}$ \\
\hline Wyoming*** & - & $\begin{array}{l}\text { District } \\
\text { Court }\end{array}$ & Appointmen \\
\hline
\end{tabular}


Table 8.1 Judicial Selection Method by State $(*=$ Justices chosen by district; $* *=$ Chief Justice chosen statewide, associate judges chosen by district; $* * *=$ Uses of the Merit System for Judicial Selection; \#=Legislative Appointment)

\section{D.I - Partisan and Non-Partisan Elections:}

As of 2006, 39 states elect some or all of their judges; this represents nearly 90 percent of state judiciaries across the country. From this statistic alone it is clear that the goals of impartiality and public accountability are both important elements of state and local government judicial selection in the U.S. Alexander Hamilton (1788) spoke for the Founding Fathers in Federalist Paper No. 78 wherein he argued that if judges in federal courts were chosen by elected officials they would harbor "too great a disposition to consult popularity to justify a reliance that nothing would be consulted but the Constitution and the laws.".27 In 1939, well over a century after Hamilton's warning, President William Howard Taft described judicial elections in the U.S. as "disgraceful, and so shocking...that they ought to be condemned.28

Alexander Hamilton and former-President Taft may well be turning in their respective graves as the results of one national survey conducted in 2000 found that 78 percent of Americans believe their state and local judges are influenced (that is, their impartiality is compromised) by having to raise campaign funds. ${ }^{29}$ Even so, voter turnout for judicial elections is habitually low as many voters skip past these elections. At times the biases in the operation of courts associated with popular elections can be severe. For example, 1990 the U.S. Justice Department used federal anti-discrimination statutes to invalidate the State of Georgia's system of electing judges 
because it was found to be discriminatory against African Americans. ${ }_{-}^{30}$

Citizens are poorly informed about judges because, in most states, there are state supreme court-issued limits or guidelines, derived from the American Bar Association's judicial canons, as to what a judicial candidate can say or do while campaigning for judicial office. These limitations tend to be especially strict in states with non-partisan elections. For example, the Minnesota Code of Judicial Conduct Canon 5(A)(3)(d)(i) prohibits judicial candidates from announcing their views on disputed legal or political issues. ${ }_{-}^{31}$ Yet there are a handful of states, such as Texas, where the judicial elections are highly partisan, extremely expensive, and vehemently contested.

According to Henry Glick and Kenneth Vines, in a great many cases judicial seats that are nominally up for election are vacated by sitting judges shortly prior to the end of their terms of office and filled by judges that are appointed by the sitting governor. ${ }^{32}$ The governor's appointee then runs as an incumbent judge during the next election. The impact of such interim appointments has greatly shaped the composition of the nation's state and local judiciary: between 1964-2004, more than half (52 percent) of the judges serving in partisan election states gained their position through an interim appointment, with the state-specific percentages ranging from 18 to 92 percent. ${ }_{-}^{33}$ These interim appointments more often than not become permanent due to the extremely high retention rate judicial incumbents enjoy in their elections once they get to the bench.

Partisan elections are those in which judicial candidates, including incumbents, run in party primaries and are listed

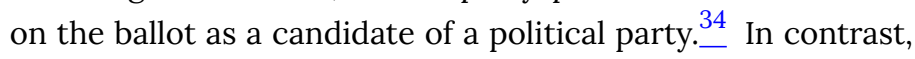
non-partisan elections are those in which the judicial candidates run on a ballot without a political party designation. There are a few cases where candidates are 
chosen in a party primary and backed by the party, but they appear without the label on the ballot. The party affiliations of judges aren't exactly the best-kept secrets; judicial candidates often list a party affiliation in their official biographies, and political parties will often endorse particular judicial candidates..

In comparing the two elective systems, each one has its own pros and cons. The proponents of partisan election tend to feel strongly that the party affiliation next to a judicial candidate's name provides important information to voters with respect to the candidate's likely political philosophy. The proponents counter that "justice is not partisan" - that is, there is no Democratic or Republican form of justice, only the impartial justice dispensed by the blindfolded Themis who is unaware of whether the parties coming before her are Democrats or Republicans. The proponents of partisan election counter that in the non-partisan judicial elections it is the voters who are blindfolded and unable to exercise popular accountability over judges as intended in the election process.

One additional drawback associated with partisan judicial elections is that they can lead to an imbalance among a state's judiciary in cases where a state features strong oneparty dominance. The State of Texas encountered this problem during the indictment of former House Majority Leader Tom Delay for corruption charges. Since Texas judges are elected on a partisan ticket, and often contribute openly to partisan causes, quite a scramble was necessary to identify an impartial trial judge who was acceptable to both the prosecution and defense in the Delay case. $\frac{36}{-}$ 


\section{D.II - Judicial Appointments and the Merit System:}

There are two common methods of judicial appointment, "simple" gubernatorial appointment and the "Merit System" of appointment. The simple gubernatorial appointment is much like that for federal judges, where the highest elected official (the President in the federal government and the Governor in the states) fill vacancies on the bench. How judges are selected by state governors depends on the governor in question and traditions in the state. Generally speaking, the background of the judge (former prosecutors, defense attorneys, type of pro bono work done, level of activity in local bar associations, etc.), the political needs of the governor (someone from a particular area of the state is needed to balance out an appellate bench), presence or absence of advocacy for particular persons by interest groups (women attorneys, minority attorneys, etc.), the views of leaders of the State Bar Association, and the preferences of the political parties are all more or less in play when state governors make their judicial appointments. $\stackrel{37}{-}$

The Merit System or Missouri Plan system for judicial appointment was designed to "take politics out of judicial selection" by combining the methods of appointment with election in a very particular way. Featuring three distinct components, it is the most complex of the judicial selection processes. Fourteen states use some version of the Missouri plan, with some additional states using a modified version of this type of selection process. Under the provision of the Missouri Plan, candidates for judicial vacancies are first reviewed by an independent, bipartisan commission of both lawyers and prominent lay citizens. From a list of nominees submitted to the commission, three names are provided to the governor from which one person is selected to fill the vacancy 
on the bench in question. If the governor doesn't pick one of the three persons put forward by the commission within sixty days, the commission is empowered to make the selection.

Once the judge selected by this process has been in office for one year or more, they must stand in a "retention election" during the next scheduled general election period. In such an election there is no opponent - voters are either voting to retain the judge in office or remove him or her from the judicial post in question. If there is a majority vote to remove the judge from office, the judge must step down and the process starts anew (Missouri Judicial Branch). By making the appointed judge stand for a retention election, the people over whom the judge exercises judicial authority have the ability to remove a judge they feel does not perform his or her duties well. Whether or not this was intentional on the plan of Missouri Plan designers, judicial removal is exceedingly rare; in the first 179 elections held under the Missouri Plan only one judge did not retain his position, and this was a case in which extraordinary circumstances were present. ${ }^{38}$

The term "merit" in the Missouri Plan judicial selection process implies that nominating commissions are disengaged from party politics, but the extent to which this disengagement is achieved depends in large measure on who selects the commissioners and how they carry out their duties. These two factors vary considerably across the states using the Missouri Plan. In a number of states, the governor has a major role in picking members of the commission, and in other states, interest groups play a significant role, thereby to some extent circumventing of the "de-politicization" goal of the merit selection system.

The geographic basis for the selection of trial court and appellate judges is somewhat different for each state, and for each type of court within the state's unified court system. For trial courts, a useful general rule of thumb is that judges are elected from within the jurisdiction over which they preside. 
For example, Montana's Municipal courts are elected in a nonpartisan election within the city wherein the court operates, while the Water Court, which exercises statewide jurisdiction, is elected in a nonpartisan election from throughout the state. In the majority of states, thirty in all, levels of the state's appellate courts are either elected or appointed statewide, while six states select all of their appellate justices by district or region.

When it comes to discussions concerning how judges should be selected, the most contentious debates occur on the question of how judges on the Courts of Last Resort should be selected. Even though they are appellate courts, and often use the same process for selecting the immediate appellate court judiciary, there are nonetheless noteworthy differences. The geographic basis for selecting a judge is usually statewide, although in eight states the Courts of Last Resort select judges via districts. This difference between district and statewide selection can be a source of considerable contention within states, particularly in those states with liberal urban centers and conservative rural areas. Terms of office for a judge on the Court of Last Resort ranges from a low of five years to a high of 14 years. There are three exceptions to the fixed-term system of judicial appointment; Massachusetts, New Jersey, and Rhode Island all appoint their justices until they reach the age of 70 or die in office. Judicial terms offices are eight years or less in 29 states, and more than eight years in 18 states. Naturally, the shorter the term of service, the more often a justice has to run in a retention election and must rely upon supporters to organize and finance their campaign. Whenever anyone runs for public office, whether they are a governor, a legislator, or a judge, they'll need to raise campaign funds and ask citizens and interest groups for their endorsements and "get out the vote" efforts for their candidacy. This type of "politics" carried out by judicial candidates and their challengers, raises the questions of "from whom and how 
much money was raised," and how much influence will that citizen or group have when the judge decides cases brought to his or her court?

An overarching question on judicial selection is this does the method of selection really matter or affect the way courts operate? Evidence suggests that different selection processes produce different results in terms both of who tends to make it to the bench and in terms of rulings made. For example, Nicholas Lovrich and Charles Sheldon found that judicial selection systems that require judicial candidates to campaign actively in competitive elections result in judicial electorates (voters who participate in elections for judges) who are better informed than judicial selection systems which feature only retention elections. ${ }_{-}^{40}$ Similarly, it has been reported that appointed judges are likely to respond to a wider variety of groups and interests, and support individual rights more strongly in their rulings than elected judges. ${ }_{-}^{41}$

\section{E - Current and Future Challenges Facing State and Local Courts}

State court systems are facing many challenges, both with respect to their workload and their resource limitations. The civil and criminal caseloads of state and local courts are rising appreciatively, but their resources are not growing to match demands being placed upon a "stressed" system of justice in America. The threat to physical safety in the courts and its judiciary is a serious one in many places and a quite justifiable concern in some urban areas in particular. Rural courts, with their broad geographic reaches, face challenges not 
contemplated in America's urban centers. The rapidly rising costs of judicial elections in many states reflect an attempt to politicize the courts on the part of some interests, and in the minds of some observers, this movement toward highcost judicial elections represents a threat to our independent judiciary. In the state of North Carolina the state legislature grew so concerned about this particular danger that they enacted a law setting up a system of publicly financed judicial elections as an experiment.

The demand upon state court systems is rising in all sectors, and at a more rapid rate than the increase of the general population. Between 1993-2002 trial courts across the country saw a 12 percent increase in civil case filings, an increase in criminal case filings by 19 percent, an increase in domestic relations case filings by 14 percent, an increase in juvenile case filings of 16 percent, and an increase in traffic cases by 2 percent. ${ }^{42}$ Though traffic cases account for about 60 percent of all cases filed in trial courts, the increase in the number of complicated and time-intensive cases such as civil, criminal and domestic relations case filings place a far greater strain on the courts than the more routine traffic cases. The number of judges and courtrooms in operation has not kept pace with the growth in caseloads; in the period 1993 to 2002, state court system judiciaries increased by only 5 percent. 43

Court-related violence and courtroom safety is a chronic, costly preoccupation for those professionals working inside the criminal justice system, but it is not one that gets much public attention. . $_{-}$Although this is an ongoing issue throughout the country, a number of high profile incidents occurred in 2005 which served to highlight the serious threats state and local courts must plan for on a regular basis. In February of 2005, a Federal judge arrived at her Chicago residence to find her husband and mother murdered by Bart Ross, a 57-year-old electrician whose medical malpractice claim was dismissed in a court hearing. A mere two weeks 
later in Atlanta, Georgia four people, including a state judge and court reporter, were murdered when a defendant on trial for rape overpowered the sheriff's deputy escorting him to the courtroom and took the deputy's gun. In a less violent, but more commonly occurring case of threatening behavior toward judges, the Florida state court trial judge who ordered the feeding tube removed from Terri Schiavo, who was severely brain-damaged, was harassed and received death threats from people who disagreed with his ruling.

In reaction to such events, a study on courtroom safety provisions present in California courts found that two-thirds of the state's courthouses lacked adequate security, and a companion survey found that 40 percent of California's state and local prosecutors felt threatened in their jobs. Areas with the poorest security provisions were rural and local courts, which usually rely on local funding for their operations. As an appellate court judge noted, "In a society as litigious as ours, the courtroom has become the theater for emotional catharsis."

Heavy caseloads, the lack of resources and inadequate courtroom security are real concerns for professionals working in the criminal justice system, but it is the increased politicization of the courts and judiciary that is considered the greatest long-term threat to the state and local court systems. This term applies to attempts made to provide one political party or major interest group an unfair advantage to promote their interests at the likely expense of the public interest. While all Americans have an interest in the existence of impartial, efficient and legally competent court services, narrow interests sometimes seek to "plant" judges on the bench to gain an advantage in cases involving the adjudication of their affairs. The independence and impartiality of the judiciary, as well as the effective operation of the checks and balances between the three branches of government, are compromised when excessive politicization occurs. The two 
means used most frequently to politicize the courts are "Court Stripping" and judicial selection.

According to the editors of the Oxford American Dictionary, "Court stripping is when legislatures try to remove power from the courts, usually federal but often state, so that the courts can't rule on laws they passed." ${ }_{-}^{46}$ The most blatant instance of this method of politicization of the judiciary occurred in 2005 when the Republican majority in the United States Congress attempted to strip Florida state courts of their jurisdiction over a state matter - in this case, the regulation of medical practice - by imposing federal jurisdiction and ordering the federal courts to consider the claims of Teri Schiavo's parents. The Florida Court ordered that Teri Schiavo's feeding tube be removed, an action which would ultimately end her life; her parents wanted the tube to remain in hopes she would one day recover from her injuries. Ultimately, the Florida state court decision stood as a consequence of the reaffirmation of state authority to regulate medical practice within their jurisdictions. There are, and will continue to be, further attempts at court stripping. Upset with some court rulings, some Arizona legislators tried, without success, to enact legislation that would have shifted the power to write court rules from the Arizona Supreme Court, their court of last resort, to the legislature. Court stripping can sometimes happen after a court ruling; for example, although clearly an unconstitutional action in violation of the separation of powers, the Delaware Legislature recently enacted legislation overturning its Supreme Court's interpretation of "life imprisonment with the possibility of parole."

Often veiled as "judicial reform," political parties and interest groups in some states are trying to alter the process of how judges are selected and retained in order to change the political makeup of the judiciary. Usually, the techniques used appear to be politically neutral "improvements," such as 
changing the geographic location of selection, the process of selection, and the term lengths. However, underlying the proposed changes are plans for "stacking the deck" with judges more friendly to their interests. For example, in 2006 Oregon Ballot Measure 40 was introduced to amend the Oregon State Constitution to require judges for the Supreme Court and the Appellate Court to be elected by district rather than statewide. The candidate would have to be a resident of the newly formed district for at least a year before the election. . $^{48}$ The ballot measure failed with 56 percent of the voters opposing. Had the measure passed and been enacted, the political makeup of the Oregon courts could have been altered as the state's sparsely populated rural areas are typically conservative and the heavily populated urban centers are generally liberal. This type of politicization of courts is nothing new, of course. In 1997 the Illinois General Assembly changed the state's Supreme Court districts to make it more difficult for Democrats to dominate the judiciary. In an attempt at politicization, a 2006 initiative in Montana was circulated permitting the recall of a judge "for any reason acknowledging electoral dissatisfaction." Due to fraud uncovered in the collection of signatures, the measure was removed from the ballot prior to the election. -49

In yet another case, state legislators, unhappy with some court decisions made in Missouri, introduced legislation to reduce the initial term of service for appellate judges from 12 to five years, and require a two-thirds voter majority rather than a simple majority for retention. Clearly, in the balance between judicial independence and popular accountability, it is likely that parties that disagree strongly with the decisions of their state courts will in some cases seek to limit the independence of the courts and create a judicial selection process more likely to put judges of their own liking on to state and local benches.

Nowhere has the politicizing of courts and the judiciary 
been more apparent than in judicial elections, especially in partisan elections. It was the 2002 U.S. Supreme Court decision in Republican Party of Minnesota $v$. White that accelerated the politicizing of judicial elections. Prior to White, judicial candidates in Minnesota, which used the nonpartisan election process for judicial selection, were forbidden by Canon 5 of the Minnesota Code of Judicial Conduct from announcing their views on disputed legal or political issues, from affiliating themselves with political parties, or from personally soliciting or accepting campaign contributions. ${ }_{-}-$In the White case, the U.S. Supreme Court ruled that the three clauses of Canon 5 violated the First Amendment rights of judicial candidates, and in so ruling invalidated them and all comparable limitations in place to other states.

The decision of the U.S. Supreme Court in the White case made nonpartisan judicial election processes nonpartisan in name only. Judicial candidates in states featuring judicial elections can now personally solicit campaign funds from lawyers or litigants, they can engage in partisan political activities, and they can declare their views on virtually any matter of public concern - whether or not the matter may be the subject of current or future litigation brought to the court. While Canons of Judicial Conduct continue to exist in all states, the ability of a state Supreme Court or state Bar Association to sanction a judicial candidate for violating such professional and ethical standards has been undermined by the White decision.

Partisan elections, as noted previously, are increasingly becoming more like those of the other two branches of government - namely, expensive, mass media oriented, and rancorous. Surprisingly, in recent years the most expensive elections have been "retention-only" elections where voters only need to decide whether or not to keep a judge in office. In 1986 almost \$12 million was spent in California to remove the 
state Supreme Court's Chief Justice and two or her colleagues because of their opposition to the death penalty and because of the claim that they were "soft on crime." ${ }_{-}$In an obvious case of conflict of interest, plaintiffs in a $\$ 25$ million punitive damages suit made contributions to two of the state's Supreme Court Justices who were up for re-election and scheduled to hear the case; the justices refused to recuse themselves - or refrain from participating because of a conflict in interest - and ruled in the favor of the plaintiffs.

Special interests are more visible in judicial elections today than ever before; the most visible and active are those with the financial resources to "contribute" and with the most to win or lose in decisions made by courts. For example, the Ohio Chamber of Commerce spent $\$ 3$ million to defeat a judge who had overturned a tort reform law worth many times as much for business; trial lawyers and unions spent about \$1 million in a counteroffensive to retain the judge in question on the Ohio court. . $_{-}$Large amounts of funding, and tides of negative advertising can be attributed to efforts by special interest groups to pursue their policy agenda. The ongoing fight between large corporations and plaintiffs' attorneys over tort reform is a current source of potential politicization.

Despite the presence of strong pressures to further politicize the courts and the judiciary, the public's general perception of the courts is still generally one of presumed independence and impartiality. A national public opinion survey conducted in 2005 found that while the public's knowledge of the judiciary is rather poor, its belief in their courts' adherence to the original principles of Themis are strong. ${ }_{-} 3$ Americans believe that their courts represent fairness, due process, impartiality, and play a key role in the preservation of citizen rights. Furthermore, 61 percent of the respondents to the 2005 survey believe that "politicians should not prevent the courts from hearing cases, even on controversial issues such as on gay marriage, because the 
purpose of the courts is to provide access to justice to everyone, even those with unpopular beliefs. ${ }_{-}$

\section{Exercises}

\section{Courts - What Can I do?}

- Find out more about state governors by visiting the National Center for State Courts (NCSC) website at http://www.ncsconline.org/ (inactive link as of 05/ 19/2021) and consider taking one of their free online courses on state judicial issues at http://www.ncsconline.org/D ICM/freeresources/ index.asp (inactive link as of 05/19/2021)

- Visit NCSC's states homepage to learn more about your own state's court system:http://www.ncsconline.org/D_kis/ info_court_web_sites.html (inactive link as of 05/19/ 2021)

- Consider visiting your local county or city court and watch the proceedings. Many court activities and trials are open to the public. Locate your local county or city court through the National Association of Counties website (http://www.naco.org/), the International City Managers Association (http://icma.org/), or the U.S. Courts website 
(http://www.uscourts.gov/courtlinks/).

\section{F - State and Local Courts and Sustainability}

The judicial branch may not "hold the sword" as does the executive branch, nor "command the purse" as does the legislative branch, but contrary to Alexander Hamilton's view, it does have great influence over American society. In many areas of American life, the courts have fostered needed change when the "political branches" could not do so. In the areas of freedom of speech, racial equality, business regulation, the rights of the accused, and environmental protection, the victories made along the way were often seen not in legislation, but rather in the American courts. State and local courts may be somewhat reluctant participants in the public policy process, but they do have an important role as policymakers nonetheless. Judges are called upon to exercise judicial review of both the legislative and executive branches, interpret laws and constitutions, and make judicial policy. While unified state courts ensure a high level of consistency in the operation of courts, the decentralized operations of local courts make it possible for judges to become key actors in local political life by dealing with litigation reflecting local social, economic, environmental and political conflicts in impartial and constructive ways. Many of the decisions trial court judges make have the potential of establishing important 
policies affecting local practices in such important areas as zoning, public access to information, the provision of legal services to indigents, permissible policing practices, and equal access to education.

Cases heard in local trial courts can have an important impact on sustainable development throughout the nation; the most recent such case is that of Kelo v. City of New London, Connecticut. The case in question, as with the Dolan case from Oregon discussed above, concerned Fifth Amendment rights set forth in the U.S. Constitution. The controversial issue arose when the City of New London chose to use its power of eminent domain to condemn some private homes so that the property on which they sat could be used as part of the city's economic development plan; a plan would result in this private property being condemned for use by another private party working in concert with the City of New London. The homeowners on the property in question filed a lawsuit in which they challenged the right of the City of New London to exercise its power of eminent domain for this purpose, and their case moved all the way from Connecticut trial and appellate courts to the U.S. Supreme Court. A majority of justices on the U.S. Supreme Court found that the benefits to the community involved justified the condemnation and that the City of New London had provided just compensation for the loss of property suffered by the affected homeowners.

In reaction to this decision, many state legislatures viewed the U.S. Supreme Court's decision as too greatly benefiting large corporations at the expense of families and neighborhood communities. As a result, legislation was introduced in several states and ballot measures were placed on the ballot in other states aimed at amending state constitutions to provide greater protection of private property rights from this type of use (i.e., economic development) of the municipal power of eminent domain. That power is typically employed when there is some pressing need for public 
ownership of some private land to serve clearly public purposes (for example, creating a roadway for traffic control).

Some could say the City of New London's action condemning some private land for the economic benefit of the entire community represents an action in line with the philosophy of sustainability since economic vitality is one of the pillars upon which sustainability rests. Others might argue that such actions threaten sustainability because they displace neighborhoods and promote social inequity in the form of privileged access to large, outside corporate interests. Such varied interpretations are clearly possible, and it is certain that more court cases such as this will be filed and heard as a consequence of municipal actions taken to promote economic viability coming into conflict with property owners seeking to preserve the current use being made of the land in question.

The Kelo case has caused the strengthening of private property rights in many states because this is a politically popular (and apparently cost-free) action for elected officials to take. However, by strengthening private property rights, states enacting greater protections to homeowners may make it more difficult to promote sustainable development. For example, should a municipality seek to use its power of eminent domain to locate solar collectors to provide cheaper and renewable energy to its utility subscribers, should private property owners adversely affected by the location of those collectors be allowed to prevent such a use of eminent domain? Should the pursuit of sustainability goals be one of the "reasonable grounds" justifying the use of eminent domain in the states where laws more protective of homeowners' rights were enacted in the wake of the Kelo case? One thing is for certain, state court and the judges sitting on trial court and appellate court benches in our states will be hearing just such cases in the years ahead.

State and local courts have impacted sustainability in the past, and they will most certainly do so in the future. 
Generally speaking, the higher the level of the court, the larger the swath of impact its actions have on sustainability. If a state's Court of Last Resort makes a precedential ruling, then the state's lower courts must follow the dictates of that ruling. This is not to say trial courts are unimportant, as they are most often the first to hear a case that could lead to a change in the law, good or bad, around the rest of the state. Illustrative of the importance of courts in the area of sustainability promotion in state and local government, the case of the widowed grandmother in Orem, Utah stands out. This elderly woman was arrested and taken away in handcuffs for refusing to give a policeman her name so he could issue her a ticket for failing to water her lawn on a regular basis, a violation of an Orem zoning ordinance. If the case goes to trial, it would be heard in the Orem Municipal Court. The reason the grandmother provided for not watering her lawn was that of inability to afford the expense associated with maintaining a green lawn. However, the national attention generated from the case has led to question as to why someone should have to defend themselves in court for a practice that is both uneconomical and wasteful of a precious natural resource - particularly since Utah is the second driest state in the nation.

\section{G - Conclusion}

There are two clear areas within the purview of state and local courts which can impact sustainability in a major way, and those would be Judicial Federalism and the maintenance of judicial impartiality. Judicial Federalism is a legal term referenced earlier which characterizes situations in which state courts give priority of a state question addressed in state constitutional law over a federal question addressed in federal 
constitutional law. In the recent past, Judicial Federalism has focused on enhancing the civil rights of a state's vulnerable minorities (e.g., racial and ethnic minorities, the criminally accused) beyond the rights provided in the U.S. Constitution. Today, in the context of the need to address global climate change and actively pursue sustainability, Judicial Federalism could expand its purview to include the protection of other vulnerable environmental minority interests such as wildlife, water resources, ecosystem services, and rural communities. The well being of these interests coincide with the economic and social vitality of local communities, and their interests could be served more flexibly in state law than in federal rules and regulations. In order for Judicial Federalism to be able to work in this area, the state legislatures must refine their constitutions and statutes to reflect the states' desire to pursue sustainable development so that judges in state and local courts can do their part to support public and private actions intended to promote sustainability.

The second area of particular concern, that of the maintenance of judicial impartiality, requires judges and their courts to be independent from outside influences, making decisions based on legal principles, fairness, and equity as opposed to the provision of special consideration based on political party or privileged interest. As much as Americans would love to maintain their current belief in the ideal of blind justice, human fallibility will always be present. The recent trends toward a politicization of the courts and the judicial selection process bought on in the wake of the White decision open the door to the possibility that private interests that benefit from unsustainable practices - such as urban sprawl, sole reliance upon automobile travel for transportation, overharvesting of forests and excessive extraction of natural resources - will seek to "plant" judges friendly to their interests on state trial and appellate court benches. Efforts are needed by those who support the goals of sustainability to 
promote both the independence of their state and local courts and to stem the rising tide of the politicization of courts and the judiciary.

\section{Terms}

Administrative Law Judges

Certiori

Common Law

Dual System (judicial power)

Eminent Domain

General Jurisdiction Courts

Judicial Federalism

Mandate of the Court

Merit System of Judicial Appointment (see "Missouri Plan")

Missouri Plan

Politicization of Courts/Judiciary

Trial Courts

Unconstitutional Taking

\section{Exercises}

\section{Discussion Questions}

1. Of the two common methods of judicial appointment - gubernatorial appointment and the merit system (Missouri Plan) - which do you think is 
the best method and why? Is it really possible to remove "politics" out of judicial appointments?

2. What are the various types of state and local courts and what functions do they serve? How about problem solving courts - do they increase the institutional sustainability of communities?

3. What are some of the current and potentially future challenges facing state and local court systems? Do you think the politicization of judicial processes will increase or decrease in the future? Why?

\section{Notes}

1. A. Hamilton, "The Federalist No. 78: The Judiciary Department," Independent Journal, June 14, 1788.

2. D.B. Rottman, "The State Courts in 2005: A Year of Living Dangerously." In The Book of the States, 2006 (Lexington: The Council of State Governments).

3. G.C. Edwards, M.P. Wattenberg, and Robert L Lineberry. 1998. Government in America: People, Politics, and Policy, 8th ed. (New York: Longman).

4. Administrative Office of the U.S. Courts. 2007. Understanding Federal and State Courts 2007 [cited Dec., 25 2007]. Available from website http://www.uscourts.gov/ outreach/resources/fedstate_lessonplan.htm 
5. H.J. Abraham, Henry Julian. 1998. The Judicial Process: An Introductory Analysis of the Courts of the United States, England, and France (New York: Oxford University Press).

G.C. Edwards, M.P. Wattenberg and R.L. Lineberry, 1998, op. cit. (see reference 3).

6. H.R. Glick, R. Henry and K.N. Vines. 1973. "State Court Systems." W. S. Sayre, ed. Foundations of State and Local Government (Englewood Cliffs, NJ: Prentice-Hall).

7. Ibid.

8. C. McGowan, The Organization of Judicial Power in the United States (Evanston, Illinois: Northwestern University Press, 1967), p. 37.

9. G.C. Edwards, M.P. Wattenberg and R.L. Lineberry, 1998, op. cit. (see reference 3).

10. Rottman, David B, and Shauna M Strickland. 2006. State Court Organization, 2004. Washington, DC: U.S. Department of Justice.

11. Ibid.

12. Administrative Office of the U.S. Courts, 2007, op. cit. (see reference 4).

13. G. Bermann and J. Feinblatt, "Problem-Solving Courts: A Brief Primer," Law and Policy 23 (2002): 125-140.

J. Feinblatt and G. Berman, "Community Courts: A Brief Primer," U.S. Attorney Bulletin 49(2001): 33-38.

14. Ibid.

15. V. Flango, "Families and Problem-Solving Courts." URL: http://contentdm.ncsconline.org/

16. D. Rottman and P. Casey, "Therapeutic Jurisprudence and the Emergence of Problem-Solving Courts," National Institute of Justice Journal (1999): 12-20.

17. G. Bermann and J. Feinblatt, 2002, op. cit. (see reference 13), p. 130.

18. National Criminal Justice Reference Service, Drug Courts. Office of National Drug Control Policy, December 5 2007. URL: 
http://www.ncjrs.gov/spotlight/drug_courts/Summary.html (accessed December 9, 2009).

19. G. Bermann and J. Feinblatt, 2002, op. cit. (see reference xiii).

20. S. Belenko, Steven, "Research on Drug Courts: A Critical Review, 1999 Update," National Drug Court Institute Review 2 (1999): 1-58.

21. Ibid.

22. State of Montana. Montana Water Court 2007. URL: http://courts.mt.gov/water/default.asp (accessed December 9, 2009).

23. Colorado Judicial Branch, Colorado Water Districts: Water Courts. URL: http://www.courts.state.co.us/supct/ supctwaterctindex.html (accessed December 9, 2009).

24. D. Schultz, "Minnesota Republican Party v. White and the Future of State Judicial Selection," Albany Law Review 69 (2006): 985-1011, p. 985.

25. D.B. Rottman and S.M. Strickland, 2006, op. cit. (see reference 10).

26. Ibid.

27. A. Hamilton, 1788, op. cit., (see reference 1).

28. R.A. Schotland, "To the End Species List, Add: NonJudicial Elections," Willamette Law Review 39 (2003): 1397-1423, p. 1404.

229. M. Scherer, "Is Justice Undermined by Campaign Contributions?: Conflicts of Interest and Nasty Ad Campaigns Deepen Public Distrust in State Judicial Elections," Capital Eye 3 (2001). URL: http://www.opensecrets.org/newsletter/ce76/ statelines.asp

30. G.C. Edwards, M.P. Wattenberg and R.L. Lineberry, 1998, op. cit. (see reference 3).

31. D. Schultz, 2006, op. cit. (see reference 24).

32. H.R. Glick, R. Henry and K.N. Vines, 1973, op. cit. (see reference 6). 
33. D.B. Rottman and S.M. Strickland, 2006, op. cit. (see reference 10$)$.

34. Ibid.

35. H.R. Glick, R. Henry and K.N. Vines, 1973, op. cit. (see reference 6).

36. D.B. Rottman and S.M. Strickland, 2006, op. cit. (see reference 10$)$.

37. H.R. Glick, R. Henry and K.N. Vines, 1973, op. cit. (see reference 6).

38. Ibid.

39. D.B. Rottman and S.M. Strickland, 2006, op. cit. (see reference 10$)$.

40. N.P. Lovrich and Charles Sheldon, "Assessing Judicial Elections: Effects Upon the Electorate of High and Low Articulation Systems," Western Political Quarterly 38 (1985): 276-293.

41. D. Schultz, 2006, op. cit. (see reference 24).

42. D.B. Rottman and S.M. Strickland, 2006, op. cit. (see reference 10$)$.

43. Ibid.

44. D. Sontag, "In Courts, Threats Have Become a Fact of Life," The New York Times, March 20, 2005. URL: http://www.nytimes.com/2005/03/20/national/

20judges.html

45. A. Goodnough, "In Schiavo Feeding-Tube Case, Notoriety Finds Unlikely Judge," The New York Times, March 17, 2005. URL: $\quad$ http://www.nytimes.com/2005/03/17/national/ 17greer.html

46. D.B. Rottman and S.M. Strickland, 2006, op. cit. (see reference 10), p. 237.

47. Ibid.

48. State of Oregon, Measure 40. URL: http://www.sos.state.or.us/elections/nov72006/guide/ meas/m40_bt.html

49. D. Rottman, "The State Courts in 2006: Surviving Anti- 
Court Initiatives and Demonstrating High Performance." In The Book of the States, 2007 (Lexington, Kentucky: The Council of State Governments, 2007).

50. D. Schultz, 2006, op. cit. (see reference 24).

51. Ibid.

52. M. Scherer, "Is Justice Undermined by Campaign Contributions?: Conflicts of Interest and Nasty Ad Campaigns Deepen Public Distrust in State Judicial Elections," Capital Eye 3 (2006). URL: http://www.opensecrets.org/newsletter/ ce76/statelines.asp

53. D. Rottman, 2006, op. cit., (see reference 49).

54. Ibid, p. 239. 


\section{Chapter 9: State and Local Bureaucracy and Administration}

\section{A - Introduction}

When many Americans think about government bureaucracies, negative stereotypes immediately come to mind - adjectives such as "red tape-bound," "impersonal," "unresponsive," "lethargic," and "undemocratic" are associated with those stereotypes. Similarly, bureaucrats themselves are often labeled as "lazy," "incompetent," "insensitive," and "power hungry." However, even though many Americans carry these negative stereotypes around in their reservoir of thinking, most adults in the workforce are employed by some type of private, public or nonprofit bureaucracy and depend on government bureaucracies for a wide range of services provided by such bureaucracies as schools, hospitals, fire and police agencies, the U.S. Postal Service, the Social Security Administration, etc. Without bureaucracy, very little in the way of public services would be provided in modern society. In addition, the social, economic and ecological sustainability we need to promote all depend on the institutional sustainability of those entities of state and local government, which endeavor to organize and implement government policies and programs.

Despite the broadcast media's inordinate focus on the national government, state and local governments actually create and implement the vast majority of public policy, often 
serving as critical linkages between elected and administrative personnel working at all levels of U.S. government. The number of sub-national governmental units, particularly special districts, continues to grow vigorously in the United States. New units of government reflect growing and changing demands on the part of local communities. More extensive government often means a greater number of elected officials and public administrators (or bureaucrats). For the reader interested in careers in state and local government, employment opportunities in public administration experienced tremendous growth over the past decade and this workforce expansion involved the creation of opportunities for persons possessing a wide variety of skill sets and abilities.

\section{Learning Objectives}

With this setting as a backdrop, this chapter will discuss:

- the basic tenets of bureaucracy,

- administration conceptualized as a system,

- networking,

- knowledge, skills and abilities of the 21st century administrator,

- women and minorities in public administration,

- e-government,

- volunteers and public and non-profit administration in local communities,

- historic trends in state and local of government employment,

- salary trends in state and local government,

- and state and local agencies' initiatives in place for 
working towards sustainability and adaptive innovation in the promotion of resilient communities.

\section{B - What is Bureaucracy?}

Bureaucracy is nearly as old as civilization itself. Any reader who has had an interest in archaeology, for instance, knows that some of the earliest examples of human writing are the official documents of bureaucrats or public administrators. The Sumerian clay-tablets, found in present day Iraq, were written by official government scribes - the bureaucrats of that long-lost society! Bureaucrats are the most visible aspect of government in daily life; consumers of government goods and services have regular contact with postal workers, law enforcement personnel, road repair or sewage engineers, the water department, traffic engineers, city planners, and many other administrators and representing local, state, and national administrative agencies.

Formally stated, the term bureaucracy reflects a rationally organized hierarchical structure and administrative process composed of professional individuals working in and communicating from well-defined positions placed within a coordinated formal structure intentionally designed to achieve complex goals with maximum effectiveness and efficiency. Bureaucracy is, therefore, a specific type of formal organization. In the late-19th century, a highly regarded 
sociologist by the name of Max Weber (pronounced "Vey-bur") wrote a now-famous treatise on the "ideal" bureaucracy, and this treatise is considered to this day the definitive definition of the term bureaucracy for scholars and researchers worldwide. 1

Weber developed his thinking on bureaucracy on the basis of a close study of many large formal organizations widely regarded as successful in his day, and he identified what he took to be the principal characteristics of a perfect or "ideal type" bureaucracy - that is, an organization of large scale that could accomplish very difficult tasks such as the mass production of complex durable goods, the harnessing of the energy of a mighty river, or the gaining of victory in armed combat with a worthy adversary. Not only was it possible to accomplish these grand tasks, but also the goals could be attained with maximum effectiveness and efficiency. One of the basic assumptions of Weber's model was that the ideal bureaucracy could accomplish any goal in any nation, be it the production of goods or services for the private market or the provision of goods and services for a town, city, state or nation. Weber thought of bureaucracy as reflecting the application of science to the task of building organizations, with science taking the form rationality (as opposed to tradition, family ties, religious preference, myth, sentiment, etc.) in the design and management of a formal organization. The design of the organization reflects a scientific division of labor and a type of management characterized by the pursuit of effectiveness and efficiency without regard to personal favor or sympathy.

Bureaucracies in this Weberian ideal type sense are composed of professional individuals who are carrying out specialized tasks requiring specialized training and/or targeted experience. Professionalism is a very important concept in bureaucracy, and the idea is closely tied to the subject of this book - namely, the capacity to build innovative, 
adaptive and sustainable communities, and to promote the ability among state and local government public administrators to develop the plans, policies and programs in their respective governments and agencies that facilitate the maintenance of sustainable communities. Professionalism first entails the idea that an individual who occupies an important position in a bureaucracy has gone through appropriate formal education and/or training that prepares him or her to carry out the duties of their position. Professionals require both appropriate prior education/ training and a commitment to lifelong learning related to their chosen profession. With respect to sustainability, such learning is an absolute necessity as our knowledge expands regarding global climate change and what types of state and local government problem solving challenged will have to be taken on in the coming decade, and beyond.

Along with professionalism, communication is another very important component in the operation of an ideal type bureaucracy. In Weber's bureaucratic model, communication was a direct function of an individual's position within the hierarchy of a bureaucratic system. Accordingly, the boss communicates "down" to the worker in a manner that is unique to being a boss; workers may communicate to each other, but they take orders from their boss and do not communicate back to him or her unless asked to do so. Formal communication, both written and oral and which concerns decision-making, is documented so that there is strict accountability for all outcomes (successes and failures alike) and a record of activities can be carefully studied to improve effectiveness and efficiency.

Finally, bureaucracy in the Weberian sense was developed to accomplish complex goals - such as the mass production of consumer goods like automobiles or the establishment of rural electrification in a nation - through the scientific division of labor. This specially created structure 
called bureaucracy designates the specialization of tasks and the careful coordination of activities, using a hierarchy of official positions. The bureaucratic system uses official channels of communication where activities are documented as to who decided what, to what effect, and at what cost to the organization. Complex goals virtually always entail long-term objectives, involving problems that cannot be solved easily or quickly. From your reading of earlier chapters, you realize that good governance in state and local government entails a strong dose of bureaucracy viewed in this Weberian framework.

Weber's ideal type model is an important place to start in our discussion of organizational forms present in state and local government, but it is fair to ask the question: Do things really work this way in practice? The simple answer is "no." While bureaucratic structure is easily discernible in state and local government, everyday work activities are a great deal more varied and complex than the ideal type model would lead one to believe. It can be said that, for the most part, formal structure does not accurately describe the nature of work carried out in state and local government. This being the case, it is fair to pose another leading question: Is there $a$ better way to inform ourselves regarding the actual role of public administration and public administrators in the governance process? Fortunately, the answer to that question is "yes!" 


\section{C - Moving from Bureaucracy to Administration as a System}

If an individual were to visualize bureaucracy as an object, how would it be represented? While some would say a python with all the negative connotations, a more common and realistic perspective would be that of a pyramid. Just as the pyramids have a single tip at the top, so too do bureaucracies - they have one official leader. The base of a pyramid is wide, which could be symbolic of a large number of offices or positions all reporting to the top of the bureaucracy. Similar to a pyramid, bureaucracy is viewed as largely immutable and enduring. Bureaucracy is seen as an inelastic and highly structured process - something that endures despite changes in the world around it. Viewing state and local government bureaucracy and bureaucrats in this Weberian light would convey the impression that they are not active participants in governance; bureaucrats would simply do the bidding of elected officials. With all of the training and professionalism required of bureaucrats, however, would it not be wasteful to leave such a large group of well-trained, well-informed and experienced persons out of the state and local government governing process? It turns out that while the Weberian ideal type model of bureaucracy would have us believe that bureaucrats in state and local government are simply passively carrying out the directives of their politically elected "bosses" in the legislative and executive offices of government, the truth is that there is a far more active role for state and local government bureaucrats in American government.

The recognition of a legitimate active engagement role for bureaucracy in governance began when Public Administration and Political Science scholars and reflective practitioners in government service began to conceptualize public administration as an organic process. What would organic 
administration look like? Unlike bureaucracy, an organic process would view public administration in the United States as a highly collaborative enterprise involving people (animate administrative professionals) rather than offices and official positions..$_{-}^{2}$ In an organic process, individuals within an organization are seen as possessing unique conditions and values, characteristics that causes them to shape the organizational mission and accomplishment as well as strategic planning for the future. . $_{-}^{3}$

Additionally, within the paradigm of active engagement the act of administration includes an interactive process occurring between professionals and citizens rather than involving simply a one-way bureaucratic enterprise of policy implementation strictly following the dictates of elected officials._. The socio-political environment is affected by what administrators will do and how they will accomplish their goals; responsiveness to changing conditions is critical for state and local government agencies. ${ }_{-}^{5}$ In the area of parks and recreation, for instance, the changing demographics of our population and changing tastes and preferences of succeeding generations require that the locations and programming available reflect changing patterns of use and demand. Organic administration entails the active interaction between legislative and executive officials and bureaucrats occurring within a network that is adaptive, one that is capable of responding to the ever changing needs of agency clientele and balancing these adaptive adjustment concerns with the need for the efficient use of public funds. Public administrators are expected to take part in this interaction as able and confident collaborators.

In the 21st century, governance at the state and local level clearly entails building and supporting sustainable communities. ${ }_{-}^{6}$ Sustainability necessarily implies the core traits of adaptability and innovation. While these traits may create desired outcomes in the statutes and ordinances placed 
into law by elected officials, the accomplishment of these outcomes requires the active involvement of public administrators responding to changing local, state, national, and even international conditions. ${ }_{-}^{7}$

Around the country - in urban, suburban and rural areas alike - public administrators, non-profit agency managers, and private organizations are increasingly working in an environment in which they attempt to learn from each other and communicate, coordinate and collaborate to bring solutions to the attention of elected officials to whom they report. ${ }_{-}^{8}$ Administrative capacity for such adaptation and innovation borne of a collaborative learning process is a critical element in the promotion of sustainability in American state and local government. It is very important that U.S. state and local government not become so much the victim of the "hollow state" phenomenon - a concept of minimalist government entities and maximum use of contracted services ${ }_{-}^{9}$ - that collaborative learning in service of sustainability does not take place. $\underline{10}$

\section{D - Networks to Somewhere: The Intertwined Process of Administrative Governance}

Network organizations are a type of formal organization that is substantially different from the Weberian ideal type bureaucratic model. The network organization is touted as a genuinely modern arrangement facilitated by the revolution in intra- and inter-organizational communication permitted by computers and the Internet, but the concept itself is quite 
long- established. A reading of the history of organizations that successfully adapt to change in their environments suggests that those organizations which maintain extensive "boundary spanning" activities do tend to make adaptations that make them resilient to changes in their environments, while those that stubbornly insist on the maintenance of longestablished practices unique to the organization tend to "collapse.".11 The adoption of a network approach to bureaucratic organization is prevalent in contemporary American state and local government._

What is a network organization? First off, network organizations require the regular interaction of individuals in a variety of positions and with a wide range of different organizations - e.g., other local, state, national, public and private organizations. Thinking back to the bureaucratic model for a second, one could say that there were two dimensions to bureaucracy - the vertical (power and authority) and the horizontal (equal communication across similar positions). In network approaches to organization, there are multiple dimensions of interaction, and there are few fixed bureaucratic relationships; this is because the character of the network is dependent on circumstances existing at any given time. Communication organizes itself at one point in time around a hub of positions or of knowledge - i.e., the persons or organizations that possess or control relevant knowledge.

Actions taken by network organizations are based on knowledge acceptance in relation to organizational will or goals. Action is oftentimes informally initiated and is referred to as swarming - the near simultaneous movement by individuals or organizations to accomplish a goal. Network organizations are so loosely and flexibly organized that the clear command and control exercised by an organizational elite - a common feature often criticized in the bureaucratic model - is often not tenable. The flexibility and looseness 
of an organization is both its strength and weakness. Weaknesses arise with respect to holding specific subunits or persons accountable for their work. On the side of strengths, a network organization that has highly professional and ethical employees and reliably follow-through on commitments made to other members of the network can be exceptionally effective. 13

Network organizations are a critical component of the innovative approach emerging in 21st century democratic governance $;_{-}^{14}$ although, due caution must be observed in establishing and maintaining networks and in assuring collaborative effort quality over time. ${ }_{-}^{15}$ Responsive public administration must be aware of private sector adaptations and be willing to engage in public-private partnerships in an increasing number of areas such as green technologies, telework options for employees, and archival database sharing and joint or collaborative analysis. ${ }_{-} 6$

\section{E - Knowledge, Skills and Abilities of the 2Ist Century Administrator}

Government's need for people with diverse sets of knowledge, skills and abilities means that no matter your specialty, a career in state and local public administration is likely an option. Good governance at all levels of government requires the education, training and skills of a wide array of backgrounds in areas as varied as physical science, social science, law, medicine, education, engineering, agriculture, criminology and linguistics, to name but a few. If you are interested in public administration and state and local 
government service as a career, it is possible to pursue educational goals directly related to your own area(s) of interest and personal passion - and, most likely, state or local government public administration will have a place for you in the years ahead. The building and governing of sustainable states and local communities will require professionals with a whole host of skills and knowledge for maintaining a vibrant local economy, becoming a steward of the natural environment, and promoting social equity.

In this regard, because new forms of knowledge are emerging at a rapid pace, public service professionals must be committed to life-long learning and networking. This adaptability will continue to be of critical importance in the coming decade. In the past, bureaucratic organizations valued this type of professionalism, but stultifying hierarchical command and control structures had a devaluing effect. Traditional bureaucracy has a clear tendency to constrain the behavior of bureaucrats rather than fostering their growth, and the inhibiting the development of personal responsibility and good judgment borne of active networking with peers in other organizations (public and private and non-profit alike). In the administrative governance paradigm described in this chapter, professionalism and a commitment to life-long learning are valued and rewarded because they foster innovation and the adaptability of thought and actions needed to develop, promote, and preserve plans, public policies, and public programs which enhance the sustainability of our communities and promote the adaptability of our states.

The ability to acquire relevant new knowledge and to determine its utility in the governance process is a multifold enterprise. First, governance in our democratic setting necessitates efficacious communication between administrators, elected officials, and citizens in order to determine the full meaning and value of the new knowledge in question. Administrative governance as we have described 
it this chapter plays a crucial role in the initiation and maintenance of this three-way dialogue. Second, the networked communication among similarly trained administrators in other jurisdictions collectively assesses the knowledge value of information, clarifying its validity and relevance to the particular state or local government in question. Finally, communication is a two-way process between a sender and a receiver of communication. An important governance role for administrators is to create dialogue with client stakeholders and elected officials in a manner that builds and empowers rather than erodes their sense of efficacy. ${ }_{-}^{17}$ In the administrative governance process, state and local government public administrators are both "doers" and "facilitators" who help others become doers.

A clear distinction between "administrators" and "elected officials" must be made here. State and local government administrators must be proficient leaders and executives, but they are not empowered to lead in the same way as elected officials. Good governance requires that public administrators convince others, through active networking, of the virtue of their solutions to problems - even though this networking activity may not always follow the established ways of doing business. Just as elected officials sometimes seek to convince voters of needed change, administrators use the public forums available to them - e.g., legislative testimony and public hearings, workshops and sponsored conferences - to demonstrate their own type of leadership in the governance process. Within their respective agencies, state and local government public administrators act as executives, directing their personnel towards large goals and seeking to develop interagency ties that will provide needed resources to promote effective current and future administrative governance. 


\section{F - Women and Minorities in Public Administration}

In the 19th century, public administrative offices were often used by elected officials to reward their political supporters. A system of patronage inordinately benefited the dominant political force of the time - namely, white men. Despite the development of professional public administration, the new civil service systems remained notably biased against ethnic and racial minorities, and against women. While the 1950s and 1960s witnessed critical national and state legislation dealing with civil rights and equal employment opportunity, substantial barriers to equal employment and equitable promotion persist nonetheless. So-called glass ceilings -barriers against advancement to executive positions within state and local bureaucracies__-remain a significant obstacle to promotion up the ranks. These barriers to advancement are often a function of both managerial bias in the promotion and evaluation process, and reflect systematic biases that have become codified into the administrative structure.

Even more noxious and persistent has been the "gendering" of certain professions within public administration. The most identifiable example of this process was the notion that secretarial and management assistant staff positions were viewed as "female jobs." Similarly in law enforcement agencies women were systematically excluded from jobs in patrol divisions because such work was seen as a man's job. The area of cultural values and beliefs has proved to be the most difficult obstacle to overcome in the further advancement of women into the managerial ranks in state and local government public administration. In many jurisdictions, women have sustained claims of sexual harassment against those who perpetrated impermissible actions; however, many other legal actions taken by women seeking to redress their 
inequitable treatment have proven extremely difficult to bring to successful conclusion.

Minorities have long faced serious challenges in gaining equal employment opportunity. Historic discrimination against minorities in state and local administration remains a serious challenge to diversifying administrative employment. While great strides towards equal treatment have been made in the law, much work remains for people carrying out discretionary actions in hiring and promotional decisions that are based on the true merit of an individual as opposed to considerations of race, ethnicity and gender. Despite the obstacles facing them, women and minorities have contributed greatly to the building of the 21st century administrative systems needed to create sustainable states and communities. Glass ceilings are beginning to shatter women have taken many notable positions as leaders in public administration. Contrary to the uninformed concerns and blatant stereotypes of white males of an earlier generation, women and minorities have regularly proven to be amongst the most effective and vocal leaders in administration today and making critically important contributions to the governance process.

\section{G-E-Government}

Creating sustainable governance is perhaps the principal challenge of the 21st century. Sustainability does not occur in isolation, but rather takes place in a competitive environment -while one state or community is attempting to create stable and livable conditions, other states and communities are competing for resources and for the attention of sustainable, 
clean industries. In this competitive environment, state and local governments frequently find themselves acting in an entrepreneurial way. A major part of being entrepreneurial in the current setting is streamlining governance. ${ }_{-}^{19} \mathrm{E}-$ government plays an important role in this streamlining process.

One example of the power of e-government concerns new efficiency in managing paperwork. In the past, private industries interested in locating plants and offices in a particular state or local region were negatively impacted by bureaucratic red tape - the seeming mountain of legal paperwork and multitude of permitting involved in attempting to pursue economic development. The time lag between the filing of paperwork and the winning of ultimate approval is said to have driven away countless private industries and entrepreneurs that sought more lucrative business climates.

Revolutionary changes in information technology in the 1980s and 1990s led to more accessible, more affordable, and faster computing systems, forever altering the interface between state and local government public administration and their business community clientele. Increasingly, state and local government public administration has moved toward what is called an e-government model. Using Internet capability, e-government makes use of on-line forms and processing that reduces unnecessary face time between administrative staff and private industry and small business representatives. This same process has also streamlined the process of requesting and issuing permits and approvals, thus reducing the costs to investors seeking to develop in a particular state or local area.

E-government frees up administrators to complete other important tasks in the pursuit of sustainable development. More attention can be devoted to unique cases, and in the process improving the quality of administrator-client relations. With more time made available, administrators 
conduct outreach efforts to actively promote business relocation and development in their states and communities. Additionally, the improved computing network system attracts and retains Generation $Y$ workers and citizens in urban areas. The continued improvement and development of the seamless administration-client interface of e-government is an important part of sustainability in 21st century governance.

\section{H - Volunteers, Non-Profits and Administration}

Governing within the paradigm of sustainability poses challenges to the manner in which administrative governance had been conceptualized previously. Until quite recently, the function of administration has been thought of as an insular activity carried out by trained professionals. Administrative governance was something that government did for or to citizen clients. There was a sense that administrators were experts who required little guidance beyond the strictures of statute, ordinance or common law. Citizens were seen as largely passive players in the modern governance process.

Recent developments have led administrators to actively recruit community volunteers to work along with administrative agencies. ${ }_{-}^{20}$ Take, for instance, the need to elicit volunteers in light of demographic changes in society that are fast approaching - namely, the oldest members of the Baby Boomer cohort are soon to enter their 60s. Many of these well-educated individuals were organizational leaders in the public and private sector and fulfilled critical roles in building the governance and private sectors. As these individuals 
retire, they are taking with them highly valuable knowledge, skills and abilities not easily replaced. The well-educated and highly motivated Generation X-ers (the generation following the Baby Boomers) is relatively small, lacking the sheer number of people needed to fully serve in critical administrative governance roles. Adding further to the problem, administrative costs are rising significantly, and as the Boomers age, the costs of employee benefits have increased dramatically. In an atmosphere characterized by both budgetary shortfalls and mounting debt, requesting additional resources to fully meet administrative goals is not likely to be rewarded with new allocations of state or local government resources. Under these circumstances "doing more with less" is the name of the game. Considering all of these factors in combination, scholars and practitioners realize that sustainable governance is not solely an administrative enterprise - it is quite clearly a genuine community enterprise.

In recognition of these circumstances, in the early 1990s President Bill Clinton promoted community-based volunteerism through his AmeriCorps initiative, a policy designed to bring a greater number of young people into a broader spectrum of volunteer community and public service activities, with the hope that some involvement in one's youth would lead to a lifelong commitment to volunteering as these youth mature into adulthood. Along with pre-existing programs such as Volunteers in Service to America, Learn and Serve America, and the Senior Corps, AmeriCorps is part of the Corporation for National Service. The AmeriCorps program is particularly noteworthy because volunteers work through a network of nonprofit organizations delivering public goods and services. Non-profit organizations are effectively serving important roles either once fulfilled by administration or are supplementing insufficient administrative resources.

Incorporating volunteers into administrative enterprise 
is both rewarding and challenging. Volunteers often bring the community closer to administration, and vice versa. Administrative governance is positively served through keeping a finger on the pulse of the community through a network of volunteers. In the case of retired volunteers, administrators often note that they are among the hardest working individuals in their office, showing up on time and expending considerable energy performing critical tasks such as answering phones, dealing with clientele, and filing paperwork. It has been observed that - well-versed in etiquette - older volunteers often put clients at ease and are very effective at obtaining needed information to best solve clients' dilemmas. Volunteers may also bring with them the tremendous enthusiasm of youth as they learn new skills and seek to help others. For example, AmeriCorps involvement in reading programs has demonstrated the role that volunteer enthusiasm can play in accomplishing the goal of adult literacy. The same is also true in environment-related programs that have young volunteers planting trees, repairing stream flows, and restoring lost indigenous species habitats.

Relying on volunteers in the administrative governance process also proves challenging. Unlike paid employees, volunteers often need to be motivated in unique ways. They generally need to feel a sense of purpose while carrying out their work, and their efforts to improve governance must be recognized in ways meaningful to them. Volunteers may indeed offer administrative agencies their time and skills, but they also require time and attention as well. If they feel ignored or underappreciated, volunteers often rapidly disengage. A downfall associated with relying on volunteers is that administrators tend to derive a false sense of their own capacity when goals are accomplished without additional full time staff. When this occurs agencies and political leaders may under-invest in full time human resources, placing agencies at future peril. All difficulties aside, however, there is 
no doubt that volunteerism continues to have a vital place in the functioning of state and local government administration.

\section{I - Historical Trends in State and Local Employment}

Over the last 25 years, the story of state and local government employment has been one of growth in scale and scope alike. While variations exist in state-by-state comparisons and across local jurisdictions, government employment at the state level grew by 35 percent overall and local government employment increased by over 48 percent. By comparison, national government employment actually decreased by approximately four percent between 1982 and 2004. However, the 2009 Great Recession took its toll on the number of state government workers due to budget cutting, however the process of recovering cut positions has begun. A recent study by the Council of State Governments found: $:_{-}^{21}$

- "From August 2008 to December 2014, a majority of states-31-added state government jobs.

- Colorado added the greatest number of positions (21,700), followed by Kentucky $(18,500)$ and California $(13,800)$.

- State government employment shrunk the most in Louisiana-by 24,800 positions-followed by Georgia, with a loss of 15,200, and New York, with a loss of 14,500.

- Over the same period, private sector employment grew by 4.1 million positions, or 3.6 percent." 


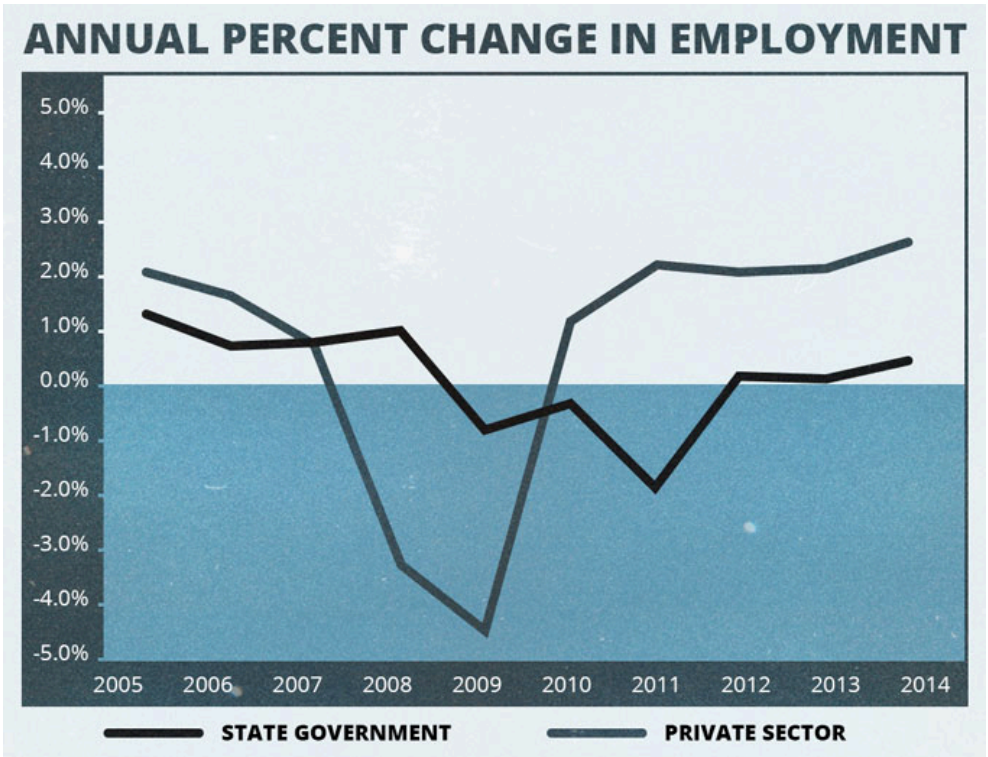

Figure 9.1 State Government Employment Trends (Source, Council of State Governments, 2015, see footnote 21).

These employment trends become even more meaningful when considering the average number of clients served by state and local civilian employees. Clearly, variation exists across state governments, but on average the ratio of citizens to state employees has decreased from approximately 62:1 in 1982 to $58: 1$ in 2004. The ratio means that in 2004, for instance, for every state employee there were roughly 58 citizens. At the local level, the ratio declined from roughly 25:1 in 1982 to 21:1 in 2015. For individuals considering employment at the state and local level, the trend indicates that employees have - on average - greater time per client, thus increasing the probability of greater personal attention and increased effectiveness. By contrast, the ratio of population to national employees has moved in the opposite direction

Workplace diversity is an important issue in state and 
local government employment. While state variation exists, on average the proportion of women in state and local government employment has increased from 41 percent in 1981 to nearly 58 percent in 2015. Additionally, the proportion of state employees identifying themselves as black is 14 percent in 2015 compared to 9 percent in the private sector. Selfidentified Hispanic employees in state government is 9 percent compared to 17 percent in the private sector. Asian employees are rough similar in the private and state government sectors at 5 percent. Being aware of how well community diversity is represented in government remains an important consideration.

\begin{tabular}{|c|c|c|}
\hline & Private Sector & State Government \\
\hline Average salary & $\$ 53,420$ & $\$ 50,461$ \\
\hline Weekly hours & 43.7 & 41.9 \\
\hline Age (mean) & 41 & 45 \\
\hline Married & $54 \%$ & $58 \%$ \\
\hline Female & $41 \%$ & $58 \%$ \\
\hline Educational Attainment & Priva & State Government \\
\hline Less than HS & $11 \%$ & $3 \%$ \\
\hline HS & $38 \%$ & $24 \%$ \\
\hline Associates Degree & $12 \%$ & $13 \%$ \\
\hline Bachelor's Degree & $28 \%$ & $32 \%$ \\
\hline Master's Degree & $8 \%$ & $18 \%$ \\
\hline Professional Degree & $2 \%$ & $6 \%$ \\
\hline Doctoral Degree & $1 \%$ & $4 \%$ \\
\hline
\end{tabular}




\begin{tabular}{lll}
\hline Race and Ethnicity & Private Sector & State Government \\
White & $78 \%$ & $76 \%$ \\
Black & $9 \%$ & $14 \%$ \\
Asian & $5 \%$ & $5 \%$ \\
Other & $7 \%$ & $5 \%$ \\
Hispanic & $17 \%$ & $9 \%$ \\
Immigrant & $20 \%$ & $10 \%$ \\
\hline
\end{tabular}

Table 9.1 Comparing State Government Employees with the Private

\section{Sector}

In terms of employment trends, clientele service, and salaries, the state and local government picture has looked increasingly rosy over the last quarter century, but all of these data must be considered carefully. First, there has been an increase in the percentage of employees at the state and local level who are part-time workers. Part-time workers are often ineligible for many of the benefits associated with full-time employment. From the managerial perspective, however, the flexibility engendered through managing part-time workers, in essence, brings workers into the workplace on needs-only basis, thus increasing organizational efficiency. In addition to the growth of part-time employment at the state and local level, private sector contractors play a much larger role in state and local government work. In some cases, private contractors have taken over the functions of government previously managed by full- or part-time state and local government employees. 


\section{J - Salaries in State and Local Government}

Analyzing state government payrolls compared to the private sector offers insight into the general trends in employee investment. Using data from the U.S. census Bureaus annual American Community Surveys from 2009-2012, the average private sector employee earned $\$ 53,420$ a year compared to $\$ 50,461$ for state government workers (see Table 9.1). While compensation levels differ greatly across states, state employees are on average slightly below their private sector counterparts.

Salaries have risen over the last quarter century in real dollar terms. When studying salaries from a diversity perspective, women are still paid substantially less than men. White employees still make noticeably more money than minority employees. In trend analysis, it is evident that the salary trends for population sub-groups are paralleling one another - in studying median salaries at the state and local level of government as a whole, there does not seem to be any movement towards greater convergence or equity in pay. Pay and benefit equity vary across state and local government serving as an incentive to attract the highly qualified and diverse workforce needed in public service. A lack of diversity in public employment tends to parallel unresponsive state and local government, particularly problematic in a period of time necessitating the strong civic community linkages that build an inclusive, innovative, and sustainability promoting society. 


\section{K - Focus on State and Local Employment: Where Do They Work? What Do They Get Paid?}

Bureaucracy is a tool of government. Earlier sections in the chapter illustrate the growth of state and local bureaucracy and the rise of a diverse workforce. But an important purpose of this book is to help readers figure out the current focus of state and local government and where they might become contributing players in governance. Therefore, a quick look at the top ten sectors for administrative employment in state and local government and a general look at the top ten average salaries is in order at this point in the chapter.

The greatest area of employment at the state level is in the higher education sector. Instructor and professors are only one aspect of higher education, of course. Administrators, buildings and grounds specialists, clerical staff, teaching and research assistants, student employees, and a whole host of other personnel play a significant role in higher education. After higher education, corrections - which deal with the incarceration and community supervision of convicted individuals - are the second largest state employment sector. Nearly ten percent of state employees across the country work in corrections. Public health and welfare are prominent employment sectors, as is street and highway management. Financial administration deals with the proper allocation and accounting of state revenues - in essence, the maintenance of fiscal accountability. Natural resource management accounts for roughly three percent of state employment.

Average salaries are determined by studying total annual payroll in state employment sectors and dividing by the 
number of employees in that sector. It is admittedly a rough measure, but nonetheless provides interesting evidence. On average, the top salaried positions at the state level tend to be in science- and engineering-intensive professional fields. Electric power, air transportation, transit and sewerage are employment sectors that usually entail substantial engineering and physical science education. If the reader wishes to pursue a well paying position in state government, it would behoove them to consider pursuing math and science education. Training in criminal justice or law is also of great value in terms of well-compensated state employment.

Elementary and secondary education employs nearly 55 percent of all local government employees. Police protection is the second largest employer, but at a drastically smaller portion of the local government sector - less than seven percent of local government employees work in police protection services. Other prominent employment sectors in local government are fire protection, public health, parks and recreation, and public welfare. General government administration accounts for three percent of local government positions.

As with the state level salaries, the best compensated positions in local government are in sectors requiring a strong science and/or engineering background. Criminal justice and legal training will also improve chances of gaining employment in high salaried local government jobs. Fire protection increasingly requires a solid understanding of knowledge in the areas of criminal justice, Homeland security, emergency medical assistance, chemistry, biology, physics, health care, engineering, and material science, to name but a few of the areas of expertise. Education is not in the top ten of highest paying jobs in this sector at either the state or the local level. 


\section{L - Administration, Governance, and Innovation}

When governments are first developed, leaders define institutions. Later, it is institutions that define and often constrain leaders. At the state and local level, for elected leadership, age old-institutional constraints shape and limit the choices possible. In many ways, elected leaders' position in state and local governance has weakened. Governance is the regular decision-making, implementation, and evaluation of policies designed to ensure that public goods are effectively managed or delivered to citizens. The process of election and re-election also limits state and local elected leaders, often drawing them towards more partisan decision-making as they seek voter support and campaign contributions.

Administrative leaders do not face the same pressures as elected officials do. First, administrative leaders are chosen based on their tenure in administrative ranks and merit-based performance. Merit relates to the knowledge, skills, and demonstrated abilities of an individual in relation to a job description within an administrative organization. Second, administrative leaders are hired based on demonstrated merit, usually evaluated in relation to objective analysis of formal training, past experience, and performance on a job-related examination. Third, administrators are generally granted tenure, a limited property right to employment so long as their job performance remains satisfactory. For these reasons, administrators are often less distracted in the governance process; constrained by statutory and common law, administrators are usually guided by principles of justice in their decision-making rather than by partisanship.

Theoretically, administrators represent the interests of no single person or group of people; instead, they pursue politically neutral goals. In the process of serving the public 
interest, however, administrators come into contact with individuals and groups of individuals who have unique needs. In some cases, groups of individuals may attempt to influence administrative governance through appeals to elected administrators or through other forms of political pressure. In either case, administrators are ultimately driven to pursue the public interest, guided by a solid knowledge and understanding of statutory and common law.

Statutes and common law are frequently silent on how day-to-day administrative governance should occur, and on what types of decisions should be made. In political decisionmaking, sources of guidance might be voter or campaign contributor preferences or even partisanship. In administrative decision making, legal precedents, administrative capacity, and a professional code of ethics are key sources of guidance in the governance process. Additionally, administrators function closely at the clientlevel, close to the consumer of a public service, placing them in good position to assess the intent of elected governing institutions in relation to statutory and common law constraints; administrators are often keenly aware of how governance decisions promote or detract from judicious outcomes.

Not all administrators serve so closely to citizen consumers. Over the course of a career, administrators are promoted from positions closely tied to a customer base into positions of senior administrator authority. The group with greater authority is generally composed of well-educated, long-serving, and tightly networked individuals. Education is a product of formal training melded with years of practical experience. Long career service can be both beneficial and distracting, however. It is beneficial to the degree that administrators have a sense of what has worked and what has not worked in past attempts at policy innovation and governance. It is potentially distracting in the sense that long 
service is often associated with a more conservative or defensive stance, and resistance to pursue important and justifiable risks in governance - risks capable of producing positive results for communities. Finally, long-serving administrators have had time to meet people, lots of people, and to cultivate trust and mutual respect through regular interaction. Administrators develop professional networks with elected leaders, interest and community group leaders, and other administrators. A solid network involves interactions with individuals and groups from different levels of government on an inter-jurisdictional basis. Senior level administrators often have access to critical governing networks, greater knowledge, and more experience with dayto-day governing than do most politicians.

\section{M - Bureaucracy and the Core Dimensions of Sustainability}

Often decried by critics, state and local bureaucracy is very well-positioned to advance the core dimensions of sustainability. Bureaucracy has both the formal and informal structure to meet a complex set objectives effectively and efficiently. While traditional formal bureaucratic structures can be viewed as hierarchically organized, the day-to-day operations of bureaucrats tend increasingly towards network structures. Individual state and local government administrators form around and connect with information/ knowledge hubs to solve problems of the moment, to meet pressing objectives. Additionally, the rise of e-government has streamlined bureaucratic processes and reduced costs at a 
time when costs are rising and demands on government are growing exponentially. Finally, bureaucracy is well-situated to meet the needs of sustainable governance because it is one of the few forms of government institutions that is designed to govern the commons, and whose basic premises focus on equitable distribution of public resources for the individual and collective benefit. Elected branches of state and local government are frequently heavily influenced by the demands of a winning coalition, and the individuals and groups who gain the most influence over elected leaders or candidates for public office are the leading forces within those electoral coalitions. Finally, unlike the elected branches, public administration has a long-term commitment to creating a diverse workforce - a workforce that reflects the nature of a community in the grandest sense of the word.

Looking at the four major objectives of sustainability, as outlined in the first chapter of this book, it should be noted that the principles of sustainable governance are embedded in the basic principles and goals of numerous familiar bureaucratic agencies. Elected officials have, in many instances, created public institutions to meet the pressing issues of a society. Social objectives are often met through public health offices, social workers, K-12 schools and universities, corrections agencies, labor bureaus, fish and wildlife agencies and a host of other bureaucratic offices. In the current economic crises facing state and local governments across the country, politicians may propose increased investment in human capital and the building of strong social capital, but it is often the work of bureaucrats at the street level that turns those often high-minded goals into real world realities. If these real world efforts to promote the enhancement of human and social capital in the service of community sustainability are not being done by public servants operating by themselves, it is the work of thousands upon thousands of hard working, highly motivated volunteers 
who support the efforts of bureaucrats working in a variety of human capital-related initiatives and enterprises.

Sustainable economic activity is one of the core dimensions of sustainability and sustainable governance. Sustainability demands that the marketplace of the future offers high quality products produced with and made use of with low environmental impact and purchased at a reasonable cost. In many cases, this means that important trade-offs must be considered and managed effectively. Locally-grown food and locally-produced goods and services require that state and local workplace dynamics and market conditions must be understood and managed to ensure the goals of sustainability are achievable in a way that is least intrusive on individual economic freedom and liberty, but that simultaneously protects the interests of the broader community in both the short and long-term. Politicians may come and go, but it is state and local bureaucrats who will serve in regulatory agencies over the long-haul, getting to know the "regulated" - i.e., the industry actors in their communities - and carefully balancing the needs of the regulated with the needs of the greater society. The networked bureaucrats in these agencies will have access to their peers in other state and local governments, and efforts to disseminate "best practices" and "evidenced-based" programs promotive of economic sustainability will be promoted first by these people, and subsequently the best ideas will be endorsed and advocated by elected officials in due course.

Environmental sustainability objectives are inextricably wedded to issues of economic sustainability. Again, bureaucratic agencies, often operating independently or semiindependently of the political process, who manage natural resources will be in forefront of public policy development. State departments of forestry, state offices of environmental quality and workplace safety, water quality offices, fish and wildlife agencies and parks and recreation offices are 
examples of agencies seeking to meet the goals of environmental sustainability. The work of these agencies is often multi-agency in character, and increasingly involves the use of multi-party collaborative processes designed to find ways in a particular state or in a specific geographic area how productive economic activity can be sustained without undue harm occurring to environmental assets.

Finally, institutional objectives such as facilitating higher population density and reduced urban sprawl in metropolitan areas are often dealt with through the interaction between a multitude of municipal, county, and state planning offices. Bureaucrats and the bureaucratic agencies in which they work have the know-how, skills and time available to conduct the long range planning processes required to anticipate changes that could call into question the sustainability of communities. Sustainability demands that state and local governments provide for adequate consideration of the needs of communities today and in the more distant future, and keep in mind the dictum that the current generation must not leave a diminished range of options to achieve prosperity, environmental health and social equity to the next generation. The infrastructure redesign for the development of renewable energy systems, for instance, will require a century or longer commitment to a better way of providing energy to permit our way of life to endure. The planners of state and local government will play a critical role in the education of elected officials and the general public alike as to the need for such long-range investment in a sustainable future. 


\section{Exercises}

\section{Bureaucracy: What Can I Do?}

When many students in political science think about post-graduate studies they typically think about law school. However, there are many other opportunities such as Master programs in Public Administration, Public Affairs and Public Policy. Learn more about these type of programs at the National Association of Schools of Public Affairs and Administration (NASPAA) website: www.naspaa.org

You can also learn more about public service and public administration through NASPPA's networking site on Linkedin:

Linkedin: http://www.linkedin.com (MPA/MPPs)

NASPPA has also created a MPA/MPP Channel on the video sharing site YouTube where you can find interviews with prominent graduates as well as student created videos:

YouTube: http://www.youtube.com/mpampp 


\section{N - Sustainable Bureaucracies}

This chapter has discussed many initiatives, policies and programs of state and local bureaucracies that contribute to sustainability. These include the use of e-government, networking, life-long learning for personnel, a diverse workforce that represents citizen diversity, and the strategic use of volunteers. State and local administrators are also reorganizing and reinventing government to improve program efficiencies, to harness resources outside government in the service of public policy goals, and to better facilitate the input of state-level interests, private sector groups, and the general public..$_{-}^{22}$ The move to share bureaucratic decision-making power with citizens and personnel in the lower reaches of organizational hierarchies, to embrace collaborative public-private and public-private-NGO (non-governmental organization) partnerships, and to reform dense rule structures and hierarchy as necessary components of an efficient and/or accountable public administration is occurring across a broad range of policy areas, including community policing, ${ }_{-}^{23}$ tax administration, ${ }_{-}^{24}$ education, ${ }_{-}^{25}$ elements of the federal Job Opportunities in the Business Sector (JOBS) program, 26 rural, ${ }_{-}^{27}$ and public. ${ }_{-}^{28}$ This effort has been called collaborative governance or cooperative governance, and could include watershed councils, granges in rural locations, and neighborhood councils in urban areas.

The propensity to adopt alternative institutional arrangements premised on decentralization, collaboration, and citizen participation is especially pronounced in the environmental and natural resources policy world. ${ }^{29}$ Regulatory negotiation, which actively involves a broad range of stakeholders in the specification and implementation of regulations, has become more widely used for pollution 
control. The federal Environmental Protection Agency has developed the Common Sense Initiative (CSI) in league with corporate America, state regulators, national environmentalists, and locally based environmental justice groups. Their goal is to encourage innovation by providing flexibility and to rationalize existing regulatory rules for each industrial sector through the use of a place-by-place approach to achieving pollution control standards. ${ }_{-}^{30}$ EPA's Project XL (Excellence and Leadership), announced in 1996, features a series of pilot projects that follows the lead of CSI. Project $\mathrm{XL}$ and authorizes site-based stakeholder collaboratives "...to allow industrial facilities to replace the current regulatory system with alternative strategies if the result achieve[s] greater environmental benefits."31 While there is still much to be learned about collaborative governance concerning where it will be most effective, it may hold much promise in solving difficult problems at state and local levels.

\section{9. $\mathrm{O}-$ Conclusion}

The chapter began by discussing the negative stereotypes many Americans have concerning bureaucracy and bureaucrats. While there are many reasons for these negative stereotypes, ultimately they may have much to do with what Barry Bozeman calls the "inherently controlling" nature of bureaucracy: $\frac{32}{-}$

Unless all action is voluntary, coordination of activity requires control. Most of us do not like being controlled, even for the collective good. Even worse, bureaucracy strives (even if it does not always succeed) to deliver even- 
handed treatment and to administer policies in a disinterested manner, showing no favoritism.

However, as this chapter has sought to communicate, while state and local bureaucracy does often involve control by seemingly "disinterested" administrators, state and local bureaucrats are also key actors in the ultimate achievement of sustainable communities.

While the bureaucratic model may be a thing of the past in American politics, good governance will always be an ongoing goal. State and local government administration are evolving into increasingly sophisticated enterprises at a rapid pace. Community needs are changing and increasing in scope - and as a consequence administrators in state and local government need to find ways to meet these needs while keeping costs of operation as low as possible. The use of e-government, as mentioned earlier, has increased efficiency and effectiveness of government administration greatly. A cooperative relationship within and across organizations is making better use of human and fiscal resources. The demand for person-to-person service has forced innovation - and the strategic use of retirees and youthful volunteers has become a prominent element in modern governance as a consequence. Employment at the state and local level is and will continue to improve in the years ahead. Bureaucrats, in the truest sense, play an essential role in the organization and administration of our state and local governments. 


\section{Terms}

Bureaucracy

Civil servants

Collaborative governance

Cooperative governance

E-government

Glass Ceiling

Governance (see also "collaborative" and "cooperative" governance)

International City/County Management Association (ICMA)

Lifelong learning

Merit-based performance (civil service)

Network approaches

Patronage

$\underline{\text { Red tape }}$

$\underline{\text { Reinventing government }}$

Tenure

\section{Exercises}

Discussion Questions:

1. What are the historic trends in state and local government employment in terms of numbers employed and demographics (race, gender)? Do you think these trends will continue into the future? 
2. What is the role of state and local bureaucracy in promoting sustainable communities? Can you think of some specific examples?

3. How about the role of "red tape" in bureaucracy? Is it always a negative phenomenon, or is it important in preventing corruption and maintaining evenhanded treatment of citizens?

4. What are some of the new skills and abilities required of state and local administrators in the 21st century?

\section{Notes}

1. M. Weber [H.H. Gerth and C.W. Mills, trans.], From Max Weber: Essays in Sociology (New York: Oxford University Press, 1958).

2. R. Agranoff, and M. McGuire, Collaborative Public Management: New Strategies for Local Governments (Washington, DC: Georgetown University Press, 2003).

3. See H.G. Fredericksen, G. Johnson, and C. Wood, "The Changing Structure of American Cities: A Study of the Diffusion of Innovation," Public Administration Review 64 (2004), 320-330.

See also T.H. Poister, and G. Streib, "Elements of Strategic Planning and Management in Municipal Government: Status after Two Decades," Public Administration Review 65 (2005): 45-56. 
N.M. Riccucci, M.K. Meyers, I. Lurie, and J.S. Han, "The Implementation of Welfare Reform Policy: The Role of Public Managers in Front-Line Practices," Public Administration Review 64 (2004): 438-448.

4. H. Bacot, and J. Christine, "What's So 'Special' About Airport Authorities? Assessing the Administrative Structure of U.S. Airports," Public Administration Review 66 (2006): 241-251.

5. M. Potoski, "Designing Bureaucratic Responsiveness: Administrative Procedures and Agency Choice in State Environmental Policy," State Politics and Policy Quarterly 2 (2002): 1-23.

6. W.M. Lafferty, ed., Governance for Sustainable Development. The Challenge of Adapting Form to Function (Northhampton, MA: Edward Elgar Publishing, 2004).

7. C.Bowling, C. Cho, and D.S. Wright. "Establishing a Continuum from Minimizing to Maximizing Bureaucrats: State Agency Head Preferences for Governmental Expansion-A Typology of Administrator Growth Postures, 1964-1998," Public Administration Review 64 (2004): 489-499.

8. For good sources on this phenomenon, see:

M.Poole, R. Mansfield, and J. Gould-Williams, "Public and Private Sector Managers Over 20 Years: A Test of the Convergence Thesis," Public Administration 84 (2006): 1051-1076.

A. Sapat, "Devolution and Innovation: The Adoption of State Environmental Policy by Administrative Agencies." Public Administration Review 64 (2004): 141-151.

C.W. Thomas, Bureaucratic Landscapes: Interagency Cooperation and the Preservation of Biodiversity (Cambridge, MA: MIT Press, 2003).

9. H. B. Milward and K.G. Provan, "Governing the Hollow State," J-PART Journal Public Administration: Research and Theory 10(2000): 359-379.

D.G. Frederickson and H.G. Frederickson, Measuring the 
Performance of the Hollow State (Washington, D.C.: Georgetown University Press, 2007).

10. M. Bowens, "Street-Level Resilience," Public Administration Review 66 (2006): 780-781.

11. J. Diamond, Collapse: How Societies Choose to Fail or Succeed (New York: Viking, 2005).

12. F.S.Berry, R. Brower, S. Choi, W.X. Goa, H. Jang, M. Kwon, and J. Word. "Three Traditions of Network Research: What the Public Management Research Agenda Can Learn from Other Research Communities." Public Administration Review 64(2004): 539-552.

13. M.P. Mandell, ed., Getting Results through Collaboration: Networks and Network Structures for Public Policy and Management (Westport, CT: Quorum Books, 2001).

14. W.J. Kickert, E.H. Klijn, and J. Koppenjan, eds., Managing Complex Networks: Strategies for the Public Sector (London: Sage Publications, 1997).

C.W. Lewis, "In Pursuit of the Public Interest," Public Administration Review 66(2006): 694-701.

J. Nalbandian, "Politics and Administration in CouncilManager Government: Differences between Newly Elected and Senior Council Members," Public Administration Review 64(2004): 200-208.

15. L. O'Toole, and K. Meier, "Desperately Seeking Selznick: Cooptation and the Dark Side of Public Management Networks," Public Administration Review 64 (2004), 681-693.

S. Page, "Measuring Accountability for Results in Interagency Collaboratives," Public Administration Review 64(2004): 591-606.

16. G. Noble, and R. Jones, "The Role of Boundary-Spanning Managers in the Establishment of Public-Private Partnerships," Public Administration 84(2006): 891-917.

17. See contributions to a conference on workplace discrimination held at Rice University in May of 2000 collected into the edited volume: Dipboye and Colella (eds.), 
Discrimination at Work: The Psychological and Organizational Bases (Mahwah, NJ: Lawrence Erlbaum Associates, 2005).

18. R. Connell, "Glass Ceilings or Gendered Institutions? Mapping the Gender Regimes of Public Sector Worksites," Public Administration Review 66(2006): 837-849.

19. D.F. Norris, and M.J. Moon, "Advancing E-Government at the Grassroots: Tortoise or Hare?" Public Administration Review 65(2005): 64-75.

D.M. West, "E-Government and the Transformation of Service Delivery and Citizen Attitudes," Public Administration Review 64(2004): 15-27.

20. B. Gazley, and J. Brudney, "Volunteer Involvement in Local Government after September 11: The Continuing Question of Capacity," Public Administration Review 65(2005): 131-142.

21. J. Burnett, "Trends in State Government Employment," The Council of State Governments. URL: http://knowledgecenter.csg.org/kc/content/stategovernment-employment

22. D. Osborne, and T. Gaebler, Reinventing Government (New York: Basic Books, 1993).

23. D.H. Bayley, Police for the Future (New York: Oxford University Press, 1994).

24. M.K. Sparrow, Imposing Duties: Government's Changing Approach to Compliance (Westport, CT: Praeger, 1994).

25. D. Matthews, Is There a Public for Public Schools? (Cleveland, OH: The Kettering Foundation, 1996).

26. E. Bardach, and C. Lesser, "Accountability in Human Services Collaboratives - For What? and to Whom?" J-PART: Journal of Public Administration Research and Theory 6(1996): 204-205.

27. See the thoughtful contributions collected in Beryl Radin et al., New Governance for Rural America: Creating Intergovernmental Partnerships (Lawrence, KS: University Press of Kansas, 1996). 
28. J. Walters, Measuring Up: Governing Guide for Performance Measurement (Washington, DC: Urban Institute, 1997), pp. 160-162.

29. M.E. Kraft, and D. Scheberle, "Environmental Federalism at Decade's End: New Approaches and Strategies," Publius 28(1998):131-146.

30. U.S. Environmental Protection Agency (EPA), "The Common Sense Initiative: A New Generation of Environmental Protection," EPA Insight Policy Paper (August, 41994 [EPA $175-\mathrm{N}-94-003])$.

31. U.S. Congress, "An Assessment of EPA's Reinvention," A Report by the Majority Staff of the Committee on Transportation and Infrastructure, House of Representatives (September, 1996), p. 10.

32. B. Boseman, Bureaucracy and Red Tape (New Jersey: Prentice Hall, 2000), pp. xi-xii. 


\section{Chapter ro: Budgeting and Sustainability}

\section{Io.A - Introduction}

Attending conferences on sustainability organized for government officials is often a very uplifting experience. Keynote speakers typically come from a variety of backgrounds - including business, science, the mass media and academia. It is clear that the sustainability tent is a large one indeed, and includes ample room for private-public sector partnerships between emerging industries and government; eager and informed citizen stakeholders and administrators can frequently be found working in cooperative enterprises of one type or another. While nearly always concluding with warnings for the challenges to be faced along the path ahead, the keynote speakers usually offer the promise of a responsible and prosperous future if all reforms of consumption and production practices and processes are achieved as expected. One generally walks away from these gatherings better informed, more deeply concerned, somewhat optimistic, and highly motivated to contribute to achieving the goal of sustainability for our progeny.

The mood tends to change a bit, however, when one faces the realities of budgeting for sustainability; it is the case that changes away from "business as usual" is generally more expensive than sticking with the status quo, and nearly always requires a substantial financial commitment to be maintained over a long timeframe. All too often, that sense of cautious optimism inspired by keynote speakers at sustainability 
conferences dissipates when the reality of getting through the end of the fiscal period sets in. Those setting the budget have to somehow justify monies requested for the year ahead. A decade ago, the state and local government budget horizon looked rather bright. The technological boom associated with computers and information processing produced needed new revenue in the 1990s. In the first decade of the 21st century, however, a much darker economic scenario looms.- The continuing cost of wars against terrorism abroad, a seriously faltering housing market, a slowdown in economic growth, unresolved healthcare system problems and pension system failures all translate into forecasts for weak revenue streams coming to state and local governments for an extended period. Energy markets have tightened as peak oil predictions look more convincing, and inflationary trends combined with a weakening currency lead many fiscal analysts to anticipate constrained public sector budgets at the state and local levels. The need to prepare for future disasters - either manmade of the type the Department of Homeland Security seeks to prevent or the natural phenomena that global climate change may well occasion - is yet another significant constraint facing budgeters in state and local government over the course of the coming decade.

\section{Learning Objectives}

This chapter will:

- discuss how the typical state and local budget process works including the various actors and institutions involved.

- present information on sustainable budgeting 
practices and revenue sources.

- $\quad$ examine historical budgeting patterns in state and local governments.

- discuss intergovernmental sources of revenues for transportation, education, public health and many more state and local services.

- examine historical state and local expenditure patterns.

- present various approaches for budget reform, which have been advocated for the state and local government.

\section{Io.B - Why do we budget? How does the typical budget process work?}

Simply put, we "budget" (both a noun and a verb) because we nearly always have limited financial resources and multiple demands on those resources that exceed actual cash balances, current assets or expected cash and financial assets available to us. Public budgeting is the process by which elected and appointed officials, acting in the interest of the governed, determine methods of collecting government resources and securing assets through forms of taxation or appropriation (e.g., the holding of public lands, forests, surface waters, etc.) and then allocate those financial and associated resources on priorities determined by the democratic political process.

The politics of budgeting entail arriving at outcomes where some priorities are deemed more important than others. The result might be that revenues collected are, as a 
result of budgeting choices, directed to certain priorities while other noteworthy issues receive less financial support - or even no support at all. Human nature being such that it is, hardly anyone relishes the thought of losing out in a budgetary process and virtually nobody who thinks that a priority is worthy of public funding would be pleased to discover that the majority of individuals making budgeting decisions think otherwise. The common result of the periodic budgeting process is that it creates great angst while it is going on, and the results of the process often are that conflict is sewn for the next round of budget allocations in each succeeding round of budgeting.

Most proponents of particular state and local budget priorities believe that becoming a funded priority of government is more likely if budget decision makers (elected and appointed officials) also value a particular priority and are acquainted with the methods for accommodating a budget request. The budgeting process is iterative, meaning existing priorities are continually "explained" and the methods for securing funding have become increasingly sophisticated over time. In the case of pursuing sustainable governance, priorities and budgeting practices have shifted somewhat. Efforts on the part of some powerful advocates to promote sustainability are adding significantly to the traditional challenges of public budgeting. Budgeting is, as a consequence, an increasingly complex process in American state and local government.

In most American state and local governments, budgeting occurs either annually or biannually. Items established in previous budget cycles, if they are politically popular, are more likely to have a higher priority and gain funding than are newer items seeking a piece of the proverbial "budget pie." Unfortunately, many of the new budgetary items involving sustainable governance and the promotion of resilient communities are too new to seem a priority for seasoned 
budget makers. This harsh reality means that the task facing sustainability advocates is a challenging one because new ideas must be promoted at the cost of established priorities and they must gain broad favor in order to receive the lifeblood of public financial investment.

\section{Io.C - Generic Budgeting Process}

As a list of major steps taken in the process of building a state and local government budget, the universal budget process appears deceptively simple:

1. Preparation of revenue and expenditure estimates takes place.

2. An executive budget is compiled and submitted to a legislative body.

3. The legislative body deliberates and issues budgetary approval.

4. The executive signs the legislative enactment containing the budget(s) into law.

5. Budget execution occurs with the allocation of resources to public agencies.

6. Systematic post-authorization audits are conducted to monitor budgetary compliance.

\section{Io.C.I - The Preparation of Budget Estimates}

The beginning of a budget cycle generally requires the input from government agencies on the financial resources they expect to need for the next budget cycle. Similarly, a process is generally in place whereby a unit of state and local 
government prepares revenue estimates for the coming year or biennium. The agency expenditure estimates are shaped by many considerations, including the following:

- Existing statutes and rules: Agencies consider the statutory requirements that they are required to accomplish. State and local elected officials often develop new policies or adjust older policies through new or revised legislation, then work to estimate the costs associated with these new policies and programs.

- Statutes and rule additions and changes: Agencies consider the costs of implementing and enforcing statutes through administrative rules and other policies. Agency interpretations of the meaning of statutes - frequently subject to the accession of elected leaders and the courts - will affect the expenditure estimates associated with implementation and goal accomplishment.

- Federalism Impacts: State and local government agencies often must consider the statutory and administrative rule requirements emanating from other levels of government. Local county and municipal governments are often constrained by state and national laws, rules, and resource provision; states are highly responsive to national politics and federal policy.

- Demographics: Many budgetary priorities are a function of population - the numbers and types of people who live in a jurisdiction currently and who are expected to live there in the future. As demographic changes occur (e.g., school-aged population, percentage of population requiring public health services, etc.), the public expenditures associated with accomplishing certain priorities change as a result.

- Agency-related issues: Public agencies at the state and local government level must consider the changing role and nature of their personnel and their operations (e.g., the computerization of records, the adoption of e-government links to the public, etc.). Agency anticipated expenditures often 
rise or fall independently of statutory additions or changes.

After agency estimates have been drawn up, these are typically submitted to an elective executive leader. At the state level, the leader in question is the state governor; at the local level, it may be the county commissioners, the mayor or the city manager.

\section{Io.C.II - Executive budget compiled and submitted to legislative body}

The political executive is powerful in the budgetary process, without exception. Executives in state or local government review, alter, and compile all agency budgets before submitting their own budget for legislative consideration. Frequently, the executive has offered agencies some guidance in the preparation of their estimates, indicating the executive's priorities as well as expressing expectations about resource availability for the budget derived from the revenue forecast as a whole, and often for constituent parts of the budget as well. In many cases state and local government agencies request resources that do not line up fully with executive expectations or preferences; often adjustments are made prior to the submission of the budget to the legislative body in question which reflect the executive's preferences and priorities.

The politically responsible, elected executive authority must take into careful consideration the priorities of different levels of government, particularly when those levels of government mandate certain expenditures. Mandates may come with funding to support a priority or may be "unfunded" - meaning that the state and/or local government must carry the cost of complying with the mandate. For example, 
Congress might require all public agencies to provide easy access to the disabled in all public buildings; if funds are set aside for the reimbursement of costs incurred, this would be a funded mandate. If, on the other hand, few if any such funds are provide this would be an unfunded mandate.

In addition to mandates, the executive budget must also consider that certain public expenditures are directly related to entitlement programs. Entitlements require that government pay for certain individual needs of a beneficiary meeting a set of prerequisites. For example, indigent people without private assets qualify for state medical benefits usually in the form of Medicaid. The high costs incurred in meeting mandated and entitlement expenditures limit resources for the introduction of new, cutting-edge policies related to sustainable communities and citizen engaged governance.

At the state and local level, the political executive usually enjoys the services of a staff budget officer and budget office, and this office is highly responsive to the political executive and his/her own set of priorities. This executive staff office works with agency budget personnel to make adjustments in the expenditure estimates sent from the agencies, and it ultimately submits a compiled budget request to a legislative body for its consideration. The executive budget is usually submitted as a balanced budget, with a discussion of expected revenues derived from the revenue forecast and a detailed accounting of expenditure priorities recommended for adoption. 


\section{Io.C.III - Legislative body deliberations and budget approval}

Both a fiscal management document AND a political document, the executive's budget reflects the current administration's ideology and establishes priorities along those lines. State and local legislative (deliberative) bodies are composed of other elected representatives with a wide range of values and issue priorities. In many cases, the executive branch and the majority of legislators are from different political parties, a common situation slowing down the budget process. A governor, for instance, may create a budget built around increases in tax revenues through tax rate adjustments, while a majority of the state legislature is opposed to increasing tax rates. In such a case, the legislature would decline to support the requested level of spending.

The result of these differences is a budget "deconstruction" (significant reconfiguration), after which an entirely new budget is created through the legislative process. Legislatures usually conduct their budgetary business through an elaborate system of subcommittees, whose work is then submitted to the principal budgetary appropriations committee. Through a combination of the subcommittees and the legislative body, the process of establishing budgetary priorities takes shape. Administrative research offices associated with the legislature, as well as the personal staff of legislators, work to coordinate the process and to offer information about various preferences and priorities, and the expected relative costs. In the spirit of institutional checks and balances, revenue analyses are conducted by legislative research offices independently of executive research work.

Eventually, the appropriations committee's work on the budget is compiled into a unified budget document that is discussed, amended, and eventually passed by the legislative 
body. The legislative budget is then subject to approval or rejection by the political executive. Potentially, the budget could continue to revert to the legislative body until it either overrides the wishes of the political executive or the political executive approves the budget. In most states and in many local government jurisdictions the executive is permitted to exercise a "line-item veto" over particular budgetary items for some period of time (30 to 60 days, generally), but this power is used sparingly where it is given to the governor, commissioner or mayor.

\section{Io.C.IV - Budget execution}

Following budget approval, budget instructions are sent to the agencies that will execute its provisions. Budget instructions are usually rather detailed accounts of the goals and priorities of the agency - relating back both to statutory requirements and county/municipal ordinances. Budget instructions and "fiscal notes" may include expenditure rates and goals, as well as the borrowing authority permitted for agencies. Borrowing authority relates to an agency's capacity to enter into loan agreements for need resources. Some public agencies may be permitted to issue government bonds as a method of gaining resources. Loans and bonds ultimately involve a promise of repayment of monies to a lender or bondholder, as well some amount of interest on principal. This aspect of public budgets is particularly important where separate operations and capital budgets are prepared. Capital projects frequently entail public borrowing, while operations budgets seldom do so.

Budget execution requires that agencies submit regular and detailed financial statements and reports to political executives and to the legislature, demonstrating that 
expenditures comply with established policy priorities. If fiscal resources from another level of government come in the form of a grant, then budget execution may also include regular reports to granting agencies. At times, the agency's expenditures will exceed the amount budgeted to it. In the executive phase, agency budget administrators promptly alert political executives and legislators of possible shortfalls in needed resources. This relatively rare event occurs when there are either unanticipated problems (e.g., a natural disaster) or a serious breakdown of administrative processes (e.g., the Enron energy price scandal), and can result in mandated budget cuts or the identification of other sources of resources through new or increased fees, through tax rate enhancements, or through the sale of public assets.

\section{Io.C.V - Post-Audit}

At the end of the budget cycle, public agencies are held accountable for their spending actions. The system of accountability that is used in state and local government involves either an independent or in-agency audit of the financial records of agencies. The purpose behind the audit is to ensure that public funds were spent in accordance with the goals and priorities intended, and to determine if any resources were misused or wasted in the process of carrying out the people's business. If an audit is positive, the fiscally responsible agency might benefit by finding its budget requests funded during in the next budget cycle. Conversely, shoddy record keeping and poor financial expenditure choices might negatively impact an agency and the provision of public funds for its priorities. 


\section{Io.D - Sustainable Budgeting and Sources of Revenue}

State and local governments are the bedrock of the U.S. federal system. The budgetary decisions made at these levels of government have a tremendous influence on the lives of citizens, community organizations and businesses. For example, some areas affected by state and local budgeting include lifestyle choices and living arrangements; spending patterns; business development or relocation. In order to attract citizens and businesses, states and local governments must contribute to the development of a welcoming, rewarding, and sustainable economic environment. New residents wishing to settle down and raise families, building their personal and professional lives in a place where they feel secure, often need the assurance of a lasting commitment on the part of government and the nonprofit and private sectors where they wish to reside. In many ways commitment is a key element in sustainability. Commitment to a secure quality of life in a specific place on the part of the public, nonprofit and private sectors often requires dedicated and persistent revenue investment in sustainable governance and enterprise support.

In a sense, revenue collected from taxpayers represents a commitment on the part of citizens to sustainability: commitment, after all, is a two-way street of mutual obligation. Most satisfying to community members is the view that money being paid to the government is fair or equitable. Likewise, revenue collected must be steady and predictable so that government can build budgets that focus on meeting the commitment of sustainability. Agreement on equitability and predictability, however, is a major challenge to state and local revenue collection systems, and both equitability and 
predictability are frequently the source of public dissatisfaction.

Taken in combination, state governments collect approximately one half trillion dollars per year in revenue. This revenue is collected in a variety of ways, to include the following typical categories of state receipts:

\section{Commonly Recognized Taxes}

- Sales and gross receipts taxes

- Personal income taxes

- License fees

- Corporate income taxes

- Property taxes

- Severance taxes

\section{Other taxes}

- Death taxes

- Gift taxes

- Stock and documentary transfer taxes

\section{Io.D.I - Sales and gross receipts taxes}

Sales taxes are those taxes paid on everything sold in retail transactions ranging from the clothing to food. Fortyfive states and the District of Columbia impose sales taxes. Each state has the authority to set its own sales tax rate. In most American states unprepared food items are not subject to a sales tax: only five states make unprepared food subject to sales tax, with Tennessee imposing the highest tax rate on unprepared food (six percent). Taxing unprepared food is often thought to impose a higher cost on low-income 
individuals and families, and this type of tax can be viewed as unfair or inequitable as a consequence.

Sales taxes fall within the general category of excise taxes - these are taxes related to consumer consumption behavior. Beyond sales taxes, three other commonly known forms of excise taxes are motor fuel taxes, cigarette taxes, and distilled spirits taxes. Motor fuel taxes generally are used to fund road construction and road and bridge maintenance. Cigarette taxes are used generally by state governments to fund public health and education programs. Tobacco product taxes are potentially inequitable, given that smokers are commonly from lower income brackets. Nevertheless, it is thought that by increasing the cost to smokers through high excise taxes the state can cause demand for tobacco products to decline, likely leading to improved community health and economic sustainability. Nearly all states have cigarette and distilled spirits taxes (so-called "sin" taxes), but the rates vary significantly from state to state.

According to a 2017 Tax Foundation study: ${ }_{-}^{2}$

- "Local sales taxes are collected in 38 states" (e.g., counties and cities).

- "The five states with the highest average combined state and local sales tax rates are Louisiana (9.98\%), Tennessee (9.46\%), Arkansas (9.30\%), Alabama (9.01\%), and Washington (8.92\%)."

- "Sales tax rates differ by state, but sales tax bases also impact how much revenue is collected from a tax and how the tax affects the economy."

- "Sales tax rate differentials can induce consumers to shop across borders or buy products online." 


\section{Io.D.II - Personal Income Tax}

One common method of collecting state and local revenue - state-level individual income tax - is used in 43 states and the District of Columbia. According to another Tax Foundation study on income taxes: ${ }_{-}^{3}$

- "Individual income taxes are a major source of state government revenue, accounting for $36 \%$ of state tax collections."

- "Forty-three states levy individual income taxes. Forty-one tax wage and salary income, while two states - New Hampshire and Tennessee -exclusively tax dividend and interest income. Seven states levy no income tax at all."

- "Of those states taxing wages, eight have single-rate tax structures, with one rate applying to all taxable income. Conversely, 33 states levy graduated-rate income taxes, with the number of brackets varying widely by state. California and Missouri each have ten brackets, the most in the country."

- "States' approaches to income taxes vary in other details as well. Some states double their single-bracket widths for married filers to avoid the "marriage penalty." Some states index tax brackets, exemptions, and deductions for inflation; many others do not. Some states tie their standard deductions and personal exemptions to the federal tax code, while others set their own or offer none at all."

The lowest bracket income tax rate is found in Iowa $(0.36 \%)$, and the highest bracket rate is found in Oregon (9.9\%). Six states have a flat rate for state income taxes. The highest flat rate state income tax is in Massachusetts (5.1\%). As a whole, state personal income taxes are the second largest source of revenue for states with income taxes and the District of Columbia. 


\section{Io.D.III - License Fees:}

License fees are collected by state government for a variety of activities. States collect license fees from businesses and individuals who incorporate within their borders. Businesses usually identify states with low incorporation fees (for example, Delaware and Nevada charge minimal fees) to reduce their costs of operation. Fees may also be collected for use permits for hunting and recreation in state parks. License fees are the third largest source of revenue for the states in total. License fees are usually "visible" only to those individuals and corporate entities that are required to pay them. Nevertheless, the cost associated with the fees, particularly in the case of business-related license fees, generally are passed on to consumers in the form of higher prices. License fees associated with hunting and outdoor recreation may be more visible to individuals, but only to those individuals interested in hunting recreation in particular locations. In regards to sustainability, license fees can be used to encourage certain types of business and recreational behavior deemed beneficial to states and communities; at other times, license fees may actually drive away business development needed for sustainable economies or encourage overuse of state recreational areas, producing environmental degradation. Fees associated with water use and recreation are of particular importance in this regard, and many sustainability efforts are aimed at the strategic imposition of fees that promote conservation of natural resources. 


\section{Io.D.IV - Corporate Income Taxes}

Corporate income taxes are another important source of state revenue. Business development and retention is a key element in developing a sustainable economic base. Businesses provide jobs to individuals, which in turn help finance other aspects of local economies. Businesses also contribute to other forms of state revenue, such as license fees. In order to attract and retain businesses, state corporate income tax rates must be competitive with other states and communities. If tax rates are too high, corporations might find it more lucrative to relocate their corporate offices and manufacturing facilities elsewhere. In many cases corporations find overseas locations more economically beneficial because corporate income tax rates typically are very low. Many states in the Northeast and California in the West have relatively high corporate income tax rates - some in the range of $7 \%$ to $9 \%$. The highest state corporate income tax rate in 2015 was found in New Hampshire, 9.3\%. The lowest state corporate income tax rates can be found in several Midwestern and Western states. Most American states that have corporate income taxes impose flat rates. A flat tax is a single rate regardless of income level.

\section{Io.D.V - Severance Taxes}

Severance taxes are tax payments imposed on the extraction of natural resources. States own sub-surface mineral rights, some own forestlands, and many protect fish runs through their ownership of surface waters. When natural resources are extracted through activities such as mining, timber harvesting or fishing, the states can collect excise taxes 
on earnings derived from those activities. From a rights-based perspective, the state collects on resources that technically belong to all citizens. The tax money collected represents a portion of the price the state is charging extractors for the resource; viewed that way, severance tax rates illustrate the very low price private enterprise pays for rights to natural resource.

High quality, well-protected, and readily accessible natural resources are key factors in maintaining sustainable states and local communities in many areas of the country. Unless the resources in question are renewable, the extraction of resources could represent a decline in sustainability potential. Hydrocarbon fuels are destroyed through combustive processes, making them non-renewable as energy sources; and while use of these resources is not a sustainable practice, hydrocarbon fuels remain the foundation of the world's energy portfolio. Technically, fisheries and timber are renewable resources, but due to restraints on habitat (for example, hydroelectric dams blocking salmon runs) and aggressive timber harvesting, these natural resources require the collective aid of humankind and the power of government regulation and planning in order to retain or regain levels of sustainability. Additionally, the viability of plant and animals communities may be compromised during the process of resource extraction by mining, fishing, and timber harvesting.

In the now famous case, Northern Spotted Owl v. Hodel 716 F. Supp. 479 (W.D. Wash. 1988), U.S. District Court Judge Thomas Zilly decided in favor of the preservation of an endangered species over the continuation of intensive timber harvesting, particularly old growth timber. The case represents a landmark decision that illustrates a governmental commitment to sustainability and the active pursuit of social and environmental justice through governmental action. This federal court decision has had a widespread impact on state and local governments throughout the country. This decision 
made it clear that the pursuit of sustainability entails much more than the sustainability of a regional lifestyle and the continual meeting of societal demands for resources and products. Rather, human needs and wants must be understood in the context of a broader view of ecological sustainability, not solely constructed as a zero-sum game in which the natural environment loses while human society gains. The court's interpretation of the Endangered Species Act as seen in the Spotted Owl decision dictates that those extracting natural resources must consider more than profit. Severance taxes go a small way towards the recognition of the environmental loss associated with many forms of resource extraction. Additionally, the taxes levied in this area raise the price of resources extracted, accounting for the hidden costs associated with the reduction of environmental degradation and reducing the demand for non-renewal natural resources.

\section{Io.E - Revenue: Past and Future}

Spending is up in state and local government, ${ }_{-}^{3}$ nonetheless revenue streams are tightening. How is this seemingly imbalance possible? Good revenue streams exist, but balancing concerns for equity and sustainability is a key aspect of sustainable budgeting. In the past, property taxes and income taxes were highly touted methods of revenue generation.- In recent decades, however, the property tax has come under severe political attack. In 1978, California voters passed a property tax limitation measure known as Proposition 13 that severely constrained the property tax as a revenue stream for state and local government in that state. In the decades since the passage of Proposition 13, voters in several other states have supported tax and expenditure 
limitation measures (TELS), resulting in decreased reliance on "broad based taxes (specifically property taxes)."

Primary reliance on the income and sales taxes persists in the American, but questions of equity remain. Elderly and low-income individuals, for instance, may be unduly burdened by income taxes. ${ }_{-}^{6}$ Sales tax rates have risen and in many cases rate increases have been linked to specific program needs, such as the building and the maintenance of transportation infrastructure. In their study of California taxes, Crabbe and his associates conclude that citizens may find tax rates and increases (specifically sales tax rates) acceptable if taxes can be clearly linked to specific program benefits.. ${ }_{-}^{7}$ Arguably, this finding is largely consistent with a more market-oriented society wherein individuals have become accustomed to think in terms of specific expenditures for tangible products.

With respect to predictability, it must be noted that both sales and income taxes are closely tied to economic cycles. The rise and decline of the tech bubble left some state and many local government revenue streams in a rather precarious situation at a time of great need. State budget processes have generally adjusted to revenue instability by tightening up spending commitments ${ }_{-}^{8}$ and through the artful display of political leadership. Government's demonstration of fiscal restraint as a timely action and government accountability as a priority are examples this political leadership. Former Arkansas Governor Mike Huckabee [a candidate for the Republican Presidential nomination in 2008] argued that political leaders must make citizens aware of fiscal constraints and their impact on budget choices. ${ }_{-}^{9}$ Making empty promises about budget inclusions only sends false signals to citizens about governments' ability to provide services in times of financial stress. Sustainable budgeting requires honest and open government and thoughtful leadership alike. ${ }_{-}$-

Despite recession, the longer-term future may not be unduly grim with respect to government revenues; 
nonetheless, state and local government budgeters will need to make tough decisions regarding the three Es of sustainability - a vibrant economy, a healthy environment, and the active promotion of social equity..- Writing during an earlier period of fiscal constraint, the proponents of reinventing government David Osborne and Ted Gaebler called upon state and local government leaders to become more entrepreneurial in their search for revenue and the operation of their agencies, to look for bargains in their acquisitions processes, and to experiment actively with new methods and techniques of governing. ${ }_{-} 2$ Budgeting in today's challenging times calls for the same level of pragmatism, being realistic about revenues, expenditures, and the needs of citizens..$_{-}^{13}$ Revenue management in state and local government also entails making good investments. Osborne and Gaebler's model for budgeting during tough economic times shows the importance of concentrating spending in areas that produce future revenue, but that type of prioritization might cause some pain and inequity in the short run.- In another model of budgetary allocations in times of highly constrained budgets, Bowen and his colleagues found that budgetary expenditures ("investments") made in urban areas produced a greater return on investment than similar investments made in rural areas.

Revenue collection and management in state and local government is more than simply fine-tuning a tax system it is also about enforcement. State and local government systems operating under fiscal stress must strive for efficient and effective tax enforcement and debt collection. Enforcement may be easier today than in the past given the advent of electronic banking and financial transactions. Former Nevada State Controller Kathy Augustine, as with her counterparts in other states, found during her term of office that the use of information technology in tax enforcement was highly effective. ${ }_{-}^{15}$

One major revenue stream for state government comes 
from the 1998 tobacco settlement. One element of the The Master Agreement requires that "U.S. tobacco companies... pay approximately $\$ 229$ billion between 1999 and 2025 to 46

states, the District of Columbia, and five U.S. territories." Johnson found that states are using the tobacco settlement monies primarily for health care, education, infrastructure projects, and as the basis for debt issuance. Nevertheless, state budget makers consider this funding a short-term fix to any future revenue problems -2025 is no longer on the dim horizon. As a slack resource, the tobacco settlement monies could serve as an important part of the public policy innovations necessary to build sustainable governance. Slack resources have been shown to have a positive effect on the budget process and on achieving favorable outcomes. ${ }_{-}^{17}$

\section{Io.F - Federal Grants-in-Aid: A Key Source of Revenue}

Federal grants-in-aid are transfers of governmental revenues from the national to state and local governments. There are a variety of types of federal grants. Categorical grants entail funds given to the state and local level for the accomplishment of specific purposes specified in federal statute and enumerated in considerable detail in administrative rules. When the federal government offers categorical grants to state and local governments, the federal government expects goals to be accomplished and attendant conditions to be maintained in the course of work being done (e.g., workplace safety standards, the use of prevailing wage rates, nondiscrimination in hiring and in workplace treatment, etc.). In contrast, the amount of federal grant money available 
to a state or local government in a formula grant is not tied to goal accomplishment, but rather is dependent on the population of individuals living in the recipient state or local government who qualify for a benefit or service to be provided by the state or local government involved.

As with categorical grants, formula grants are usually given to a state or local government to accomplish a national policy goal adopted by Congress. Categorical and formula grants are usually directed towards specific state and local units of government facing particularly difficult policy dilemmas (e.g., high incidence of domestic violence, the presence of endangered or threatened specifies, a high level of incidence of infectious disease) or are widely available to all state and local governments willing to make an effort to address a public problem (e.g., conduct a hazardous material in transport study for emergency management planning, promote the recycling of waste materials, etc.). Alternatively, competitive grants require that state and local governments demonstrate their need for resources as well as develop innovative policy proposals for how a national public policy goal would be addressed in a favorable way if the requesting government was awarded the grant monies.

Unlike competitive grants, block grants do not require a state or a county or municipal government to follow strict grant guidelines in policy development or implementation. Rather, grant recipients exercise a great deal of discretion in establishing policy goals and developing innovative implementation strategies. The goal of block grants is to provide seed money for the development of local government policy innovations. While block grants have the potential to be misused and wasted, they have been used to great benefit to promote sustainable community development, globalization of the economic processes, and mediation of the effects of global climate change. 


\section{Io.G - Federal Grants for Transportation}

Beyond doubt, sustainable communities will require more energy-efficient modes of transportation. The cost of fossil energy is high and vehicle emissions are a growing concern for climate change phenomena. Renewable energy and hybrid vehicles face escalating demand and short supply. Mass transportation systems might be one very important method of reducing demand for fossil energy. Alternative energy mass transportation vehicles are becoming increasingly visible in society - natural gas and clean diesel-powered buses are now quite common across the nation. Similarly, cutting-edge hydrogen powered buses are part of several mass transportation demonstration projects in the U.S., and in several cities abroad. Nevertheless, it is fair to say that federal transportation-related grant trends would seem to provide more support for a tenuous status quothan promote more efficient and sustainable transportation schemes.

For leaders and administrators functioning at the state and local level, sustainable transportation requires grassroots policy innovation and funding. Many states have instituted their own transportation and energy initiatives to counteract the rather tepid commitment of the federal government to support transportation policy renewal through grants-in-aid. Also, rebuilding city centers and developing high concentration housing units, such as condos, may increase use of public transportation and bring about subsequent reductions in reliance on the personal automobile. 


\section{Io.H - Federal Grants for Education}

Education grants have risen steadily since 1990. Money for education workforce enhancement and training has risen most noticeably; in large part these grants have resulted from the increased emphasis on teacher quality and retention. Education and social services funding has increased in response to new awareness of the relationship between educational achievement and social conditions of student learners. Federal funding for special education and the education of the disadvantaged is a significant portions of the federal funds transferred to states and local governments in the form of grants-in-aid. Noticeably, money for school building improvement has declined, despite increased awareness of classroom overcrowding and school building disrepair. School building infrastructure grants are not only an important part of current education quality, but they are also critical to the sustainability of public schools as a core element of civic infrastructure.

\section{Io.I - Federal Grants for the Least Advantaged - Public Health and Income Security}

Federal grants for public health services for the least well off in society are critical in efforts to create and maintain sustainable communities. A community's level of success or failure depends on the achievement of both individual and collective goals. While individual goals may be highly varied, collective goals are defined by what we share in common and 
our common responsibility to one another. Recognition of our collective commitment legitimizes the social contract to which we have agreed.

Our commitment to the most needy members of society is and always will be a work in progress, as we learn more about the nature of our society and the social ills shaped by demographic, socioeconomic, political, and even environmental change. In dollar terms alone, the chart above illustrates our growing commitment to serve the needs of the least advantaged. Since 1990, the federal grant commitment has more than quadrupled, and will likely rise even more significant in the years ahead. While a strong commitment is noteworthy, federal grants-in-aid will continue to be necessary as states and local communities struggle to establish sustainability along multiple dimensions.

\section{ro.J - Federal Grants for Children, Families, and Veterans}

The chart above places a number of program areas into comparative terms for an important reason. We believe that the comparison featured is across groups of individuals in our society who are among the most vulnerable and yet critically important to our social sustainability. Commitment to caring for children, families, and veterans represents a core value in American society. While all dimensions of sustainability will ultimately require "commitment," it struck us as a unique opportunity to illustrate in one table some of the most recognizable examples of commitment!

Commitment to children and families has risen enormously since 1990. While some might applaud the growing commitment, it also signals something else - as with 
all the other charts discussed previously in this chapter - it signals critical disparities in our states and local communities that American society, through private actions, public policy and budgetary choices, has determined must be overcome if sustainability is to be achieved. The decline in Temporary Assistance to Needy Families (TANF) in terms of grant funding might in part be explained by the success of President Clinton's collaborative efforts with a Republican congressional majority to hammer out welfare reform provisions; those reforms resulted in moving many individuals off of welfare rolls and into the workforce. Alternatively, it has been argued that TANF and welfare reform has resulted in an ebbing commitment to families__ 18 - the decline in grant funding started shortly after Republicans regained control of both chambers in Congress in 2003.

Federal grants for veteran's programming at the state and local level has been flat for several years, despite the rise in the number of disabled veterans resulting from warfare in Afghanistan and Iraq. Veterans of the Second World War, Korea, Vietnam, and the Persian Gulf War eras have been joined by veterans of more recent military commitments arising from the Global War on Terrorism. Rather incredibly, federal grant monies have remained rather steady in nominal terms - and if inflation were factored in, the amount of grant money being provided for veterans' programming is actually declining in real terms. 


\section{Io.K - Federal Funding for Programs of Hope and Corrections}

Again, we have placed in comparison a number of federal grant areas that often impact young adults who find themselves in trouble with the law. How youth are treated is a significant factor in community resiliency; each generation in a community must achieve progress and improve its performance in order for its community to be sustained in the context of ever-changing global, regional and local conditions.

The program funding in the chart above shows our commitment via federal grants to programs that are intended to deal with such issues. As can be seen, the commitment to most of the program areas began to decline in the early years of the 21st century. The one program area that has not declined pertains to funding for vocational and adult education.

Federal grants are important sources of revenue indeed, and many of these grants contribute directly to economic vitality, environmental protection and social equity. The federal revenues provided in these grants are often attached to national policy goals, and this connection to goals gives us some ability to make comparisons over time between grant efforts made and goals being accomplished. Funding for many policy areas is on the rise, but in some cases funding is either stagnating or even declining. While federal grants to state and local governments are very important to our discussion of budgeting and sustainability, it is equally important to explore independently the budget expenditures of state and local governments. 


\section{Io.L - State and Local Budget Expenditures}

Budget expenditures are a good way of determining the priorities of state and local governments. In looking at total state budget expenditures (Figure 10.8), it is clear that education and public welfare represent over one half of state budget expenditures. The third most common expenditure is for Insurance Trust funds, an allocation that covers public employee retirement benefits and private sector unemployment insurance. Highways and bridges and health/ hospital expenditures also constitute large portions of state government expenditures. All other functions of government - for example, law enforcement, corrections, courts, natural resource management, and utilities - are covered by less than one quarter of the total state budget expenditures. The area of Veterans' Services garners only the tiniest of fractions of total state budget expenditures.

As with state governments, local government expenditures are predominantly focused on education expenditures. Approximately one third of total local government expenditures in the United States are spent on elementary and secondary education. Public assistance expenditures are roughly one quarter of local government expenditures, while allocations to Insurance Trust funds are between 15-20 percent of total local government expenditures. A little over a quarter of local government expenditures covers all other government services - for example, fire, parks and recreation, and criminal justice (courts, jails and law enforcement).

In both state and local governments, public assistance and education are by far the biggest expenditure categories in public budgets. In terms of sustainability, education represents a direct investment in the future. With the proper education, tools, technology and knowledge, a new generation 
could be better prepared to deal with the challenges of the future than past and current generations. For example, the adoption of renewable energy sources requires that citizens understand the bigger system of energy generation, distribution, and use. Through local communities, welleducated citizens will have to make wise choices about energy supply and demand. Education is also a key ingredient in government and private sector innovation. Future quality of life will rely heavily on new knowledge and scientific breakthroughs.

As with education, the area of social assistance consumes a significant portion of the state and local tax dollar, as well as intergovernmental transfers (frequently in the form of grants) coming from the federal government. A sustainable society promotes social justice. A tenant of social justice is that society and government actively address the socioeconomic disadvantage. A horizontally divided society - a society in which a small group of individuals controls a large proportion of available resources while a large number of individuals have little or no access to resources - is not a sustainable society. The horizontally divided society, particularly a society facing near term shortfalls of basic energy and natural resources, will prove to be politically and socially volatile and could even lead to disarray. Social assistance programs represent a commitment to addressing such inequities, and preventing social and political conflict.

It is very clear that many important categories of expenditure associated with sustainability - categories related to natural resource protection, environmental protection and basic infrastructure maintenance - tend to be overshadowed by the education and social assistance functions. Commitment to funding those who have suffered in personal efforts to protect us - the veterans of our wars is paltry compared to other functions of government. Is the 
commitment to fund these items that tend to be overlooked important to sustainability? The answer is an emphatic, "Yes!"

\section{Io.M - Budget Reforms}

Over the years, state and local governments have tried to use various techniques to manage expenditures more effectively while accomplishing goals related to good governance. In many cases, budgetary techniques have been driven by partisan politics, and these techniques have proven to be myopic in design and self-limiting in execution. ${ }_{-}^{19}$ At times, attention has been focused on the input side of budgeting - essentially, tightly controlling agency spending as a method of increasing efficiency in the budget process. Spending control has been attempted through state-level debt limitation measures and the use of the executive line item veto. At other times, some states and local governments have focused on the output side of budgeting - through control of public spending. Finally, the methods by which services are delivered have also been related to the budget process and the promise of more efficient and effective budgeting and related policy outcomes.

Debt limitation measures are commonly found at the state and local level. Most states ${ }_{-}^{20}$ and virtually all-local governments require that annual budgets be balanced. Revenue in balanced budgets could be in the form of tax revenue or revenue from bond issuances. Both forms of revenue are monitored and approved by state and local governments. Debt issuance limitations prove to be very important in maintaining a long-term rational budgeting process. ${ }_{-}^{21}$

Another method of controlling the input side of budgeting is the executive line item veto. We often hear about 
the line item veto in terms of presidential politics. Presidents have requested a long-term solution to the budgeting process that would result in line item veto authority. The line item veto is often believed to be a solution to out-of-control wasteful spending habits. In a study of Georgia's line item veto, it was found that the executive power was often not used for the purpose of removing spending categories. ${ }^{22}$ Instead, Georgia's governors have used the power to influence the construction of budget documents. Interviews with former governors, such as President Jimmy Carter, find that the threat of line veto is more common than the actual use of the power in the budget process.

Performance-based budgeting is an important part of connecting expenditure to outcomes. ${ }_{-}^{23}$ Performance-based budgets link requests for resources with documentation illustrating the outcomes of budget choices made in previous years. If sustainability is to be attained under budget constraints it will be necessary for budget writers to understand how efficiently and effectively expenditures are at accomplishing stated goals. Since the budget process is cyclical and iterative, good information about outcomes in the previous budget cycle can lead to informed budgetary decisions in future years. Performance-based budgeting is most commonly found in bureaucratic agencies or related to a specific program. All-encompassing performance evaluations are not as common in the U.S. states.

Performance budgets are potentially critical to longterm sustainability goals despite the significant amount of time and effort necessary for their preparation. Documentation on previous performance must be linked with previous expenditures, and then tied directly to justifications for future expenditures. As with all budgeting techniques, performance-based budgeting remains a work in progress. However elegant it may be in its current form, this budgeting practice will always need to be improved because policies, 
circumstances and budgets are constantly changing; this dynamism is especially true for sustainable communities. In numerous American cities_- and state governments performance-based budgeting is being attempted, with only mixed results being documented to date. -25 In recent years, performance-based budgeting has waxed then waned in popularity, and is currently in a stage of witnessing renewed interest. ${ }_{-}^{26}$

Finally, the contracting out of government functions is frequently hailed as a method of reducing costs and creating better public sector budgets. Contracting out means that private sector providers are paid to accomplish certain government functions and the government discontinues its direct delivery of services. Irene Rubin concludes that contracting out cannot be equated with better budgeting because contracting authority and costs are oftentimes hidden within program or agency budgets and are largely invisible to most decision makers. ${ }_{-}^{27}$ She suggests that contracting should become a budget line independent of agency or program general funds; in this way contracting out would become more visible and its outcomes would be better understood.

\section{ro.N - Sustainable Budget Focus: Five Key Areas of Future State and Local Budget Needs}

The traditional budget categories discussed previously will continue to consume much of state and local budget revenues, but a sustainable future will require a continued and likely stronger budget commitment to growing areas of need. Projecting need is a tricky business because so much about the future remains unknown to us. Nevertheless, it is a fairly safe 
bet that the following five categories will require substantial increases in state and local budget commitment soon and for the foreseeable future:

\section{Io.N.I - Alternative Energy Sources \& Energy Conservation}

It is projected that "peak oil" will occur within the next fifteen years - that is, if it has not already occurred. Towards the end of the 21st century, much of the globe's accessible petroleum will have been depleted. Reliable access to energy is a prerequisite for the modern society and key to sustainability. Alternative energy will likely be produced using a variety of methods. So-called "4th Generation" nuclear energy is very likely to play a significant role in electricity generation, as is thermal energy generation. Fossil fuel-based energy sources will continue to be harnessed in the form of coal and natural gas. Renewable energy in the form of solar electric, solar thermal, wind generation, ocean thermal energy conversion, tidal generation, and geothermal will be used to provide a sizeable portion of state and local energy needs in future years where state and local governments have access to those sources. As we near a time when greenhouse gas emission restrictions and carbon sequestration will become common terminology, the development of locally-suited alternative forms of renewable energy will be priority concerns for American state and local governments. Sustainable communities will require significant participation from state and local government in the form of financial commitments to public-private partnerships and tax incentives for the development of alternative energy systems that will contribute to community sustainability. 


\section{Io.N.II - Climate Change Impacts}

Significant climate change impacts are projected to occur within the next few decades. Depending upon the location of a community, climate change may lead to rising ocean levels and flooding, severe heat and drought, increased extreme weather behavior, and more frequent range and forest fires - to name but a few possible adverse climate-related phenomena. The widespread destruction witnessed along the Gulf Coast produced by Hurricanes Katrina and Rita; the multi-year drought in the early years of the 21st century impacting the South; and devastating wildfires in California and other Western states have all been attributed to climate change. Preparing for highly probable and disruptive climate-related events is a key part of the pursuit of sustainability and community resiliency, and such preparation will require significant budget resource commitments.

Climate change studies frequently tie back to the issue of carbon emissions from fossil energy use. The development of alternative energy, as discussed previously, is an important part of meeting future energy demands, but it is also beneficial in terms of reduced carbon emissions into the atmosphere which lead to ozone depletion.

\section{Io.N.III - Infrastructure Renewal}

Infrastructure renewal is a multi-faceted phenomenon. Tremendous resource commitments are required just to maintain current infrastructure. In the long run, commitment to maintaining infrastructure is less costly than neglect and subsequent failure. For example, in 2007, a major urban highway bridge collapsed in Minneapolis-St. Paul, Minnesota 
killing and injuring many citizens. The bridge collapse opened a policy window,,- and brought the issue of U.S. infrastructure renewal to the national, state, and local policy agendas. It is estimated that hundreds, if not thousands, of the nation's highway and road bridges may require substantial retrofitting or replacement if we are to avoid a repeat of the Minneapolis experience.

In addition to this long-neglected problem, it is very likely that the suburban sprawl of U.S. cities, and the long commutes to and from work that are associated with this sprawl, are not sustainable. It may well be the case that infrastructure renewal may require a commitment to redesign as well as selective renewal. Rising energy costs may likely affect residential choice and give rise to the need for new forms of transportation infrastructure in American population centers.

Beyond roads, many government buildings such as schools, administrative offices, and corrections facilities are aging and beginning to show signs of disrepair. The technology available in these buildings is often insufficient to the needs of e-government and effective data management, analysis, and transfer. Older buildings frequently "leak" thermal energy, as well as entail the inefficient use of electricity due to poor use of natural light. Sustainability means investing in upgrades and making a sincere commitment to good ("green") design and timely maintenance.

\section{Io.N.IV - Bio-Equity}

Bio-equity calls for equal treatment for both human society and other elements of the "biosphere," and acting on a commitment to building communities that do not develop at the expense of the environment in which they exist. 
Understanding and mandating bio-equity through regulation may have begun with the National Environmental Policy Act (NEPA) in 1969 and the passage of the Clean Air Act, the Clean Water Act, and the Endangered Species Act, but has been interpreted and has evolved on the local level to encompass more.

\section{Io.N.V - Technology and Innovation}

Sustainable communities will manifest lower demands for transportation corridors and transport infrastructure if technological development and communications innovation continue into the future. Public-private partnership commitments to the promotion of new environmentregarding technologies will make resource use more efficient, creating well-paying jobs while simultaneously reducing the relative cost of living. For example, it is possible that many of the industrial manufacturing jobs of the future could be completed from home computers managing robotic systems on a distant factory floor. In fact, much of the technology needed to expand these systems is already readily available; a budgetary commitment on the part of government might speed the process towards more widespread use of these technologies. And, of course, what the long term future holds in the way of related communication technology innovations will likely only bring us closer to sustainable communities. 


\section{Io.O - Budgeting and the Core Dimensions of Sustainability}

Budgeting establishes or formalizes communal or individual priorities. Accomplishing goals within the core dimensions of sustainability will require effective budgeting. Budgeting for sustainability is not a one-time event - within the sustainability paradigm, circumstances evolve and priorities change due to increased understanding and changing preferences. The social objectives of sustainability, for instance, will change as demographics change. As the Baby Boomer generation fades into history, a new demographic will likely emerge - a more youthful, more energetic, more mobile, and more diverse society lies ahead. Investing in human capital will become more complex as traditional transmission of human capital within traditional family units becomes less common and as the changing educational needs of a mobile workforce become increasingly evident. Traditional perspectives of social capital - e.g., lifelong commitment to civic institutions in particular communities - continues to decline and is replaced by non-profits that draw youthful participation and which change as times and conditions change. Budgeting plays a big role in the ever-changing sustainable communities, offering tax incentives and grant resources to help support the public welfare, education, and community needs of a future society.

As with the social objectives of sustainability, economic objectives can be encouraged or discouraged through the state and local government budget process. Tax incentives to sustainable industries encourage growth of new green economies, while restrictive tax codes might discourage polluting or non-sustainable industries. In creating equitable market conditions and reducing economic disparity, budget resources in communities built around the sustainability 
paradigm will likely offer a helping hand to the least benefitted members of states and the poorest local communities through redistributive policy.

Environmental objectives are advanced through budgeting for environmental regulation. The sustainability paradigm will require that state and local government strictly regulate polluting industries and products. Regulation, however, requires a strong and well-financed bureaucracy that monitors environmental quality and ensures industry and broader community compliance.

Finally, the institutional change needed to advance the sustainability paradigm will most likely occur if clear priorities are established through the budgeting process. Agencies and policy objectives that are of higher priority can be bolstered through a strong financial commitment on the part of budgeters. Social welfare, education, and environmental policy agencies and policies, for instance, would likely receive even greater financial assistance. In the future, particularly when the health and welfare costs of the large Baby Boomer generation have faded, budget resources will likely shift in new and different directions to meet the evolving objectives of sustainability.

\section{Exercises}

\section{Budgeting - What Can I Do?}

As we are writing this book state and local governments are climbing out of the Great Recession of 2008-2009 budget shortfalls and restoring the funding of many agencies and programs. As we have discussed in this 
chapter, budgeting in good times can be a complicated process let alone in times of severe fiscal stress.

Learn how your state compares to other states' tax rates, tax burden, and tax sources at the Federation of Tax Administrators website:

\section{http://www.taxadmin.org/}

Learn more about your own state's budget process through the National Association of State Budget Officers (NASBO) at:

\section{http://www.nasbo.org/}

\section{Io.P - Conclusion}

Sustainability requires commitment. Commitment, however, is only a word of promised future action; it means very little of consequence until acted upon. Analyzing public budgets is a very critical method of determining what we mean by commitment, and determining how that commitment ties into the issue of sustainability at the state and local level. 
Through our analysis of budgeting in state and local government, we found that commitment requires the expenditure of considerable resources over time. The resources in question will come from a variety of sources both internal to and external from state and local government, and sustainability requires the development of reliable and noninjurious resource bases to support the programs and policies required to meet the needs of the private sector and civil society. While the needs to be addressed are many and the challenges facing us are rather daunting, the resource base available to state and local governments is likely to be relatively constrained for quite some time into the future. The challenge for the accomplishment of sustainability in state and local government in the years ahead may have less to do with resource provision and much more to do with strategic spending choices. In terms of sustainability, the "healthy" and resilient community relies less on the size of its tax base and much more on the wise spending and budgetary vision featuring the balanced pursuit of economic vitality, environmental protection, and social equity.

\section{Terms}

Bio-equity

Balanced Budget

Block grants

Categorical grants

Clean Air Act

Clean Water Act

Competitive grant

Endangered Species Act

Excise tax 
Flat rate tax

Formula grant

Graduated tax

Line item veto

Master Agree (tobacco agreement)

National Environmental Policy Act (NEPA)

Northern Spotted Owl v. Hodel

Performance-based budgeting

Tax and expenditure limitation measures (TELs)

Temporary Assistance to Needy Families (TANF)

\section{Exercises}

\section{Discussion Questions}

1. How does the typical state budget process work, and what are the various actors involved in that process?

2. What are the various sources of intergovernmental revenues that states and local governments use to support services?

3. What have been the various approaches advocated to reform budgeting processes at the state and local levels?

4. What are the main characteristics of a sustainable budget?

5. What are the main sources of revenues for states and local governments? Is it possible to balance the demands for government services with existing revenue sources? 


\section{Notes}

1. I. Rubin, "The State of State Budget Research," Public Budgeting and Finance 25 (2005): 46-67.

D.L. Sjoquist, ed., State and Local Finances Under Pressure (Northampton, MA: Edward Elgar, 2003).

2. Tax Foundation, "State and Local Sales Tax Rates, 2017." URL: $\quad$ https://files.taxfoundation.org/20170131121743/ TaxFoundation-FF539.pdf

3. Tax Foundation, "Facts and Figures: How Does your State Compare, 2018." URL: https://taxfoundation.org/factsfigures-2018/

4. Ibid.

5. Ibid.

6. Ibid.

7. A.E. Crabbe, R. Hiatt, S.D. Poliwka, and M. Wachs, "Local Transportation Sales Taxes: California's Experiment in Transportation Finance," Public Budgeting and Finance 25 (2005): 91-121.

8. T.P. Lauth, "Budgeting During a Recession Phase of the Business Cycle: The Georgia Experience," Public Budgeting and Finance 23 (2003): 26-38.

9. M. Huckabee, "State Budget Shortfalls and Arkansas' Strategies," Spectrum: The Journal of State Government 75 (2002): 32-34.

10. K. Willoughby, "Governors' Initiatives in 2005: Facing up to the Problem?" Spectrum: The Journal of State Government 78 (2005): 8-13.

11. Ibid.

12. D. Osborne, and T. Gaebler, Reinventing Government (New York: Addison-Wesley, 1992). 
13. D. Osborne, and P. Hutchinson, "Budgeting in Tough Times: The Three Decisions and Nine Strategies," Spectrum: The Journal of State Government 76 (2003): 18-22, 34.

14. See W.M. Bowen, M. Haynes, and M.S. Rosentraub, "Cities, Tax Revenues, and a State's Fiscal Future: The Value of Major Urban Centers," Public Budgeting \& Finance 26 (2006): 47-65.

15. K. Augustine, "Effective Debt Collection Efforts in Nevada," Spectrum: The Journal of State Government 75 (2002): 36-37.

16. C. Johnson, "The State of the Tobacco Settlement: Are Settlement Funds Being Used to Finance State Government Budget Deficits? A Research Note," Public Budgeting and Finance 24 (2004): 113.

17. J. Marlowe, "Fiscal Slack and Counter-Cyclical Expenditure Stabilization: A First Look at the Local Level," Public Budgeting and Finance 25 (2005): 48-72.

18. K.V. Byers, and M.A. Pirog, "Local Governments' Fiscal Responses to Welfare Reform." Public Budgeting and Finance 23 (2003): 86-107.

H. Chernick, and A. Reschovsky, "State Fiscal Responses to Welfare Reform During Recessions: Lessons for the Future," Public Budgeting and Finance 23 (2003): 3-21.

19. J, Musso, E. Graddy, and J. Grizard, "State Budgetary Processes and Reforms: The California Story," Public Budgeting and Finance 26 (2006): 1-21.

20. Y. Hou, and D.L. Smith, "A Framework for Understanding State Balanced Budget Requirement Systems: Reexamining Distinctive Features and an Operational Definition," Public Budgeting and Finance 26 (2006): 22-45.

21. D. Denison, M. Hackbart, and M. Moody, "State Debt Limits: How Many are Enough?" Public Budgeting and Finance 26 (2006): 22-39.

22. T.P. Lauth, and C.C. Reese, "The Line-Item Veto in Georgia: Fiscal Restraint or Inter-Branch Politics?" Public Budgeting and Finance 26 (2006): 1-19. 
23. J.M. Kelly, and W.C. Rivenbark, Performance Budgeting for State and Local Government (Armonk. New York: Sharpe, 2003).

24. L. Friedman, "Performance Budgeting in American Cities," Public Productivity Review 3 (1979): 50-62.

25. For a discussion of state level adoption and use, see: S. Pattison, and N. Samuels, "Trends and Issues in Performance-Based Budgeting," Spectrum: The Journal of State Government 75 (2002): 12-13.

26. R.C. Burns, and R.D. Lee, "The Ups and Downs of State Budget Process Reform: Experience of Three Decades," Public Budgeting and Finance 24 (2004): 1-19.

J.E. Melkers, and K.G. Willoughby, "Budgeters' Views of State Performance-Budgeting Systems: Distinctions Across Branches," Public Administration Review 61 (2001): 54-64.

27. I. Rubin, "Budgeting for Contracting in Local Government," Public Budget and Finance 26 (2006): 1-13.

28. J.W. Kingdon, Agendas, Alternatives, and Public Policy (New York: Longman, 2003). 


\section{Chapter iı: Entitlements}

\section{II.A - Introduction}

An entitlement is a governmental benefit to which a person is legally entitled if they meet certain eligibility criteria. For example, if an individual is accused of a serious crime and is unable to afford an attorney, he or she is entitled to legal representation at public expense. Similarly, an individual who loses their job may be entitled to unemployment compensation from the state in which they reside. A third example would be that of an elderly person living in the United States who is entitled to an old age pension and healthcare benefits from the federal government in the form of monthly Social Security payments and Medicare benefits.

Entitlements play a very important role in the promotion of sustainability in several ways. First, social and economic justice is a core element of sustainability. Sustainability entails more than just survivability - it is survivability within the context of an equitable social, political, and economic value structure. In modern democratic societies, the value structure providing for an equal voice in elections and equal protection under the law points us in the direction of fairness in the distribution of goods and services (often expressed in terms of the "social safety net" concept). The challenge of promoting sustainability into the future will bring us face-toface with issues of limited resources again and again, and the difficult tradeoffs to be made between the economic vitality, environmental protection and social equity core values of sustainability will require the utmost care and skill to manage. The nation's state and local governments and the citizens of the communities involved will be called upon to engage in 
this difficult tradeoff management process repeatedly in the coming decades. Given the importance of this area of concern to every community, this chapter is included in this book as a key element of the study of state and local government.

\section{Learning Objectives}

This chapter will discuss:

- the background of state and local government entitlement programs.

- the relationship between entitlements and sustainable communities.

- $\quad$ types of public assistance programs.

- $\quad$ state and local government health care programs and policies.

- the role of state and local governments in Medicare and Medicaid programs.

- the State Children's Health Insurance Program (SCHIP).

- $\quad$ public unemployment compensation programs. 


\section{II.B - Background and Types of Entitlements}

While virtually all observers of modern democratic countries would agree that entitlements are essential to good governance, it is also the case that the boundaries of discussions related to governmental entitlements are often unclear. In part, this is due to the ever-changing conceptualization of the nature and proper scope of entitlements. Public health protection, for instance, once meant principally that government authority was used to isolate individuals who were infected with communicable diseases via quarantine. In some cases, such persons were simply left to die in isolated asylums. Similarly, assistance for the chronically unemployed often revolved around private charity, almshouses, and public begging in designated places. These examples from the past may appear quaint or laughable to many Americans today, but they were the most common forms of public health and welfare promotion practiced in this country in the not-to-distant past. As the demographics of our state and local government populations have changed, our collective understanding of entitlement has changed either becoming broader in scope or more exclusive of client eligibility. This chapter will highlight a few basic entitlements associated with sustainable communities, and illuminate some of the dynamics associated with expanding and contracting conceptions of governmental entitlements. The chapter will identify some areas of likely entitlement growth, and highlight some areas where governmental entitlements might become more limited as our society seeks to promote sustainability.

Meanings of "Entitlement."

In his 2004 Columbia Law Review article, "The Political Economy of Entitlement," legal scholar David Super outlines six principal definitions of entitlement: 
1. Subjective entitlement: this represents a belief that an individual has certain benefits due them, regardless of whether a legal foundation for that belief exists. Politicians will sometimes use phrases such as, "everyone has a right to own a home" even if there is no legal foundation to the statement.

2. Unconditional entitlement: According to Super, ${ }_{-}^{1}$ this represents a "benefit that is not subject to conditions or reciprocal obligations." As Super correctly notes, most governmental entitlements are conditioned upon some aspect of reciprocal obligation. For example, a person receiving unemployment benefits must have been previously employed and been part of a layoff and must be looking for a job actively in order to continue to receive benefits.

3. Positive entitlement: This represents "a legally enforceable individual right."2 This is the most familiar definition of entitlement. Individuals have a form of property right attached to a positive entitlement, such that an illegal deprivation of such an entitlement provides ground for a lawsuit based on the suffering of substantive harm.

4. Budgetary entitlement: The concept is often referred to as "mandatory spending" in the law. Social programs that are budgetary entitlements are prioritized above all other expenditures in that they are not subject to caps on spending. ${ }_{-}^{3}$

5. Responsive entitlement: These governmental expenditures are made based on a need-based formula. ${ }_{-}^{4}$ Public education programs driven by student headcounts are an example of a responsive entitlement; government payments to the victims of natural disasters would be another example of this type of entitlement.

6. Functional entitlement: There are some governmental programs that meet "some qualitatively definable need of its beneficiaries.". programs assume that "healthful sustenance" will be accomplished for a person if a certain food and nutritional 
benefits level is established. His example in this area is food stamps - a certain benefit level is established with the idea that a recipient household's food needs will be met.

Super's distinctions drawn in his effort to define the concept of governmental entitlement are valuable, helping us to understand what it is we mean by entitlement and, thinking normatively with respect to 'good' and 'bad' forms of government entitlement, what entitlements should be maintained to promote sustainability in the communities served by American state and local governments. In many cases where the major state and local governmental entitlement programs are discussed, it will be clear that several of Super's subtypes of entitlements might apply to any particular policy discussed.

In contrast to Super, John Skinner provides a greatly simplified approach to thinking about entitlements. ${ }_{-}^{6} \mathrm{He}$ distinguishes between only two forms of governmental entitlement, those being earned and those being implied. According to Skinner, Social Security is an example of an "earned" entitlement because one contributes a portion of one's earnings to Social Security and the level of contribution directly affects the level of benefit received. In contrast, Medicare is an example of an implied entitlement because it is assumed that once one reaches retirement age one is entitled to Medicare health benefits regardless of one's contribution level through payroll deductions over a career and regardless of your extent of need. 


\section{II.C - Entitlements and Sustainability}

While the social justice and equity concepts underlying governmental entitlements are rather evident, it must be noted that the cost of providing entitlements is tremendous. As a percentage of total costs, state and local health and public assistance programs consume a substantial portion of state and local government budgets. Critics of "social spending" argue that if existing health entitlement programs are left unchanged, they will consume an ever-growing portion of state and local budgets, thus limiting the ability of government to allocate resources on other important needs. ${ }_{-}^{7}$ One solution proposed by critics is to thoroughly reform the current public assistance and health care entitlement programs; to judiciously trim costs where possible, and to adopt "best practices" and innovative programs to more effectively target health and public assistance funds. Another approach to reform in this area is the promotion of investments in prevention of illness and early screening and diagnosis, hence achieving cost containment via citizen wellness practices and early treatment of preventable illnesses. In the 1990s, state and local governments across the country took the lead in reforming existing public assistance programs and placing limits on welfare eligibility and promoting active reengagement in the workforce for many recipients. ${ }_{-}^{8}$ The result was a precipitous decline in the number of welfare recipients in nearly all states.

From the perspective of the former welfare recipients, many of them benefited from welfare-to-work programs; however, simply getting individuals off of welfare rolls and into the workforce is not the end of the sustainability story when it comes to entitlements. In the case of welfare reform, one of the biggest issues facing former public assistance recipients beyond employment is the difficulty of maintaining and 
improving existence; for example, balancing new employment with the need for quality childcare. ${ }_{-}^{9}$ The stresses and strains of life off of the welfare rolls after years of dependence often prove to be too much all at once, and the ability to deal with these pressures comes at time when the costs of services is rising and the range of family needs (e.g., access to cable TV and the Internet) is growing.

One of the areas of entitlement that was almost immediately affected by welfare entitlement reform falls under the health care policy arena. The meteoric rise of expenditures for health care entitlement programs such as Medicaid and S-CHIP, for instance, are frequently bewildering to the average citizen. Why should health care cost so much? What are the health care professionals doing with all the money? These questions may prove maddening until one understands what the term health care really means. Unfortunately, health care conjures up many out-of-date images. One image is the clean hospital bed with the considerate and caring nurse attending to the young patient with tonsillitis. Another image is that of the physician examining the expectant mother. Perhaps another image is the kindly country doctor listening to a man's heartbeat with a stereoscope. These are all very appealing images; however, not one of them accurately captures the direction and scope of health care today...and perhaps they never did capture the true meaning of health care. Nonetheless, the myth of health care derived from the long-gone past proves persistent.

In the U.S., health care policy has been tied closely to issues of defense, economics, urban planning, immigration, age, class, race/ethnicity, and a whole host of other issues. National programs in health care began as early as the 18th century with the Marine Hospital Service. Community-level health care initiatives were primarily privately managed until the late 19th century when large-scale immigration resulted in rapid urbanization. 10 Major epidemics such as a cholera 
outbreak in New York City led to the widespread creation of public programs for sanitation and health care in state and local governments across the entire country._ As our society has continued to urbanize, the need for such programs has increased tremendously. Health care has progressively come to be viewed as a benefit not only to the individual receiving health care services but also to the community as a whole. Healthy people provide a good workforce, they spend more time in productive activity than under medical care, and they occasion less need for collective resources to be devoted to health care services for the indigent.

In sustainable economies of the future, all elements of production must be able to work in unison; healthy workers are a critically important part of the economic enterprise. Beyond work, there is the issue of healthy children. As a society, we commit a tremendous amount of money and time to educating and caring for young people; proper investment in the future is, after all, a critical dimension of sustainability. Children who are not healthy are unable to benefit from education, and will likely develop other physical ailments that adversely affect their social and economic potential. Technology has made us more aware of new and growing issues related to pre-natal and child health care. Problems such as birth defects and autism can be treated if diagnosed early, and those conditions can be medically managed far better today than was the case in the past.

As the Baby Boomer generation ages, an increasing proportion of our governmental resources will necessarily be spent on medical needs. A sustainable community, facing this known pending demand on its resources, must be both compassionate and pragmatic. The demonstration of governmental compassion for the elderly and infirm is very important to building inclusively within society and to promoting social justice. Pragmatically, a sustainable community is aware of the great benefit of maintaining a 
healthy and productive population. Older, often richly experienced individuals often bring with them economic resources (e.g., skills, social networks, accumulated wealth, etc.) that can help local economies and generate employment. Older individuals often have substantial intellectual capital gained from years of experience in the workforce; through the employment of these retirees into new professions, this intellectual capital can be tapped to improve society. Disabled individuals often possess many valuable skills and knowledge that is all too frequently "lost" to society and to the individual when physical limitation separates them from the larger community. 12 While many of these individuals receive some level of federal health care benefits, there are a substantial number of disabled individuals who, in midlife and early older age years, would remain inaccessible if it were not for state and local government health resource entitlements. Health care for the elderly, therefore, is critical to improving community sustainability.

The very meaning of the word "healthy" has changed substantially. One could have perfect physical health - e.g., normal blood pressure, cholesterol, heart rate, and eyesight but suffer from severe mental health maladies. Health issues related to depression, bipolarism, and personality disorders have long existed in society. However, in the past individuals had little or no access to health care solutions for the problems of mental illness. What solutions did exist often involved institutionalizing individuals in sanitariums rather than helping them to remain within the general community and achieve a productive and respected role in society. Addressing the problems of mental health has become an increasingly important matter for state and local governments in the United States as the size of the population affected and the problems arising from mental illness for society have become more evident. ${ }_{-}^{13}$

The stresses of the school setting (high stakes testing 
associated with the No Child Left Behind (NCLB) policy discussed elsewhere), the workplace, and living in general under the conditions of the threat of terrorist attack and prospects of global climate change have become overwhelming for many individuals and the families within which they live. Work schedules have become extended with the advent of computers and advances in communication technology, changing the boundaries that once separated office and home settings. The itinerant nature of contemporary society and the high technology world tend to separate people from one another rather than bringing them together. The aging of the U.S. population in many cases means that older individuals have either become separated from their families or, alternatively, have become so reliant on their relatives that social and economic strains begin to appear within caregiver families. Health care issues, then, clearly extend to problems previously known, such as mental health, but all too frequently ignored as a matter of governmental concern.

As a final example, the issue of substance abuse is a growing public health care concern. In the past, substance abuse was assumed to be the rational choice of individuals - addiction and possible death, as a result, was viewed as the price one paid for a bad personal choice. A sustainable community, however, cannot rationally make the choice to simply ignore problems associated with substance abuse and drug addiction. Philosophically, societies agree to care for their members. Practically-speaking, it is a serious drain on society to simply let the forces of drug addiction and substance abuse sap the strength of the community. In all state and local government settings, drug addiction and substance abuse prevention and treatment have become important aspects of health care (and the criminal justice system). Substance abuse problems cross age, gender, and ethnicity boundaries. While substance abuse among the youth 
remains troublesome, there is evidence to indicate that the rate of substance abuse is either leveling off or declining among this sub-population. A rising trend, however, is the incidence of substance abuse among Baby Boomers, ${ }_{-}{ }_{-}$that will likely require local communities to refocus their substance abuse efforts on this demographic group.

Public assistance and health care are closely intertwined, and both areas constitute an important part of a dialogue on sustainability. Termed entitlements, policy programs falling under the auspices of public assistance and health care are far-reaching and have inspired a next generational perspective on social programs designed to address public assistance and public health problems. Many of the governmental programs previously discussed in terms of entitlements - the implication being that there are narrowly defined givers and receivers of benefit - are increasingly discussed in terms of "community" assistance and health-promotion programs. The new perspective to be discussed next recognizes that the entitlement of yesterday is more properly seen as a collective community commitment or investment made to proactively address shared needs, and that this collective response to public assistance and public health needs benefits communities as a whole.

\section{II.D - Public Assistance}

In 1996, a bipartisan coalition of Senators and Representatives in the U.S. Congress passed the Welfare Reform Act and President Clinton signed the act into law. With an eye to achieving outcomes similar to those associated with the state and local welfare reforms of the prior decade, the Republican majority in Congress hoped to eradicate one major element of the "welfare state." The state and local 
welfare policy reforms preceding the 1996 Act generally tightened eligibility requirements for recipients and placed time limits on the length of time one could receive welfare benefits. After over a decade of experience with the welfare reform movement, we can say with some confidence that the 1996 act represents the beginning of a change in American thinking about what public assistance as an entitlement might mean in a new millennium. The new target of public assistance is less the individual recipient of the benefit than it is the community as a whole. Temporary Assistance for Needy Families (TANF) is the primary federal policy on public assistance in the United States. As a result of the 1996 Welfare Reform Act, TANF replaced Aid to Families with Dependent Children (AFDC). A block grant program, TANF requires states to develop specific public assistance plans to reflect state and local values, but within the general TANF requirements.

The Office of Family Assistance (OFA), Administration on Children and Families (ACF), a unit within the U.S. Department of Health and Human Services (HHS), is the federal office, which oversees TANF block grant dispersals and oversees state policy requirements to determine if they meet TANF eligibility guidelines. With the 1996 federal statute as the primary guideline, OFA outlines four major goals for the TANF program: $:_{-}^{15}$

- "assisting needy families so that children can be cared for in their own homes

- reducing the dependency of needy parents by promoting job preparation, work, and marriage

- preventing out-of-wedlock pregnancies

- encouraging the formation and maintenance of two-parent families"

The TANF program limits individuals who receive federal TANF money to five years, although states can impose either 
shorter or longer time limits - but no more than 20 percent of the state welfare caseload can go beyond the five-year time limit. If a state wishes to use its own resources to extend welfare benefits, they may do so at their own discretion. Proponents of TANF argue that the time limits are flexible enough to allow states to make their own choices about public assistance, but critics argue that states with the greatest need are often incapable of self-financing extended welfare benefits and may not be able to access other federal, state, or local revenues to meet the needs of citizens and local communities requiring this form of support.

TANF requires that recipients meet work requirements unless approved waivers are granted by state and national TANF administrators. Two-parent families must work 35-40 hours per week, while single-parent family work requirements are 30 hours per week. Certain exceptions are made for single parents who have children under six years of age who cannot find adequate childcare, and thus cannot balance their employment requirements with childcare responsibilities. "Work" may constitute full-time employment in salaried positions, but may also include participation in employment training programs, on-the-job training, civic service activities or even successful participation in formal secondary education. Proponents of TANF argue that the work requirements are broad enough to provide TANF recipients the opportunity to gain skills necessary for financial independence post-assistance. Criticism of the work requirement generally focuses on the potential for limited access to the full scope of "work" activities in states and local communities. Ultimately, post-TANF program participation gainful employment must be found; unfortunately, in communities lacking employment opportunities TANF recipients are faced with little hope for the future after their benefits have expired. TANF does make accommodation for states to create jobs directly or provide job incentives for 
private employers so that TANF recipients will have a greater chance of obtaining gainful employment when their eligibility expires.

TANF monitors all U.S. state programs to determine if the federal statutory requirements associated with the program are being met. If a state fails to meet these requirements, then TANF grant amounts to the state can be reduced administratively. As a consequence of these strong sanctions, state reporting requirements are quite stringent. Proponents of TANF argue that reporting requirements keep states in line with the national goal of streamlining the program and moving welfare recipients into the workforce. Critics of TANF argue that reporting requirements excessively limit each state's ability to be innovative and responsive with public assistance programming to meet state and local needs. Despite these complaints, however, it is indeed clear that state and local governments in the United States have a great deal of latitude in crafting public assistance programs for both individuals and the communities within which they reside as a consequence of the 1996 Welfare Reform Act.

TANF requires that the states spend a certain percentage of their own funds to support public assistance programming efforts. These local fund matches are calculated by TANF under their Maintenance of Effort (MOE) as a percentage of the amount of money spent by ACF-TANF in a given state. MOE monies are calculated in terms of state MOE requirements and in terms of state separate voluntary MOE commitments. The rate of annual increase in state monies allocated toward MOE requirements grew tremendously from 2000 until 2004, then declined in real dollar percentage terms in 2005 and 2006. Separate state MOE allocations tend to be the most variable in the analysis, possibly reflecting state budget commitments in other areas and state economic conditions. The steadiest resource base for TANF is the federal government, but as noted previously that commitment 
is clearly flattening out - even showing some diminishment in real dollar year-on-year percentage terms. In part, this decline in federal funding reflects the decline in the average number of recipients in TANF programs - a possible sign of success for the long process of welfare reform in the United States.

As noted in the chart above, a very significant portion of TANF expenditures is for non-assistance purposes (i.e., administrative expenditures). Between 2000 and 2002, the trend for administrative expenditure as a proportion of TANF total expenditure was on the rise. The trend reflects the fact that many expenditures made under TANF are not benefits to individuals but rather reflect administrative investments in the local community for job preparation training and job creation for the clients making a transition from public assistance to employment. According to the Child Trends Data Bank, the trends of TANF recipients is as follows: ${ }_{-}^{16}$

After rising from 6.1 million in 1970 to 9.5 million in 1993, the number of children receiving AFDC/TANF payments fell to 2.9 million in 2008. Similarly, the percentage of all children receiving AFDC/TANF steadily decreased from 14 percent in 1993 to four percent in 2008. Among children living in families below the poverty threshold, the proportion receiving AFDC/TANF decreased from 62 percent in 1995 to 21 percent in 2008. Following the recession that began in late 2007, the number of children receiving TANF payments rose to 3.3 million in 2010 and 2011, then fell to 2.6 million in 2014 (preliminary estimates), the lowest number in recent recordkeeping. The percentage of children receiving benefits also increased slightly, to five percent in 2010, before decreasing to four percent in 2014. However, as a proportion of all children living in poverty, the percentage receiving TANF has declined over this period; in 2014, the proportion was 17 percent. 


\begin{tabular}{|c|c|c|c|c|c|c|}
\hline & 1998 & 2000 & 2002 & 2006 & 2010 & 2014 \\
\hline $\begin{array}{l}\text { CHILD RECIPIENTS IN THE } \\
\text { STATES (IN THOUSANDS) }\end{array}$ & 5,781 & 4,260 & 3,790 & 3,185 & 3,307 & 2,601 \\
\hline $\begin{array}{l}\text { CHILD RECIPIENTS AS A } \\
\text { PERCENTAGE OF TOTAL CHILD } \\
\text { POPULATION }\end{array}$ & 8.1 & 5.9 & 5.2 & 4.3 & 4.5 & 3.5 \\
\hline $\begin{array}{l}\text { CHILD RECIPIENTS AS A } \\
\text { PERCENTAGE OF CHILDREN IN } \\
\text { POVERTY }\end{array}$ & 42.9 & 36.8 & 31.2 & 24.8 & 20.3 & 16.7 \\
\hline
\end{tabular}

Figure 11.1 TANF Recipients, Average in Fiscal Year (1998-2014)

\section{II.E - Health Care}

Whereas it can be said with some confidence that welfare reform is showing some progress towards flexible adaptation and proper orientation toward sustainable community development in state and local governments across the country, health care largely remains an unresolved issue in many states and local communities. Health care entitlement programs are the subject of a great deal of current political debate, and it became a major campaign issue in the 2008 presidential election. Health care reform is clearly imminent in the United States, and serious efforts must be made to streamline the process of service delivery, improve the quality of care provided in many areas (especially in early diagnosis and preventative care), and temper rising costs. ${ }_{-}^{17}$ While revolutionary changes have and continue to occur in American health care services available to those who can pay for them by virtue of insurance coverage,,$\frac{18}{-}$ a great deal of additional change is needed to extend that access to the many citizens who are not covered by insurance. Perhaps the greatest 
tragedy lies in the fact that a very substantial portion of the nation's youth are not covered by parental health insurance and are at best only unevenly covered by state insurance programs (more on that subject below), hence the benefits of preventive medicine and early diagnosis of illness are being lost with this portion of our population whose contribution to the sustainability of our local communities is essential.

The United States is "graying" as the Baby Boom generation moves towards retirement. Aging populations are the single greatest challenge to the nation's health entitlement programs in terms of uncontrollable costs; this is the case in our country as it is in other developed nations. ${ }_{-}^{19}$ Some additional new challenges face the U.S. health care system which are not related to Baby Boomers, such as the virtual epidemic of childhood obesity and diabetes and the need to address the mental health and substance abuse and addiction issues alluded to above. In addition, the character of the American family unit has changed, with single and divorced parents facing multiple health challenges for themselves and their children.- At this writing, three major forms of health care policy entitlement exist in the United States that affect state and local governments in major ways; those entitlement programs are:

- Medicare

- Medicaid

- S-CHIP

Medicare is a federal health care program for the elderly. Medicaid is a state program, cooperatively managed at the state and federal levels of government to meet the health care needs of low-income individuals and families. S-CHIP, or the State Children's Health Insurance Program, is also a state program, cooperatively managed at the state and federal level, 
intended to meet the health care needs of uninsured middleand low-income children.

\section{II.F - Medicare and Medicaid}

While a national program, Medicare is an important part of maintaining sustainable state and local communities. The Medicare plan provides for the health care needs of individuals 65 years of age or older. Recognized Medicare program health care providers privately supply health care under Medicare. There are three major components to coverage:

Part A - Hospital insurance: Part A covers specified costs of hospitalization, nursing care facility stays, home health care, hospice care, and blood transfusions for patients staying in the hospital or during covered stays in a skilled nursing care facility. Medicare does not cover all costs of every medical procedure.

Part B - Medical insurance: The Medicare program covers a percentage of Medicare-approved procedures. Costs that exceed those covered by Part B are the responsibility of the patient. The patient may choose to enroll in private health insurance plans to cover additional expenses, or choose to enroll in the government-sponsored Medigap insurance. Expenses not covered by either private insurance or Medigap are the responsibility of the patient. ${ }_{-}^{21}$

Part D - Prescription Drug Program: The prescription drug program covers expenses for various generic and brand name drugs. The co-payment of the patient will vary, depending upon the type of drug prescribed. Medicare Part D coverage limits the amounts of drug dispensed at any given time.

The oldest members of the Baby Boom generation are now in their early 60's, close to retirement, and becoming increasingly susceptible to the infirmities of age. By 2030, it 
is estimated that there will be 2.7 workers for every retiree drawing health and retirement benefits. ${ }_{-}^{22}$ Clearly, economic sustainability is potentially challenged by a growing tax burden and budget constraints. The sustainability of the Medicare program, as it currently exists without significant change, is highly dubious. Either a reduction in benefits or changes in eligibility might be necessary to make the program viable for future generations if no alternative health care financing system is created. ${ }^{23}$ These policy changes at the national level, however, will not reduce the expanding health care needs of the elderly. Preventative care, good health practices, and effective outreach to at risk populations are all important ways of limiting health care needs and economizing on health care expenses. Regular exercise and balanced diets are important to maintaining good health, and avoidance of smoking (and second-hand smoke environments) and moderation in the use of alcohol are likewise important means of reducing health care costs. Public-private partnerships involving national, state, and local government are critical to making available the "wellness" information, healthful foods, and exercise facilities needed to stay healthy and providing access to geriatric nutrition information for the elderly.

The health care entitlements of Medicare are of critical importance to the health status of the nation, but they will likely fall short in providing for many of the basic everyday needs of the elderly. While the Administration on Aging, Department of Health and Human Services, provides significant guidance for eldercare and endeavors to protect the elderly from abuse, most of the resources and energy needed to sustain a quality of life for our elderly citizens will come from the hard work, personal resources, and patience of private individuals living within our local communities. Community eldercare is an important part of developing sustainability in our nation's local communities. A growing number of middle-aged adults are seeking to balance child- 
raising, career, and eldercare responsibilities for relatives and friends. Many individuals already face these challenges, and more will do so in the coming years. Cooperative effort will be necessary to cope with the added responsibilities, and "family friendly" workplace policies will be needed to accommodate the persons taking on these caregiver roles.

Medicare, and its related health care programs for the elderly, provides a solid foundation for health care entitlement in the United States. Sustainable eldercare, however, involves much more than health care dollars for hospitalization, health insurance, and prescription drug benefits. The essential margins of health care sustainability for the elderly will most likely be provided by sustainable community-based eldercare; those communities which provide for the needs of both young workers and the elderly individuals for whom they care on a daily basis will likely prosper; those that leave their elderly to rely entirely upon the federal government's Medicare program will experience serious dislocation as the Baby Boomers move into their retirement years.

\section{II.G - Medicaid}

Medicaid is a national-state cooperative health care plan designed to serve the medical service needs of low-income individuals and families. Standards commonly associated with eligibility for the Medicaid entitlement benefit include the following: ${ }^{24}$

1. "Families who meet states' AFDC/TANF eligibility requirements in effect on July 16, 1996;

2. Pregnant women and children under age 6 whose family income is at or below $133 \%$ of the Federal poverty level; 
3. Children ages 6 to 19 with family income up to $100 \%$ of the Federal poverty level;

4. Caretakers (relatives or legal guardians who take care of children under age 18 (or 19 if still in high school);

5. Supplementary Security Income (SSI) recipients [who meet certain requirements];

6. Individuals and couples who are living in medical institutions and who have monthly income up to $300 \%$ of the SSI income standard..."

In addition to these standards, states can establish their own eligibility requirements. Individuals who qualify for Medicaid receive hospitalization, insurance, and drug benefits similar to those received by Medicare recipients.

Medicaid is a very important program with respect to advancing sustainable states and local communities. Without the benefits provided under the Medicaid program, a great many low-income individuals would have extremely limited access to health care. In many cases, low-income individuals are the virtual backbone of a sustainable community, working in low salary jobs in the agricultural, service and production industries. Increasingly, private sector employers are eliminating employer-provided health care benefits for their workers, leaving low-income workers and their families in a highly vulnerable position. Without access to health care, worker absenteeism tends to be high and productivity low; undiagnosed illness, which could be treated inexpensively frequently become acute and require extremely expensive emergency treatment and hospitalization. Poor access to health care for children, in particular, has a depressing effect upon their school attendance and learning. Sustainable communities will require high levels of employee productivity and the production of high quality goods and services, and they will require that children are making adequate progress in their education. Health care entitlement programs, such as Medicaid, represent a critically important societal 
commitment to low income individuals and the sustainability of the local communities in which they live and work. The Medicaid program is a quintessential illustration of how the "social safety net" connects to the promotion of sustainability.

While clearly a direct benefit to the promotion of sustainable communities and to the low-income individuals who need attention to health care concerns, Medicaid is a substantial and growing financial burden on state government. Beneficiary enrollments since the beginning of the millennium increased by 28 percent, from 42.8 million to 50.1 million individuals between 2000 and 2004. Even more dramatically, health care payments during that same period increased by a staggering 53 percent, from $\$ 168.4$ billion in 2000 to $\$ 257.2$ billion in 2004. Despite dramatically rising costs, Kronick and Rousseau conclude from their careful studies that with close management of costs and a modest degree of reform, the Medicaid program is sustainable for a considerable period. ${ }_{-}^{25}$ A streamlined and more efficient process of Medicaid benefit delivery and a reformed reimbursement for service schedule are two methods of reforming Medicaid believed to improve program viability.

According to Medicare.gov in 2018: ${ }^{26}$

73,355,220 individuals were enrolled in Medicaid and CHIP in the 51 states reporting June 2018 data. 66,861,199 individuals were enrolled in Medicaid and 6,494,021 individuals were enrolled in CHIP (please see contextual information below regarding CHIP enrollment). More than 15.7 million additional individuals were enrolled in Medicaid and CHIP in June 2018 as compared to the period prior to the start of the first Marketplace open enrollment period (July - Sept. 2013), in the 49 states that reported relevant data for both periods, representing Nearly a 28 percent increase over the baseline 
period. (Connecticut and Maine aren't included because they did not report data for both periods).

More than 35.4 million individuals are enrolled in CHIP or are children enrolled in the Medicaid program in the 48 states that reported child enrollment data for June 2018. Children enrolled in the Medicaid program and individuals enrolled in CHIP make up over 50.6 percent of total Medicaid and CHIP program enrollment.

Community health centers are another important tool in developing sustainable community health programs. The health centers are particularly important in rural communities, which lack readily accessible hospital facilities. Farmers, ranchers, and farm laborers and their families are important beneficiaries of community health services. In urban settings, community health services can reduce the inflow of patients into emergency rooms for medical care. Urgent care facilities set up in local communities are also designed to ease the burden on emergency rooms. In terms of cost, community health care and urgent care facilities are often far cheaper to operate and maintain than hospital emergency room facilities. In smaller communities, local hospitals are acquiring the role of community health centers, not only providing the hospital bed and surgical services but also conducting active health-promotion campaigns of many types that promote prevention and early detection of illness.

Community health centers serve as important costeffective hubs for preventative care services. Child immunization services and health screening can be done effectively in community health facilities. Health education classes can be taught in community health centers for both the young and the elderly. Drug and alcohol dependency programming are also important parts of community outreach services to be coordinated through community health centers. In essence, community health centers represent the 
widespread recognition in urban and rural areas alike that sustainable communities require high quality health care provide through a variety of means. Wellness and good health practices are seen as both individual benefits and community benefits rather than as commodities to be purchased solely by those individuals who can afford it.

Community health centers might also help to overcome current inequities in Medicaid patient care delivered by private commercial providers. Landon and his colleagues found that Medicaid patients served by commercial providers tend to receive lower quality care than privately enrolled patients in commercially provided care programs. ${ }_{-}^{27}$ Community health centers might also be a long-term solution to the need to combine health and public assistance benefits with day care for working mothers, an unfilled need, which may weaken the benefits of the aforementioned programs. ${ }_{-}^{28}$

\section{II.H - State Children's Health Insurance Program (S-CHIP)}

The S-CHIP program is a state and nationally funded program that began in 1997. The program is intended to extend health insurance to children who would not meet the income requirements of Medicaid. Eligibility for S-CHIP is a function of a child's age, family size, and household income level. The S-CHIP program serves children from working class and middle-income families. This health care entitlement helps these families remain in the middle class and working poor categories - without this health care entitlement, the eligible families would likely lose their socioeconomic status in the case of any type of serious medical condition arising for their children. As with Medicaid, S-CHIP offers health 
insurance, emergency medical care, immunization programs, and a health-screening program. S-CHIP also helps reduce the cost of adult health care by managing health care needs of adolescents before health problems become chronic and expensive to treat.

Childhood obesity, for instance, has led to serious concerns about the future health care needs of Americans. Related to obesity, many children are being diagnosed with diabetes, which can lead to other serious health care issues, principally vision, renal, coronary and circulatory disorders. Obesity itself can also lead to heart problems, stroke, and premature death. Increasing access to medical testing, preventive treatment and information through the insurance resources of the S-CHIP program mean that chronic health issues can be either prevented or effectively treated to forestall serious health consequences in many cases.

Enrollment in S-CHIP has risen dramatically since 2000. In just six years, enrollment increased from 3.36 million children in 2000 to over 6.6 million children in 2006. In percentage terms, the increase has been over 97 percent! S-CHIP expenditures also reflect this tremendous rise in program enrollment, which increased from $\$ 1.93$ billion in 2000 to a staggering $\$ 7.03$ billion in 2006 - nearly a 511 percent increase in expenditures in just six years. A statefederal entitlement, S-CHIP is a noteworthy commitment to many middle class American families with young dependents, helping many of those families to avoid economic devastation and offering hope to millions of children. What certainly cannot be ignored, however, is the rapid growth of the program and the constraints that level of growth places on state budgets; state program managers must prioritize and manage a myriad of state and local community needs. However, to place matters into some perspective, it is useful to consider the following: as a program, S-CHIP costs less 
than 0.5 percent of all state and local government receipts combined. . $^{29}$

Successful sustainable communities possess the capability of relying upon the ability of the individuals and families living in those communities to respond to changing conditions and needs. S-CHIP helps working class families, whose relatively acceptable economic status could quite easily be transformed into economic devastation by the health care needs of their children should serious illness occur. ${ }_{-}^{30}$ This program allows these families to maintain the slack resources needed to respond to other changing needs, such as care for an elderly relative or to cover the costs of further education. Slack resources might also be used to help other community members in times of need - providing shelter and food for a neighbor who lost their home or suffered a medical malady that will require the support of their close friends.

\section{II.I - Unemployment Compensation}

A national government policy administered through and supplemented by the states, $<\mathrm{P}>$ UUOr unemployment compensation represents a commitment made to address temporary economic dislocations. The program is funded at the national, state, and local levels, using a combination of sources of funds. It is intended to provide financial assistance to unemployed individuals through direct payments to be used to purchase many of the basic necessities of life. Unemployment compensation is an example of a policy commitment type of entitlement, recognizing that there are times when other members of our local and state communities are incapable of fending for themselves due to circumstances beyond their control.

The states and the federal governments have different roles 
in managing unemployment compensation. Federal government responsibilities include the following: ${ }_{-}$

1. ensure conformity and substantial compliance of state law, regulations, rules, and operations with federal law;

2. determine administrative fund requirements and provide money to states for proper and efficient administration;

3. set broad overall policy for administration of the program, monitor state performance and provide technical assistance as necessary; and

4. hold and invest all money in the unemployment trust fund until drawn down by states for the payment of compensation.

State government responsibilities under this program include the following: $\frac{32}{-}$

1. determine operation methods and directly administer the program;

2. take claims from individuals, determine eligibility, and ensure timely payment of benefits to workers; and,

3. determine employer liability and assess and collect contributions.

Unemployment compensation is generally fixed at 26 weeks, although some states such as Massachusetts offer a 30-week initial compensation period. During periods of sustained high unemployment, where it is highly unlikely that an unemployed person would be able to regain employment, extended unemployment benefits are generally paid for an additional 13 weeks. FedeUUUnemployment compensation tax money is collected from employers by state governments, but is then deposited with the federal government under federal statutory guidelines. 


\section{II.J - Entitlements and the Core Dimensions of Sustainability}

In the broadest consideration, the sustainability construct we are using in this book can be viewed as a requiring a rather inclusive discussion of the need to balance rights and responsibilities in a society that relies less on resource extraction and environmental degradation and more on the careful and wise use of the renewable resources available to all individuals. Sustainability requires due consideration of the needs of today but keeps in mind the needs and conditions of future generations. For now, we are here - alive, thinking, speaking creatures. One of the reasons that societies first formed was because individuals and groups of individuals tried to figure out a better way to amass and distribute the resources needed to make life bearable and to increase the likelihood that their offspring and future generations would both survive and be able to improve their respective lots in life.

Viewed in the context of sustainability, entitlements focus our attention on both short term and long-term goals associated with the community well being. In the short term, entitlements are designed to meet the immediate objectives of providing for the educational, economic and social welfare benefits of individuals who are often unable to provide for themselves. In doing so, entitlements provide for the longterm goal of making survival and improvement possible for the beneficiaries and for future generations of people living in that community. In this sense, the entitlement programs discussed in this chapter touch directly upon the social and economic objectives of sustainability.

Reform efforts are bringing social safety net entitlements closer into line with the environmental and economic core objectives of sustainability. The evolution of entitlements in the 20th century focused attention on the rights of the 
individual within society. Many entitlement policies focused state and local government efforts on issues of social welfare for the indigent; policies designed to help those who had or who were currently suffering from the effects of historic racial, ethnic, and gender-based discrimination; and policies promoting equality in education. The sustainability paradigm embraces these initiatives to promote social equity; however, sustainability calls for a somewhat broadened view of rights and responsibilities. Increasingly, the focus of our attention is on communal rights and the rights of nature. Should community benefit and the environment, broadly defined, be considered in a discussion of entitlements? The focus on such issues is so current that it would be foolhardy to decide how it will be decided in the end; nevertheless, it is a central part of the sustainability paradigm and would significantly change the way states and local communities consider the issue of sustainability in the governance process.

A major reason for writing this book in this way at this time is that the present generation of college students will doubtless be the deciding generation for this critical question. If the core values of economic vitality, environmental protection, and social equity are to be achieved in our communities, the challenge of providing a sustainable set of entitlements as a collective benefit to all citizens will have to be met by those who manage our state and local governments and those citizens who take an active interest in the wellbeing of their communities - through participating in civic affairs, through volunteering in community organizations, and through doing their fair share to promote wellness and good health in their own lives and those of their family members.

The concept of individual rights and responsibilities is deeply embedded in the institutional arrangements of American state and local governance. Liberal democratic governance was built around the idea of inalienable individual rights and the promotion and protection of individual freedom 
and equality, carried out within the confines of orderliness in civil society. Notions of global justice and trans-generational justice, for instance, were likely not at the forefront of 17th and 18th century liberal democratic thinkers' minds. Nonetheless, $t$ the thoughts and words of our Founding Fathers and their predecessors continue to govern American political institutions. A major challenge facing the leaders of state and local government today is that of incorporating into the American individual rights tradition sufficient regard for the thoughtful consideration of future consequences so that collective action can take place to preserve the social safety net as progress is made toward maintaining vitality in our economic activities and protecting our environmental heritage.

\section{Exercises}

\section{Entitlements-What Can I do?}

As we learned in this chapter, the nation's largest health insurance program is Medicare, which covers people 65 or older and some people under 65 who are disabled. Perhaps you have someone in your family-such as parents or grandparents-who receives Medicare benefits? Ask them about how the program works for them including costs and benefits of coverage.

Go to your city's or county's website and try to identify what types of entitlement programs are offered by your local government. Try to identify if these programs contain 
intergovernmental revenues from the state or federal governments.

Go to Google's video search website and type in "entitlements." There are many videos of elected officials, commentators, and interest groups of all ideological orientations. Try to identify videos of different perspectives, watch a couple, then see what you think of the various perspectives. Many of the videos will argue that entitlements are not sustainable with the upcoming retirement of many "baby boomers" (the generation born in the middle of the twentieth century).

Google video search: http://video.google.com/

\section{II.K - Conclusion: The Relationship Between Entitlements and Sustainability}

Governing for sustainability means that we are committed to one another in our individual and collective pursuit of a good society. Part of commitment means ensuring that vulnerable individuals are offered assistance based on their needs. The elderly, children, unemployed individuals and the poverty-stricken are four examples of groups who are vulnerable and who often require the special attention of society. In sustainable governance, commitment is not about charity; it is about maximizing the opportunity of all members of society to contribute to the common welfare. For the 
elderly, opportunity means the chance to live a good life and to contribute the wisdom of experience to the community - be it the shared knowledge of living through challenging times and experience implementing tried-and-true methods of meeting those challenges, or sharing child-rearing responsibilities for young adult family or community members who work full time. For children, among the most vulnerable of any community's residents, opportunity means the chance to grow up and mature into healthy and happy adults; reliable access to quality health care is a critical part of achieving this goal. For the unemployed and the poverty-stricken, opportunity means the chance to regain the dignity associated with economic independence; the opportunity to experience gainful employment provides that dignity.

The concept of "entitlement program" is used here because it is a term that is most frequently associated with the aforementioned programs; it is one that reflects a philosophically liberal tradition regarding the rights of the individual and the need for the state to promote social justice. While the rights of the individual are critical in sustainable governance, the programs detailed here are equally important for the preservation of sustainable community existence. A focus on sustainability, therefore, requires policy makers and citizens to re-conceptualize the meaning of entitlements, painting for themselves a broader understanding of the use and value of such programs. We are increasingly aware that we are all givers and we are all recipients of the benefits offered by such programs, and there is evidence that the entitlement policies of the United States are responding to this recognition. 33 


\section{Terms:}

Baby Boomers

Medicaid

Medicare

No Child Left Behind (NCLB)

S-CHIP

Social Safety Net

Sustainable Community-based Eldercare

Temporary Assistance for Needy Families (TANF)

Unemployment Compensation

Welfare Reform Act, 1996

Welfare-to-work programs

\section{Discussion Questions}

1. What are the various types of state and local government entitlement programs? What is (are) the purpose(s) of these programs?

2. Discuss the relationship between entitlement programs and sustainable communities? Is it possible to cut entitlement programs and yet maintain sustainability?

3. What are the various types of state and local public assistance and health care programs? 
4. Discuss the role of state and local governments in the Medicare and Medicaid programs.

\section{Notes}

1. D.A. Super, "The Political Economy of Entitlement," Columbia Law Review 104(2004): 633-656, p. 644.

2. Ibid, p. 648.

3. Ibid, p. 653.

4. Ibid, p. 654.

5. Ibid, p. 655.

6. J.H. Skinner, "Entitlements: What do they Mean?" Generations 15(1991): 16-19.

7. See D. Friedman, "Credit Crisis, Health Costs Threaten States' Economies," Congress Daily (December 5, 2007), p. 10.

D. Malpass, "Monetary Policy and the Growing Fiscal Imbalance," CATO Journal 27(2007): 219-230.

8. A. Meyerson, "Land of Milk and Money," Policy Review 56(1991): 31-35.

9. E.C. Smith, "Moving from Welfare to Work: A Snapshot Survey of Illinois Families," Child Welfare 74(1995): 1091-1106.

10. C.A. Simon, Public Policy: Preferences and Outcomes, 2nd Edition (New York: Longman, 2010).

11. G. Rosen, A History of Public Health, Expanded Edition. (Baltimore, MD: Johns Hopkins University Press, 1993). 
12. See Utne Reader, "Age-Old Wisdom," Utne Reader 136(2006): 12.

13. See Mental Health Weekly, "In case you haven't heard...," Mental Health Weekly 17(2007): 8.

14. See R. Murdock, "Drug Use Falls Among Teen, But Increases Among Baby Boomers," Nation's Mental Health 36(2006): 8.

15. Office of Family Assistance, "Fact Sheet." URL: http://www.acf.hhs.gov/opa/fact_sheets/ tanf_factsheet.html (accessed December 30, 2008)

16. Child Trends Data Bank, Child Recipients of Welfare (AFDC/TANF), December 2015, URL: https://www.childtrends.org/wpcontent/uploads/2012/07/ 50_AFDC_TANF.pdf

17. See H.J. Aaron, "Budget Crisis, Entitlement Crisis, Health Care Financing Problem-Which Is It?" Health Affairs 26(2007): 1622-1633.

L.D. Schaeffer, "The New Architects of Health Care Reform," Health Affairs 26(2007): 1557-1559.

18. See T.S. Bodenheimer, Understanding Health Policy: A Clinical Approach, 4th Edition (New York: Lange Medical Books/McGraw-Hill, 2007).

P. Starr, The Social Transformation of American Medicine: The Rise of a Sovereign Profession and the Making of a Vast Industry (New York: Basic Books, 1982).

19. I. Sanz, and F.J. Velázquez. "The Role of Aging in the Growth of Government and Social Welfare Spending in the OECD," European Journal of Political Economy 23(2007): 917-931.

20. See S.M. Ross, American Families: Past and Present (New Brunswick, NJ: Rutgers University Press, 2006).

21. J.M. Wilmoth, and C.F. Longino, Jr., "Demographic Trends that will Shape U.S. Policy in the Twenty-First Century," Research on Aging 28(2006): 269-288. 
22. D.P. Rice, and N. Fineman, "Economic Implications of Increased Longevity in the United States," Annual Review of Public Health 25(2004): 466.

23. J.L. Palmer, "Entitlement Programs for the Aged: The Long-Term Fiscal Context," Research on Aging 28(2006): 289-302.

24. Medicaid, "Medicaid Eligibility." URL: http://www.cms.hhs.gov/MedicaidEligibility/ (accessed the December 31, 2008).

25. R. Kronick, and D. Rousseau, "Is Medicaid Sustainable? Spending Projections for the Program's Second Forty Years," Health Affairs Special Issue (2007): 271-287.

26. J. Medicaid.gov, June 2018 Medicaid \& CHIP Enrollment Data Highlights. URL: https://www.medicaid.gov/medicaid/ program-information/medicaid-and-chip-enrollment-data/ report-highlights/index.html

27. B. Landon, E.C. Schneider, S.L. Normand, S.H. Schoelle, L. Pawlson, L. Gregory, and A.M. Epstein, "Quality of Care in Medicaid Managed Plans and Commercial Health Plans," Journal of the American Medical Association 298(2007): 1674-1681.

28. E.K. Pavalko, and K.A. Henderson, "Combining Care Work and Paid Work: Do Workplace Policies Make a Difference?" Research on Aging 28(2006): 359-374.

P.K. Robins, "Welfare Reform and Child Care: Evidence from 10 Experimental Welfare-to-Work Programs," Evaluation Review 31(2007): 440-468.

29. U.S. Census Bureau, Statistical Abstract of the United States (Washington, DC: U.S. Census Bureau, 2008).

30. See V. Feeg, "Why SCHIP is Such a Good Deal for Children's Access to Care," Pediatric Nursing 33(2007): 299, 312.

31. Work Force Security. Unemployment Insurance Benefits. URL: http://workforcesecurity.doleta.gov/unemploy/ pdf/ partnership.pdf (accessed December 30, 2008).

32. Ibid. 
33. J. Quadagno, and D. Street, "U.S. Social Welfare Policy: Minor Retrenchment or Major Transformation?" Research on Aging 28(2006): 303-316. 


\section{Chapter I2: Traditional and Visible Services: Criminal Justice, Education, Transportation and Emergency Management}

\section{I2.A - Introduction}

This chapter covers four of the largest and most "visible" - in terms of budget allocations - services that are provided by state and local government: criminal justice, education, transportation, and emergency management. By "visible" we mean those public services encountered frequently, or services we are likely to be aware of on a continual basis. The criminal justice system in each state includes state and local police, prosecutors, crime labs, prisons and jails, various corrections programs such as work release and community service, state and local probation and parole officers, and numerous other types of uniformed and plain-clothed personnel. The state, county, and municipal court systems are also a part of the criminal justice system, but given the great importance of the courts, this branch of government is discussed separately in Chapter 8.

The education system, which is often the largest single expenditure at the state and local level of government, includes K-12 public schools and school districts, Head Start Programs, disability, and special education programs, 
community colleges, and public universities. In addition, each state typically has a Department of Education, or similar agency, that administers education policy and monitors implementation for compliance with national and state school standards. Because every state has compulsory education required to a certain level, all citizens have some exposure to the education system, whether it is through public schools or private schools and academies (private schools are regulated by state and local governments).

Another service that many citizens take largely for granted, but which is an integral part of everyday life for everyone, is the transportation system. Depending on location, this could include mass transit (e.g., buses, light rail trains, and subways), airports, park-and-ride lots, streets and alleyways, freeways and turnpikes, car and passenger ferries, waterways, port facilities and marinas, streetlights, bike and walking paths, and bridges and overpasses. State and local governments are also involved in the regulation of private transportation services such as bus lines, taxis, rental vehicles, trucking, and the like. As with public education, state governments typically have departments of transportation established to coordinate and monitor commercial and common transport and travel activities and services.

Finally, services and programs concerning emergency management and homeland security have become much more visible after the terrorist events of September 11, 2001, in the wake of natural disasters such as Hurricanes Katrina and Rita in 2005, and since the arousal of international health concerns over matters such as mad cow disease and possible avian and swine flu [H1N1] pandemics. Often acting in cooperation with the federal government, state and local governments have been developing plans, procedures, and programs to ensure public safety and assistance the next time a major disaster takes place. The state and local Public Health authorities, the state and local fire and Emergency Medical Technicians, and 
local law enforcement (often the county Sheriff) are all involved in the identification of hazards and vulnerabilities and planning for prevention, mitigation, response, and recovery associated with either man-made or natural disasters requiring emergency services.

As discussed in Chapter 1, all four of these government services and programs are integral factors in developing and maintaining sustainable and resilient states and communities. Lack of investment or proper maintenance and management of these services threatens the social and economic basis of communities, as well as threatens the ability to adapt to the various socio-economic changes taking place in postindustrial America. In addition, unfunded mandates by the federal government, such as the recently enacted stormwater management standards of the Clean Water Act, and such as some components of the 2002 No Child Left Behind Act requiring high stakes testing and intensive instruction in math and science literacy (see below), have added weighty responsibilities to state and local governments without adequate resources. ${ }^{1}$ With the rising costs of delivering these services and the additional burdensome unfunded mandates, state and local officials must now consider new approaches to service delivery and new ways of finding adequate funding. We will discuss some of these new public policy and public finance approaches in this chapter.

\section{Learning Objectives}

More specifically this chapter will:

- $\quad$ Compare and contrast state criminal justice systems and policies, including a focus on new and 
innovative approaches to adult and juvenile crime prevention, and discuss criminal justice programs and operations that promote community sustainability rather than expand the reach of the criminal justice.

- Examine the government's role (federal, state and local) in K-12 and higher education systems, and how education can serve to promote sustainability.

- Discuss the importance of state and local governments in the development and management of a variety of transportation systems and infrastructure investments that promote sustainability.

- Present information on the increasing role of state and local governments in the planning and implementation of emergency management services.

\section{I2.B - Criminal Justice}

In the U.S. state and local (county and municipal) governments are the most important actors in the criminal justice policy area. While federal law enforcement agencies such as the Federal Bureau of Investigation (FBI) and the Drug Enforcement Administration (DEA) are frequently headlined in the mass media, it is the case that the vast majority of criminal justice activity takes place at the state and local levels of government. State and local criminal justice systems consist of agencies and personnel who are responsible for enforcing criminal codes, state statutes, and local ordinances. These agencies and personnel include commissioned law enforcement officers, criminal and general jurisdiction courts, 
correctional facilities (e.g., jails and prisons) and communitybased corrections programs, prosecutors, crime victim advocates and legal aid (including public defenders). While these many agencies and legal system professional groups can be found in any state, very different perspectives on criminal justice inform criminal justice policy at the state and local levels of governance. The debate over criminal justice policy is often fueled by a profound disagreement about the causes of crime, and what those causes imply for the appropriate countermeasures to be adopted. In general, policymakers hold three different views regarding the causes of crime, the origins, and characteristics of offenders, and the purposes of criminal law. These three views can be labeled the sociogenic, the psychogenic and the biogenic perspectives.

The sociogenic school of thought focuses on the criminogenic (crime-causing) aspects of the environment and its advocates place primary responsibility for the occurrence of crime on society. Poverty, poor education, high unemployment, unstable homes, the absence of affection, and improper socialization into social norms are cited as common causes of crime. ${ }_{-}^{2}$ The sociogenic approach typically reflects a liberal political ideology.

The psychogenic school of thought reflects a psychological approach that considers the individual's propensity and inducement to violate social norms and commit a crime. ${ }_{-}^{3}$ That propensity is determined by the individual's ability to conceptualize right and wrong, to manage impulses, to take reasonable risks, and to anticipate the future consequences of one's actions. Inducement refers to situational factors, such as unguarded access and easy opportunity, which can act as incentives to crime. According to this view, the individual is responsible for his/her behavior because a choiceis made whether or not to commit a crime. This view generally underlies conservative thought, and it explains why the advocates of this understanding of criminal 
motivation favor severe penalties (such as capital punishment) thought to deter individuals from making the wrong choices.

A third approach to crime is the biogenic or "sociobiological" explanation._ This viewpoint is not highly common among criminologists, but has been popularized by the scholar James Q. Wilson. This school of thought relates criminal behavior to such fundamental biological phenomena as brain tumors, endocrine abnormalities, neurological dysfunctions from pre-natal and post-natal experiences, and chromosomal abnormalities. ${ }_{-}^{6}$ Preventive crime policies would entail the development of appropriate screening and other diagnostic tests for persons suspected of such physical or mental disorders.

Those who subscribe to the sociogenic school of thought are less likely to be supporters of punishment as the sole solution to crime than are those who adhere to either the psychogenic or biogenic schools of thought. Proponents of sociogenic explanation do not hold the individual as always primarily responsible for his/her criminal behavior and, because of this, do not see punishment as an effective deterrent to most types of criminal behavior. Instead, they tend to favor a civil libertarian approach, which emphasizes the rights of individuals accused of crimes and advocate treatment and rehabilitation-focused programs for juvenile offenders and most adult offenders alike.

In contrast, those who view criminal behavior as a matter of individual choice (the psychogenic school) are likely to see swift and certain punishment as an effective deterrent because punishments constitute a tangible consequence as individuals calculate the amount of risk involved in committing a crime in relation to the potential consequence. Adherents of this perspective will support policies that take a law and order approach, where the emphasis is placed on protecting the public order by close monitoring of conduct and the 
imposition of stern punishments on those who commit offenses.

Those who adhere to the biogenic school differ slightly from the psychogenic ideology in that they may or may not view punishment as a deterrent to crime, but they most likely feel that capital punishment is the appropriate punishment for individuals who cannot be cured of their criminal predispositions. However, the primary emphasis for the advocates of the biogenic perspective would be on preventive policies that identify those persons who are biologically predisposed to commit crimes measurable through reliable diagnostic tests of various kinds.

\section{I2.B.I - Crime in America}

The two most comprehensive sources of crime data in the United States are the annual National Crime Survey(NCS) and the F.B.I.s Uniform Crime Report(UCR). The NCS conducts very large-scale household surveys each year to determine whether citizens have been the victims of major crimes such as rape, robbery, burglary, larceny or other crimes. The NCS is a good measure of crime because it collects data on crimes that have occurred that have not been reported to the police. The $\mathrm{UCR}$, in contrast, is a measure of crimes known to police - i.e., those that are actually reported to the authorities. Typically the NCS reveals far more serious crimes being committed than the UCR registers because many crimes go unreported for a variety of reasons, such as fear of retribution, a belief that the police could do nothing about the crime, or the desire to "drop the charges" on the party responsible for the crime. The Bureau of Justice Statistics is also a great source of crime and law data. For example, a 2016 report by the Bureau (Bureau of Justice Statistics, 2016: 1).? 
- "The number of adults supervised by the U.S. correctional system dropped for the ninth consecutive year in 2016. The correctional population includes persons supervised in the community on probation or parole and those incarcerated in prisons or local jails. This report from the Bureau of Justice Statistics is the latest official snapshot of the state of the U.S. correctional population.

- From 2007 to 2016, the proportion of the adult population under the supervision of U.S. correctional authorities decreased by 18 percent, from 3,210 to 2,640 adults under correctional supervision per 100,000 residents. The number of adults under correctional supervision per 100,000 U.S. adult residents was lower in $2016(2,640)$ than at any time since 1993 (2,550). Overall, about 1 in 38 adults were under some form of correctional supervision at year-end 2016.

- An estimated 6,613,500 persons were under correctional supervision on December 31, 2016, about 62,700 fewer persons than on January 1 . The total correctional population declined 0.9 percent during 2016 due to decreases in both the community supervision population (down 1.1 percent) and the incarcerated population (down 0.5 percent).

- The incarcerated population decreased from 2,172,800 in 2015 to $2,162,400$ in 2016. All of the decreases in the incarcerated population was due to a decline in the prison population (down 21,200), while the jail population remained relatively stable. The number of persons held in prison or local jail per 100,000 U.S. adult residents (incarceration rate) has declined since 2009 and is currently at its lowest rate (860 per 100,000 in 2016) since 1996 (830 per 100,000).

- During 2016, the community supervision population fell from $4,586,900$ on January 1 to $4,537,100$ at year-end. All of the decrease in the community supervision population in 2016 was due to a decline in the probation population (down 52,500). The parole population increased 0.5 percent in 2016 (up 4,300 persons). More than two-thirds (69 percent) of the correctional 
population were supervised in the community at year-end 2016, similar to the percentage observed in 2007."

Using data from the UCR, the F.B.I. periodically publishes a "crime clock" for serious crimes reported from across the nation. The data in Table 12.1 for 2015 indicates that every 20.0 seconds there is a burglary, every 5.5 seconds a larcenytheft, every 44.6 seconds a motor vehicle theft, every 33.5 minutes a murder, every 4.2 minutes a rape and a robbery every 1.6 minutes. While crime rates - both reported to the authorities and crime victimization - can vary from year to year, these are disturbing numbers and are an indication of the enormous challenge and burden facing state and local government criminal justice systems. Not only are the human costs of these crimes enormous - such as loss of life and longterm debilitating effects - but the monetary costs are great as well, not only for the victims but also for state and local government budgets. According to the U.S. Bureau of Justice, "local jails" (locally-operated correctional facilities) have the following traits: ${ }_{-}^{8}$

- EVERY 3.1 SECONDS: ONE PROPERTY CRIME

- One burglary every 20.0 seconds

- One larceny-theft every 5.5 seconds

- One motor vehicle theft every 44.6 seconds

- EVERY 23.1 SECONDS: ONE VIOLENT CRIME

- One murder every 33.5 minutes

- One rape every 4.2 minutes

- One robbery every 1.6 minutes

- One aggravated assault every 41.3 seconds

Table 12.1 FBI Crime Clock, 2015

The majority of inmates in both our prisons and local 
jail facilities are Black or Latino, possess few educational or vocational skills for legitimate employment, are more often involved in the chronic use of drugs, are likely to have grown up in poverty, and received relatively little nurturance from parents or extended families. In fact, in one of the first most comprehensive studies on the "prevalent handicaps" among prison inmates, Albert Roberts identified five characteristics common to most institutional correctional facility inmates: ${ }_{-}^{9}$

1. The first is "character disorder," which means antisocial behavior due to inappropriate socialization as a child.

2. "unemployability," the lack of job-related skills and work motivation.

3. "relationship hang-ups," lack of constructive interpersonal relationships and support with family and friends.

4. "social stigma," being labeled a felon or socially undesirability.

5. "immaturity" inability to take appropriate responsibility for one's own actions and to make socially acceptable life choices.

These same five characteristics are as relevant today as they were in the early 1970s when Roberts did his pioneering research.

\section{I2.B.II - Remedies}

As discussed previously, there are differing theories concerning the causes of crime, and as a consequence, there are different remedies offered by the advocates each theory. The three main countermeasures to crime advocated are punishment, rehabilitation and treatment; in many instances, a combination of all three approaches is being attempted in 
state and local settings across the country. Punishment has been a very popular approach to crime in the U.S., as evidenced by historically popular support for the death penalty; large majorities of citizens support its use in cases of murder and other heinous crimes (see Table 12.2). While only 58 countries in the world used the death penalty in 2016 (including China, Iran, Syria, and the United States), 35 percent of U.S. citizens in 2014 support its use for purposes of revenge, ("an eye for an eye") and punishment thought to deter serious crime (see Table 12.3). 


\begin{tabular}{|c|c|c|c|}
\hline & FAVOR & NOT IN FAVOR & $\begin{array}{l}\text { NO } \\
\text { OPINION }\end{array}$ \\
\hline 2017 OCT 5-11 & $55 \%$ & $41 \%$ & $3 \%$ \\
\hline 2016 OCT 5-9 & $60 \%$ & $37 \%$ & $3 \%$ \\
\hline 2015 OCT 7-11 & $61 \%$ & $37 \%$ & $2 \%$ \\
\hline 2014 OCT 12-15 & $63 \%$ & $33 \%$ & $4 \%$ \\
\hline 2013 OCT 3-6 & $60 \%$ & $35 \%$ & $5 \%$ \\
\hline 2012 DEC 19-22 & $63 \%$ & $32 \%$ & $6 \%$ \\
\hline 2011 OCT 6-9 & $61 \%$ & $35 \%$ & $4 \%$ \\
\hline 2010 ОСТ 7-10 & $64 \%$ & $29 \%$ & $6 \%$ \\
\hline 2009 ОСТ 1-4 & $65 \%$ & $31 \%$ & $5 \%$ \\
\hline 2008 OCT 3-5 & $64 \%$ & $30 \%$ & $5 \%$ \\
\hline 2007 OCT 4-7 & $69 \%$ & $27 \%$ & $4 \%$ \\
\hline 2006 ОСТ 9-12 & $67 \%$ & $28 \%$ & $5 \%$ \\
\hline 2006 MAY 5-7 & $65 \%$ & $28 \%$ & $7 \%$ \\
\hline 2005 OCT 13-16 & $64 \%$ & $30 \%$ & $6 \%$ \\
\hline 2004 OCT 11-14 & $64 \%$ & $31 \%$ & $5 \%$ \\
\hline 2003 ОСТ 6-8 & $64 \%$ & $32 \%$ & $4 \%$ \\
\hline 2003 MAY 19-21 & $70 \%$ & $28 \%$ & $2 \%$ \\
\hline 2002 OCT 14-17 & $70 \%$ & $25 \%$ & $5 \%$ \\
\hline 2001 OCT 11-14 & $68 \%$ & $26 \%$ & $6 \%$ \\
\hline 2001 FEB 19-21 & $67 \%$ & $25 \%$ & $8 \%$ \\
\hline 2000 AUG 29-SEP 5 & $67 \%$ & $28 \%$ & $5 \%$ \\
\hline 2000 JUN 23-25 & $66 \%$ & $26 \%$ & $8 \%$ \\
\hline
\end{tabular}

Table 12.2 Public Support for the Death Penalty for a Person Convicted of Murder 


\begin{tabular}{|c|c|c|c|c|}
\hline & $\begin{array}{l}2014 \\
\text { Oct } \\
12-15\end{array}$ & $\begin{array}{l}2003 \\
\text { May } \\
19-21\end{array}$ & $\begin{array}{l}2001 \\
\text { Feb } \\
19-21\end{array}$ & $\begin{array}{l}1991 \\
\text { Jun } \\
13-16\end{array}$ \\
\hline $\begin{array}{l}\text { AN EYE FOR AN EYE/THEY TOOK A } \\
\text { LIFE/FITS THE CRIME }\end{array}$ & $35 \%$ & $37 \%$ & $48 \%$ & $50 \%$ \\
\hline $\begin{array}{l}\text { SAVE TAXPAYERS MONEY/COST } \\
\text { ASSOCIATED WITH PRISON }\end{array}$ & $14 \%$ & $11 \%$ & $20 \%$ & $13 \%$ \\
\hline THEY DESERVE IT & $14 \%$ & $13 \%$ & $6 \%$ & - \\
\hline $\begin{array}{l}\text { THEY WILL REPEAT CRIME/KEEP } \\
\text { THEM FROM REPEATING IT }\end{array}$ & $7 \%$ & $7 \%$ & $6 \%$ & $19 \%$ \\
\hline $\begin{array}{l}\text { DETERRENT FOR POTENTIAL } \\
\text { CRIMES/SET AN EXAMPLE }\end{array}$ & $6 \%$ & $11 \%$ & $10 \%$ & $13 \%$ \\
\hline $\begin{array}{l}\text { DEPENDS ON THE TYPE OF CRIME } \\
\text { THEY COMMIT }\end{array}$ & $5 \%$ & $4 \%$ & $6 \%$ & - \\
\hline FAIR PUNISHMENT & $4 \%$ & $3 \%$ & $1 \%$ & - \\
\hline SERVE JUSTICE & $4 \%$ & $4 \%$ & $1 \%$ & $3 \%$ \\
\hline $\begin{array}{l}\text { IF THERE'S NO DOUBT THE PERSON } \\
\text { COMMITTED THE CRIME }\end{array}$ & $3 \%$ & $3 \%$ & $2 \%$ & - \\
\hline $\begin{array}{l}\text { SUPPORT/BELIEVE IN DEATH } \\
\text { PENALTY }\end{array}$ & $3 \%$ & $2 \%$ & $6 \%$ & - \\
\hline $\begin{array}{l}\text { DON'T BELIEVE THEY CAN BE } \\
\text { REHABILITATED }\end{array}$ & $3 \%$ & $2 \%$ & $2 \%$ & - \\
\hline BIBLICAL REASONS & $3 \%$ & $5 \%$ & $3 \%$ & - \\
\hline $\begin{array}{l}\text { LIFE SENTENCES DON'T ALWAYS } \\
\text { MEAN LIFE IN PRISON }\end{array}$ & $2 \%$ & $1 \%$ & $2 \%$ & - \\
\hline RELIEVES PRISON OVERCROWDING & $2 \%$ & $1 \%$ & $2 \%$ & - \\
\hline $\begin{array}{l}\text { WOULD HELP/BENEFIT FAMILIES } \\
\text { OF VICTIMS }\end{array}$ & $1 \%$ & $2 \%$ & $1 \%$ & - \\
\hline OTHER & $1 \%$ & $4 \%$ & $3 \%$ & $11 \%$ \\
\hline NO OPINION & $4 \%$ & $2 \%$ & $1 \%$ & $2 \%$ \\
\hline
\end{tabular}

Table 12.3 Reasons for Favoring the Death Penalty Among the U.S. Public

The popularity of punishment among citizens and elected officials has led to the adoption in most states of mandatory sentencing laws, including three-strikes laws.

Chapter 12: Traditional and Visible Services: Criminal Justice, Education, Transportation and Emergency Management | 511 
These state statutes are aimed at deterring potential offenders and incapacitating convicted criminals through long-term prison terms. One of the unfortunate results of mandatory sentencing and the punishment approach, in general, is that many new state and local correctional facilities have had to be constructed to house an increasing number of prisoners where that investment of public funds could be afforded. Where that investment was not possible, existing correctional facilities have been filled to capacity or overfilled. In this connection, correctional facilities in 18 states were either filled or over-filled in prisoner capacity in 2014. . $_{-}$

As costs and the number and nature of participants in the overwhelmingly punishment-based criminal justice systems have dramatically increased, many scholars and practitioners believe the current system is neither economically, nor socially, nor institutionally sustainable. ${ }_{-}^{12}$ Alternatives to punishment and imprisonment include new community-based policing procedures, juvenile aftercare programs, community service and residential centers, fines, restitution, intensive probation, and shock incarceration-boot camps, among others. ${ }_{-}^{13}$ For example, due to prison overcrowding and the high costs of incarceration, many state and local governments have moved to the use of "intermediate sanctions" for nonviolent offenders. One such intermediate sanction is intensive probation supervision, a conditional release program which features strict curfews, routine and random (unscheduled) drug testing, community service, and restitution to victims. While this is not the approach taken for violent or habitual offenders, it is much less costly and provides an opportunity for rehabilitation for the first-time offender. In this manner of program, offenders are both held accountable for their actions and are given the opportunity to act responsibly in the community to make proper amends.

Other approaches to building sustainable criminal justice systems include community policing. In general, community 
policing can involve the following activities: police officers being assigned to specific neighborhoods rather than being on call for responding to 911 calls citywide; the creation and maintenance of neighborhood police stations or "storefronts" in high crime areas; participation in neighborhood meetings and the making of home visits by police officers, etc. All of these activities are undertaken in an attempt to connect police with citizens in their respective neighborhoods and communities instead of just performing drive-by patrols in their cars. Community policing also emphasizes "problemsolving methodologies" and partnership building policies, where police agencies work closely with community groups and local businesses to identify current and future problems and then work together collaboratively to address those problems. The federal government's U.S. Department of Justice established the Office of Community Oriented Policing Services (COPS) in the 1994 Crime Bill to provide federal resources to local communities so that they could train their officers in community policing and implement these programs designed to sustain safe and crime-free communities wherein the police and the citizens they serve are involved in an active partnership to preserve public order and promote public safety.

Many innovations in dealing with crime as well as new programs reflect the values of sustainability, and some of these successful approaches should be noted. One example includes: "...designing, implementing, and monitoring sentencing guidelines that balance several goals of crime response; establishing mandatory drug treatment instead of prison for first- and second-time drug possession," providing in prison "...basic schooling and drug and alcohol treatment to those offenders who can benefit from those services," to help prisoners "graduate" to freedom at the end of their term. Prison and jail programs that can provide job training and job placement at the end of prison terms have also been found to 
reduce recidivism. ${ }_{-}^{14}$ In addition, some programs that target at-risk youth - such as early intervention programs including counseling, organized constructive activities, and out-ofhome placement for serious offenses - have been found to be effective as well. ${ }_{-}^{15}$ While there is no one single approach or combination of approaches that will completely eradicate crime, many states and communities have been trying new and different approaches to criminal justice that represent alternatives to incarceration and move toward the goal of sustainability.

\section{I2.C - Education}

Provision of public education is typically one of the largest expenditures and entails the most visible service provided by state and local governments. With over 48 million students, over 93,000 schools, more than 3 million teachers, and nearly 3 million support staff and administrators involved in $\mathrm{K}-12$ education in the United States, public education has an enormous effect on state and local budgets, on local economies, and on the socio-economic fabric of communities. Add to this set of totals the 1,720 4-year public universities, the 2,516 2-year public colleges, and their respective professors, administrators, and staff, the effects of public education on society are even greater. The connection of public education to the effective promotion of sustainability is clear and direct as schools, colleges and universities are a key part of the visible services experienced by virtually all citizens. How the education system teaches about and models behavior regarding sustainability is a matter of great 
importance to contemporary professional educators and education policymakers.

The history of education policy in the United States reflects the nation's steady transformation from a rural natural resource-based and agricultural economy in the 1700s and 1800 s to the development of postindustrial society in the late twentieth and early twenty-first centuries (see Table 12.4). The first public school in the U.S. was established in Boston in 1635 to educate the sons of the city's wealthy elites. Elite access to education was primarily the norm until the period of industrialization in the mid-1800s. At this time there was an expansion of educational opportunities - especially in the growing cities - for students of middle and working-class families. This is the period when mandatory attendance laws began to be enacted by state legislatures in recognition of the fact that an industrial workforce and economy require adequate levels of literacy. In the twentieth century, as the U.S. was developing into a postindustrial economy, many efforts were made by the federal and state governments alike to insure better education opportunities for all races and for disadvantaged students as well. 
YEAR: EVENT:

1635 First Latin Grammar School established in Boston to educate sons of wealthy families for leadership positions.

1635 First "free school" established in Virginia.

1636 Harvard College becomes the first higher education institution.

Massachusetts Law of 1647 decrees that every town with at

1647 least 50 families hire a schoolmaster to teach reading and writing.

1821 First public high school opens in Boston.

1827 Massachusetts passes a law requiring public high schools in towns of 500 families or more.

1829 New England Asylum for the Blind is the first school in the U.S. for children with disabilities.

1837 Mount Holyoke becomes the first college for women.

1852 First mandatory attendance law is passed in Massachusetts; all states will have mandatory attendance laws by 1918 .

1856 First kindergarten is started in Wisconsin.

1862 Land Grant Act ("First Morrill Act") donates public lands to states to establish colleges and universities.

1890 Second Morrill Act provides more public land for colleges, including the creation of 16 Black land grant colleges.

Supreme Court rules "separate but equal" schools are

1896 constitutional in Plessy versus Ferguson; the decision affirms racially segregated schools.

1916 American Federation of Teachers is founded.

1926 Scholastic Aptitude Test (SAT) is developed and used.

1944 Servicemen's Readjustment Act ("G.I. Bill") is passed, providing education for returning WWII veterans.

1952 Veteran's Readjustment Act is passed for Veterans of the Korean War.

U.S. Supreme Court decision Brown vs. Board of Education

1954 overturns 1896 case Plessy v. Ferguson, by ruling separate educational facilities are inherently unequal.

1957 President Eisenhower sends federal troops to enforce integration in Little Rock, Arkansas public schools. 
As a result of the Soviet Union's successful launch of Sputnik,

1958 the National Defense Education Act is passed increasing funding for science education.

Civil Rights Act is passed. It prohibits discrimination based on race, sex, color, religion or national origin.

1965 Project Head Start provides preschool education for low-income children.

The Equality of Educational Opportunity Study (the "Coleman

1966 Report") concludes that African American children benefit from attending integrated schools. Study serves as the basis for busing to integrate schools.

1972

Title IX of the Education Amendments of 1972 prohibits sex discrimination in education.

The Education of All handicapped Children Act is passed

1975 requiring free, appropriate public education for all handicapped children.

2002

No Children Left Behind (NCLB) becomes law, holding school accountable for student achievement.

Every Student Succeeds Act (ESSA) replaces NCLB. States are responsible for holding schools accountable for achievement, but it's a flexible approach with each state setting its own goals for student achievement.

Table 12.4 Key Dates in U.S. Education Policy History

State governments are primarily responsible for the provision of educational services in our country, although the federal government has passed many laws concerning access and quality of state school systems (i.e., the 2001 No Child Left Behind Act and its replacement the 2015 Every Student Succeeds Act). Every state has established a department of education of some type and enacted laws regulating curriculum, teacher qualifications, school finance, student attendance, and the like. The almost 15,000 local school districts operating in the U.S. today oversee the day-to-day administration of schools. Many school districts are heavily supported by local taxes, a fact which ties schools closely to their communities and can influence the types of programs and curriculum offered as well as affect the quality and 
quantity of educational infrastructure and school personnel. However, there are many differences among states in how school funding is provided and who provides it. For example, there is quite a wide variation in average state and local spending per pupil as well, with New York spending on average $\$ 20,156$ per students in 2013-14 compared to Utah at $\$ 6,546$ (see Table 12.5). This wide variation can also be found in higher education tuition as well, with an average resident public university in Massachusetts at $\$ 40,761$ per student compared to Idaho at $\$ 6,006$. ${ }_{-}$ 


\begin{tabular}{|c|c|c|c|}
\hline STATE & $\begin{array}{l}\text { 2013-14 PER PUPIL } \\
\text { STATE AND LOCAL } \\
\text { SUPPORT FOR } \\
\text { PUBLIC K-12 }\end{array}$ & $\begin{array}{l}2014-15 \\
\text { PUPILS PER } \\
\text { TEACHER IN } \\
\text { PUBLIC K-12 }\end{array}$ & $\begin{array}{l}\text { 2015-16 AVERAGE } \\
\text { RESIDENT PUBLIC } \\
\text { UNIVERSITY } \\
\text { TUITION AND } \\
\text { REQUIRED FEES } \\
\text { FOR FULL-TIME }\end{array}$ \\
\hline United States & 11,066 & 16.1 & 27,951 \\
\hline Alabama & 9,036 & 17.4 & 15,359 \\
\hline Alaska & 18,466 & 16.9 & 19,957 \\
\hline Arizona & 7,457 & 23.1 & 12,667 \\
\hline Arkansas & 9,752 & 13.9 & 20,936 \\
\hline California & 9,671 & 23.6 & 29,516 \\
\hline Colorado & 9,036 & 17.3 & 22,332 \\
\hline Connecticut & 18,401 & 12.9 & 37,679 \\
\hline Delaware & 13,793 & 13.9 & 14,200 \\
\hline Florida & 8,955 & 15.3 & 22,793 \\
\hline Georgia & 9,236 & 15.6 & 25,754 \\
\hline Hawaii & 12,400 & 15.6 & 15,561 \\
\hline Idaho & 6,577 & 18.6 & 6,006 \\
\hline Illinois & 13,321 & 15.5 & 29,639 \\
\hline Indiana & 9,396 & 18.5 & 30,533 \\
\hline Iowa & 10,647 & 14.2 & 25,308 \\
\hline Kansas & 10,240 & 13.2 & 17,827 \\
\hline Kentucky & 9,411 & 16.6 & 24,258 \\
\hline Louisiana & 10,853 & 15.5 & 32,733 \\
\hline Maine & 13,267 & 12.2 & 34,277 \\
\hline Maryland & 14,217 & 14.8 & 38,352 \\
\hline Massachusetts & 15,886 & 13.3 & 40,761 \\
\hline Michigan & 10,649 & 18.1 & 22,018 \\
\hline Minnesota & 11,427 & 15.4 & 29,377 \\
\hline Mississippi & 8,265 & 15.2 & 16,438 \\
\hline Missouri & 9,938 & 13.6 & 22,416 \\
\hline
\end{tabular}

Chapter 12: Traditional and Visible Services: Criminal Justice, Education, Transportation and Emergency Management | 519 


\begin{tabular}{|c|c|c|c|}
\hline Montana & 10,941 & 14.1 & 22,961 \\
\hline Nebraska & 11,877 & 13.6 & 21,641 \\
\hline Nevada & 8,275 & 21.2 & 18,827 \\
\hline $\begin{array}{l}\text { New } \\
\text { Hampshire }\end{array}$ & 14,601 & 12.5 & 31,979 \\
\hline New Jersey & 18,780 & 12.2 & 34,040 \\
\hline New Mexico & 9,403 & 15.2 & 20,532 \\
\hline New York & 20,156 & 13.5 & 36,361 \\
\hline $\begin{array}{l}\text { North } \\
\text { Carolina }\end{array}$ & 8,287 & 15.6 & 29,307 \\
\hline North Dakota & 12,032 & 11.8 & 13,883 \\
\hline Ohio & 11,434 & 16.2 & 28,953 \\
\hline Oklahoma & 7,995 & 16.4 & 23,658 \\
\hline Oregon & 9,959 & 21.6 & 35,034 \\
\hline Pennsylvania & 13,824 & 14.3 & 37,237 \\
\hline Rhode Island & 15,372 & 15.0 & 37,406 \\
\hline $\begin{array}{l}\text { South } \\
\text { Carolina }\end{array}$ & 9,608 & 15.3 & 23,167 \\
\hline South Dakota & 9,036 & 13.8 & 22,164 \\
\hline Tennessee & 8,662 & 15.2 & 25,053 \\
\hline Texas & 8,602 & 15.3 & 28,880 \\
\hline Utah & 6,546 & 23.2 & 7,571 \\
\hline Vermont & 18,066 & 10.6 & 39,518 \\
\hline Virginia & 10,955 & 14.2 & 21,016 \\
\hline Washington & 10,305 & 18.0 & 34,412 \\
\hline West Virginia & 11,371 & 14.0 & 11,721 \\
\hline Wisconsin & 11,345 & 14.9 & 29,777 \\
\hline Wyoming & 15,903 & 12.4 & 18,021 \\
\hline
\end{tabular}

Table 12.5 State Education Statistics-2013-16 


\section{I2.C.I - Importance of Education}

Education is one of the most important factors underlying the promotion of sustainable communities. Higher levels of education have been associated with a wide range of individual, social and economic lifelong benefits; similarly, communities and taxpayers derive a multitude of benefits when citizens have access to education. In fact, most research concerning resilience and sustainable communities identifies education as a pivotal variable for the simultaneous achievement of economic vitality, a civil society, healthy families, low rates of crime and environmentally sensitive practices. The following facts about education translate into individual and societal benefits: $:_{-}^{17}$

- There is a correlation between levels of education and higher earnings for all racial/ethnic groups, and for both men and women.

- Higher levels of education correspond to lower levels of unemployment and poverty, so in addition to contributing more to tax revenues than others do, adults with higher levels of education are less likely to depend on social safety-net programs, generating decreased demand on public budgets.

- Higher levels of education are associated with lower smoking rates, more positive perceptions of personal health, and lower incarceration rates.

- Higher levels of education are correlated with higher levels of civic participation, including volunteer work, voting, and blood donation. 


\section{I2.C.II - Politics and Education}

While the benefits of education are recognized among most segments of society, education policy, like criminal justice policy, has historically been a battleground for different value systems and ideologies. For example, supporters of the religious right and many conservatives have objected to content taught in public schools, from Darwinian evolution theory in biology to the contemporary emphasis on contributions by minority groups to American history and the writing of women in literature. In response, many highly religious conservatives have withdrawn their children from public schools and engage in homeschooling. In some states, these people use a voucher system to enroll their children in religious schools. Supporters of a voucher system argue that such educational systems provide parents more freedom in deciding what schools their child may attend. This choice to parents comes in the form of a voucher, which has depending on the state - a predetermined amount of money to cover student tuition. However, while many conservatives strongly support such systems, liberal and pro-public education groups, such as the National Education Association (NEA), strongly oppose voucher systems for the following reasons:

Teachers, parents, and the general public have long opposed private school tuition vouchers - especially when funds for vouchers compete with funds for overall improvements in America's public schools. The NEA and its affiliates have been leaders in the fight to improve public schools - and oppose alternatives that divert attention, energy, and resources from efforts to reduce class size, enhance teacher quality, and provide every student with books, computers, and safe and orderly schools. ${ }_{-}^{18}$ 
The next step for those opposed to public schools, for a variety of reasons, has been the establishment of a large number of charter schools as alternatives to traditional public schools in 46 states (6 states have no charter school legislation). Charter schools are public schools that can operate with fewer regulations than apply to traditional public schools. The "charter" that establishes such schools is a contract detailing the desired curriculum, mission, goals, and methods used to assess achievement of educational outcomes and student performance. Each state has different legislation concerning the length of time charters are granted, but most are issued for 3-5 years with the possibility of renewal. Charter schools are accountable to either a local school district or a state agency. Charter schools are granted increased autonomy in return for enhanced accountability. The main reasons often given for charter schools are: they can serve a special population, they allow for more innovative teaching methods, and they can specialize in certain areas of academic study. ${ }_{-}^{19}$ Similar to the use of voucher systems, pro-public school organizations and advocates such as the NEA have been opposed to the creation of charter schools for a variety of reasons, including concerns about the quality of instructional facilities, the content of the curriculum and the credentials of teachers. The NEA proposes the following alternative to the use of charter schools:

NEA believes that what's really needed to improve student achievement are programs and resources - smaller class sizes, quality pre-K and after-school programs, expanded professional development for educators, safe and modern schools - that will result in great public schools for all children. 20

Another area where there has been much political conflict in public education concerns the issue of busing children to achieve racially and ethnically integrated schools. The 
desegregation of public facilities preceded the desegregation of public schools. In 1896, the U.S. Supreme Court ruled in Plessy v. Ferguson that "separate but equal" public facilities provided for in public policy were consistent with the equal protection clause of the 14th Amendment to the U.S. Constitution. The Supreme Court's ruling meant that racial segregation was acceptable so long as the services provided by government for different races were basically comparable. In this case, Homer Plessy, who was 7/8 white and 1/8 African American, lost his lawsuit to be treated equally based on his attempt to sit in a "whites-only" railroad passenger car instead of a racially segregated car provided for blacks. This decision wasn't overturned until nearly 60 years later in 1954 when the U.S. Supreme Court, in the landmark case Brown v Board of Education, ruled that separate schools for blacks and whites were unconstitutional. In upholding the decision in 1955 in Brown $v$ Board of Education II, the Court held that:

...the problems identified in Brown required varied local solutions. Chief Justice Warren conferred much responsibility on local school authorities and the courts, which originally heard school segregation cases. They were to implement the principles which the Supreme Court embraced in its first Brown decision. Warren urged localities to act on the new principles promptly and to move toward full compliance with them "with all deliberate speed."

Since this time, many school districts and subsequent state and local government court decisions supported the busing of racial and ethnic minorities to schools that were predominantly white. In 1971, the U.S. Supreme Court ruled in Swann v. Charlotte-Mecklenberg Board of Education that local education districts across the nation use mandatory busing as a policy to achieve racial integration in their schools. This decision led to the development of court-supervised 
desegregation busing plans in cities during the 1970s and 1980s. Much turmoil and conflict occurred among contending groups in many U.S. communities. Conflict was intense in many locations in the South and North alike, including Boston, Massachusetts, where police had to escort African American schoolchildren bused into white neighborhoods in 1974. There are still those who ardently support or strongly oppose busing for racial integration in many communities today, and some observers continue to note the extreme inequality that continues among school districts. For example, Jonathan Kozol, author of many books detailing inequality in America's schools (including Savage Inequalities), has argued:

Many Americans who live far from our major cities and who have no firsthand knowledge of the realities to be found in urban public schools seem to have the rather vague and general impression that the great extremes of racial isolation that were matters of grave national significance some thirty-five or forty years ago have gradually but steadily diminished in more recent years. The truth, unhappily, is that the trend, for well over a decade now, has been precisely the reverse. Schools that were already deeply segregated twenty-five or thirty years ago are no less segregated now, while thousands of other schools around the country that had been integrated either voluntarily or by the force of law have since been rapidly re-segregating. ${ }_{-}^{22}$

\section{President Johnson's 1965 Elementary and Secondary} Education Act (ESEA) represents the first major effort made by the federal government to provide aid to low income and disadvantaged children through the distribution of federal funds to state and local educational systems. The assumption underlying ESEA was that children from low-income homes required more educational resources and services than children from higher-income households. As part of the ESEA, Title I allocated billions of federal dollars every year to schools 
with high concentrations of low-income children. Several programs emerged from ESEA over time, including the Head Start program. This is a pre-school program for young disadvantaged children with the stated purpose of getting these children ready for the rigors of the first grade. However, as Hess notes: "Over time, critics of both the left and right expressed concerns about the failure of Title I to improve achievement visibly among low-income students. ${ }_{-}^{23}$ The slowly emerging consensus among liberals, conservatives, Democrats, and Republicans alike was that ESEA, as well as state and local education efforts of similar design and purpose, were not working for all children. This consensus led in time to the passage of the No Child Left Behind(NCLB) act in 2002.

The Every Student Succeeds Act (ESSA) replaced NCLB in 2018. President Obama signed the bipartisan ESSA into law on December 10, 2015. Below are a few of the key provisions of the law according to the Department of Education: ${ }_{-}^{24}$

- Advances equity by upholding critical protections for America's disadvantaged and high-need students.

- Requires-for the first time-that all students in America be taught to high academic standards that will prepare them to succeed in college and careers.

- Ensures that vital information is provided to educators, families, students, and communities through annual statewide assessments that measure students' progress toward those high standards.

- Helps to support and grow local innovations-including evidence-based and place-based interventions developed by local leaders and educators.

- Sustains and expands this administration's historic investments in increasing access to high-quality preschool.

- Maintains an expectation that there will be accountability and action to effect positive change in our lowest-performing schools, where groups of students are not making progress, 
and where graduation rates are low over extended periods of time.

\section{I2.C.III - Higher Education}

So far we have discussed the role of the states and their local governments in the K-12 education arena. States are also heavily involved in providing higher education opportunities to their citizens - such as community colleges, trade schools, four-year colleges, and research universities - as well. There are 4,236 higher education institutions in the United States, with 1,720 public 4-year schools, 1,086 2- year public schools, 1,896 private 4 -year schools, and 620 private 2 -year schools. ${ }^{25}$ Many states have coordinating boards that set out a broad policy for public universities. For example, the State of Washington has the Washington Higher Education Coordinating Board, a state agency governed by a 10-member citizen board. The charge of the board is to represent the "broad public interest" in higher education and to review and approve all degree programs at the state's public four-year universities and colleges. Also common in many states, Washington also has a Board for Community and Technical Colleges that plays a similar role with respect to the state's 2-year community and technical colleges. Some states also have a chief executive officer for the entire state public university system who serves as the leader of the higher education board.

In most states, there have been three major issues facing public higher education in recent years: access, affordability, and accountability. As Heller has argued, "With more than 80 percent of all undergraduates in the United States attending public colleges and universities, very few discussions on higher education take place without one or more of these 
issues being central to the debate. ${ }^{26}$ As Chapter 10 on state and local budgeting describes, state budgets have been severely strained by the increasing costs of providing services while revenue sources have not kept up with the pace of inflation and growing demand. Often public higher education budgets suffer the adverse consequences of constrained revenues as other essential services, such as K-12 education, criminal justice, and health care, are given higher priority.

\section{I2.C.IV - Higher Education Access}

As discussed previously, education is one of the most important factors for the creation of sustainable communities. However, there are grave concerns in most states concerning who has access to public higher education. The more highly educated are less likely to be in poverty, make higher incomes, are more likely to participate in their communities, are more likely to vote in elections, are likely to have higher levels of policy-relevant and civic knowledge, are less likely to be in poverty or unemployed, and have higher levels of life satisfaction (see Tables 12.6 and 12.7). ${ }_{-}^{27}$ As a report by the State Higher Education Executive Officers Association concludes:

No state can prosper with a poorly educated workforce, nor can it continue to prosper if its workforce fails to learn continuously. Most of the workers of the next two decades are already over twenty-five years old. These simple truths require states to assess the knowledge and skills of their adult population and to develop and implement policies that enable current workers, as well as the next generation, to compete more effectively in the global economy. $\underline{28}$ 


\begin{tabular}{lll}
\hline $\begin{array}{l}\text { EDUCATIONAL } \\
\text { ATTAINMENT }\end{array}$ & $\begin{array}{l}\text { UNEMPLOYMENT } \\
\text { RATE }\end{array}$ & $\begin{array}{l}\text { MEDIAN USUAL WEEKLY } \\
\text { EARNINGS }\end{array}$ \\
$\begin{array}{l}\text { Less than high school } \\
\text { graduate }\end{array}$ & $6.5 \%$ & $\$ 520$ \\
$\begin{array}{l}\text { High school graduate or } \\
\text { equivalent }\end{array}$ & $4.6 \%$ & $\$ 712$ \\
Some college & $4.0 \%$ & $\$ 774$ \\
Associates degree & $3.4 \%$ & $\$ 836$ \\
Bachelors degree & $2.5 \%$ & $\$ 1,173$ \\
Master's degree & $2.2 \%$ & $\$ 1,401$ \\
Professional degree & $1.5 \%$ & $\$ 1,836$ \\
Doctoral degree & $1.5 \%$ & $\$ 1,743$ \\
\hline
\end{tabular}

Table 12.6 Educational Attainment Related to Unemployment Rates and Income, 2017

\section{EDUCATIONAL ATTAINMENT}

Less than high school graduate

High school, no college

Some college, no degree

Bachelors degree or higher
POVERTY RATES, AGES 25+

$29 \%$

$14 \%$

$10 \%$

$5 \%$

Table 12.7 Educational Attainment and Poverty Rates, 2014. (TOTAL: $12 \%)$

A comprehensive study conducted by the College Board concerning access to and participation in higher education found the following: ${ }^{29}$

- Among students with the top $10 \%$ SAT scores, virtually all in the top half of the household income level enroll in some form of higher education, yet only 80 percent of those in the lowest fifth of household income continue to pursue higher 
education.

- Participation rates in higher education vary by race and ethnicity, with whites and Asians more likely than African Americans and Hispanics to enroll in higher education institutions.

- After high school graduation, students of parents who attended college are significantly more likely to attend college when compared to those with similar incomes whose parents do not have a college education.

One approach that many states have pursued to increase diversity and enhance the number of underrepresented racial and ethnic minorities in public higher education has been through the use of affirmative action - specifically with respect to admission policies. The idea of affirmative action was first promoted by President Kennedy in 1961 as a policy for redressing historical discrimination in both education and employment. Affirmative action policies have typically required active measures to ensure that African Americans, Hispanics and other racial and ethnic minorities receive the same educational opportunities as whites for admissions, scholarships and financial aid. While affirmative action was originally justified as a temporary remedy until equal opportunities for minorities and non-minorities could be secured, it has been a highly controversial policy from the outset and continues to be controversial, leading to ongoing complaints of "reverse discrimination" among some disadvantaged whites and conservatives in general.

In 1978, Allan Bakke, a white male, had been rejected two years in a row by the University of California-Davis medical school. The medical school in both years had admitted less qualified minority applicants through its affirmative action program (16 out of 100 places were reserved for minority applicants). Bakke sued the medical school on the grounds of reverse discrimination (Regents of the University of 
California v. Bakke). The U.S. Supreme Court ruled by a 5-4 vote that inflexible quota systems in affirmative action were not permissible under the equal protection clause of the 14thAmendment of the constitution; however, in the same decision the Court also upheld the legality of affirmative action in general so long as the remedies applied were carefully tailored to the situation at hand, contributed to the quality of education for all students, and were temporary in nature. Eventually, a citizen's initiative-Proposition 209-passed in 1996, banned all forms of affirmative action in California.

Another important case following the Bakke decision was that of Grutter v. Bollinger heard in 2003. In this case, the U.S. Supreme Court upheld the University of Michigan Law School's affirmative action policy, deciding as it did in the Bakke case that race can be one of several factors considered when making admission decisions because it furthers "...the educational benefits that flow from a diverse student body." However, the Court also ruled that the university's undergraduate admission program, which used a formula that awarded extra points to minority students, was not constitutional and ordered the original trial court to work on an appropriate modification to pass muster on equal treatment. As a consequence of this decision, state public colleges and universities that wish to enhance diversity can consider race and ethnicity in their admissions, but they cannot use strict formulas or quotas to make such decisions on who is admitted to study. 


\section{I2.C.V - Higher Education Affordability}

Closely rated to the access to higher education issue is the question of affordability. Higher levels of tuition obviously restrict access for lower-income students. The National Center for Public Policy and Higher Education's biennial study entitled The National Report Card on Higher Education(2008) documents the increasing problem of higher education affordability for students and parents wishing to attend public colleges and universities. ${ }^{30}$ The report gave 43 states an "F" for affordability, which is an increase in the number of failing states from the previous report issued 2 years prior. Most other states received "Ds," except for California and Utah, which both received "C" grades. According to Patrick Callan, a contributor to the report:

College affordability continues to decline in the United States. Of all the performance categories in the Measuring Up report cards, the state results for affordability are the most dismal. Since our previous edition of Measuring Up, the number of states receiving " $F$ " grades increased from 36 to 43. Even after all financial aid is taken into account, students and their families must devote an increasing share of their income and borrow more to pay for a year of college education at almost all public and private two- and fouryear campuses. Only the wealthiest of American families are exempted from declining college affordability. ${ }_{-}^{31}$

The study also reports that since the 1980s, the annual rate of increase "...in the price of college has far outstripped price increases in other sectors of the economy, even health care. Over these years, median family income increased by $127 \%$; college tuition and fees by $375 \%$. 32 While higher education costs have also increased, the data displayed in Table 12.5 indicate some of the disparity between the states in terms 
of per state support for public higher education and average resident public university tuition. While there are several factors involved in state support of higher education, such as regional and state differences in the cost of doing business (e.g., Alaska and Hawaii) as well as the health and size of the state budget, there are still enormous differences between the states in this area.

Besides having states increase higher education budgets to keep tuition costs down and therefore provide more student access, several reforms have been suggested to enhance the capacity of higher education. These reforms include, but are not limited to:

1. improving the quality of $\mathrm{K}-12$ education, thereby eliminating the need for remedial courses (e.g., writing, foreign language) offered at the university for unprepared students.

2. allowing high school students to take more advanced placement (AP) courses to earn college credit.

3. encouraging more collaboration between community colleges and universities so that the transition from 2-year to 4-year institutions is more efficient.

4. encouraging more students to attend lower-cost community colleges, thereby creating greater efficiencies in the state higher education systems.

5. and improving retention and graduation rates at universities to ensure greater efficiency and student success. 


\section{I2.C.VI - Higher Education Accountability}

In the last decade, there has been a call for increased accountability in higher education by policymakers, business leaders, college administrators, and some voices among the public at large. There is a sense that higher education in the United States has lost its competitive edge internationally, and the higher education community needs to assess what is working well and what things don't deserve to be continued. For example, the State Higher Education Executive Officers (SHEEO) established the National Commission on Accountability in Higher Education, which issued a report arguing the following:

The United States system of higher education led the world in the 20th century by creating wide access to opportunity and a network of exceptional colleges and universities. But these achievements are no longer good enough. The status quo in higher education is unacceptable because: 1) a high school diploma is no longer adequate for work in a competitive economy, supporting a family, or meeting the full responsibilities of citizenship; 2) other countries are beginning to attain and surpass our educational achievements;and 3) the fastest growing segments of our population - minorities and low-income students - have been the least successful in our educational system. We must improve performance. $\stackrel{33}{-}$

Following the momentum of accountability measures and policies in K-12 and state higher education systems, institutions are adopting accountability standards that set minimum learning outcomes for students and require the use of an appropriate assessment process for measuring those outcomes. It is common now for universities and colleges to have specified learning outcomes for the institution at large, 
for individual colleges within the institution, for individual departments within the colleges, and for specific courses. While most states are just beginning to adopt such accountability programs, some states such as Arizona, Florida, North Carolina and the University of Wisconsin system already have well-established accountability reporting procedures in place. ${ }^{34}$

The National Governors Association (NGA) has also weighed in on enhanced accountability systems for higher education. The NGA has taken the position that effective accountability systems should include 5 goals that are very closely attuned to increasing affordability: ${ }_{-}^{35}$

1. increasing the number of high school graduates who go on to college.

2. reducing the number of high school students needing remedial courses in college.

3. increasing retention and 5-year graduation rates.

4. increasing the number of community college transfers to 4-year schools.

5. and increasing the amount of resources spent on instruction as opposed to other uses (such as administration, research, and faculty salaries).

Given the importance of higher education to state economic and social development in a postindustrial, knowledge-based society, it is likely that the issue of higher education accountability will remain an important issue for U.S. state governments for years to come. 


\section{I2.C.VII - Higher Education, Technology and Sustainability}

Advances in technology over the last decade and a half have created new ways of educating that have potentially enormous benefits for higher education's role in the states and their respective communities. Virtual education, distance education, and asynchronous learning offer new forms of course and program delivery, which may well enhance the sustainability of higher education systems (e.g., Oregon State University's Ecampus programs). As Heller has argued, "The impact of Technology cannot be overstated. It is becoming ubiquitous in all aspects of university life: teaching, learning, research, administration, service. ${ }^{36}$ He further identifies various potential benefits of enhanced use of information and communication technology, including: (1) the ability to overcome geographic boundaries and offer courses and programs to place-bound students, such as someone living in an isolated rural community; (2) the opportunity for students to overcome "temporal boundaries," allowing them to take classes when the time is convenient for them, such as after work in the evening; (3) depending on the college or university, distance education courses that can reduce the cost of delivering education (e.g., not needing a physical classroom space reduces infrastructure and energy costs, and the use of computer simulations can reduce the cost of using expensive experiments); (4) a reduction of library costs by the use of electronic versions of materials; (5) and more effective, interesting, stimulating and visually appealing materials, exercises, and simulations that are available through technology. 


\section{I2.D - Transportation}

One very visible service that some citizens take for granted - until a disaster strikes such as the 2007 catastrophic I-35 bridge collapse in Minnesota - is the transportation system, which involves a complicated and extensive system of public and private roads, bridges, tunnels, highways, railroads, subways, light-rail, ferries, airports, bicycle and pedestrian lanes, waterways, and ports. The transportation system is used by millions of individuals, by thousands of businesses and by hundreds of government agencies every day and affects the delivery of numerous services such as health care, education, business transactions, jobs, housing, etc. All levels of government - including the federal, state, county, municipal, and even special districts - are involved in the building and maintenance of the transportation infrastructure. For roads and streets alone, Table 12.7 details who manages the nearly 4 million miles in the U.S. It should be noted, however, that the transportation system is not the same in each state. ${ }_{-}^{37}$ For example, in many states in the East such as Connecticut, Massachusetts and Vermont county governments are not involved in road building and maintenance, which are the prerogative of state and municipal governments. In stark contrast, in other regions of the country such as the West and Midwest and South, county governments are likely to build and maintain more roads than state governments. 


\begin{tabular}{|c|c|c|}
\hline & $\begin{array}{l}\text { RURAL } \\
\text { MILEAGE }\end{array}$ & $\begin{array}{l}\text { URBAN } \\
\text { MILEAGE }\end{array}$ \\
\hline Under state control & 652,522 & 120,033 \\
\hline Under country control & $1,623,786$ & 156,598 \\
\hline Municipal, town, township control & 580,825 & 647,448 \\
\hline $\begin{array}{l}\text { Other jurisdictions (e.g. parks, toll roads, } \\
\text { etc.) }\end{array}$ & 55,792 & 13,331 \\
\hline Under federal control & 120,208 & 3,560 \\
\hline Total miles & $3,033,133$ & 940,970 \\
\hline
\end{tabular}

Table 12.8 Total Road and Street Mileage in the United States

All 50 states have either a department of transportation, roads or highways that is responsible for designing, planning, and operating the streets, highways, transit systems, ports, airports, and railroads under state control to provide for the safe movement of people, goods and services. These statelevel departments also work with and oversee local county government road departments as well, often sharing financial and regulatory responsibilities with local government. In comparison to the U.S. federal government, state and local governments play the largest role in terms of financing and managing the nation's transportation systems. Of the approximately \$416 billion public funds spent on transportation in 2014 at all levels of government, federal funds represented $\$ 100$ billion with $\$ 300$ billion coming from state and local governments. This is about 2.4 percent of gross domestic product. 38

Most federal transportation aid to states is financed through collections made on the federal gasoline tax, which currently is 18.4 cents per gallon. Highway trust fund

However, the U.S. Department of Transportation has documented a steady decline in the fund in 2017 and 2018. . $^{39}$ As a result, states will likely be responsible for an ever-increasing 
share of transportation funding in future years. As the federal government does, the U.S. states also levy gas taxes to fund their transportation services. State gas taxes are levied in various ways, including a flat rate per gallon, a tax similar to a sales tax in that it applies to the cost of the gasoline sold, and in some states, local governments are allowed to levy gasoline taxes in addition to state taxes (e.g., Florida). As federal grant funding for the transportation system declines, states will face many challenges to find additional revenues.

The U.S. Chamber of Commerce has argued that additional funding by the federal government and private sector is necessary to maintain current economic growth:

America has always been a nation on the move. But an aging and crumbling transportation system is not only slowing Americans down, it's reducing productivity, undermining our ability to move products across the country and around the world, and increasing congestion and air pollution. Our transportation system is a tremendous national asset we've built up over generations. It has fueled economic growth, enhanced our competitiveness, and created a lot of good jobs. If well-maintained, it can continue to deliver outstanding benefits to all Americans. ${ }_{-}^{40}$

This situation also has led the National Governors Association to state the following:

The present transportation finance structure does not appear sustainable. Although the public was willing to be taxed to build the national transportation system over the last 50 years, there seems to be less support for the more diffuse benefits of system reconstruction, maintenance, operation, and integration - the financing needs of the future. State and regional proposals to increase gas, sales, and property or other taxes to fund transportation needs may draw less public support as well. ${ }_{-}^{41}$ 
Although increased state and local financing of the transportation system will be needed in the future, there will be competition for resources from such services as education, criminal justice, health care, and a host of other services provided by state and local governments. This situation has led some groups, such as the National Governors Association, the U.S. Chamber of Commerce, and the Government Accountability Office to advocate some new approaches, including the use of toll roads and bridges, road-pricing strategies such as paying a premium to drive in less congested lanes or locations, the increased use of debt financing, and new strategies to reduce the growth of travel demand or even increased use of mass transit systems, especially in metropolitan areas. These last two strategies - reducing travel demand and mass transit - have been advocated by organizations and policy-makers interested in smart growth and sustainable transportation systems.

\section{I2.D.I - Sustainable Transportation Systems}

The Government Accountability Office (GAO) recently convened a group of transportation experts to provide policy guidance on how to build a more sustainable transportation system. .42 Their report concluded that the present system of transportation finance would be adequate to maintain present conditions and to fund some growth over the next 15 years, but that traffic congestion levels could not be reduced with the current transportation finance system. In addition, the report raised other concerns about the current transportation system that is heavily reliant on the use of cars and trucks, including environmental degradation (loss of habitat and wetlands, water and air pollution, energy use, etc.), social equity (transportation access, especially for the growing 
retiree population), and quality of life issues such as sense of community and the development of cohesive, inclusive, diverse and resilient local communities.

The GAO study, as well as the National Governors Association, recommended a host of funding mechanisms and a rethinking of how taxes are collected for the support of transportation services. ${ }^{43}$ For example, one problem with the current system "that taxing fuel consumption, rather than street and highway use, disconnects the price travelers pay for using the transportation system from the actual cost of providing the capacity they use...As a result, efficient use of the system is not rewarded, and inefficient use is not penalized, precipitating a variety of adverse productivity, environmental, and community impacts." ${ }_{-}$It follows that a tax on-road use rather than a tax on fuel consumption would constitute a more equitable system that properly rewards conservation and preservation of the environment.

Other sustainability-oriented reforms could include congestion pricing, a practice used in cities abroad which tries to influence driver behavior by charging drivers higher fees to use public roads during peak congestion hours. An example of this approach can be found in London where drivers of private vehicles must pay 5 pounds (about $\$ 10$ dollars) to drive in London's central city between 7:00 a.m. and 6.30 p.m., Monday through Friday, excluding holidays. This sanction has been successful in discouraging private car traffic and congestion in the inner city by taxing drivers. The GAO and NGA also suggest the increased use of tolls to finance road and bridge maintenance and improvements as well as other types of user fees. They also call for more public-private partnerships in transportation to reduce costs and leverage resources. 45

Many advocates of sustainable transportation system suggest a comprehensive paradigm shift in how local communities think about transportation. For example, these advocates suggest that walking and the use of bicycles - 
where feasible - will greatly reduce costs, pollution and congestion while promoting public health and wellness among citizens. It follows that planning for bike lanes and paths is important, along with the development of urban "hubs" that have commercial space for jobs and stores and restaurants located nearby to high-density residential areas to encourage walking and biking. One community that has encouraged this approach to urban planning would be Davis, California where residents voted to eliminate school bus transportation to encourage children to walk or bike to school. The community explicitly included bike and walking plans into the development of new neighborhoods. Davis is relatively small in terms of population at approximately 64,000 people. Portland, Oregon serves as an example of a larger city of over half a million people committed to providing for pedestrians and bikers. Portland has a bicycle network that connects most parts of the city. Additionally, 60 percent of Portland's downtown police officers ride bikes as their principal means of transportation.

Other modes of urban transportation considered sustainable in terms of less pollution, less congestion and perhaps more feasibility for those people with longer commutes are light rail and/or metro elevated rail and subway systems. The Metrorail and Metrobus transit services in Washington, D.C., Maryland and Virginia, the Bay Area Rapid Transit District (BART) in the San Francisco-Oakland metropolitan area, the New York Subway system, and Chicago's Metra Railroad and integrated bus system all provide relatively cheap, rapid and reliable service for millions of citizens every day. In addition, some cities - most notably Portland, Oregon, Salt Lake City, Utah and Seattle, Washington - have been building light-rail systems similar to what an American tourist might find in many European cities. Metropolitan Area Express (i.e., "MAX") is integrated with "Trimet" public bus services that provide mass transit to most 
of the three-country Portland metropolitan area. While there are some opponents of adopting such systems due to initial construction and operating costs, as well as by the urban neighborhoods that might be affected or displaced due to the location of lines, light rail and other urban rail systems do offer a sustainable alternative to congestion and the automobilebased urban society.

\section{I2.E - Emergency Management}

Emergency management is the process of how governments prepare to protect citizens from perceived threats, and how they seek to prevent, respond to, and recover from natural and man-made disasters. These threats to public health and safety can include natural disasters, terrorist actions, political crises, and public health emergencies. Preparedness planning focuses on events beyond a minimum calculated probability that could have potentially catastrophic results for a community. ${ }_{-}^{46}$ Government preparedness efforts embody collective security ideals achieved by unifying local governments and relevant state and federal agencies to thoughtfully prepare for potential emergencies.

Because different emergencies require different responses, decisions must be made about which particular risks to prioritize. State and local agencies often prepare for the catastrophes which are most feared rather than those that are more probable. $\stackrel{47}{-}$ Often the potential depth of a catastrophe guides collective pre-emptive actions, regardless of how remote the likelihood of occurrence. Government emergency planners from federal, state and local governments work to determine which potential disasters could be lessened 
by the institutional response, and they make subjective consensus judgments based on a combination of experience, specialized training, and political agenda-setting influences. Emergency management is a way of anticipating surprises, coordinating plans for collective action, educating the public on steps they can take to promote preparedness and resilience while calming public fears.

Planning for emergency management collectivizes individual risk instead of securing the population at large. ${ }_{-18}$ Emergency management can be examined by the protection of individuals and groups, as well as by the preservation of critical infrastructures. Government institutions help vulnerable communities during a crisis because of a collective dependence on infrastructure, such as health care, communication, and transportation systems. In large part, emergency management is the process of formalizing an institutional response to a wide array of crises.

\section{I2.E.I - Emergency Management Strategies}

Emergency management prepares communities to maintain order during a catastrophe, regardless of how likely that crisis is to happen. Emergency preparedness differs from risk avoidance because it is a strategy of how to respond after a major event rather than how to avoid contingent harm. . $_{-}$ External, largely unpredicted danger is then the basic premise of emergency management. ${ }^{50}$ Because major emergencies affecting large numbers of people can range widely from political to environmental events, diverse strategies are required to deal with potential crises. Establishing an emergency plan serves to coordinate response efforts and assists with procuring relief resources from outside the area immediately affected by the disaster. 
Emergency management systems are carried out by local, state and federal level government agencies. Professional emergency responders include over 30,000 local fire departments and 18,000 local police departments that act in conjunction with 30,000 local government agencies and 3,031 county governments. To help coordinate the efforts of all of these actors, the U.S. employs two major institutional response strategies: the National Response Plan (NPR) and the National Incident Management System (NIMS). These federally-instigated management systems rely heavily on state and local response during an emergency. ${ }_{-}^{51}$ These complex inter-governmental relationships are established and maintained to collect, evaluate, and disseminate emergency management information and coordinate relief efforts in the case of mobilization during a disaster.

Emergency simulation training is used extensively in all levels of government to expose institutional vulnerabilities and strengthen response capabilities. By engaging in a staged crisis, first responder and emergency management administrative personnel learn to execute efficient decisionmaking strategies and prioritize multiple sub-crises. Government agencies simulate different scenarios periodically to improve their communication, increase their speed of response, and enhance their ability to limit the scope of various threats.

Immediately after an emergency management event has occurred, government agencies utilize community networks to foster efficient response efforts. Strategies to maximize social capital (mutual sentiments of concern and capacity for effective collection action) within communities and fortify regional networks of information sharing and trust do indeed increase the sense of collective efficacy among community residents. .52 In order to reinforce social capital, technology is needed to connect professional emergency responders to civilians. Strategies to unite these often-disparate groups 
include the Internet and mobile communication devices such as cell phones and PDA's. Reverse 911 texts and calls from emergency managers to residents help disseminate critical information needed by citizens in order to be helpful in disaster recovery. Cellular telephone and other portable wireless devices need to be integrated in order to serve as an uninterrupted channel of high level of communication during a crisis. Access, affordability, and training for various webbased interfaces are key elements of effective utilization of response technology. Improved networks of communication allow civilians to help each other and aid in more effective emergency response. $\stackrel{53}{-}$

Utilizing technological innovations and community response networks also connect government efforts with many non-governmental, community-based organizations. Key emergency management volunteer organizations include the American Red Cross, Doctors without Borders, and the Voluntary Organizations Active in Disasters. These organizations serve a critical role in disseminating services and resources to citizens in times of dire need, simply because public trust can be higher with non-governmental organizations than with governmental agencies in some circumstances. The perceived objectivity and noble motivations of these groups allow them to gain greater penetration within some local social networks.

\section{I2.E.II - Political Crisis Preparedness}

An important facet of emergency management is civil defense, which is relying on military mobilization (National Guard) to maintain political peace and public order and to protect human life. $\underset{-}{-}$ To prepare for wide-scale attacks involving either conventional weapons or nuclear or biological 
weapons, state and local governments depend on the ability of government acting collectively to deploy appropriate military forces immediately. Civil defense aims to protect the population against war and terrorism, and minimize the devastating impacts of either form of man-made disaster.

As a result of the September 11, 2001 attacks on the power centers of U.S. government, the Department of Homeland Security (DHS) was created to bolster the nation's domestic security efforts. DHS utilized an 'all-hazards' approach to enhance emergency management capabilities across the country. Preparedness in this context is the "measurable relation of capabilities to vulnerabilities, given a selected range of threats. ${ }_{-}$- DHS examines the relative likelihood for a crisis, as compared to other government efforts, which are guided by the greatest fear and not the greatest probability. Agencies such as DHS have changed the expectations of Americans regarding government response to a political crisis. By centralizing emergency management planning efforts, firstresponder agencies and major political leaders can strengthen their efforts at cooperation and collaboration.

\section{I2.E.III - Natural Disaster Preparedness}

Natural disasters are unplanned geographical and environmental events affecting human populations; natural disasters include earthquakes, floods, hurricanes, tornadoes, fires and wildfires, volcanic eruptions, tidal waves (tsunami) and droughts. Natural disasters are managed both through preventative measures and pre-planned recovery efforts. The effect of floods can be mitigated through levees, fires may be prevented through forest management, and earthquake damage can be reduced by building codes. However, not all emergencies can be prevented or fully anticipated as to scope 
and scale of damage and harm to humans, and as a result, proper reactive actions need to be planned in anticipation of a possible engagement in the case of a disaster.

At the growing interface between human populations and vulnerable landscapes is the greater probability that extreme natural events will affect life and property. For example, as the U.S. population grows and moves outside of its urban boundaries, more people are living within floodplains, in the midst of dense forests, and out in high desert areas prone to seasonal fires. As communities expand into these potentially more volatile areas, extreme natural events will create a greater impact.

Preparation for natural disasters in many ways mimics strategies of civil defense. While both efforts rely on the anticipatory mobilization in the event of a possible catastrophe, the governing structures for the two types of emergency management situations have differed traditionally. Civil defense relies on a hierarchical command structure, but natural disaster management utilizes a decentralized system within many levels of the government. 56 The creation of the Federal Emergency Management Agency (FEMA) in 1979 was a result of combining these previously disparate management strategies. FEMA consolidated "federal emergency management and civil defense functions under the rubric of 'all-hazards planning., ${ }_{-}^{57}$ Combining federal strategies and local efforts to manage natural disasters led to new collaborations and funding opportunities for emergency management personnel at all levels of government. Despite the efforts of FEMA officials, tensions exist between civil defense and natural disaster planning largely because of the disparity in the required scale of government response. 


\section{I2.E.IV - Health Emergency Preparedness}

Public health preparedness is a wide-ranging process intended to mitigate the effects of bioterrorism, infectious disease outbreaks, and attacks upon citizens. Public health crises may also entail shortages in food, water, medicine, and medical staff. Health preparedness involves many federal, state and local agencies dedicated to protecting human health in both normal times and times of crisis. 


\begin{tabular}{|c|c|c|}
\hline STATE & $\begin{array}{l}\text { EMERGENCY MANAGEMENT } \\
\text { ORGANIZATION }\end{array}$ & $\begin{array}{l}\text { HOMELAND SECURITY } \\
\text { ORGANIZATION }\end{array}$ \\
\hline Alabama & $\begin{array}{l}\text { Dept. of Emergency } \\
\text { Management }\end{array}$ & Homeland Security Dept. \\
\hline Alaska & $\begin{array}{l}\text { Adjutant General/Military } \\
\text { Affairs }\end{array}$ & $\begin{array}{l}\text { Adjutant General/Military } \\
\text { Affairs }\end{array}$ \\
\hline Arizona & Governor's Office & Governor's Office \\
\hline Arkansas & $\begin{array}{l}\text { Dept. of Emergency } \\
\text { Management }\end{array}$ & Emergency Management \\
\hline California & Governor's Office & Governor's Office \\
\hline Colorado & Dept. of Local Affairs & Public Safety \\
\hline Connecticut & $\begin{array}{l}\text { Emergency Management/ } \\
\text { Homeland Security }\end{array}$ & $\begin{array}{l}\text { Emergency Management/ } \\
\text { Homeland Security }\end{array}$ \\
\hline Delaware & $\begin{array}{l}\text { Dept. of Safety \& Homeland } \\
\text { Security }\end{array}$ & $\begin{array}{l}\text { Dept. of Safety \& Homeland } \\
\text { Security }\end{array}$ \\
\hline Florida & Dept. of Community Affairs & $\begin{array}{l}\text { Law Enforcement Dept. } \\
\text { Comm. }\end{array}$ \\
\hline Georgia & Governor's Office & Governor's Office \\
\hline Hawaii & Dept. of Defense & Department of Defense \\
\hline Idaho & $\begin{array}{l}\text { Adjutant General/Military } \\
\text { Affairs }\end{array}$ & $\begin{array}{l}\text { Adjutant General/Military } \\
\text { Affairs }\end{array}$ \\
\hline Illinois & Governor's Office & Emergency Management \\
\hline Indiana & Dept. of Homeland Security & Homeland Security Dept. \\
\hline Iowa & Dept. of Public Defense & Dept. of Public Defense \\
\hline Kansas & $\begin{array}{l}\text { Adjutant General/Military } \\
\text { Dept. }\end{array}$ & Emergency Management \\
\hline Kentucky & $\begin{array}{l}\text { Adjutant General/Military } \\
\text { Dept. }\end{array}$ & Governor's Office \\
\hline Louisiana & Governor's Office & Governor's Office \\
\hline Maine & $\begin{array}{l}\text { Adjutant General/Military } \\
\text { Dept. }\end{array}$ & $\begin{array}{l}\text { Adjutant General/Military } \\
\text { Dept. }\end{array}$ \\
\hline Maryland & $\begin{array}{l}\text { Adjutant General/Military } \\
\text { Dept. }\end{array}$ & Governor's Office \\
\hline Massachusetts & Public Safety & Public Safety \\
\hline Michigan & State Police & Emergency Management \\
\hline Minnesota & Public Safety & Public Safety \\
\hline
\end{tabular}




\begin{tabular}{|c|c|c|}
\hline Mississippi & Governor's Office & Public Safety \\
\hline Missouri & $\begin{array}{l}\text { Adjutant General/Military } \\
\text { Dept. }\end{array}$ & Public Safety \\
\hline Montana & $\begin{array}{l}\text { Adjutant General/Military } \\
\text { Dept. }\end{array}$ & Emergency Management \\
\hline Nebraska & $\begin{array}{l}\text { Adjutant General/Military } \\
\text { Dept. }\end{array}$ & Emergency Management \\
\hline Nevada & Public Safety & Public Safety \\
\hline $\begin{array}{l}\text { New } \\
\text { Hampshire }\end{array}$ & Public Safety & Public Safety \\
\hline New Jersey & State Police & Attorney General \\
\hline New Mexico & Public Safety & Governor's Office \\
\hline New York & Public Safety & Governor's Office \\
\hline $\begin{array}{l}\text { North } \\
\text { Carolina }\end{array}$ & Public Safety & Emergency Management \\
\hline North Dakota & $\begin{array}{l}\text { Adjutant General/Military } \\
\text { Dept. }\end{array}$ & $\begin{array}{l}\text { Adjutant General/Military } \\
\text { Dept. }\end{array}$ \\
\hline Ohio & Public Safety & Public Safety \\
\hline Oklahoma & Governor's Office & Public Safety \\
\hline Oregon & Governor's Office & Homeland Security Dept. \\
\hline Pennsylvania & Governor's Office & Governor's Office \\
\hline Rhode Island & $\begin{array}{l}\text { Adjutant General/Military } \\
\text { Dept. }\end{array}$ & Emergency Management \\
\hline $\begin{array}{l}\text { South } \\
\text { Carolina }\end{array}$ & $\begin{array}{l}\text { Adjutant General/Military } \\
\text { Dept. }\end{array}$ & State Police \\
\hline South Dakota & Public Safety & Public Safety \\
\hline Tennessee & $\begin{array}{l}\text { Adjutant General/Military } \\
\text { Dept. }\end{array}$ & Governor's Office \\
\hline Texas & Governor's Office & Governor's Office \\
\hline Utah & Public Safety & Homeland Security Dept. \\
\hline Vermont & Public Safety & Public Safety \\
\hline Virginia & Public Safety & Governor's Office \\
\hline Washington & $\begin{array}{l}\text { Adjutant General/Military } \\
\text { Dept. }\end{array}$ & $\begin{array}{l}\text { Adjutant General/Military } \\
\text { Dept. }\end{array}$ \\
\hline West Virginia & Military Affairs \& Public Safety & Governor's Office \\
\hline
\end{tabular}

Chapter 12: Traditional and Visible Services: Criminal Justice, Education, Transportation and Emergency Management | 551 


\begin{tabular}{lll} 
Wisconsin & $\begin{array}{l}\text { Adjutant General/Military } \\
\text { Dept. }\end{array}$ & $\begin{array}{l}\text { Adjutant General Military } \\
\text { Dept. }\end{array}$ \\
Wyoming & Dept. of Homeland Security & $\begin{array}{l}\text { Dept. of Homeland } \\
\text { Security }\end{array}$ \\
\hline
\end{tabular}

Table 12.9 State Emergency Management and Homeland Security

Health care providers and hospitals, particularly, can be challenged during an emergency because of limited resources to expand pre-existing capacity. Health care systems may be limited in space, staffing, and by competing priorities within each regional system. Innovative solutions are based on collaborations between public health systems and emergency management response teams, such as local police and fire departments. 58

The threat against the nation's biosecurity is a highly regarded concern within the public health professions. Biosecurity efforts aim to prevent the development and deployment of biological weapons and germ warfare using pathogens such as bacteria or a virus to attack human populations. After the Cold War, access to biological agents increased greatly due to reduced safeguards and changes in the geopolitical balance of power. Genetic technology has also improved, creating greater access to some of the most virulent weapons. To ensure biosecurity, U.S. public health professionals require strong communication systems with emergency management responders, immunized and trained staff, as well as the ability to interrupt likely patterns of attacks accurately. ${ }^{59}$ After the events of September 11, 2001, the Council of State and Territorial Epidemiologists (CSTE) was created to bolster state preparedness programs. The budgets of state governments have been adjusted to reflect greater preparedness efforts in compliance with federal guidelines from the Department of Homeland Security. While greater investment in this area is clearly in evidence, there is no way 
of knowing with certainty whether current preparations for emergency management are adequate. 60

\section{I2.E.V - Sustainability in Preparedness Efforts}

Fostering sustainability within emergency management involves supporting the governments' ability to respond to a variety of crises. To maintain effective response, organizational and communication infrastructure needs to be supported through adequate funding, targeted training, and ongoing agency collaborations. Coordination between locallybased public health, law enforcement, and emergency response teams can also foster a strong response to a crisis. ${ }_{-} 1$ Planned preparedness activities and periodic "tabletop exercises" simulating extreme events increase response capacity through the interagency collaboration they generate.

Mobilizing communities during a crisis effectively involves weaving together the social fabric to create an "emergency community." Reinforcing existing infrastructures within communities, such as schools, church spaces, and community centers establishes a base for disseminating information and distributing aid. Emergency management involves the process of preparing for a variety of threats, including the devastation resulting from natural disasters, environmental crises and the many weapons which might be used in political warfare carried out through terrorist attacks. This relatively new field of government is based on the fear of a catastrophic event. Because the nature of such emergencies is that they are unpredictable, perfect knowledge to guide government intervention does not exist. Even if we were able to forecast future extreme events with far greater precision, there is no consensus as to which risks should be prioritized. 62 


\section{Traditional and Visible Services: What Can I}

do?

Is your college or university a participant in the Association for the Advancement of Sustainability for Higher Education (AASHE)? If not, take steps to organize your campus for participation. If yes, then play a leadership role in sustainability on your campus and apply for a Student Leadership Award with the Association. For more information go to: http://www.aashe.org/

As mentioned in the text, some states have "three strikes" laws or other legislation that increase the number of individuals in state and local jails and prisons. The movement to be "tough on crime" with more frequent and longer jails sentences for repeat offenders appeals to many Americans. However, these laws sometimes include nonviolent crimes as the third strike (e.g., shoplifting and drug possession) leading to increased costs of incarceration at the expense of other state programs and services (e.g., education, social services, etc.). What do you think about this issue? Contact your state or local law enforcement officials and ask them what they think about this issue at: https://en.wikipedia.org/wiki/ List of United States state and local law enforcemen t_agencies

- How close to capacity are the facilities?

- What offenses receive jail time? 
- Has there been recent legislation that is increasing the number of individuals incarcerated? If so, how much will it cost?

- What do local officials suggest as effective ways to maintain the sustainability of the system? Education programs? Tougher laws?

\section{I2.F - Conclusion}

This chapter has reviewed some of the most visible services provided by state and local government, and some of the largest items found in state budgets and in county and city budgets. For example, 21.4 percent of the average state operating budget in 2006 went to K-12, followed by 10.4 percent for higher education, 8.1 percent for transportation, and 3.4 percent for corrections. All of the services discussed are central to the building and maintenance of sustainable states and sustainable local communities within those states. Lower crime rates and less recidivism, higher levels of educational attainment, reliable, safe and energy-efficient transportation systems, and efficacious and responsive emergency services are pivotal for resilient states and communities as they adapt to the many changes coming their way in modern America. As we noted throughout this chapter, many of these vital services currently are not adequately funded or managed properly, potentially limiting how public 
officials adapt to changes as well as the long-term viability of each and every state and local government. Given these circumstances, the "laboratories of democracy" provided by the American federal system will have to provide the framework for the creation of best practices and innovations in funding schemes which will give rise to the essential services to be disseminated across state and local governments in the U.S. Just as biodiversity is an asset to ecosystem sustainability and resilience, so should the diversity of approaches taken to solve common problems prove to be of lasting value in the pursuit of sustainability in American state and local government.

\section{Terms}

At-risk youth

Brown v. Board of Education

Brown v. Board of Education II

Charter schools

Community policing

Elementary and Secondary Education Act (ESEA)

Every Student Succeeds Act (ESSA)

Grutter v. Bollinger

Head Start Program

Law and order approach (criminal justice)

No Child Left Behind Act (NCLB)

Pivotal variable

Plessy v. Ferguson

Recidivism

Regents of the University of California v. Bakke

Swann v. Charlotte-Mecklenberg Board of Education 
Three strikes laws

Unfunded mandates

User fees

Voucher system

\section{Discussion Questions}

1. How do state and local criminal justice policies affect community sustainability? What types of programs have been suggested for enhancing sustainability?

2. What responsibilities do federal, state and local governments have in K-12 and higher education? How can education promote sustainable communities?

3. Discuss the importance of state and local governments in the transportation sector. How can transportation policy affect community sustainability?

4. What is the role of state and local governments in providing emergency management services? How do these services affect sustainability? 


\section{Notes}

1. F. Hess, "No Child Left Behind: Trends and Issues." In The Book of the States, 2006 (Lexington, Kentucky: The Council of State Governments, 2006).

2. R. Clark, Crime in America (New York:Simon and Schuster, 1970).

3. E. Banfield, The Unheavenly City Revisited (Boston: Little, Brown, 1974).

4. S.A. Shah and L.H. Roth, "Biological and Psychophysiological Factors in Criminality." In Daniel Glaser, ed., Handbook of Criminology (Chicago, ILL: Rand McNally, 1974).

5. J.Q. Wilson, Thinking About Crime (New York: Random House, 1985).

6. S.A. Shah and L.H. Roth, 1974, op. cit., (see reference 4).

7. Bureau of Justice Statistics, "U.S. Correctional Population Declined for the Ninth Consecutive Year," (April 26, 2016). URL: https://www.bjs.gov/content/pub/press/cpus16pr.cfm

8. U.S. Department of Justice, "Criminal Victimization, 2006," Bureau of Justice Statistics Fact Sheet, December 2007 (Washington, D.C.:U.S. Department of Education, 2007), p. 1.

9. A. Roberts, Critical Issues in Crime and Justice (Thousand Oaks, CA: Sage, 1994).

10. The Council of State Legislators, Book of the States, 2006 (Lexington, Kentucky: The Council of State Governments, 2018).

11. U.S. Department of Justice, "Total Prison Populations"

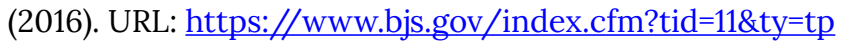

12. A. Roberts, 1994, op. cit. (see reference 9).

H. Ruth and K. Reitz, The Challenge of Crime: Rethinking Our Response (Cambridge, MA: Harvard University Press, 2003). 
13. U. Bondeson, Alternatives to Imprisonment: Intentions and Reality (Boulder, CO: Westview Press, 1994).

14. H. Ruth and K. Reitz, 2003, op. cit. (see reference 12), pp. 285, 287.

15. J. Mooradian, Disproportionate Confinement of AfricanAmerican Juvenile Delinquents (New York: LFB Publishers, 2003).

T. O'Neill, Children in Secure Accommodation(London: Jessica Kingsley Publishers, 2001).

16. The Council of State Legislators, 2016, op. cit. (see reference 10).

17. S. Baum and K. Payea, Education Pays: The Benefits of Higher Education for Individuals and Society. URL: www.collegeboard.com.

18. National Education Association, The Educational Case Against Vouchers. URL: http://www.nea.org/vouchers/ index.html

19. U.S. Department of Education. 2000. The State of Charter Schools 2000: Fourth Year Report. Washington DC: U.S. Department of Education.

20. National Education Association. 2006. Charter Schools Show No Gains over Public Schools. URL: http://www.nea.org/ charter/naepstudy.html

21. Oyez Project. 2009. Brown v. Board of Education (II), 349 U.S. 294 (1955). URL: www.oyez.org/cases/

22. Kozol, J. 2005. "Still Unequal: America's Educational Apartheid," Harper's Magazine, 311(1864), September: 41-54.

23. F. Hess, 2006, op. cit. (see reference 1), p. 474.

24. U.S. Department of Education, Every Student Succeeds Act. URL: https://www.ed.gov/essa?src=policy

25. The Council of State Legislators, 2016, op. cit. (see reference 10).

26. D. Heller, The States and Public Higher Education(Baltimore, MD: The John Hopkins Press, 2001).

27. S. Baum and K. Payea, 2005, op. cit. (see reference 17). 
R. Inglehart, Modernization and Postmodernization: Cultural, Economic and Political Change in 43 Societies(Princeton: University of Princeton Press, 1997).

28. P. Lingenfelter and T. Flint. 2003. Adult Learners and State Policy (Denver, CO: State Higher Education Executive Officers, 2003), p. 3.

29. S. Baum and K. Payea, 2005, op. cit. (see reference 17), p. 8.

30. National Center for Public Policy and Higher Education, Measuring Up: The National Report Card on Higher Education (Washington, DC: The National Center for Public Policy and Higher Education, 2008).

31. P. Callan, "Colleges, States Increase Financial Burdens for Students and Families." In Measuring Up: The National Report Card on Higher Education (Washington, DC: The National Center for Public Policy and Higher Education, 2008), p. 19.

32. Ibid.

33. State Higher Education Executive Officers, Accountability for Better Results: A National Imperative for Higher Education. URL: www.sheeo.org

34. Ibid.

35. National Governors Association, Higher Expectations (Washington, DC:National Governors Association, 2002), p. 12.

36. D. Heller, 2001, op. cit. (see reference 31), p. 243.

37. State Higher Education Executive Officers, 2005, op. cit. (see reference 38), pp. 6, 7.

38. Congressional Budget Office, "Spending on Infrastructure and Investment," March 1, 2017. URL: https://www.cbo.gov/publication/52463

39. U.S. Department of Transportation, "Status of Highway Trust Fund," 2018. URL: https://www.fhwa.dot.gov/ highwaytrustfund/

40. National Chamber Foundation, Future Highway and Public TransportationFinance: Phase I: Current Outlook and 
Short-term Solutions (Washington, DC: U.S. Chamber of Commerce, 2005), pp. 2, 3.

41. National Governors Association, State Policy Options for Funding Transportation(Washington, DC: National Governors Association, 2007).

42. Governmental Accountability Office, Transforming Transportation for the 21stCentury, Washington, DC: Governmental Accountability Office, 2007).

43. Ibid.

National Governors Association, 2007, op. cit. (see reference 46).

44. National Governors Association, 2007, op. cit. (see reference 46), p. 2.

45. Ibid.

Governmental Accountability Office, 2007, op. cit. (see reference 47).

46. A. Lakoff, "Social Life of Risk: Preparing for the Next Emergency," Public Culture19 (2007): 247- 271.

47. Ibid, p. 253.

R. Ericson, "Ten Uncertainties of Risk-Management Approaches to Security." Canadian Journal of Criminology and Criminal Justice48 (2006): 345-357.

48. A. Lakoff, 2007, op. cit. (see reference 51), p. 250.

49. R. Ericson, 2006, op. cit (see reference 52), p. 346.

50. S. Collier, A. Lakoff and P. Rabinow, "Biosecurity: Toward an Anthropology of the Contemporary," Anthropology Today20 (2004): 3-7.

51. P. Jaeger, B. Shneiderman and K. Fleischmann, "Community Response Grids: E-government, Social Networks, and Effective Emergency Management," Telecommunications Policy31 (2007): 592-604.

52. Ibid.

53. Ibid.

54. A. Lakoff, 2007, op. cit. (see reference 51).

55. Ibid, p. 267. 
56. Ibid, p. 261.

57. Ibid, p. 262.

58. A. Katz, A. Stati, and K. McKenzie, "Preparing for the Unknown, Responding to the Unknown: Communities and Public Health Preparedness," Health Affairs25 (2006): 946-957.

59. S. Collier, A. Lakoff, and P. Rabinow, 2004, op. cit. (see reference 55 ).

60. Ibid, p. 5.

61. A. Katz, A. Stati, and K. McKenzie, 2006, op. cit. (see reference 63).

62. M. Douglas and A. Wildavsky, Risk and Culture: An Essay on the Selection of Technological and Environmental Dangers (Berkeley, CA.: University of California Press, 1982). 


\section{Glossary}

Adaptive Capacity: The ability of institutions, systems, and individuals to adjust to potential damage, to take advantage of opportunities, or to cope with the consequences

Administrative Law Judges: "Hearings officers" who work within administrative agencies, engaging in regulatory actions that give rise to many disputes (environmental regulations, labor/ management actions under collective bargaining agreements, compensation for damages incurred from state government action on one's property, etc.)

Administrative Rules: Rules and regulations issued by state executive branches

Amenities: Something that conduces one to comfort and convenience; a luxury.

Anthropocentric Concerns: A philosophical perspective that views human needs and interests as of the highest value and importance-contrasting with various biocentric (life-centered) perspectives, which assume that nonhumans are also carriers of value.

At-Risk Youth: Population of children and teenagers who are considered especially vulnerable and engage in activities that might put expose them to far-reaching negative consequences

Baby Boomers: A term used for a person who was born between 1946 and 1964 that makes up approximately 20 percent of the U.S. population.

Balanced Budget: A budget is balanced when governmental expenditures are equivalent to revenues

Bio-Equity: Advocates for equal treatment of individuals in human society and the other elements of the "biosphere"

Block Grants: Broad grants to states for certain 
activities-welfare, child care, education, social services, preventive health care, and health services

Broker Parties: Political parties trying to appeal to the largest number of people, more concerned with gaining votes than with maintaining rigid ideologies, and willing to alter policies in order to gain

Brown v. Board of Education: A landmark case where the court ruled that separate schools for black and white children were unconstitutional

Brown v. Board of Education II: A court decision in 1955 conferring the responsibility on local school authorities and the courts for implementing the principles of integrating public school students as stated in the 1954 Brown v. Board of Education decision

Brundtland Report: The common name for the Our Common Future report created by the United Nations World Commission on Environment and Development (WCED) and published in 1987. The Report is deemed the origin of sustainability and sustainable development, and laid the groundwork for the convening of the 1992 Earth Summit.

Bureaucracy: A governmental organization characterized by adherence to fixed rules, specialization of functions, hierarchy of authority

Bureaucratic Capacity: The ability of government agencies to attract and retain professional to bureaucratic positions that requires public agencies to be relatively well-funded, professional in operation, and effectively organized

Categorical Grants: Congress-appropriated funds for a specific purpose, such as school lunches or for building airports and highways; subject to detailed federal conditions, often on a matching basis

Caucus: A meeting, in particular a meeting of people whose goal is political or organizational change

Certiori: A writ of superior court to call up the records of an inferior court or a body acting in a quasi-judicial capacity 
Charter Schools: Public schools that can operate with fewer regulations that apply to traditional public schools

Checks and Balances: When the three branches of government share power rather than allowing one branch to have substantial power over the others

Citizen Groups: Organized groups advocating for specific public policycivil libertarian approach (criminal justice): ideology emphasizing the rights of individuals accused of crimes and advocating treatment and rehabilitation programs

Civil Service: Refers to government or federal employment

Classical Liberalism: A political philosophy placing high value on individual freedom based on a belief in natural rights that exist independent of government

Clean Air Act: The law defining EPA's responsibilities for protecting and improving the nation's air quality and the stratospheric ozone layer; this legislation authorized the development of comprehensive federal and state regulations to limit emissions from both stationary (industrial) sources and mobile sources; the adoption of this very important legislation occurred at approximately the same time as the National Environmental Policy Act that established the U.S. Environmental Protection Agency (EPA)

Clean Water Act: Based on the Federal Water Pollution Control Act from 1972, the Clean Water Act (CWA)-named in 1977-establishes the basic structure for regulating discharges of pollutants into the waters of the United States and regulating quality standards for surface waters. The CWA made it unlawful to discharge any pollutant from a point source into navigable waters, unless a permit was obtained.

Closed Primary: A primary wherein only persons who are registered members of a political party can vote using the ballot of that political party

Collaborative Governance: The move to share bureaucratic decision-making power with citizens and personnel in the lower reaches of organizational hierarchies, to embrace public-private 
collaborative partnerships, and to reform rule structures and hierarchy for efficiency

Common Law: Is a system of legal principles established on judicial precedents rather than statutory laws; may be codified into a statute or overruled by a statute passed by the government

Community Policing: Movement to connect police with citizens, emphasizing problem-solving methodologies and partnerships, and building policies to identify current and future problems

Competitive Grant: Grant proposal in which the applicant designs a project and a funding agency ranks the proposals to provide grant awards in a competitive process.

Constitutional Convention: The most traditional method to propose a new state constitution or revise an existing constitution, the initiation of which requires a formal call from the legislature, which all 50 state legislatures and the District of Columbia have the ability to do

Constitutional Democracy: A system of government functioning with the belief that government can and should be legally limited in its powers, and that its rightful exercise of authority depends on observing these limitations

Constituency Service: The assistance given to constituents by Members of Congress in non-legislative areas

Cooperative Federalism: Concept of federalism where federal, state, and local governments are integrated to act cooperatively, solving common problems, rather than making policies separately but more or less equally, or clashing over a policy in a system dominated by the national government

\section{Cooperative Governance: (See Collaborative Governance)}

County Service Area: Local government unit that provide minimum public services such as police protection, library facilities, and television translator services

Commission Government: City government that divides the responsibilities of the municipality among council members; each commissioner held executive power over a major public works department (e.g., water, sanitation, and roads) 
Communitarism: A political philosophy emphasizing the need to balance individual rights and interests with that of the community, positing that individuals are shaped by the culture and values of their communities

Confederal Systems: System of government where the states operate as a sovereign government and the legislature of any one state can set its own laws independently of any other state

Democracy Versus Technocracy Quandary: Arising due to rapid technological innovation in the United States where many policy problems are highly technical in nature and require scientific knowledge to manage effectively; this "quandary" questions whether the authority of those with specialized technical knowledge will supplant the democratic process of decision-making

Dependent (Special) Districts: A type of special district with a population of residents occupying a specific geographic area, featuring a legal governing authority, maintaining a legal identity separate from any other governmental authority, possessing the power to assess a tax for the purpose of supplying public services, and exercising autonomy

Developed Community: A community intentionally planned with specific goals for function in mind; developed communities can be freestanding homes, condominiums or apartment complexes

Dillon's Rule: State-national government power relations are embedded in the U.S. Constitution, granting the states almost unlimited authority aside from limitations imposed by the Constitution and resulting federal statute; in terms of state-local power relations, Dillon argued that states create local government and hold supreme power over local governments

Dual Federalism: Concept of federalism positing that the Constitution allows a limited list of powers to the national government, leaving the rest to the sovereign states; each level of government is dominant within its own sphere; the Supreme Court serves as the mediator between the national government and the states 
Dual System (Judicial Power): The system of separate state and federal courts that make up the judicial system

E-Democracy: Technological innovation where government uses the Internet to engage citizens in the policy-making process through electronic voting technologies, electronic information exchange, and online forums

E-Government: The use of information technology to provide and improve government services, transactions and interactions with citizens, businesses, and between branches of the government; this technological development has also been referred to as "on-line government," and "transformational government"

Elementary and Secondary Education Act (ESEA): Provision that aids low income and disadvantaged children through the distribution of federal funds to state and local educational systems

Elite Challenging Politics: Political action aimed at creating change through challenging the powerful elite through direct action such as demonstrations, petitions, and boycotts

Elite Theory: The theory that political power is held by a small and wealthy group of people sharing similar values and interests and mostly coming from relatively similar privileged backgrounds; the power elite can effectively dictate the main goals for policy making by virtue of their control over the economic resources of the major business and financial organizations in the country

Eminent Domain: The law by which the government can appropriate private property

Endangered Species Act: Enacted in 1973, this act provides for the conservation of ecosystems upon which threatened and endangered species of fish, wildlife, and plants depend.

Engaged Citizenship: A type of citizenship where members of a community take a more active role in matters of social welfare

Every Student Succeeds Act: Replaced the 2002 No Child Left Behind Act in 2015 that supports local evidenced-based and placebased K-12 education initiatives.

Excise Tax: Taxes related to consumer consumption behavior, 
these comprise sales taxes, motor fuel taxes, cigarette taxes, and distilled spirits taxes

Fiscal Federalism: In public economics, refers to how the central government applies grants and payments to lower levels of government

Flat Rate Tax: A single tax rate regardless of income level

Formula Grant: Grant given to a state or local government to accomplish a national policy goal adopted by Congress

Gated Community: A developed community with a few common characteristics: physical barriers to entry and movement, the privatization and communal control of public spaces, and privatization of public services such as trash removal and police forces

General Jurisdiction Courts: Courts that deal with both civil and criminal cases, and whose jurisdiction is based on geographical area

General Purpose Government: Responsible for a wide range of public services including counties, parishes and manipulates (cities, towns, villages, townships); can be contrasted with special purpose governments (or special districts), such as school districts, water districts and transit districts

Gentrification: The transformation occurring neighborhoods that includes the renewal and rebuilding of deteriorating areas and the displacement of low-income residents living in inexpensive housing with high-income residents living in high cost housing

Gerrymandering: The process whereby district lines are redrawn to maximize the strength of the majority party and weaken the minority party

Glass Ceiling: An intangible barrier within an organization that prevents minorities or women from advancing to upper-level positions

Globalization: The current worldwide expansion of economic markets through trade and financial flows, and the transfer of culture and technology

Governance (see also "Collaborative" and "Cooperative" governance) 
Graduated Tax: Tax rate based on percentage of income where those with higher income pay higher taxes

Grutter v. Bollinger: U.S. Supreme Court case upholding the University of Michigan Law School's affirmative action policy, deciding that race can be one of several factors considered when making admission decisions because it furthers "...the educational benefits that flow from a diverse student body"

Head Start Program: A pre-school program for young disadvantaged children with the stated purpose of getting these children ready for the rigors of the first grade

Higher Order Needs: Theory developed by Abraham Maslow related to motivation showing how when lower needs such as physiological, safety, love/belonging are met, higher needs such as esteem and, finally, self-actualization become attainable

Home Rule: The power of a local city or county that is granted by states limited-and reversible-to independently create and manage policy at the local level

Independent (Special) Districts: A type of special district that includes more than one county

Individualistic Political Culture: Problems are seen in terms of individual solutions - communal solutions are not highly valued; this school of thought emphasizes the conception of the democratic order as a marketplace, in which government is instituted for strictly utilitarian reasons, to handle those functions demanded by the people it is created to serve

Initiative: A form of direct democracy by which a petition signed by a minimum number of registered voters can force a public vote on a proposed statute, constitutional amendment, charter amendment or ordinance

Institutional Actors: The subjects including legislative bodies, executive departments, and the judicial branch involved in the public policy process are governments and governmental agencies that deal with public affairs

Institutional Resiliency: The ability of institutions to withstand 
or react to major stressors without crossing a threshold to a situation with different structure or outputs

Integration of Powers: A political system, such as in a parliamentary system, where the executive and legislative branches are integrated

International

City/County

Management

Association: Professional association started in 1914 to provide professional support and research for cities and counties

Intergovernmental Agreement (IGA): Directly related to federalism and multi-state arrangements within the American federal system, this term refers to national-state or national-local agreements or inter-state and inter-local agreements of various kinds

Jacksonian Democracy: A political philosophy promoting the strength of the executive branch of government over the legislative branch, while also seeking to broaden the public's participation in government

Judicial Federalism: Refers to the allocation of power between federal courts and state courts, where state courts address their own state's constitutional claims first in a case, and only consider federal constitutional claims when cases can not be resolved on state grounds (the increased influence of states' constitutions within their judicial system, particularly in regards to civil rights.)

Law and Order Approach (Criminal Justice): Ideology emphasizing the protection of public order through close monitoring of conduct and severe punishment on proven criminals

LEED: Leadership in Environment and Energy Design is an ecology-oriented building certification program run under the name U.S. Green Building Council (USGBC); there are five key areas of environmental and human health: energy efficiency, indoor environmental quality, materials selection, sustainable site development, and water savings; LEED focuses on these five areas

Legislative Oversight: The legislature's review and evaluation of selected activities of the executive branch, and the responsibility of developing the state budget 
Legislative Referral: Action by the legislature and the governor that places the legislation on the ballot for voters to decide approval or disapproval

Lifelong Learning: The continual acquisition of knowledge and skills throughout one's life

Line Item Veto: Power of an executive to strike or cancel specific provisions of a bill, usually budget appropriations, without vetoing the entire legislative package. Subject to the legislative override.

Linkage Mechanisms: How institutions and the associated governmental processes affect the lives of citizens

Mandate of Court: An authorization to act given to a representative

Master Agree (Tobacco Agreement): Settlement agreement from 1998 with the tobacco industry where tobacco companies agreed to compensate for some medical costs associated with the effects of smoking-related illnesses as well as to curtail the production of tobacco products

McDonaldization Effect: The phenomenon of international homogenization in culture, life styles, and technology that accompanies globalization first coined by George Ritzer, whose own ideas of "McDonaldization" and "hyperrationality" came from the theories of Max Weber

Medicaid: A national-state cooperative health care plan designed to serve the medical service needs of low-income individuals and families

Medicare: National plan providing for the health care needs of individuals 65 years of age or older; the three major components include: hospital insurance, medical insurance, and prescription drug assistance

Merit-Based Performance (Civil Service): System of pay where compensation is dependent on the performance of employees

Memorandum of Understanding: An agreement between two parties in the form of a legal document, which can define partnerships between departments or agencies

Merit System of Judicial Appointment (see "Missouri Plan") 
Missionary Party: Rather ideological in orientation, these parties enter elections with a "manifesto" or "platform" to be undertaken; these parties tend to maintain a high degree of control over membership and carefully monitor who is allowed to make use of the party label as a candidate

Missouri Plan: Complex system for judicial appointment that was designed to combine methods of appointment with election; under the provision of the Missouri Plan, candidates for judicial vacancies are reviewed by independent, bipartisan commissions of lawyers and prominent lay citizens prior to selection by a governor. An election for retention of the judge is put to voters after one year of the judge's service

Moralistic Political Culture: Problems are seen in terms of community dilemmas that must be identified through interchange and community choice; this school of thought emphasizes the commonwealth conception as the basis for democratic government, whose responsibility it is to promote the general welfare

Multi-Member District: A multimember district is an electoral district returning more than one member to a representative assembly

National Environmental Policy Act (NEPA): One of the first environmental laws ever written, NEPA requires federal agencies to consider the environmental impacts of proposed federal projects which could significantly affect the environment

Neo-Liberalism: This political view promoting the importance of economic growth, free market and free trade, and reduced government regulation of the economy; it asserts that social justice occurs with minimum interference by the government and by the forces of the free market

Network Approach: A system of organizing where there are multiple dimensions of interaction, few fixed bureaucratic relationships, and communication organizes itself at one point in time around a hub of positions or of knowledge - i.e., the persons or organizations that possess or control relevant knowledge

New Deal Era: Economic reform package initiated by Franklin D. 
Roosevelt in the 1930s that sought to relieve the effects of the Great Depression through reforming of financial and business practices and aid to the unemployed

No Child Left Behind (NCLB): Federal educational act created to improve the performance of schools using standard-based reform to measure goal attainment in primary and secondary public school

Non-Institutional Actors: Individuals or groups independent of the government and involved in the policy process, including political parties, interest groups, social movements, nongovernmental organizations (NGOs), and the mass media, and individual citizens

Nonpartisan Offices: Offices where elected candidates run for office without listing a political affiliation and generally held for local government offices such as for school districts, local special districts, judicial and boards and commissions

Northern Spotted Owl v. Hodel: A famous case in favor of preserving an endangered species over the continuation of timber harvesting; this case is considered a landmark decision in social and environmental justice through governmental action

Open Primary: Primary elections where voters may cast a vote on a ballot of any part and do not need to be members of a specific political party in order to vote for that party's candidates

Ordinances: An authoritative decree or law set forth by governmental authority

Oregon System: A system of government where voters are able to initiate and vote upon statutes or constitutional revisions

Organizational Culture: Underlying values, beliefs, and ways of interacting that contribute to the psychological and social environment of an organization.

Parliamentary Style Systems: Common legislative form using the integration of powers and where the legislative branch chooses the prime minister or president

Patronage: The power to make appointments to government jobs especially for political advantage

Performance-Based Budgeting: Process for budgeting that links 
requests for resources with documentation illustrating the outcomes of budget choices made in previous years

Pivotal Variable: The focal point upon which other variables depends

Plessy v. Ferguson: The 1896 U.S. Supreme Court case ruling that "separate but equal" public facilities were consistent with the equal protection clause of the 14th Amendment to the U.S. Constitution; the Supreme Court's ruling meant that racial segregation is acceptable so long as the services provided by government for different races were basically comparable

Pluralist Theory: An ideal-type democratic theory positing that American democratic political process is genuinely open to the involvement of any group that wishes to participate; some of the fundamental constitutional principles embedded in the U.S. Constitution (freedom of speech, freedom of assembly, and freedom to petition government for the redress of grievances) constitute core elements of pluralist theory

Point Sources: The U.S. Environmental Protection Agency defines point source pollution as a single identifiable source of pollution that is discharged from a pipe, factory, ship, smokestack ditch, etc.

Political Culture: Attitudes, values and beliefs about a political system

Political Trust: The expectation of a citizen that the rules and practices derived from public institutions are fair and unbiased; that the performance of a political institution competent and appropriate; and that rules and procedures encourage innovation and produce outcomes that improve governance and society

Politicization of Courts/Judiciary: The perception that courts function politically and ideologically in decision-making rather than objectively

Pork Barrel: Refers to the appropriation of government spending for projects that are not necessarily economically viable but pursued because of their appeal and benefit to particular constituents

Postindustrial Society: A society where the resources of labor 
and capital have been replaced by knowledge and information as the main sources of wealth creation by a shift in focus from manufacturing industries to service industries and is enabled by technological advances

Post-Materialist Needs: A phenomena occurring due to the new wealth accumulated in advanced societies where priorities have shifted from survival to a focus on well-being, self-expression, and quality of life

Presidential Style Systems: Common legislative form using the separation of powers between the executive, legislative, and judicial branches

Price Subsidies: Financial assistance granted by the government to a certain person or group whose actions are regarded as being in the public interest

Primary Election: A preliminary election where voters nominate candidates for office

Professionals: Individuals who are carrying out specialized tasks requiring specialized training and/or targeted experience

Progressive Era: Period during the late 19th and early 20th century that sought to mediate changes brought on by the industrial revolution through economic, political, social, and moral reform

Progressivism: A political and social term that refers to ideologies and movements favoring or advocating progress, changes, improvement, or reform

Proportional Representation: Legislative seats are proportionally distributed based on the percentage of the vote a particular party wins

Protest Politics: Form of activism where the contemporary grassroots citizen organizations and social movements participate in activities such as demonstrations and boycotts to assert political will

Public Goods: Refers to economics where the consumption of a good by one individual does not reduce availability of the good 
for consumption by others; and where no one can be effectively excluded from using the good

Public Interest Groups: Interest groups promote issues of general public concern (e.g., environmental protection, human rights, and consumer rights)

Recidivism: A tendency to relapse into a previous condition or mode of behavior

Red Tape: Colloquial term referring to the forms and procedures required to gain bureaucratic approval for something, often seen as overly complicated an unnecessary

Referendum: A specific measure put to the voters by the legislature for approval or disapproval

Regents of the University of California v. Bakke: Case where the Supreme Court ruled that inflexible quota systems in affirmative action were not permissible under the equal protection clause of the 14th Amendment of the constitution; in the same decision the Court upheld the legality of affirmative action in special cases

Reinventing Government: The move of state and local administrators to reorganize to achieve efficiency, better programs, better use of resource, and the input of state-level interests, private sector groups, and the general public

Renewable Energy Portfolios: A requirement that state utilities obtain a certain percentage or output (measured in kilowatt-hours) of their power supply from renewable energy sources; RPSs (renewable energy portfolio standards) are benchmarks for the portion of energy used by state consumers that must be supplied by renewable sources

Republican Government: Within this system of government there is separation of powers, divided up by executive, legislative and judicial powers; additionally, government responsibilities can be centralized at one level of government, or they may be decentralized among multiple layers

Reserved Powers: Based on the 10th Amendment, a provision of the constitution which holds that all governmental powers not 
explicitly granted to the national government in the constitution are reserved to the states and their people

Scientific Division of Labor: Careful analysis of subtasks that, in a coordinated effort, combine to achieve complex and ambitious goals

Select Committees: A temporary legislative committee established for a limited time period and for a special purpose

Sine Ira Ac Studio: Ruthless pursuit of effectiveness and efficiency without regard to personal favor or sympathy

Single Member District: The most common electoral system in the United States used to elect House members and many state and local officials; each district votes on one person to represent them in a legislative body

Single Purpose Governments: Latter carries out a specific function such as education, the provision of utilities, the irrigation of farmlands, or the provision of transportation services, for example

Smart Growth: A theory for urban growth and planning that attempts to concentrate growth in the center of a city, thereby avoiding urban sprawl

Social Capital: The values and norms held by citizens that reflect trust in others, the active pursuit of engagement in networks of interpersonal relations of a wide variety, and standards of interchange among people involving the principles of reciprocity (return a favor with a favor) and mutual respect

Social Movements: Group action characterized by focus on a specific political or social issue by individuals who share a common outlook on society and organized to cause social change

Social Safety Net: Includes government programs that support low-income Americans

Social Trust: Relates to the ways in which people interact with one another, publicly and privately, and rests on the belief that others are act with honesty, integrity and reliability of others

Standing Committee: A permanent committee established in a legislature, usually focusing on a policy area 
State Children's Insurance Program (S-CHIP): A state program, cooperatively managed at the state and federal level, intended to meet the health care needs of uninsured middle- and low-income children

Strong Mayor-Council: A form of local government consisting of both an elected executive branch and a legislative branch, where one of the most significant powers afforded the mayor is that of budget director

Sunset Provision (or Clause): A provision in a statute that terminates or repeals all or portions of the law after a specific date, unless further legislative action is taken to extend it

Sustainable Community-Based Eldercare: Community-based provision for the needs of elderly residents that seeks to maintain a community's retired population by providing for them within the community

Supremacy Clause: The clause establishing the Constitution, Federal Statutes, and U.S. treaties as the supreme law of the land, mandating that state judges uphold them, even if state laws or constitutions conflict

Sustainability: The manner in which the social, economic, institutional, and environmental needs of a community are met without compromising the ability of future generations to meet their own needs; meeting the present needs of a community without compromising the ability of future generations to meet their needs

Swann v. Charlotte-Mecklenberg Board of Education: Supreme Court case ruling that local education districts across the nation use mandatory busing as a policy to achieve racial integration in their schools

Task Force: A temporary group formed to work on a special defined task or activity

Tax and Expenditure Limitation Measures (TELs): Limits on the amount of revenue that can be collected without the excess having to be refunded to taxpayers

Temporary Assistance to Needy Families (TANF): Formerly 
known as welfare, TANF provides cash assistance to families with dependent children

Tenure: A status of seniority granted after a trial period

Term Limits: In many states, constitutional term limits control the number of terms - consecutive or otherwise - which a legislator is allowed to serve

Three Strikes Laws: State statute requiring a mandatory and extended sentence to criminals of serious offenses convicted three or more times

Traditionalistic Political Culture: School of thought that accepts government as an actor with a positive role in the community, but limiting that role to securing the continued maintenance of the existing social order; in this system, political parties are not important, but rather, political competition is expressed through factions, an extension of the personal politics characteristic of the system their activity, although not necessarily by direct pecuniary gain

Trial Courts: The courts in which most civil or criminal cases begin

Two Party Systems: Refers to a government in which the same two political parties are nearly always elected to dominate the political process and where one party will hold the majority in the legislature

Unconstitutional Taking: Taking of private property by government without just compensation

Unemployment Compensation: Money that substitutes for lost wages or salary due to unemployment under a program administered by a government

Unfunded Mandate: Requirement imposed by Congress on state or local governments with no funding to pay for it

User Fees: Fee charged for public service or facility

Voucher System: The option within the educational system for parents to receive a predetermined amount of money (depending on the state) to cover student tuition at a school of choice

Weak Mayor-Council: Form of local government where the 
mayoralty is a ceremonial position; executive leadership is a cooperative effort on the part of the entire city council, which collectively decides and approves appointments; the budget is a collegial endeavor and the mayor is just one of the council members involved in the budgeting process

Welfare Reform Act, 1996: Public assistance as focused less on the individual recipient of the benefit than it is the community as a whole and requiring work in exchange for temporary relief; a limit of two years to be used before parents would be working or in job training; additionally, no recipient could have more than five years of assistance cumulatively

Welfare-To-Work Program: Social program instituted in 2004 seeking to encourage those on public assistance to return to work rather than depend on income support

Whole Building Design: Holistic building design with the building's purpose, workforce, future, and operations and maintenance costs taken as a comprehensive whole

Xeriscape Design: Landscaping to maximize water efficiency; xeriscape practices include: good planning and design, practical lawn areas, efficient irrigation, soil improvement, use of mulches, and native plants 


\section{Creative Commons License}

This work is licensed by Christopher A. Simon, Brent

S. Steel \& Nicholas P. Lovrich (C2018) under a

Creative Commons Attribution-NonCommerical-Share

Alike 4.0 International License (CC BY-NC-SA)

You are free to:

Share - copy and redistribute the material in any medium or format

Adapt - remix, transform, and build upon the material

The licensor cannot revoke these freedoms as long as you follow the license terms.

\section{Under the following terms:}

Attribution - You must give appropriate credit, provide

a link to the license, and indicate if changes were made. You may do so in any reasonable manner, but not in any way that suggests the licensor endorses you or your use.

NonCommercial - You may not use the material for commercial purposes.

ShareAlike - If you remix, transform, or build upon the material, you must distribute your contributions under the same license as the original.

No additional restrictions - You may not apply legal terms or technological measures that legally restrict others from doing anything the license permits. 


\section{Recommended Citations}

APA outline:

Source from website:

- (Full last name, first initial of first name). (Date of publication). Title of source. Retrieved from https://www.someaddress.com/full/url/

Source from print:

- (Full last name, first initial of first name). (Date of publication). Title of source. Title of container (larger whole that the source is in, i.e. a chapter in a book), volume number, page numbers.

\section{Examples}

If retrieving from a webpage:

- Berndt, T. J. (2002). Friendship quality and social development. Retrieved from insert link.

If retrieving from a book:

- $\quad$ Berndt, T. J. (2002). Friendship quality and social development. Current Directions in Psychological Science, 11, 7-10.

MLA outline:

Author (last, first name). Title of source. Title of container (larger 
whole that the source is in, i.e. a chapter in a book), Other contributors, Version, Number, Publisher, Publication Date, Location (page numbers).

Examples

- Bagchi, Alaknanda. "Conflicting Nationalisms: The Voice of the Subaltern in Mahasweta Devi's Bashai Tudu." Tulsa Studies in Women's Literature, vol. 15, no. 1, 1996, pp. 41-50.

- Said, Edward W. Culture and Imperialism. Knopf, 1994.

Chicago outline:

Source from website:

- Lastname, Firstname. "Title of Web Page." Name of Website. Publishing organization, publication or revision date if available. Access date if no other date is available. URL .

Source from print:

- Last name, First name. Title of Book. Place of publication: Publisher, Year of publication.

Examples 
- $\quad$ Davidson, Donald, Essays on Actions and Events. Oxford: Clarendon, 2001.

https://bibliotecamathom.files.wordpress.com/ 2012/10/essays-on-actions-and-events.pdf.

- $\quad$ Kerouac, Jack. The Dharma Bums. New York: Viking Press, 1958. 


\section{Versioning}

This page provides a record of changes made to this guide. Each set of edits is acknowledged with a 0.01 increase in the version number. The exported files for this toolkit reflect the most recent version.

If you find an error in this text, please fill out the form at bit.ly/ 33cz3Q1

\begin{tabular}{|l|l|l|l|}
\hline Version & Date & Change Made & $\begin{array}{l}\text { Location in } \\
\text { text }\end{array}$ \\
\hline 1.0 & $\begin{array}{l}\text { MM/DD/ } \\
\text { YYYY }\end{array}$ & & \\
\hline 1.01 & $\begin{array}{l}09 / 24 / \\
2020\end{array}$ & $\begin{array}{l}\text { Links to external sources } \\
\text { updated }\end{array}$ & All \\
\hline & & & \\
\hline
\end{tabular}

